José Carlos de Hoyos, Cécile Poix, Adam Renwick, Corina Veleanu (editores / éditeurs)

\title{
DESAFÍOS DE LA NEOLOGÍA EN LAS LENGUAS ROMÁNICAS EN EL SIGLO XXI
}

\section{DÉFIS DE LA NÉOLOGIE EN LANGUES ROMANES AU XXI ${ }^{\mathrm{e}}$ SIÈCLE}

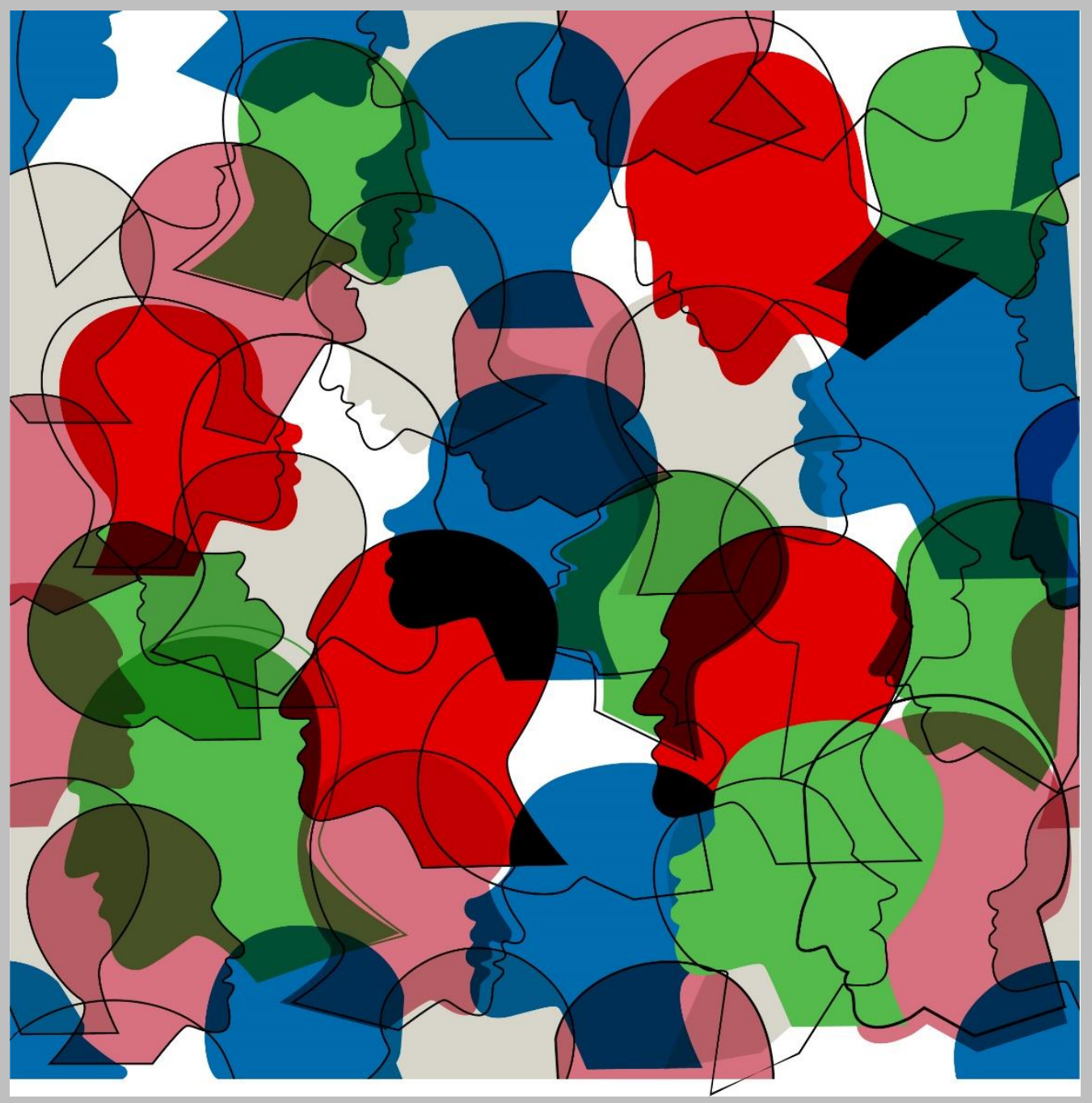


Esta publicación ha sido posible gracias al apoyo de la universidad Lumière Lyon 2, del centro de investigación Centre de Recherche en Terminologie et Traduction (EA 4162), de la Délégation générale à la langue française et aux langues de France (DGLFLF), del Instituto Cervantes de Lyon, del Institut de Lingüística Aplicada de la Universitat Pompeu Fabra (Barcelona) y de la Métropole de Lyon.

Imagen de la portada C Getty Images, 2018

J. C. de Hoyos, C. Poix, A. Renwick, C. Veleanu, éds./eds. (2020): Défis de la néologie en langues romanes au XXI siècle / Desafíos de la neología en las lenguas románicas en el siglo XXI, Ediciones Universidad de Murcia, Murcia.

(C) José Carlos de Hoyos (editor científico y autor de la introducción), Cécile Poix (editora científica), Adam Renwick (editor científico), Corina Veleanu (editora científica), 2020.

(C) EDITUM. Ediciones de la Universidad de Murcia, 2020

Primera edición: 2020

ISBN: 978-84-09-23398-4 
José Carlos de Hoyos

Cécile Poix

Adam Renwick

Corina Veleanu

(editores / éditeurs)

\section{DESAFÍOS DE LA NEOLOGÍA \\ EN LAS LENGUAS ROMÁNICAS EN EL SIGLO XXI \\ DÉFIS DE LA NÉOLOGIE \\ EN LANGUES ROMANES AU XXI' SIÈCLE}

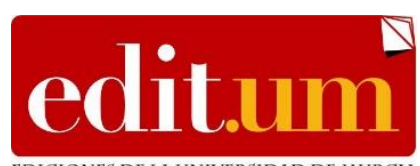

EDICIONES DE LA UNIVERSIDAD DE MURCIA

2020 


\section{TABLE DE MATIÈRES ÍNDICE}

Introduction / Introducción.

\section{Néologie terminologique / Neología terminológica}

Vega Moreno, Érika: Las creaciones neológicas por acronimia en el lenguaje de la publicidad.........................................................

Pozuelo-Ollé, Òscar; Estopá, Rosa; Lorente, Mercè: Diagnosticar, hemopoètic, naixement: neologicitat i morfologia de les unitats terminològiques eventives en medicina.

Enăchescu, Mihai: El reemplazo de los arabismos en español: remedios curativos medievales

Park, Morgan: Diferentes imágenes del medio ambiente se adaptan a diferentes tipos de expresiones

Torres Rivera, Andrés; Estopà Bagot, Rosa; Torres-Moreno, Juan Manuel: Detección de neologismos semánticos: Una aproximación estadística y de aprendizaje automático que combina corpus generales y especializados.........

66

\section{Sociolinguistique de la néologie / Sociolingüística de la neología}

Favreau, Hélène: Commentaires épilinguistiques et sentiment néologique : évaluation comparative de quelques néologismes par deux groupes d'étudiants

Nitti, Paolo: «Ma si può dire architetta e avvocata? Non sono errori?». Un'indagine sull'accettabilità dei neologismi per i nomi femminili delle

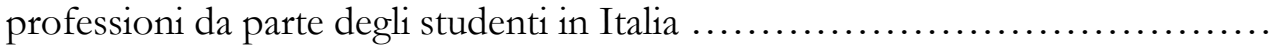

Grimaldi, Claudio : Mots, couleurs et néologie : analyse des dénominations de couleur en français contemporain

Balthazard, Matthieu : La néologie wallonne aujourd'hui. Étude d'un concours de néologismes subventionné : la Bate dès noûmots 
III. Médias et néologie / Medios de comunicación y neología

Maldussi, Danio: Guerre des isotopies dans la conceptualisation de la néologie d'emprunt : le «quantitative easing » de la BCE et sa figuralité à l'épreuve du discours de presse francophone..............................

Altmanova, Jana; Piro, Rosa: Figement des composés néologiques du type $\mathrm{N}+\mathrm{Npr}$ et $\mathrm{Npr}+\mathrm{N}$ en français et en italien...............................

Jabłonka, Edyta : La néologie par emprunt: analyse des blogs féminins portugais

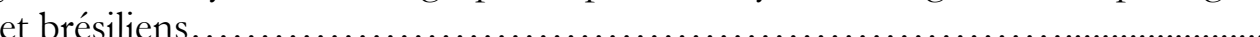




\section{Introduction / Introducción}

El campo de la neología ha recibido atención universitaria de manera intensiva desde al menos los años 80 del pasado siglo en las grandes lenguas de cultura y especialmente en las lenguas románicas, objeto de la presente monografía. Hoy en día nos encontramos con un corpus científico sólido, como pueden demostrarlo las diferentes monografías de los profesores Sablayrolles (2019) o Humbley (2018), con revistas especializadas que dedican atención a este tema (Neologica, fundada en el año 2007 y con un ritmo de publicación de un número por año), además de con eventos científicos recurrentes centrados en la neología como pueden ser los diferentes congresos organizados bajo la marca CINEO: Congreso Internacional de Neología de las lenguas románicas, cuyas cuatro ediciones entre los años 2009-2018 (Barcelona, Sao Paulo, Salamanca y Lyon) ${ }^{1}$ dan muestra de su amplia internacionalización y del intento de la comunidad científica de encontrar eventos que puedan federar la disciplina de los estudios en Neología ${ }^{2}$.

En medio de tal ebullición científica en torno a la dinámica léxica de las lenguas, nos hemos planteado dar respuesta a la pregunta general de cuáles serían los desafíos intelectuales más acuciantes en el campo de la neología en las lenguas románicas. Diferentes posibilidades de respuesta a esta problemática se encuentran en las doce contribuciones que presentamos en este volumen y que, si no se refieren a todas las lenguas románicas, toman al menos en cuenta el español, francés, italiano, catalán, portugués (en sus versiones brasileña y europea) y el dialecto valón en un intento políglota raro en las disciplinas científicas, cada día más centradas en las lenguas de mayor difusión.

Ordenamos las contribuciones del volumen en tres ejes principales: neología terminológica, sociolingüística de la neología y medios de comunicación y neología. El primer eje científico se concentra en la intersección de dos grandes dominios, como nos explica Joaquín García Palacios en su contribución de 2009:

En el estudio de la neología terminológica se produce la intersección de los dos campos que integran el sintagma elegido para esta denominación tan transparente: el de la neología, entendida ésta como el estudio del proceso de generación e incorporación de nuevas unidades en una lengua, y el de la terminología, en su sentido más amplio, de ámbito dedicado al estudio de las unidades especializadas de una o varias lenguas. (García Palacios, 2009, p. 18)

Las lenguas de especialidad son uno de los grandes campos generadores de nuevas formaciones léxicas y los investigadores vuelcan su atención, como no podía ser de otro modo, en las dinámicas creativas de los corpus de tales lenguajes. Cinco contribuciones se centran en esta temática, utilizando como terreno de análisis cuatro tecnolectos diferentes: la medicina, la publicidad, la informática y los discursos relacionados con el medioambiente (a medio camino entre la ciencia, la política y el discurso periodístico). La medicina será analizada desde un punto de vista sincrónico y diacrónico, confirmando así que es uno de los campos de estudio que genera mayor

\footnotetext{
1 A continuación citamos esquemáticamente los datos básicos relacionados con los cuatro eventos internacionales dedicados a la neología de las lenguas románicas (edición, lugar de celebración y fechas): CINEO I, Barcelona, 7-10 de mayo 2008; CINEO II, Saõ Paulo, 5-8 de diciembre de 2011; CINEO III, Salamanca, 22-24 de octubre de 2015; CINEO IV, Lyon, 4-6 de julio de 2018. 2 Cada edición del congreso CINEO ha producido diferentes tipos de publicaciones. Citamos al menos una referencia vinculada a cada congreso, sabiendo que en ocasiones la producción ha sido muy variada y que han podido realizarse publicaciones fuera de los canales que mencionamos a continuación: CINEO I, Cabré et alii (2010); CINEO II, Ieda Alves y Eliane Simoes Pereira (2015); CINEO IV, García Palacios et alii (2016); CINEO IV, Makri-Morel, Dury y Renner (2020). Las referencias desarrolladas podrán encontrarse en la bibliografía del final de la introducción.
} 
interés entre neólogos o entre los lingüistas que se interesan por el entrecruzamiento de los ámbitos de la ciencia y del lenguaje.

Este primer apartado, dedicado a la neología terminológica, se abre con la contribución de la investigadora de la universidad de Cádiz, Érika Vega Moreno, titulada "Las creaciones neológicas por acronimia en el lenguaje de la publicidad". Se analizan en el artículo combinaciones léxicas como yolado (de la fusión de yogurt+helado), ligesistible (ligera+irresistible) o capuchila (capucha+mochila), de gran productividad en el tecnolecto estudiado debido, según nos explica la investigadora, a su gran transparencia y a su capacidad evocadora. Al mismo tiempo que se estudian el impacto en el locutor de tales formaciones, la autora aporta aclaraciones sobre las tendencias en este tipo de compuestos, explicando, por ejemplo, cómo las formaciones binominales son las más frecuentes, a pesar de convivir con otras como las formadas por sustantivo y adjetivo.

El segundo artículo es una contribución escrita por varios investigadores de la universidad Pompeu Fabra pertenecientes al IULA dedicada a la lengua catalana y a la creatividad léxica de la predicación eventiva en el lenguaje de la medicina. Òscar Pozuelo-Ollé, Rosa Estopà y Mercè Lorente, del equipo IULATERM, analizan dieciséis unidades terminológicas desde una óptica lexicográfica, cruzando datos de dos diccionarios especializados (TCS-Terminologia de ciències de la salut y DEMCAT- Diccionari enciclopèdic de medicina), en su contribución: "Diagnosticar, hemopoètic, naixement: neologicitat i morfologia de les unitats terminològiques eventives en medicina".

Siguiendo con el lenguaje de la medicina, el tercer artículo de este primer capítulo se dedica a observar desde una perspectiva diacrónica la evolución de veintidós términos de origen árabe utilizados corrientemente durante la Edad Media en el ámbito de los remedios curativos. Mihai Enăchescu, investigador de la universidad de Bucarest, nos presenta un estudio de neología histórica donde analiza unidades como talco, alcohol, albarraz, con el objetivo de determinar si tales denominaciones se han mantenido, han sido sustituidas o han desaparecido de la lengua española. Con un sólido apoyo en los corpus históricos del español y en la bibliografía relativa a los estudios de arabismos, el investigador traza la trayectoria de este conjunto léxico en su contribución: "El reemplazo de los arabismos en español: remedios curativos medievales".

La cuarta contribución de este apartado se dedica a estudiar la metáfora en el discurso ambiental en las traducciones de la lengua inglesa hacia el español. Morgan Park, investigadora de la universidad de Salamanca, estudia de forma contrastiva las metáforas utilizadas en la revista juvenil TUNZA, publicada por el Programa de las Naciones Unidas para el Medio Ambiente, según la perspectiva de la teoría de la Relevancia (Sperber y Wilson) y aplicando los procedimientos de análisis del grupo Pragglejaz. Entre las conclusiones de la contribución "Diferentes imágenes del medio ambiente se adaptan a diferentes tipos de expresiones. Discurso ambiental de la metáfora", encontraremos la afirmación de que los traductores prefieren la traducción literal ante los fenómenos metafóricos como estrategia principal.

Cierra este primer apartado la contribución de tres investigadores de la universidad Pompeu Fabra, Andrés Torres Rivera, Rosa Estopà Bagot, Juan Manuel Torres-Moreno, centrada en el funcionamiento de un programa de detección y extracción semiautomática de neologismos semánticos para las lenguas catalana, española y francesa, el sistema DENISE ${ }^{3}$. $\mathrm{Al}_{\text {mismo tiempo }}$ que se nos muestra el funcionamiento del sistema, se presta atención al léxico de especialidad de la informática y su asentamiento en corpus generales y especializados en el artículo "Detección de neologismos semánticos: Una aproximación estadística y de aprendizaje automático que combina corpus generales y especializados".

Si citando a Émile Benveniste, como hace la investigadora Hélène Favreau, "La langue n'est pas un répertoire immobile [...] Elle est en elle-même le lieu d'un travail incessant" (Benveniste 1966: 155), consideramos que la lengua no es un objeto inmóvil, sino más bien en plena dinámica, deberíamos preguntarnos de dónde proceden tales dinámicas de renovación léxica. En el segundo

${ }^{3}$ Detector de neologismos semánticos por sus iniciales en sus lenguas de trabajo: catalán, español y francés. 
apartado de nuestro volumen, cuatro autores intentan dar respuesta por medio de análisis sociolingüísticos a los cambios, avances o creaciones léxicas que encontramos en lenguas como el francés, el italiano o el dialecto valón.

Un primer bloque de este apartado podría estar constituido por las dos primeras contribuciones que abren el capítulo de Sociolingüística de la neología. Ambos trabajos parten del estudio de un corpus sociológico compuesto por estudiantes para proporcionarnos datos sobre los usos sociolingüísticos de diferentes tipos de neologismos. Por un lado, la investigación de Hélène Favreau, centrada sobre la neología formal del francés contemporáneo, y, por otro, la contribución de Paolo Nitti sobre los problemas de género lingüístico y de la feminización de las profesiones en italiano.

Desde una perspectiva puramente morfológica (neología formal), Hélène Favreau nos explica en su contribución "Commentaires épilinguistiques et sentiment néologique : évaluation comparative de quelques néologismes par deux groupes d'étudiants" cómo perciben los neologismos dos grupos de 20 hablantes cada uno: por un lado, estudiantes francófonos y, por otro, estudiantes que aprenden la lengua francesa y que siguen las clases de la investigadora en la universidad de Angers. Ambos grupos de estudiantes cursaban la materia de sociolingüística impartida por Hélène Favreau en tercer año y realizaron la encuesta en octubre de 2017 sobre un corpus de 72 neologismos extraído en el verano de ese mismo año. La contribución podría responder a la pregunta, tantas veces formulada entre neólogos, ¿cómo se integran las nuevas palabras en la lengua y qué percepción tiene el hablante de esta neología formal? Neologicidad y criterios de integración formarán parte de las cuestiones tratadas por la investigadora.

Responder a la pregunta “¿es la lengua italiana sexista y sus usos discriminatorios?” podría ser el eje de la contribución presentada por el profesor italiano Paolo Nitti de la Universitá delgi Studi dell'Insubria, en la que se esfuerza por comprender las modalidades de feminización de los nombres de profesiones y su percepción por los estudiantes italianos de diferentes niveles. A partir de la pregunta de si se puede ser architetta o avvocata y la duda que surge en la mente del hablante de "¿serán errores?”, el profesor Nitti nos pasea por los usos sexistas y su percepción en su contribución, "Ma si può dire architetta e avvocata? Non sono errori?. Un’indagine sull'accettabilità dei neologismi per i nomi femminili delle professioni da parte degli studenti in Italia".

La siguiente contribución del investigador de la universidad italiana de Nápoles "Parthenope", Claudio Grimaldi, nos introduce en las actitudes neológicas de los términos relacionados con el color en el mundo de la moda con su contribución: "Mots, couleurs et néologie : analyse des dénominations de couleur en français contemporain". El tema central de la contribución son los neologismos cromáticos en el francés contemporáneo encontrados en 50 artículos de la prensa (publicados en el año 2018), prestando especial atención a las estructuras de sustantivo seguido de adjetivo (gris clair) u otras más complejas que buscan precisar la tonalidad: sustantivo+sustantivo (bleu ciel, rose barbie), sustantivo+sustantivo + sustantivo (bleu tie \& dye), sustantivo+prep+sustantivo (terre de sienne). Estas novedades léxicas son una muestra de las presiones sociales y culturales manifiestas en el mundo de la moda y cuyas producciones más evidentes podemos encontrar en la lengua.

La última contribución del apartado dedicado a la sociolingüística de la neología se sitúa en los estudios sobre normalización impulsada institucionalmente, cayendo así dentro del campo de la política lingüística. El investigador de la universidad de Lieja, Matthieu Balthazard, nos traza la situación de los diferentes romances del sur de Bélgica donde el francés convive, o ha convivido, con diferentes dialectos de origen latino como el valón o el picardo. Tras informarnos de que el valón es un dialecto que ha perdido potencia como medio de comunicación, pero por el que existe una voluntad de revitalización, se analiza una interesante acción de normativización de la neología. Una forma de contribuir a su revitalización es la organización de un concurso neológico durante la Fiesta de las lenguas de Valonia, financiado por la Federación Valonia Bruselas. La Bate dès Noûmots, que traducido literalmente significa 'el combate de los neologismos', es el nombre del concurso y 
es el objeto de estudio del investigador en su contribución: "La néologie wallonne aujourd'hui. Étude d'un concours de néologismes subventionné : la Bate dès noûmots".

Por último, el tercer apartado de estos Défis o Desafíos está dedicado a estudiar los medios de comunicación y la presencia de formaciones neológicas. No solo se prestará atención a la prensa entendida en un sentido tradicional (publicaciones periódicas en papel, aunque con versiones electrónicas como puedan ser Le Monde, La Tribune, Les Échos...), sino también a las nuevas formas de comunicación como son los blogs. En este apartado encontraremos análisis detallados de las lenguas francesa, italiana y portuguesa.

En primer lugar, presentamos un trabajo sobre terminología económica, donde se estudia el sintagma inglés quantitative easing y sus diversas adaptaciones en la lengua francesa. El término estudiado fue divulgado en Europa a través de las acciones económicas de la BCE llevadas a cabo durante el mandato de M. Draghi (2011-2019). El interés de tal término es toda la red sémica que instala en el discurso caracterizada la mayoría de las veces por su opacidad conceptual, con marcos metafóricos como 'el dinero es un líquido', 'el quantitative easing es un arma' o la metonimia de la emisión de moneda (planche à billets, en francés). La traducción quantitative easing, según aparece en las bases de datos más representativas (IATE, por ejemplo), es assouplissement quantitatif, objeto de estudio del profesor de la universidad italiana de Bolonia Danio Maldussi. Este sintagma terminológico será analizado entre el año 2012 y octubre de 2018 en los corpus de cuatro publicaciones francesas: La Tribune, Le Monde, Les Échos et Le Figaro. Los resultados nos harán comprender mejor la guerra de metáforas en juego en el medio periodístico para transmitir esta noción, como bien indica el título del artículo escrito por el investigador Danio Maldussi: "Guerre des isotopies dans la conceptualisation de la néologie d'emprunt : le «quantitative easing » de la BCE et sa figuralité à l'épreuve du discours de presse francophone".

$\mathrm{Al}$ trabajo sobre terminología económica le sigue el artículo de Jana Altmanova y Rosa Piro, investigadoras de la universidad italiana de Nápoles L'Orientale, quienes presentan un trabajo a caballo entre el francés y el italiano donde se analiza la presencia de neologismos por composición yuxtapuesta. Estos pueden estar formados por un sustantivo y un nombre propio, en una sintaxis completamente asimilada por las lenguas románicas con valor de epíteto para el nombre propio (plan Marshall), o por una encadenación invertida más característica de los fenómenos sintácticos propios de los préstamos de la lengua inglesa (Crimi-boys). Las investigadoras analizarán formaciones como las siguientes: effet Compton, loi Macron, o calcos del inglés como sarkoboy, para la lengua francesa; capitalismo Gucci, legge Fornero y formaciones exógenas como Salvini-tax, Ciampi boys, para la lengua italiana. Entre los resultados de la investigación, "Figement des composés néologiques du type $\mathrm{N}(+) \mathrm{NPR}$ et $\mathrm{NPR}(+) \mathrm{N}$ en français et en italien", encontraremos la confirmación de que el italiano es una lengua más permeable al préstamo procedente de la lengua inglesa que la lengua francesa, incluso en sus formas de mayor crudeza sintáctica.

Por último, y como cierre de nuestro volumen, presentamos la única contribución sobre la lengua portuguesa de la mano de la investigadora Edyta Jabłonka: "La néologie par emprunt: analyse des blogs féminins portugais et brésiliens". En lengua portuguesa el neologismo por préstamo es muy productivo y está justificado, según la investigadora de la universidad Marie CurieSklodowska, principalmente por razones estilísticas. Préstamos como green beans, jeans, jumpsuits, trend, red lispstick u otros, forman parte del acervo léxico utilizado en los blogs de la prensa femenina portuguesa y brasileña analizados por la investigadora en la contribución que cierra el volumen.

No queremos cerrar estas páginas introductorias sin agradecer a todas las personas e instituciones su colaboración en el éxito de esta edición. En primer lugar, nos gustaría agradecer a todos los autores la paciencia que han demostrado en el proceso de selección, con la laboriosa pero necesaria lectura por pares, y la rapidez en sus respuestas cuando fueron solicitados en la última etapa del proceso editorial. Al mismo tiempo nos gustaría dejar constancia de la implicación de nuestro centro de trabajo, el centro de investigación CRTT'-Centre de Recherche en Traduction et Terminologie de la universidad Lumière Lyon 2, en el desarrollo de los estudios neológicos de forma 
general y, de forma particular, en la realización del proyecto que aquí presentamos, su apoyo humano y financiero han sido fundamentales para edición de estos Desafios. Otras instituciones como la Délégation générale à la langue française et aux langues de France (DGLFLF), el Instituto Cervantes de Lyon, el Grand Lyon o el IULA de la universidad Pompeu Fabra, con diferentes acciones, mostraron su sensibilidad hacia los estudios neológicos apoyando este proyecto o proyectos paralelos que permitieron, o animaron, iniciativas que han culminado en el volumen hoy presentado. A todos ellos gracias.

José Carlos de Hoyos

Université Lumière Lyon 2

CRTT-Centre de Recherche en Traduction et Terminologie

\section{Bibliografía citada}

Alves, Ieda; SimÕes PereirA, Eliane (2015): Neologia das linguas românicas, Humanitas, São Paulo.

Benveniste, Emile (1966), Problèmes de linguistique générale (tome 2), Paris, Gallimard.

Cabré, Teresa; Domènech, Ona; EstopÀ, Rosa; FreiXA, Judit; Lorente, Mercè (dirs.) (2010): Actes del I Congrés Internacional de neología de les Llengües Romàniques, Universitat Pompeu Fabra, Barcelona.

DEMCAT = INSTITUT D’Estudis CATAlans, Fundació ACAdÈmia DE CiènCies MÈdiques i de la SAlut de Catalunya i de Balears; EnCiClopèdia Catalana SAU; TERMCAT, CEntre de Terminologia; Generalitat de Catalunya - DePartament de SALUT (2015-2018). Diccionari enciclopèdic de medicina (DEMCAT): Versió de treball. Barcelona: TERMCAT, Centre de Terminologia.

http://www.termcat.cat/ca/Diccionaris En Linia/183/

GARCÍA PALACIOS, Joaquín (2009). «La competencia neológica especializada en el estudio y la actuación sobre la neología terminológica». Revue française de linguistique appliquée 14 (2). 17-30

García Palacios, Joaquín; De Sterck, Goedele ; Linder, Daniel ; Maroto, Nava ; SÁNCHEZ IbÁÑEZ, Miguel; TORRES DEL REY, Jesús (eds) (2016): La neología en las lenguas románicas. Recursos, estrategias y nuevas orientaciones, Peter Lang, Frankfurt am Main.

HuMBLEY, John (2018) : La néologie terminologique, Éd. Lambert-Lucas, Limoges.

Makri-Morel, Julie ; Dury, Pascaline ; Renner, Vincent (2020) : Neologica, nº 14, Perception, réception et jugement des néologismes.

SABLAYROLLES, Jean-François (2019): Comprendre la néologie. Conceptions, analyses, emplois, Éd. Lambert-Lucas, Limoges.

TCS = TERMCAT, CENTRE DE TERMINOLOGIA (2015-2018). Terminologia de ciències de la salut. Barcelona: TERMCAT, Centre de Terminologia.

http://www.termcat.cat/ca/Diccionaris En Linia/198/. 


\title{
Las creaciones neológicas por acronimia en el lenguaje de la publicidad ${ }^{1}$
}

\author{
Érika Vega Moreno ${ }^{2}$ \\ Universidad de Cádir.
}

Resumen: A partir de las diferentes investigaciones realizadas sobre el estudio de las creaciones neológicas en el lenguaje de la publicidad (cf., sobre todo, Vega Moreno, 2010 y 2016a), hemos observado un abundante predominio del empleo de la acronimia como procedimiento peculiar de creación de nuevas unidades léxicas en el ámbito publicitario. Es por eso que, en el presente trabajo, se abordarán, además de una serie de cuestiones relativas al fenómeno de la creatividad léxica, o neología, en general, y del resultado o producto de este proceso, o sea, del neologismo en particular dentro de la publicidad, de manera más concreta las unidades léxicas creadas mediante el mecanismo de la acronimia, centrándonos particularmente en el análisis de las tendencias más actuales que está tomando este procedimiento lingüístico en este tipo de lenguaje.

Palabras-clave: neología; neologismo; lenguaje de la publicidad; acronimia.

\begin{abstract}
From the different investigations carried out on the study of neological creations in the language of advertising (cf., especially, Vega Moreno, 2010 and 2016a), a predominance in the use of acronymy as a peculiar procedure to create new lexical units in the field of advertising has been observed. That is why this paper will address not only questions concerning the phenomenon of lexical creativity, or neology, in general, but also, questions about the result of this process, that is, neologisms, in particular those within the language of advertising, and, more specifically, the lexical units created by this mechanism of acronymy, with special attention paid to the analysis of current tendencies of this linguistic procedure in this kind of language.
\end{abstract}

Keywords: neology; neologism; advertising language; acronym.

\footnotetext{
${ }^{1}$ Este trabajo se inserta en la línea de investigación en "Neología" del "Gabinete de Industrias de la Lengua" del "Instituto Universitario de Investigación en Lingüística Aplicada” de la Universidad de Cádiz, línea que es desarrollada, bajo la dirección de la Profa. Dra. María Tadea Díaz Hormigo, por miembros del grupo de excelencia del Plan Andaluz de Investigación, Desarrollo e Innovación "Semaínein" (HUM 147) en el marco del nodo NEOUCA, integrado en la red de observatorios NEOROC (Red de Observatorios de Neología del Castellano), coordinada por el Observatori de Neologia de la Universitat Pompeu Fabra, mediante convenio específico de colaboración entre la Universidad de Cádiz y la Universitat Pompeu Fabra para la participación en la red NEOROC y la cooperación en investigación en neología (cf. http://www.iula.upf.edu/rec/neoroc).

Asimismo, el trabajo que presentamos se enmarca en el proyecto "Comunicación especializada y terminografía: usos terminológicos relacionados con los contenidos y perspectivas actuales de la semántica léxica” (FFI2014-54609-P) (Calificación: A), dirigido por el Prof. Dr. Miguel Casas Gómez y financiado por el Ministerio de Economía y Competitividad (Programa Estatal de Fomento de la Investigación Científica y Técnica de Excelencia. Subprograma Estatal de Generación del Conocimiento).

${ }^{2}$ Correo electrónico: rrika.vega@uca.es
} 


\section{Introducción}

Teniendo en cuenta la originalidad que presenta a veces la publicidad y prestando atención a la lengua empleada en dicho sector, en estas páginas, estudiaremos el fenómeno de la creatividad léxica, ya que es en el léxico el nivel en el que más se manifiesta, destacando el uso de la acronimia como uno de los mecanismos más empleado actualmente en la creación de nuevas unidades léxicas en el lenguaje de la publicidad, algo que ya auguraba R. Almela Pérez (1999: 210).

Como hemos comprobado en diferentes investigaciones realizadas (cf., fundamentalmente, É. Vega Moreno 2010, 2015, 2016a, 2016b, 2017a, 2017b y 2018), la utilización de nuevas unidades léxicas, no solo por acronimia, sino por cualquier otro procedimiento de formación léxica ${ }^{3}$ existente en nuestra lengua, es un recurso bastante frecuente en el sector publicitario, algo que puede deberse bien a cuestiones denominativas o referenciales, bien a razones expresivas o estilísticas, contribuyendo así al impacto visual y persuasivo que busca este tipo de lenguaje.

En nuestros trabajos citados, hemos analizado diferentes cuestiones relacionadas con la neología y la mayoría de los procedimientos y mecanismos en los que se basa la creación de nuevas unidades neológicas. Por ello, en este caso, hemos querido centrarnos en la acronimia, por ser un mecanismo tan utilizado en la actualidad en la publicidad. Para ello, caracterizamos este procedimiento, observando las distintas denominaciones que ha recibido en los distintos tratados de formación y creación léxica, además de ver las peculiaridades que este presenta. Así, una vez definido y caracterizado, presentaremos las distintas tipologías de acronimia existentes, que se basan en diferentes parámetros. Finalmente, a partir de diferentes ejemplos extraídos del ámbito publicitario, analizaremos las tendencias y particularidades que está tomando dicho mecanismo ${ }^{4}$ en este sector.

\section{Clasificación}

A la hora de analizar este recurso ${ }^{5}$ de creación léxica, hay que señalar que se trata de un procedimiento incluido dentro de la neología formal, caracterizándolo como un tipo de acortamiento, esto es, como un mecanismo de construcción de nuevas unidades léxicas mediante la reducción de

\footnotetext{
${ }^{3}$ Cuando hablamos de los procedimientos de formación de palabras, estamos haciendo referencia a los mecanismos de creación léxica o neológica, entendiendo la formación de palabras, como señala M. T. Díaz Hormigo (2000: 14 y 2003: 276-278), en su sentido amplio, es decir, como el conjunto de todos los procedimientos con los que cuenta la lengua para aumentar su patrimonio léxico, que son:

a) dentro de los procedimientos citados en la neología formal: la creación ex nibilo, por onomatopeya, por prefijación, por sufijación, por prefijación y sufijación simultáneas, por sustracción o regresión afijal, por composición léxica u ortográfica, por composición culta, por composición sintagmática o sintagmación, por abreviación o abreviamiento, por acronimia, por siglación, el préstamo adaptado, el no adaptado y el calco lingüístico o semántico;

b) dentro de los procedimientos incluidos en la neología semántica: la creación por conversión categorial o sintáctica, por lexicalización de una forma flexiva, por metáfora, por metonimia y sinécdoque, por elipsis originada en combinatoria léxica y el préstamo semántico, $\mathrm{y}$

c) por último, están aquellos procedimientos de creación léxica que no son tratados ni en la neología formal, ni en la semántica, como son: la creación expresiva, por etimología popular, el cruce o juego de palabras, etc.

${ }^{4}$ Para una revisión de los distintos ejemplos encontrados en el ámbito publicitario con sus respectivos contextos y datos de localización, véase, al respecto, el apéndice.

${ }^{5}$ Véase, al respecto, É. Vega Moreno (2010, 2016a y 2016b).
} 
elementos no afijales, por ejemplo, after o multi, por lo que se diferencia de la sustracción o regresión afijal, en la que se produce una supresión de un afijo, por ejemplo, retén ${ }^{8}$ o legislar?

Ahora bien, cuando hablamos de esa eliminación de segmentos no afijales, es necesario saber que esta puede ser de dos tipos:

a) si la reducción que se da es fonética, con repercusión gráfica, estamos ante una abreviación o abreviamiento, por ejemplo, corto ${ }^{10}<$ cortometraje y

b) si es el acortamiento es solo gráfico, se habrá dado lo que conocemos como abreviatura, por ejemplo, admón. ${ }^{11}<$ administración.

Asimismo, centrándonos en el procedimiento de la abreviación o abreviamiento, que es aquel, como ya adelantamos, por el que se crean nuevas unidades léxicas formadas a partir de la reducción fonética de segmentos no afijales de una palabra, distinguiremos, siguiendo a J. A. Miranda (1994: 172), M. T. Díaz Hormigo (2003: 324) y J. M. García Platero (2006: 6), dos tipos:

\section{- el abreviamiento o abreviación simple y \\ - la acronimia.}

El abreviamiento o abreviación simple afecta solo a una palabra y consiste en la reducción fonética, con repercusión gráfica, de segmentos no afijales de esta. Dicha reducción puede ser por aféresis, apócope o sincopa, creándose, como apunta M. Casado Velarde (1999: 5077-5079 y 2015: 63-65), un nuevo significante, que conserva la misma categoría lingüística y el mismo significado del vocablo original. Sirva como ejemplo, promo ${ }^{12}<$ promoción. Además, el nuevo significante respetará el género del original del que proviene y, con respecto al número, no presentará peculiaridades en la formación del plural, pero sí una dislocación acentual respecto al primitivo. Así, este mecanismo se caracterizará por ser un procedimiento sencillo de sustracción y eliminación de fragmentos.

A diferencia de este, la acronimia es un mecanismo más complejo que el anterior, ya que primero se da la reducción, no solo de una palabra, como en el abreviamiento o abreviación simple, sino de un grupo sintagmático, y luego, además, la combinación de fragmentos resultantes, formando una nueva unidad léxica, que generalmente respeta en la fusión el orden de aparición de sus constituyentes. Así es ejemplo de acronimia amosto (ejemplo creado a partir de las reducciones de amor y agosto, para hablar de un sentimiento de afecto, inclinación y entrega a todo lo que se hace y se da en el mes de agosto).

\section{Caracterización}

Una vez clasificada la acronimia como procedimiento formal, dentro del acortamiento, como un tipo de abreviación o abreviamiento, vamos a proceder primeramente a tratar el problema terminológico derivado de su denominación y posteriormente su caracterización, puesto que es, junto al abreviamiento o abreviación simple, un recurso de formación léxica bastante rentable en el español general.

\footnotetext{
6 “El Ayuntamiento de Barcelona clausuró ayer el after número 40 de los últimos meses” (El País, 6 de octubre de 2004).

7 "Al lavarse los dientes se encontrará a las dos multi tanto si tiene un cepillo eléctrico como si es manual, y para pasta, la que queda en los dientes" (Levante, 9 de marzo de 2005).

8 "Un retén de la policía de fronteras de Israel integrado por ocho agentes fuertemente armados controlaba el cruce con la carretera de Jericó, el único acceso que sigue abierto a esta barriada de 20.000 habitantes que se extiende por la ladera opuesta al Monte de los Olivos" (El País, 16 de octubre de 2015).

9 "Las dos comunidades recaudan y pueden legislar sobre los principales impuestos como IRPF y Sociedades, entre otros, sobre la base de un concierto o convenio pactado con la administración central y que está anclado en la Constitución española" (El País, 8 de octubre de 2015).

10 "El corto que arrasó en Internet" (El País, 23 de septiembre de 2009).

11 "La implantación de la admón. electrónica, en todo caso, llegará de manera progresiva en los próximos meses" (Cadena SER, 10 de julio de 2017).

12 “La 'promo' de Cuatro de la sexta temporada de 'Perdidos', la mejor del mundo" (El País, 2 de diciembre de 2009).
} 
Cuando hablamos de acronimia, estamos haciendo referencia a lo que otros investigadores y estudiosos de la materia han denominado:

- combinación, entrecruzamiento, cruce o acronimia (cf. R. Almela Pérez, 1999: 205);

- combinación ${ }^{13}$ (cf. M. F. Lang 1992: 32 y J. A. Miranda. 1994: 161);

- acronimia o cruce léxico (cf. S. Varela Ortega, 2005: 94);

- acronimia (cf. M. Casado Velarde, 1999: 5085 y 2015: 69; M. T. Díaz Hormigo, 2003: 324; J. M. García Platero, 2006: 8, y M. Estornell Pons, 2006: 270 y 2009: 276), o

- cruce léxico $^{14}$ (cf. S. Guerrero Salazar 2007: 214).

Asimismo, una situación similar encontramos con el producto resultante de este proceso acronímico, puesto que encontramos:

- palabra-percha, palabra-maleta, palabra-centauro, encaje, contaminación, palabra macedonia o palabra amalgamada (cf. R. Almela Pérez, 1999: 206);

- combinación (cf. M. F. Lang, 1992: 258 y J. A. Miranda, 1994: 161-162);

- acrónimo (cf. S. Varela Ortega, 2005: 94-95; M. Casado Velarde, 1999: 5085 y 2015: 69; M. T. Díaz Hormigo, 2003: 325; J. M. García Platero, 2006: 8, y M. Estornell Pons 2009: 277);

- cruce léxico (cf. S. Guerrero Salazar 2007: 214).

Para evitar esta amplia proliferación terminológica, nos referiremos a él simplemente con la denominación de acronimia, ya que, como hemos podido comprobar, es el término más ampliamente empleado en la mayoría de artículos y tratados específicos de formación de palabras consultados. Asimismo, el resultado de este proceso es el acrónimo ${ }^{15}$.

Así, por acronimia entendemos un procedimiento formal, mediante el que se crean nuevas unidades léxicas resultantes de la fusión mediante truncamientos de iniciales o finales de otros lexemas unidos, por ejemplo, guepardete (derivado de la fusión de guepardo y jinete, para vender la doble velocidad real).

Estos lexemas, como señala M. Casado Velarde (1999: 5085 y 2015: 69), suelen ser generalmente, dos, como en bicifestación (unidad formada a partir de bicicleta y manifestación, para anunciar una manifestación a favor de la creación de un carril exclusivamente para bicicletas), o muy raramente tres, por ejemplo, Banesto (de Banco Español de Crédito).

Además, estos elementos forman juntos un grupo de palabras que debe tener un funcionamiento unitario, el cual servirá de base para formar estos nuevos elementos léxicos.

En este mecanismo, las unidades constituyentes reducen previamente sus formas para posteriormente fusionarse. Asimismo, como apuntan F. González Ollé y M. Casado Velarde (1992: 107), R. Almela Pérez (1999: 210), y M. Casado Velarde (1999: 5087 y 2015: 70), los constituyentes de esta nueva unidad quedan unidos entre sí, sin separación gráfica o guion que recuerde la existencia de componentes.

De esta forma, este procedimiento es, como señala R. Almela Pérez (1999: 210), a diferencia de la abreviación o el abreviamiento simple e igual que la siglación, un recurso mixto, pues primero se da la sustracción y eliminación, y luego la adición o unión de fragmentos.

Pero, a pesar de que tanto en la acronimia como en la siglación se da un proceso doble, no debemos confundirlos porque, como señala R. Almela Pérez (1999: 205), presentan distintas características. Así, mientras que en la acronimia se eliminan partes de dos o más palabras que forman un grupo sintagmático y se unen los fragmentos no eliminados para formar una nueva unidad

\footnotetext{
13 Véase nota anterior.

${ }^{14}$ Como puede derivarse de esta revisión, tanto M. F. Lang (1992: 32 y 258) como J. A. Miranda (1994: 162-162) y S. Guerrero Salazar (2007: 214) utilizan la misma denominación para el proceso de creación y el resultado de dicho proceso: combinación en el primer y segundo caso y cruce léxico en el tercero.

15 Para evitar el abuso del empleo del término acrónimo en este trabajo, hemos hablado también de creación o unidad acronímica.
} 
léxica; en la siglación se suprimen fragmentos de todos los elementos de un grupo sintagmático, excepto las iniciales, y los elementos resultantes se juntan para formar un nuevo vocablo.

Ahora bien, las creaciones por acronimia o acrónimos presentan una serie de peculiaridades, que, siguiendo a R. Almela Pérez (1999: 207-209), son las que exponemos a continuación.

- En primer lugar, como ya adelantamos, generalmente estas unidades están formadas por dos constituyentes, por ejemplo, botequilla (derivada a partir de botella y mantequilla, para presentar una mantequilla líquida en botella). Raramente, encontramos acrónimos de tres, si bien, en estas situaciones, normalmente las dos primeras aportan sus fragmentos iniciales y la tercera el final, por ejemplo, Eurafrasia ${ }^{16}$ (de Europa, África y Asia).

- En segundo lugar, es posible, a veces, que algunas de las unidades se combinen íntegramente con las otras y esta combinación puede darse de dos maneras:

a) por un lado, a partir de la fusión de un fragmento + una unidad completa, por ejemplo, apartaestudio (unidad formada a partir de apartamento y estudio, para publicitar una pequeña vivienda en un edificio, por lo general con un único espacio) $y$,

b) por otro, unidad completa + fragmento, por ejemplo, avenacao (de avena y cacao, para presentar copos de avena con sabor a cacao).

- En tercer lugar, la naturaleza y estructura del fragmento de la unidad que sufre el truncamiento no sigue una pauta fija, ya que a veces no respeta la división silábica, por ejemplo, talonotel (de talón y hotel, creando una nueva unidad para presentar un cuadernillo de talones utilizados como forma de pago en un hotel).

- En cuarto y último lugar, como unidad léxica nueva que es el acrónimo, producto resultante del doble proceso de sustracción y adición, esta tiene unidad acentual y puede admitir prefijos y sufijos, por ejemplo, teleñequería ${ }^{17}$.

Además, con este procedimiento se pueden formar series léxicas. La frecuente aparición de determinados componentes fragmentados, como señalan F. González Ollé y M. Casado Velarde (1992: 107), R. Almela Pérez (1999: 209), M. Casado Velarde (1999: 5089-5090 y 2015: 72) y J. M. García Platero (2006: 9), en diferentes unidades acronímicas, ha dado lugar, al igual que en la composición sintagmática binominal (cf. É. Vega Moreno 2016a), a series de acrónimos o acronímicas.

Así, en el lenguaje de la publicidad, hemos encontrado series acronímicas tanto con fragmentos iniciales como finales. De esta forma, tenemos como fragmento inicial, a partir de credi$<$ crédito:

- por ejemplo, credivuelo (de crédito y vuelo, para anunciar una clase de financiación para poder viajar rápido y pagar lento), o

- por ejemplo, credirenta (de crédito y renta, para publicitar un tipo de préstamo inmediato para cubrir las necesidades surgidas de la renta), y,

como fragmento final, a partir de -ccino < cappuccino:

- por ejemplo, frappuccino (de la palabra francesa frappé y capuccino, para presentar un batido de capuccino espeso con helado), o

- por ejemplo, chococino (de chocolate y capuccino, para presentar un tipo de capuchino con sabor a chocolate).

\footnotetext{
16 Unidad acronímica localizada en R. Almela Pérez (1999: 2008), M. Casado Velarde (1999: 5086) y M. I. Rodríguez Ponce (2005: 11).

${ }^{17}$ Creación por acronimia tomada de R. Almela Pérez (1999: 209).
} 


\section{Tipología}

Asimismo, dentro de la acronimia, pueden ser distinguidos diferentes subtipos, atendiendo a diferentes parámetros. Para ello, seguiremos la tipología establecida por M. Casado Velarde (1999: 5087-5088 y 2015: 70-71):

a) según el número de unidades que lo integran,

b) atendiendo a la categoría lingüística de los lexemas constituyentes, y

c) dependiendo del componente fragmentado.

De esta forma, observamos, que, según el número de unidades que lo integran, diferenciamos, como ya comentamos:

a) acrónimos de dos constituyentes, por ejemplo, bolahuete (de bola y cacahuete, para presentar un cacahuete bañado en chocolate en forma de bolas) y

b) acrónimos de tres, por ejemplo, Banibao ${ }^{18}$ (de Banco Industrial de Bilbao).

Atendiendo a la categoría lingüística de los lexemas que sirven de base para su creación, podemos encontrar, entre las combinaciones más fructíferas, ordenadas de mayor a menor productividad:

a) las creaciones acronímicas formadas por sustantivo + sustantivo, por ejemplo, amodio (de amor y odio, para hablar de una característica de los seres humanos de odiar y amar lo mismo en función de la situación y nuestro estado de ánimo);

b) las de sustantivo + adjetivo, por ejemplo, yolado (de yogurt y belado, unidad extraída de un anuncio para presentar un tipo de yogur helado), $y$

c) las de adjetivo + adjetivo, por ejemplo, ligesistible (de ligera e irresistible, creación para anunciar un tipo de agua que presenta lo ligero del agua Font Vella y lo irresistible del zumo de frutas).

Además, dependiendo del componente fragmentado, como apunta M. Casado Velarde (1999: 5087-5088 y 2015: 70), distinguimos entre:

a) acrónimos que solo fragmentan un constituyente, que puede ser bien el primero, por ejemplo, amodio (de amor y odio, ya citado), o bien el segundo, por ejemplo, pizzalada (de pizza y ensalada, ejemplo detectado para presentar una combinación de pizza y ensalada), y

b) acrónimos que fragmentan los dos, por ejemplo, capuchila (de capucha y mochila, unidad léxica formada para anunciar una mochila con capucha que regala en promoción).

De todas estas tipologías, las más productivas son la segunda y la tercera, por lo que si combinamos estas tipologías, podemos encontrar:

a. acrónimos de sustantivo + sustantivo, entre los que descubrimos,

a.1. acrónimos de sustantivo + sustantivo que solo fragmenta uno de los dos componentes, por ejemplo, el ya citado pizzalada, $\mathrm{y}$

\footnotetext{
${ }^{18}$ Ejemplo de acrónimo encontrado en M. Casado Velarde (1999: 5086) y M. I. Rodríguez Ponce (2005: 11).
} 
a.2. acrónimos de sustantivo + sustantivo que fragmenta los dos componentes, por ejemplo, abejonejo (de abeja y conejo, creación para publicitar un producto que alivia y calma rápidamente las molestias en la piel irritada por insectos);

b. acrónimos de sustantivo + adjetivo, entre los que localizamos,

b.1. acrónimos de sustantivo + adjetivo que solo fragmenta uno de los dos componentes, por ejemplo, arrozistible (de arroz e irresistible, unidad creada para anunciar su arroz con leche al chocolate, que es irresistible), y

b. 2. acrónimos de sustantivo + adjetivo que fragmenta los dos componentes, por ejemplo, yolado, que ya comentamos anteriormente;

c. acrónimos de adjetivo + adjetivo, entre los que hallamos,

c.1. acrónimos de adjetivo + adjetivo que solo fragmenta uno de los dos componentes, por ejemplo, alfanumérico ${ }^{19}$ (de alfabético y numérico), y

c.2. acrónimos de adjetivo + adjetivo que fragmenta los dos componentes, por ejemplo, tiernoso, de tierno y cremoso (unidad creada para presentar un queso tierno y cremoso).

En todos estos tipos de creaciones léxicas, los segmentos fusionados pueden, según M. Casado Velarde (1999: 5086), sufrir alteraciones fonológicas, nada fuera de lo normal, pues es algo muy característico en todos los mecanismos de formación léxica. Además, el significado de estas formaciones, en la mayoría de los casos, como apunta el citado autor (1999: 5085 y 2015: 70), resulta de la combinación del contenido semántico de sus constituyentes.

\section{Conclusiones}

A partir de las diferentes unidades acronímicas detectadas en el sector publicitario, hemos observado que este recurso alcanza una enorme productividad en la actualidad dentro del lenguaje de la publicidad, aspecto que puede deberse fundamentalmente al impacto visual que puede provocar este tipo de creaciones léxicas en el receptor, de manera que, una vez capturada la atención del consumidor, se podrá informar sobre las cualidades que el producto presenta o recordar sus características, si ya ha sido lanzado por primera vez, y, fundamentalmente, persuadir para que se adquiera.

Además, el significado que aportan estas unidades suele ser generalmente composicional, esto es, la mayoría de las veces el significado de la nueva formación léxica puede inferirse a partir del significado de sus partes, algo que puede deberse a que la publicidad busca la claridad por encima de todo.

Incluso, estas creaciones léxicas responden al principio de economía que rige el lenguaje publicitario, pues ayudan a la brevedad que estos mensajes buscan.

Con respecto a las tendencias encontradas en este tipo de lenguaje en relación con el mecanismo estudiado, hemos visto que cuando se emplea este recurso suele ser más frecuente las creaciones de dos constituyentes que de tres, no habiendo encontrado en la actualidad ningún caso en el lenguaje publicitario que resulte de la acronimia de tres unidades.

Así, dentro de las de formaciones de dos constituyentes, predominan las unidades formadas por sustantivo y sustantivo y, en menor medida, las de sustantivo y adjetivo, y las de adjetivo y adjetivo. Además, abundan las formaciones acronímicas que fragmentan los dos constituyentes, que las que solo fragmentan uno.

${ }^{19}$ Unidad acronímica hallada en M. Casado Velarde (1999: 5086 y 2015: 71) y M. I. Rodríguez Ponce (2005: 11). 
Asimismo, hemos detectado frecuentes casos que, según M. Casado Velarde (1999: 5090 y 2015: 72) y J. M. García Platero (2006: 9), se denominan series de acrónimos o acronímicas, no solo con fragmentos iniciales, sino también con fragmentos finales.

Por todo ello, pensamos que, dentro de las particularidades que presenta el lenguaje de la publicidad, debería aparecer la creación léxica como rasgo peculiar, característico e imprescindible de este lenguaje, además de ser requisito de obligado desarrollado dentro de los tratados que caracterizan este tipo de lenguaje e, incluso, dedicarle un capítulo entero a este aspecto de tanto relieve e importancia. Asimismo, su rentabilidad y productividad debe ser referida en los tratados de formación de palabras, que deben actualizar sus presupuestos atendiendo a las nuevas tendencias de creación léxica que se observan en la actualidad (cf. Díaz Hormigo, 2012 y 2015, y Díaz Hormigo y Vega Moreno, 2018).

En este sentido, debemos realizar una llamada de atención sobre el estudio de la creación léxica dentro del ámbito publicitario, ofreciendo una revisión amplia sobre los recursos existentes en nuestro idioma para ello, dándole la importancia que tiene y haciendo referencia a todas aquellas posibilidades que nuestra lengua nos ofrece, no limitándose a la formación de palabras en sentido restringido y atendiendo solo a los denominados tradicionalmente procedimientos morfológicos de la formación de palabras, esto es, la derivación, la composición y la parasintesis.

\section{Referencias bibliográficas}

Almela PÉrez, Ramón (1999), Procedimientos de formación de palabras en español, Barcelona, Ariel.

Casado Velarde, Manuel (1999), “Otros procesos morfológicos: acortamientos, formación de siglas y acrónimos”, en Bosque, Ignacio y Demonte, Violeta: Gramática descriptiva de la lengua española, Madrid, Espasa Calpe, pp. 4993-5040.

CASAdo Velarde, Manuel (2015), La innovación léxica en el español actual, Madrid, Editorial Síntesis.

DíAz Hormigo, M. Tadea (2000), Disciplinas lingüísticas y formación de palabras, Cádiz, Servicio de Publicaciones de la Universidad de Cádiz.

Díaz Hormigo, M. Tadea (2003), Morfología, Cádiz, Servicio de Publicaciones de la Universidad de Cádiz.

DíAz Hormigo, M. Tadea (2012), "La formación de palabras: tendencias predominantes en la derivación", en Montoro del Arco, Esteban Tomás (ed.): Neología y creatividad lingüistica, Quaderns de Filologia de la Universitat de València, Anejo no 77, pp. 83-112.

DíAz Hormigo, M. Tadea (2015), "Neología aplicada y lexicografía: para la (necesaria) actualización de las entradas de los elementos de formación de palabras en diccionarios generales" Revista de Lingüistica y Lenguas Aplicadas, 10, pp. 12-20.

Díaz Hormigo, María Tadea y Vega Moreno, Érika (2018), "Algunas de las aplicabilidades actuales de las investigaciones en neología y sobre los neologismos", Pragmalingüística, 26, pp. 54-68.

EsTORNELl PONS, María (2006), "Los neologismos: procesos de formación”, en Aleza Izquierdo, Milagros (coord.), Lengua española para los medios de comunicación: usos y normas actuales, Valencia, Tirant lo Blanch, pp. 267-280.

ESTORNELL PONS, María (2009): El reconocimiento de neologismos y su caracterización en un corpus de prensa escrita (2004-2007), Tesis doctoral inédita, València, Universitat de València.

García Platero, Juan Manuel (2006), La parasintesis. El acortamiento. Las siglas, Liceus, pp. 1-17.

GonzÁlez Ollé, Fernando y CASAdo Velarde, Manuel (1992), "Formación de palabras", en Holtus, Günter, Metzeltin, Michael y Schmitt, Christian (eds.), Lexikon der Romanistischen Linguistik, vol. 6.1, Tübingen. Max Niemeyer Verlag, pp. 91-109.

Guerrero SALAZAR, Susana (2007), La creatividad en el lenguaje periodístico, Madrid, Cátedra.

LANG, Mervyn F. (1992), Formación de palabras en español, Madrid, Cátedra.

MirANDA, J. Alberto (1994), La formación de las palabras en español, Salamanca, Colegio de España. 
RodríGuEZ Ponce, María Isabel (2005): Otros procesos de formación de palabras, Madrid: E-excellence - Liceus.

VArela OrTega, Soledad (2005), La morfología léxica: Formación de palabras, Madrid, Gredos.

Vega Moreno, Érika (2010), Las creaciones neológicas en el lenguaje de la publicidad, Trabajo de investigación inédito para la obtención del Diploma de Estudios Avanzados, Cádiz, Universidad de Cádiz.

Vega Moreno, Érika (2015), “La creación neológica como herramienta publicitaria, en Álvarez López, C. J., Garrido Martí, B. y González Sanz, M. (coords.), Jóvenes aportaciones a la investigación lingüistica, Sevilla, Ediciones Alfar, pp. 351-365.

Vega Moreno, Érika (2016a), La creatividad léxica en el lenguaje de la publicidad. Análisis lingüístico de los mecanismos de producción e interpretación neológicas en los sectores de la estética y la peluquería, Tesis doctoral inédita, Cádiz, Universidad de Cádiz.

Vega Moreno, Érika (2016b), "Bases metodológicas del estudio de las creaciones neológicas en el lenguaje de la publicidad”, en Ruano San Segundo, P., Nieto Caballero, G. y Fernández de Molina Ortés, E. (eds.), Nuevos enfoques en investigación lingïística, Cáceres, Servicio de Publicaciones de la Universidad de Extremadura, pp. 57-74.

Vega Moreno, Érika (2017a), "Productividad de los mecanismos de creación léxica en el lenguaje de la publicidad", en Olza, I., Pérez-Salazar, C. y Celayeta N. (eds.), Semántica, léxico y fraseología, Frankfurt am Main, Peter Lang, pp. 145-160.

Vega Moreno, Érika (2017b), "La creatividad léxica en el lenguaje de la publicidad. Análisis lingüístico de los mecanismos de producción e interpretación neológicas en los sectores de la estética y la peluquería”, en Fernández Gómez, S., Martínez Aguirre, R., Núñez Bayo, Z. y Ureña Tormo, C. (eds.), Investigaciones actuales en Lingüistica. Vol. VII: Planes de investigación de doctorado, Alcalá de Henares, Servicio de Publicaciones de la Universidad de Alcalá, pp. 63-77.

Vega Moreno, Érika (2018), “Acercamiento al estudio de las unidades neológicas en el sector publicitario de la alimentación”, en Díaz, M.; Vaamonde, G.; Varela, A.; Cabeza, M. C.; García-Miguel, J. M. y Ramallo, F. (eds.), Actas do XIII Congreso Internacional de Lingüística Xeral, Vigo, Universidade de Vigo, pp. 912-919.

\section{Apéndice}

1) abejonejo, de abeja y conejo, creación de Afterbite de 2009, en el contexto "¿Y si te pica un abejonejo? Te pique el insecto que te pique, ten a mano Afterbite" (Anuncio televisivo, 25/07/2009), para publicitar un producto que alivia y calma rápidamente las molestias en la piel irritada por insectos.

2) amodio, de amor y odio, ejemplo localizado en un spot de Campofrío a finales de 2017, en el contexto "Buenas, vengo a por el diagnostico. Pase. Estamos aquí un poco desquiciados, ¿eh? Esto es una pandemia. Y de esta no se libra nadie. Pero, ¿qué nos pasa, doctor? ¿Es amor? Eso va a ser odio. Odio, odio... No, no, es amodio. ¿Amodio. ¿Cómo que amodio? $¿ Y$ eso es grave? Yo me encargo, doctor. En este país somos así, nadie odia al cien por cien, y nadie ama al cien por cien. Nadie es incondicional. ¿Y cómo no nos lo han dicho antes? No hubiéramos llegado hasta aquí. El amor se mezcla con el odio, y viceversa. Y es que nos pierden los sentimientos. Somos hipérboles emocionales. Amodiamos" (Anuncio televisivo, 18/12/2017), para tratar una característica de los seres humanos de odiar y amar lo mismo en función de la situación y nuestro estado de ánimo. 
3) amosto, de amor y agosto, unidad hallada en la página web de Volkswagen en 2017, en el contexto "Amosto. Amor a todo lo que te da agosto", para hablar de un sentimiento de afecto, inclinación y entrega a todo lo que se hace y se da en el mes de agosto.

4) apartaestudio, de apartamento y estudio, ejemplo localizado en Booking en 2016, en el contexto "Apartaestudio independiente, con un ambiente acogedor tranquilo y muy limpio. Cama de 1,60 confortable y muy limpia. Hay un sofacama para uso adicional" (Pagina web, 18/10/2016), para publicitar una pequeña vivienda en un edificio, por lo general con un único espacio.

5) arrozistible, de arroz e irresistible, unidad creada por Danone en 2014, en el contexto "Si te gusta el chocolate, te gustará el arroz con leche al chocolate. Nuevo arroz con leche al chocolate de Danone. ¡Arrozistible!" (Anuncio televisivo, 24/01/2014), para anunciar su arroz con lecha al chocolate, que es irresistible.

6) avenacao, de avena y cacao, ejemplo detectado en un anuncio de Cola Cao en 2017, en el contexto "Me voy. ¿Otro día sin desayunar? ¿Cuándo empezarás a cuidarte? Hoy no puedo, pero te digo una cosa: mañana empiezo. Empieza a desayunar mejor con Avenacao, la unión de todo lo bueno de la avena y del cacao natural para que sea muy fácil empezar mejor cada mañana. Avenacao. Empieza a desayunar mejor" (Anuncio televisivo, 20/10/2017), para presentar copos de avena con sabor a cacao.

7) bimbollo, de Bimbo y bollo, creación formada por Nestlé en 2008, en el contexto "Y para el recreo, ¿qué? Bimbollo. Su mamá le pone siempre dos bimbollos, ricos bollos de leche y huevo para su recreo" (Anuncio televisivo, 06/07/2008), para presentar una pasta dulce, esponjosa y cocida al horno de la marca Bimbo.

8) bicifestación, unidad formada a partir de bicicleta y manifestación, ejemplo localizado en un cartel en la ciudad de Cádiz en 2009, en el contexto "Próxima bicifestación: Mayo / Junio día a concretar; posible: 29 / 30 mayo" (Folleto publicitario, 06/05/09), para anunciar una manifestación a favor de la creación de un carril exclusivamente para bicicletas.

9) bolahuete, de bola y cacabuete, ejemplo sacado de un cartel de M\&M's en 2010, en el contexto "Consigue la auténtica bolahuete. Hay varias maneras de conseguir tu propia bolahuete. ¿Cuál prefieres?” (Folleto publicitario, 16/08/10), para presentar un cacahuete bañados en chocolate en forma de bolas.

10) botequilla, derivada a partir de botella y mantequilla, ejemplo extraído de un anuncio de Central Lechera Asturiana en 2010, en el contexto "Mantequilla, mantequilla. Más me gusta cada día para untar de maravilla por el pan. Mantequilla, mantequilla. Va del bote a la tostada, tan sabrosa, tan sencilla y tan fácil de untar. Mantequilla, mantequilla. Llega la revolución a tus desayunos. Nueva botequilla de Central Lechera Asturiana. + fácil de usar. + fácil de untar. Central Lechera Asturiana. Lo mejor por naturaleza" (Anuncio televisivo, 01/06/2010), para presentar una mantequilla líquida en botella.

11) capuchila, de capucha y mochila, unidad léxica extraída de un spot de Nesquik en 2017 , en el contexto "No es una mochila. Es una capuchila, la mochila con capucha de Nesquik. Puedes conseguirla gratis en los packs grandes de Nesquik" (Anuncio televisivo, 18/10/2017), para anunciar una mochila con capucha que regala en promoción. 
12) chococino, de chocolate y cappuccino, ejemplo extraído del envase de un tipo de capsula de Nestlé Dolce Gusto en 2017, en el contexto "Descubre NESCAFÉ Dolce Gusto Chococino, un delicado e indulgente chocolate caliente con el sofisticado sabor de selectas semillas de cacao" (Página web, 06/08/2017), para presentar un tipo de capuchino con sabor a chocolate.

13) colibrista, derivado de la fusión de colibrí y velocista, creación extraída de la campaña de ONO en 2010 , en el contexto "Un colibrí es velocidad y un velocista también es velocidad, pero un colibrista es el doble de velocidad. Ahora $\mathrm{ONO}$ da a sus clientes el doble de velocidad real" (Anuncio televisivo, 02/03/10), para vender la doble velocidad real.

14) credirenta, de crédito y renta, ejemplo localizado en la página web del Banco Sabadell en 2012, en el contexto "CrediRenta. Un préstamo inmediato para cubrir las necesidades surgidas de la renta." (Pagina web, 12/04/2012), para publicitar una clase de financiación inmediata para cubrir las necesidades surgidas de la renta.

15) credivuelo, de crédito y vuelo, ejemplo encontrado en un anuncio de Iberia, en el contexto "Viaje rápido... pagando lento! Ahora puede volar por Iberia pagando en cómodos plazos con credivuelo Iberia" (Folleto publicitario), para anunciar un tipo de préstamo para poder viajar rápido y pagar lento.

16) despertachock, unidad formada a partir de despertador y el préstamo del inglés shock, que, sin embargo, tal vez por influencia tanto de la pronunciación inglesa como de la grafía y pronunciación españolas, aparece erróneamente transcrito como chock, localizada en un anuncio de Colacao en 2008, en el contexto "Véngate del despertador. Colacao te regala el único despertador que se apaga lanzándolo. Despertachock gratis en los colacaos grandes" (Anuncio televisivo, 28/09/08), para anunciar un reloj que, a la hora en que previamente se le dispuso, hace sonar una campanilla, timbre o zumbido, para despertar y se apaga chocándolo contra algo.

17) frappuccino, de la palabra francesa frappé y cappuccino, ejemplo extraído de una marca registrada de bebidas de café congelados vendidos por Starbucks, cadena internacional de café, en el contexto "Ahora Starbucks lanzará el Mermaid Frappuccino. Estará inspirado en la icónica y mitológica sirena de dos colas, emblema de su marca" (Página web), para presentar un batido espeso con helado.

18) guepardete, derivado de la fusión de guepardo y jinete, ejemplo extraído de la campaña de ONO en 2010 , en el contexto "Un guepardo es velocidad y un jinete también es velocidad, pero un guepardete es el doble de velocidad. Ahora ONO da a sus clientes el doble de velocidad real" (Anuncio televisivo, 09/03/10), para vender la doble velocidad real.

19) ligesistible, de ligera e irresistible, creación de Font Vella en 2016, en el contexto "Esto es ligero. Esto es irresistible. Pero esto es ligesistible como Fontvella Levité. La experiencia ligera de Fontvella y lo irresistible del zumo de frutas. Una mezcla tan única que te será difícil de encontrar las palabras a no ser que te las inventes. Fontvella Levité. Tremendamente ligesistible" (Anuncio televisivo, 17/03/2016), para anunciar un tipo de agua que presenta lo ligero del agua Font Vella y lo irresistible del zumo de frutas. 
20) pizguesa, de pizza y hamburguesa, unidad detectada en un anuncio de Telepizza en 2016, en el contexto "Vamos a hablar hija mía. ¿Qué te ocurre? Tengo pizguesa ¿Pizguesa? Las mimas ganas de pizza que de hamburguesa. Tranquila, hija, si a mí también me pasa. ¿Qué a ti también te pasa? Presentamos la nueva Telepizza Burger, queso chédar, carne de vacuno y tomate, cubierta por una fina masa y salsa Burger. Descubre el nuevo sabor de la hamburguesa hecha pizza" (Anuncio televisivo, 11/01/2016), para indicar que se tienen las mismas ganas de pizza que de hamburguesa.

21) pizzalada, de pizza y ensalada, ejemplo detectado en un anuncio de Telepizza en 2014, en el contexto "Telepizza presenta pizzalada, una deliciosa combinación de pizza bacón crispy, cubierta con ensalada cesar y pops de pollo. Descubre la pizza más sorprendente. Telepizza" (Anuncio televisivo, 02/07/2014), para presentar una combinación de pizza y ensalada.

22) talonotel, de talón y hotel, ejemplo detectado en la página web de Carrefour en 2010, en el contexto "Compra ahora un talonario Talonotel y Viajes Carrefour te regala un talón por valor de 60 Euros para que puedas escaparte cuando quieras a alguno de los 3.000 hoteles, en más de 1.000 destinos" (Página web, 19/06/10), para presentar un cuadernillo de talones utilizados como forma de pago en un hotel.

23) yofre, de yogurt y gofre, creación localizada en Danone en 2016, en el contexto "El Yofre es un gofre hecho con masa de yogur, que hace que la masa sea más ligera, jideal para esos momentos de más frío!” (Página web, 30/01/2016), para presentar un gofre hecho con masa de yogurt.

24) yolado, de yogurt y helado, unidad extraída de un anuncio de Danone en 2012, en el contexto "Noticia, noticia. Hoy de postre queremos yogurt. Pero eso no es ninguna noticia. ¿Pero que sea helado? Sí. ¿Yogurt o helado? Yolado de Danone. El nuevo helado de Danone tiene toda la salud del yogurt y el placer del helado. Y con menos calorías. Esto sí que es una buena noticia. Tan simple como buscarlo entre tus yogures. Al llegar a casa congelarlo. Y cada día disfrutarlo. Tu Danone hecho helado" (Anuncio televisivo, 22/05/2012), para presentar un tipo de yogur helado. 


\title{
Diagnosticar, hemopoètic, naixement: neologicitat i morfologia de les unitats terminològiques eventives en medicina
}

\author{
Òscar Pozuelo-Ollé, Rosa Estopà, Mercè Lorente ${ }^{1}$ \\ Universitat Pompen Fabra - IULA
}

Resum: Els predicats eventius es poden vehicular amb unitats lèxiques de diverses categories gramaticals (noms, verbs, i adjectius). En aquest estudi descrivim el tractament lexicogràfic de setze unitats terminològiques (ULE) eventives formades per sufixació, derivació zero, o composició culta. Establim la neologicitat de les ULE per a dos diccionaris especialitzats en ciències de la salut (TCS i DEMCAT), i verifiquem, si escau, el valor eventiu del contingut de la definició de les ULE. Paraules clau: eventivitat, neologicitat, neonímia, morfologia, medicina

\begin{abstract}
Eventive predicates may be conveyed by lexical units of different parts of speech (nouns, verbs, and adjectives). This study, based on a lexicographical approach, analyzes sixteen eventive terminological units (ULE) formed through suffixation, conversion, or classical compounding. Neologicity for each ULE is established according to health-sciences specialized dictionaries (TCS and DEMCAT), and, when relevant, the eventive value of ULE is supported by their definitions.
\end{abstract} Keywords: eventivity, neologicity, neonymy, morphology, medicine

\footnotetext{
11Correos electrónicos: oscar.pozuelo@upf.edu,rosa.estopa@upf.edu, merce.lorente@upf.edu
} 


\section{Introducció}

Els neònims, neologismes terminològics, o neologismes especialitzats, són les unitats lèxiques noves que s'utilitzen en un àmbit d'especialitat concret.

En el estudio de la neología terminológica se produce la intersección de los dos campos que integran el sintagma elegido para esta denominación tan transparente: el de la neología, entendida ésta como el estudio del proceso de generación e incorporación de nuevas unidades en una lengua, y el de la terminología, en su sentido más amplio, de ámbito dedicado al estudio de las unidades especializadas de una o varias lenguas. (García Palacios, 2009, p. 18)

La producció de neònims es vincula amb la creació i la difusió del coneixement especialitzat (neonímia primària o néonymie d'origine), o bé amb la traducció del coneixement especialitzat (neonímia secundària o néonymie d’appoint) (Rondeau, 1981; Cabré, 1992). En tots dos casos, per la seva doble condició d'unitats lèxiques noves i d'unitats lèxiques especialitzades, els neònims presenten les característiques següents (Cabré, 1992, 2004; García Palacios, 2009; Estopà, 2010):

- Univocitat

- Monoreferencialitat

- Inserció en el sistema ontològic d'un àmbit d'especialitat

- Necessitat denominativa

- Variació denominativa

- Formació a partir dels procediments morfològics productius en cada àmbit d'especialitat

- Estabilitat en l'ús vinculada a la difusió

- Possibilitat d'adequació semàntica entre la forma i el contingut mitjançant redenominacions successives

- Possibilitat de banalització o pèrdua del valor especialitzat

- Possibilitat de datació precisa del primer ús

\section{Marc teòric}

El marc teòric en el qual fonamentem aquesta recerca parteix del principi que totes les unitats terminològiques, o unitats lèxiques especialitzades (ULE), s'integren naturalment en el discurs. Des d'aquesta perspectiva, les ULE poden vehicular propietats semàntiques com la predicació eventiva.

\subsection{Eventivitat i discurs}

Els esdeveniments constitueixen un tipus de predicat, que s'oposa principalment als resultats (incloses les entitats), i que denota accions perceptibles sensorialment.

It is events, processes, and actions, and not facts or results, that occur, take place, begin, last, and end. The former, and not the latter, can be watched, heard, followed, and observed; they can be sudden[,] gradual, violent, or prolonged. (Vendler, 1967, p. 141)

\subsubsection{La predicació eventiva}

Els predicats oracionals presenten les característiques següents d'acord amb la Teoria Generativa (Napoli, 1989): 
- Són unitats semàntiques.

- No constitueixen necessàriament unitats lèxiques o unitats sintàctiques.

- Es projecten lingüísticament en forma de participants a través de papers semàntics.

- Consten d'un nucli, generalment amb modificadors (unitats lèxiques que restringeixen el significat del predicat) $i$ especificadors (altres unitats lèxiques amb significat eventiu).

- Tenen com a nucli unitats lingüístiques amb significat lèxic: alguns adjectius, la majoria de verbs, i els noms abstractes.

- Presenten un correlat amb els arguments a través del nucli, que és una unitat lèxica amb estructura eventiva.

L'eventivitat es realitza lingüísticament a través d'unitats lèxiques. Els nuclis prototípics són verbs, que poden incloure un component semàntic implícit de durada o finalització (Vendler, 1967). $\mathrm{Al}$ voltant del verb es genera un conjunt de relacions sintacticosemàntiques en forma de papers temàtics (representació lògica) i arguments (expressió lingüística) (Grimshaw, 1990; Williams, 1994).

\subsubsection{L'eventivitat en terminologia}

En terminologia, la recerca sobre eventivitat lèxica se centra en les unitats verbals. S’han identificat quatre tipus de verbs, dels quals només els dos primers són pròpiament especialitzats (Lorente, 2007):

- Verbs quasiterme: verbs que es relacionen amb un nom del mateix paradigma i s'insereixen en un sintagma verbal, en el qual hi ha un terme

- Verbs fraseològics: verbs que es relacionen amb un nom del mateix paradigma i s'insereixen en un sintagma verbal, en el qual no hi ha un terme

- Verbs de relació lògica: verbs que es relacionen amb un nom del mateix paradigma i no s'insereixen en un sintagma verbal

- Verbs performatius del discurs: verbs que no es relacionen amb un nom del mateix paradigma

La relació paradigmàtica amb les unitats verbals justifica el valor eventiu de les unitats nominals (Bretonnel Cohen, Palmer, \& Hunter, 2008) i les unitats adjectivals (Kornfeld \& Resnik, 2003). Algunes unitats adjectivals també poden fer referència a propietats mesurables (eventives): temps, grau, qualitat, quantitat, i modalitat epistèmica (Maniez, 2001).

\subsection{Eventivitat i morfologia}

Els neònims que analitzem en aquesta recerca corresponen a unitats lèxiques especialitzades (ULE) utilitzades en medicina en català. La neonímia primària, en aquest àmbit d'especialitat, es basa en tres procediments morfològics principals: la sufixació, la derivació zero, i la composició culta. 


\subsubsection{La sufixació $i$ la derivació zero}

La sufixació i la derivació zero són els procediments morfològics que, a efectes del present estudi, permeten de completar paradigmes morfològics per recategorització d'una base lèxica.

A partir del criteri lexicogràfic invers —una unitat lèxica és neològica si no es recull en els diccionaris de referència no especialitzats en català-, l'Observatori de Neologia de la Universitat Pompeu Fabra documenta 1007 lemes nous formats per sufixació (un 10,6 \% del total), i 145 lemes nous formats per derivació zero (conversió sintàctica i lexicalització) (un 2,6 \% del total) entre els anys 2007 i 2009 (Bernal \& Cabré, 2015; Lorente \& Cantero, 2015). Aquestes diferències quantitatives es mantenen sistemàticament en el període 2007-2017 (mitjanes anuals de 725 i 175 lemes nous, respectivament) (BOBNEO).

Tots dos procediments morfològics poden vehicular eventivitat, que s'observa prototípicament en els noms o els adjectius formats a partir de bases verbals, i també en els verbs (Cabré, 2002; Institut d'Estudis Catalans, 2016). En neonímia catalana, la sufixació es considera el procediment morfològic preferent per als noms deverbals (sufixos -atge, -ció, i -ment) i els verbs deadjectivals (sufixos -ificari -itzar); els verbs denominals poden presentar derivació zero (desinència -ar) i sufixació (sufixos -ejar, -ificar, i -itzar), a vegades en concurrència amb una mateixa base (Rull, 2004).

\subsubsection{La composició culta}

La composició culta és un procediment morfològic que, a efectes del present estudi, permet d'obtenir neonímia utilitzada prototípicament en l'àmbit mèdic.

A partir del criteri lexicogràfic invers —una unitat lèxica és neològica si no es recull en els diccionaris de referència no especialitzats en català-, l'Observatori de Neologia de la Universitat Pompeu Fabra documenta gairebé 1143 lemes nous formats per composició culta (un 8,6 \% del total) entre els anys 2007 i 2009 (Cañete et al., 2015). Aquestes dades es mantenen bastant estables en el període 2007-2017 (mitjana anual de 583 lemes nous) (BOBNEO).

La composició culta pot vehicular eventivitat en la mesura que el formant culte (d'origen grecollatî) situat més a la dreta, que és el nucli de la paraula (nom, verb, o adjectiu) en la qual s'insereix, té un valor eventiu (Gràcia, 2002; Institut d'Estudis Catalans, 2016). En neonímia catalana, aquest formant culte final es pot combinar amb altres formants cultes (solució més habitual) o bé amb bases patrimonials; destaca la productivitat de formants sufixals cultes eventius com -cidi 'mort', -fôbia 'aversió', i -teràpia 'tractament' (Cañete et al., 2015).

\section{Estudi de casos}

Per a l'estudi de casos de la present recerca seleccionem un conjunt representatiu d'unitats lèxiques especialitzades (ULE) que tenen un valor predicatiu eventiu. Aquestes ULE, obtingudes mitjançant els procediments morfològics descrits, i agrupades segons el paradigma morfològic, són susceptibles de figurar en diccionaris especialitzats en medicina.

\subsection{Metodologia}

Les unitats lèxiques especialitzades (ULE) objecte d'estudi s'agrupen d'acord amb els tres procediments morfològics pertinents $i$ les tres categories lèxiques eventives descrites en el marc teòric (nom, adjectiu, i verb; en endavant referim la categoria lèxica de cada ULE mitjançant els subíndexs $\mathrm{N}, \mathrm{A}, \mathrm{i} \mathrm{v}$, respectivament). Llistem aquestes ULE d'acord amb les propietats morfològiques i morfosintàctiques a continuació. 


\begin{tabular}{|c|c|c|}
\hline ULE & Categoria lèxica & Procediment morfològic \\
\hline $\begin{array}{l}\text { esplenectomia }_{\mathrm{N}} \\
\text { esplenectomic } \\
\text { esplenectomitzar }\end{array}$ & $\begin{array}{l}\text { Nom } \\
\text { Adjectiu } \\
\text { Verb }\end{array}$ & $\begin{array}{l}\text { Composició culta } \\
\text { Sufixació } \\
\text { Sufixació }\end{array}$ \\
\hline $\begin{array}{l}\text { bemopoesi } i_{\mathrm{N}} \\
\text { hemopoètic }\end{array}$ & $\begin{array}{l}\text { Nom } \\
\text { Adjectiu }\end{array}$ & $\begin{array}{l}\text { Composició culta } \\
\text { Sufixació }\end{array}$ \\
\hline $\begin{array}{l}\text { diagnòstic }_{\mathrm{N}} \\
\text { diagnòstic }_{\mathrm{A}} \\
\text { diagnosticar }_{\mathrm{V}}\end{array}$ & $\begin{array}{l}\text { Nom } \\
\text { Adjectiu } \\
\text { Verb }\end{array}$ & $\begin{array}{l}\text { Composició culta } \\
\text { Derivació zero } \\
\text { Derivació zero }\end{array}$ \\
\hline $\begin{array}{l}\text { esclerosi }_{\mathrm{N}} \\
\text { esclerosant }_{\mathrm{A}} \\
\text { esclerosar }\end{array}$ & $\begin{array}{l}\text { Nom } \\
\text { Adjectiu } \\
\text { Verb }\end{array}$ & $\begin{array}{l}\text { Composició culta } \\
\text { Derivació zero } \\
\text { Derivació zero }\end{array}$ \\
\hline $\begin{array}{l}\text { naixement } \mathrm{N} \\
\text { néixer } \mathrm{v}\end{array}$ & $\begin{array}{l}\text { Nom } \\
\text { Verb }\end{array}$ & $\begin{array}{l}\text { Sufixació } \\
\text { (Formació patrimonial) }\end{array}$ \\
\hline $\begin{array}{l}\text { fosforilación }_{\mathrm{N}} \\
\text { fosforilatiu } \\
\text { fosforilar }\end{array}$ & $\begin{array}{l}\text { Nom } \\
\text { Adjectiu } \\
\text { Verb }\end{array}$ & $\begin{array}{l}\text { Sufixació } \\
\text { Sufixació } \\
\text { Derivació zero }\end{array}$ \\
\hline
\end{tabular}

Taula 1: Llista d'ULE, classificades segons la categoria lèxica i el procediment morfològic de formació

La selecció d'aquestes ULE obeeix a sis criteris lingüístics no excloents entre si. Resumim aquests criteris a continuació.

\section{A. Criteris textuals}

1. Criteri terminològic

2. Criteri discursiu

B. Criteris gramaticals

3. Criteri morfològic

5. Criteri semàntic

C. Criteri lexicogràfic

6. Criteri terminogràfic
Inclusió de la ULE en els textos

Aparició de la ULE en un context especialitzat i eventiu

Realització explícita d'algun morfema eventiu en la ULE:

- Formant sufixal culte eventiu

- Sufix eventiu

- Prefix eventiu

Relació paradigmàtica amb alguna altra ULE identificada:

- ULE nominal (terme prototípic)

- ULE verbal (unitat eventiva prototípica)

- ULE adjectival

Compleció del camp semàntic respecte a la gradació o complementarietat de la ULE

Inclusió de la ULE en els diccionaris especialitzats

Quadre 1: Llista de criteris lingüístics per a la selecció de les ULE 
Els criteris textuals (criteri terminològic i criteri discursiu) s'apliquen amb relació a un corpus textual constituït per documents sobre malalties minoritàries. El criteri lexicogràfic (criteri terminogràfic) s'aplica amb relació a un corpus lexicogràfic constituït per dos diccionaris especialitzats. Exposem les característiques d'aquests corpus a continuació.

\begin{tabular}{|c|ll|ll|}
\hline \multirow{2}{*}{ Registre } & Corpus textual & & Corpus lexicogràfic & \\
\cline { 2 - 5 } & Documents & Paraules & Diccionaris & Entrades \\
\hline Més & 16 resums de tesi & 9253 & DEMCAT & $>75300$ \\
especialitzat & 10 articles de recerca & 26878 & TCS & 16066 \\
\hline Menys & 14 articles divulgatius & 8356 & & \\
especialitzat & 12 guies divulgatives & 9315 & & \\
\hline
\end{tabular}

Taula 2: Caracterització dels corpus de referència per a la selecció de les ULE

A efectes de validar les hipòtesis, en el present estudi de casos es prioritzaran el criteri morfosintàctic i el criteri terminogràfic. S'entén que totes les ULE objecte d'estudi podrien haver figurat en el corpus textual, per bé que no sempre es dona aquesta circumstància. Especifiquem el compliment dels criteris — en sentit positiu $([+])$ o negatiu $([-])$ — per a cada ULE a continuació.

\begin{tabular}{|c|c|c|c|c|c|c|}
\hline ULE & Criteri 1 & Criteri 2 & Criteri 3 & Criteri 4 & Criteri 5 & Criteri 6 \\
\hline esplenectomia $a_{\mathrm{N}}$ & {$[+]$} & {$[+]$} & {$[+]$} & {$[+]$} & {$[-]$} & {$[+]$} \\
\hline esplenectòmic ${ }_{\mathrm{A}}$ & {$[+]$} & {$[-]$} & {$[-]$} & {$[+]$} & {$[-]$} & {$[-]$} \\
\hline esplenectomitzar & {$[-]$} & {$[-]$} & {$[+]$} & {$[+]$} & {$[-]$} & {$[-]$} \\
\hline bemopoesi $i_{\mathrm{N}}$ & {$[-]$} & {$[-]$} & {$[+]$} & {$[+]$} & [-] & {$[+]$} \\
\hline bemopoètic $_{\mathrm{A}}$ & {$[+]$} & {$[-]$} & {$[-]$} & {$[+]$} & {$[-]$} & {$[-]$} \\
\hline diagnòstici & {$[+]$} & {$[+]$} & {$[+]$} & {$[+]$} & {$[-]$} & {$[+]$} \\
\hline diagnòstic $\mathrm{A}$ & {$[+]$} & {$[-]$} & {$[-1$} & {$[+]$} & {$[-]$} & {$[+]$} \\
\hline diagnostican & {$[+]$} & {$[+]$} & {$[-]$} & {$[+]$} & {$[-]$} & {$[+]$} \\
\hline esclerosi $i_{\mathrm{N}}$ & {$[+]$} & {$[+]$} & {$[+]$} & {$[+]$} & {$[-]$} & {$[+]$} \\
\hline esclerosant $t_{\mathrm{A}}$ & {$[-]$} & {$[-]$} & {$[-]$} & {$[+]$} & {$[-]$} & {$[+]$} \\
\hline esclerosar ${ }_{\mathrm{V}}$ & {$[-]$} & {$[-]$} & {$[-]$} & {$[+]$} & {$[-]$} & {$[-]$} \\
\hline naixement $\mathrm{N}$ & {$[+]$} & {$[+]$} & {$[+]$} & {$[+]$} & {$[+]$} & {$[+]$} \\
\hline néixer & {$[+]$} & {$[+]$} & {$[-]$} & {$[+]$} & {$[+]$} & {$[+]$} \\
\hline fosforilación & {$[+]$} & {$[+]$} & {$[+]$} & {$[+]$} & {$[-]$} & {$[+]$} \\
\hline fosforilatiu $_{\mathrm{A}}$ & {$[+]$} & {$[+]$} & {$[+]$} & {$[+]$} & {$[-]$} & {$[-]$} \\
\hline fosforilan & {$[+]$} & {$[+]$} & {$[-]$} & {$[+]$} & {$[-]$} & {$[-]$} \\
\hline
\end{tabular}

Atesos els objectius del present estudi de casos, el criteri morfosintàctic (criteri 4) es compleix indefectiblement: cada bloc d'ULE inclou, com a mínim, un nom del mateix paradigma. Així mateix, la combinació dels criteris textuals (criteris 1 i 2) amb el criteri morfològic (criteri 3) permet de distingir inicialment tres grups d'ULE:

- Les ULE eventives amb marcatge morfològic explícit (esplenectomia $a_{\mathrm{N}}$ esplenectomitzar hemopoesi $i_{\mathrm{N}}$, diagnòstic $c_{\mathrm{N}}$, esclerosi $i_{\mathrm{N}}$, naixement $\mathrm{N}_{\mathrm{N}}$, fosforilació $\hat{\mathrm{N}}_{\mathrm{N}}$, fosforilatiu $\mathrm{A}_{\mathrm{A}}$ )

- Les ULE eventives sense marcatge morfològic explícit (diagnosticarv, néixer, fosforilarv)

- Les ULE no eventives (esplenectòmic $c_{\mathrm{A}}$, hemopoètic $\mathrm{A}_{\mathrm{A}}$, diagnòstic $\mathrm{A}$ )

Per a validar les hipòtesis del present estudi de casos a partir del criteri lexicogràfic, és pertinent d'analitzar les definicions que proporcionen els diccionaris terminològics (TCS i DEMCAT). Destaquem diversos elements pertinents d'un article lexicogràfic: el definit (en aquest cas, la ULE) 
i el definidor (els elements lingüístics de la definició); el definidor s'inicia amb un descriptor (una paraula de la mateixa categoria lèxica que el definit) o un transpositor (una paraula d'una categoria lèxica diferent a la del definit) (Seco, 1987).

\subsection{Objectius}

El present estudi de casos s'emmarca en una recerca de tesi doctoral sobre l'eventivitat en terminologia (Pozuelo-Ollé, 2019). L'originalitat respecte d'aquell treball consisteix en una aproximació eminentment lexicogràfica per a analitzar el valor eventiu d'una selecció representativa de les unitats lèxiques especialitzades (ULE).

Ens basem en els problemes que suposa la representació lexicogràfica de l'eventivitat en terminologia, i ens proposem de cobrir algunes mancances lexicogràfiques, tenint en compte les limitacions metodològiques de la recerca. Exposem els quatre objectius a partir dels quals enfocarem l'anàlisi a continuació:

- Objectiu 1: comprovar el grau d'inclusió terminogràfica de les ULE.

- Objectiu 2: contrastar la inclusió terminogràfica entre les categories lèxiques.

- Objectiu 3: contrastar la inclusió terminogràfica entre els procediments morfològics.

- Objectiu 4: identificar marques lèxiques explícites d'eventivitat en les definicions terminogràfiques.

\subsection{Anàlisi}

\subsubsection{La inclusió terminogräica de les ULE}

En la present anàlisi valorem el caràcter neològic de les unitats lèxiques especialitzades (ULE) a partir del criteri lexicogràfic: una ULE és neològica si no figura en els diccionaris especialitzats del nostre corpus lexicogràfic (TCS i DEMCAT). Aquest criteri permet d'establir caracteritzacions diverses segons les propietats lingüístiques de les ULE.

L'anàlisi superficial de la neologicitat de les ULE té en compte tres variables pertinents, que hem especificat en els apartats anteriors: la categoria lèxica, el procediment morfològic, i el compliment del criteri lexicogràfic. Reproduïm la caracterització de les ULE segons aquests criteris a continuació. 


\begin{tabular}{|c|c|c|c|}
\hline ULE & Categoria lèxica & $\begin{array}{l}\text { Procediment } \\
\text { morfològic }\end{array}$ & $\begin{array}{l}\text { Compliment del criteri } \\
\text { lexicogràfic en el lemari }\end{array}$ \\
\hline esplenectomia $a_{\mathrm{N}}$ & Nom & Composició culta & {$[+]$} \\
\hline esplenectòmic ${ }_{\mathrm{A}}$ & Adjectiu & Sufixació & {$[-]$} \\
\hline esplenectomitzar & Verb & Sufixació & {$[-]$} \\
\hline bemopoesi $i_{\mathrm{N}}^{2}$ & Nom & Composició culta & {$[+]$} \\
\hline bemopoètic $\mathrm{A}$ & Adjectiu & Sufixació & {$[-]$} \\
\hline diagnòstic $\mathrm{N}_{\mathrm{N}}$ & Nom & Composició culta & {$[+]$} \\
\hline diagnòstic & Adjectiu & Derivació zero & {$[+]$} \\
\hline diagnostican & Verb & Derivació zero & {$[+]$} \\
\hline esclerosi $\dot{i}_{\mathrm{N}}$ & Nom & Composició culta & {$[+]$} \\
\hline esclerosant $_{\mathrm{A}}$ & Adjectiu & Derivació zero & {$[+]$} \\
\hline esclerosan ${ }^{3}$ & Verb & Derivació zero & {$[-]$} \\
\hline naixement $\mathrm{N}$ & Nom & Sufixació & {$[+]$} \\
\hline néixer $\mathrm{V}$ & Verb & (Formació patrimonial) & {$[+]$} \\
\hline fosforilación & Nom & Sufixació & {$[+]$} \\
\hline fosforilativi & Adjectiu & Sufixació & {$[-]$} \\
\hline fosforilar & Verb & Derivació zero & {$[-]$} \\
\hline
\end{tabular}

Taula 4: Anàlisi bàsica de la neologicitat de les ULE

Observem una regularitat en la inclusió sistemàtica de les ULE nominals en el lemari, sense distinció per procediments morfològics. Aquesta constatació és coherent amb el principi teòric segons el qual els termes prototípics són noms, i les unitats lèxiques d'altres categories s'hi subordinen (Cabré, 1999). Per tant, els diccionaris especialitzats prioritzen la descripció de les unitats terminològiques prototípiques, és a dir, els noms utilitzats en l'àmbit d'especialitat pertinent.

Per a obtenir conclusions més precises, convé d'afegir dues subvariables a l'anàlisi: el diccionari especialitzat (TCS o DEMCAT), i la ubicació de la ULE en el diccionari (lemari o altres elements de la microestructura). Adaptem la taula anterior per a donar compte del tractament diferenciat segons el diccionari a continuació.

\footnotetext{
${ }^{2}$ La forma hemopoesi figura com a variant (sinònim complementari) de hematopoesi, definit d'aquesta entrada lexicogràfica en el TCS $\mathrm{i}$ en el DEMCAT. A efectes de l'anàlisi subsegüent del tractament lexicogràfic, en aquest cas farem referència a l'entrada corresponent al definit hematopoesi.

${ }^{3} \mathrm{La}$ forma esclerosat-ada figura en el lemari del DEMCAT amb funció adjectival.
} 


\begin{tabular}{|c|c|c|c|c|}
\hline \multirow[t]{2}{*}{ ULE } & \multicolumn{2}{|c|}{\begin{tabular}{|cc} 
Compliment & del \\
lexicogràfic en el lemari
\end{tabular}} & \multicolumn{2}{|c|}{$\begin{array}{l}\text { Compliment del criteri } \\
\text { lexicogràfic en la microestructura }\end{array}$} \\
\hline & TCS & DEMCAT & TCS & DEMCAT \\
\hline esplenectomia ${ }_{\mathrm{N}}$ & {$[-]$} & {$[+]$} & {$[-]$} & {$[+]$} \\
\hline esplenectòmic $\mathrm{c}_{\mathrm{A}}$ & {$[-]$} & {$[-]$} & {$[-]$} & {$[-]$} \\
\hline esplenectomitzan & {$[-]$} & {$[-]$} & {$[-]$} & {$[-]$} \\
\hline bemopoesi $i_{\mathrm{N}}$ & {$[+]$} & {$[+]$} & {$[+]$} & {$[+]$} \\
\hline bemopoètic & {$[-]$} & {$[-]$} & {$[-]$} & {$[+]$} \\
\hline diagnòstic $_{\mathrm{N}}$ & {$[+]$} & {$[+]$} & {$[+]$} & {$[+]$} \\
\hline diagnòstic $_{\mathrm{A}}$ & {$[+]$} & {$[+]$} & {$[+]$} & {$[+]$} \\
\hline diagnosticar $\mathrm{V}_{\mathrm{V}}$ & {$[+]$} & {$[+]$} & {$[+]$} & {$[+]$} \\
\hline esclerosi $i_{\mathrm{N}}$ & {$[+]$} & {$[+]$} & {$[+]$} & {$[+]$} \\
\hline esclerosant $t_{\mathrm{A}}$ & {$[-]$} & {$[+]$} & {$[+]$} & {$[+]$} \\
\hline esclerosar ${ }^{4}$ & {$[-]$} & {$[-]$} & {$[-]$} & {$[-]$} \\
\hline naixement $\mathrm{N}$ & {$[-]$} & {$[+]$} & {$[+]$} & {$[+]$} \\
\hline néixer $\mathrm{v}$ & {$[-]$} & {$[+]$} & {$[+]$} & {$[+]$} \\
\hline fosforilación & {$[+]$} & {$[+]$} & {$[+]$} & {$[+]$} \\
\hline fosforilatiu $_{\mathrm{A}}$ & {$[-]$} & {$[-]$} & {$[-]$} & {$[-]$} \\
\hline fosforilar $\mathrm{V}$ & {$[-]$} & {$[-]$} & {$[+]$} & {$[+]$} \\
\hline
\end{tabular}

Taula 5: Anàlisi detallada de la neologicitat de les ULE

Observem una tendència contrastiva en la inclusió de les unitats lèxiques que matisa la regularitat inicial: l'abast del diccionari determina la presència d'ULE no nominals en el lemari. En aquest sentit, el factor que pot explicar aquestes diferències respon a un criteri quantitatiu (nombre d'entrades), atesa la coincidència en els criteris qualitatius (grau d'expertesa dels autors i dels destinataris, extensió del domini, propòsit del diccionari, i metodologia de tractament de les dades).

\subsubsection{La representació lexicogräfica de l'eventivitat de les ULE}

En la present anàlisi valorem la presència de marques lèxiques que especifiquin el valor eventiu de les unitats lèxiques especialitzades (ULE) a partir de les definicions corresponents. Atesa l'estructura morfològica, considerem que totes les ULE poden aparèixer en un context discursiu eventiu (dins o fora del nostre corpus textual).

Per a identificar les marques lèxiques eventives, en aquesta anàlisi ens basem en el contingut de les definicions, i no incloem les ULE neològiques estrictes (les ULE que no compleixen el criteri lexicogràfic en el lemari). Indiquem la presència de marques lèxiques eventives - marca eventiva $([+])$, marca resultativa $([-])$, o marca mixta eventiva-resultativa segons el descriptor $([ \pm])$ — per a cada ULE no neològica estricta a continuació.

\footnotetext{
${ }^{4}$ Alguns definidors inclouen la unitat lèxica especialitzada esclerosat (i les formes flexionades corresponents) amb funció adjectival en el DEMCAT, dins de les entrades corresponents als definits esclerectomia, esclerós -osa, infart miocardíac, parafimosi, i pols tard.
} 


\begin{tabular}{|c|c|c|c|c|}
\hline \multirow[t]{2}{*}{ ULE } & \multicolumn{2}{|c|}{$\begin{array}{l}\text { Compliment del criteri } \\
\text { lexicogràfic en el lemari }\end{array}$} & \multicolumn{2}{|c|}{$\begin{array}{l}\text { Presència de marques lèxiques } \\
\text { eventives en la microestructura }\end{array}$} \\
\hline & TCS & DEMCAT & TCS & DEMCAT \\
\hline esplenectomia $\mathrm{N}$ & {$[-]$} & {$[+]$} & & {$[ \pm]$} \\
\hline esplenectòmic $c_{\mathrm{A}}$ & {$[-]$} & {$[-]$} & & \\
\hline esplenectomitzan & {$[-]$} & {$[-]$} & & \\
\hline hemopoesi $i_{\mathrm{N}}$ & {$[+]$} & {$[+]$} & {$[+]$} & {$[+]$} \\
\hline hemopoètic $\mathrm{A}_{\mathrm{A}}$ & {$[-]$} & {$[-]$} & & \\
\hline diagnòstic $_{\mathrm{N}}$ & {$[+]$} & {$[+]$} & {$[-]$} & {$[-]$} \\
\hline diagnòstic $_{\mathrm{A}}$ & {$[+]$} & {$[+]$} & {$[ \pm]$} & {$[ \pm]$} \\
\hline diagnosticar $\mathrm{V}_{\mathrm{V}}$ & {$[+]$} & {$[+]$} & {$[+]$} & {$[+]$} \\
\hline esclerosi $i_{\mathrm{N}}$ & {$[+]$} & {$[+]$} & {$[-]$} & {$[-]$} \\
\hline esclerosant $_{\mathrm{A}}$ & {$[-]$} & {$[+]$} & & {$[ \pm]$} \\
\hline esclerosan & {$[-]$} & {$[-]$} & & \\
\hline naixement $\mathrm{N}_{\mathrm{N}}$ & {$[-]$} & {$[+]$} & & {$[+]$} \\
\hline néixer & {$[-]$} & {$[+]$} & & {$[+]$} \\
\hline fosforilación & {$[+]$} & {$[+]$} & {$[-]$} & {$[-]$} \\
\hline fosforilatiu & {$[-]$} & {$[-]$} & & \\
\hline fosforilar $\mathrm{V}$ & {$[-]$} & {$[-]$} & & \\
\hline
\end{tabular}

Reproduïm les definicions íntegres de les ULE i les classifiquem segons el valor predicatiu (eventiu, resultatiu, o mixt eventiu-resultatiu) a continuació. 
A. ULE amb valor eventiu d'acord amb la microestructura

hemopoesin: procés de formació, maduració i pas a la sang dels diferents tipus de cèl·lules sanguínies a partir de cèl·lules mare

(TCS;DEMCAT)

diagnosticarv: fer el diagnòstic d'una malaltia

(TCS;DEMCAT)

naixement $t_{\mathrm{N}}$ acció de néixer, de sortir del claustre matern el fetus viable

$(D E M C A T)$

néixerv: sortir, un fetus viable, del claustre matern

(DEMCAT)

\section{B. ULE amb valor resultatiu d'acord amb la microestructura}

diagnòstic $\mathrm{N}_{\mathrm{N}}$ determinació de la naturalesa de la malaltia d'un pacient per mitjà de l'estudi dels seus símptomes i signes i de la realització d'exploracions complementàries (TCS)

diagnòstic $c_{\mathrm{N}}$ determinació d'un problema de salut a través d'una característica definidora o d'una malaltia a través dels signes i símptomes que li són propis

diagnòstic $_{\mathrm{N}}$ : coneixença que s'adquireix de l'estat psicofísic del malalt per l'observació dels signes patològics

diagnòstic $\mathrm{N}_{\mathrm{N}}$ determinació de la naturalesa de la malaltia o problema de salut d'un pacient per mitjà de l'estudi dels seus símptomes i signes i de la realització d'exploracions complementàries

$(D E M C A T)$

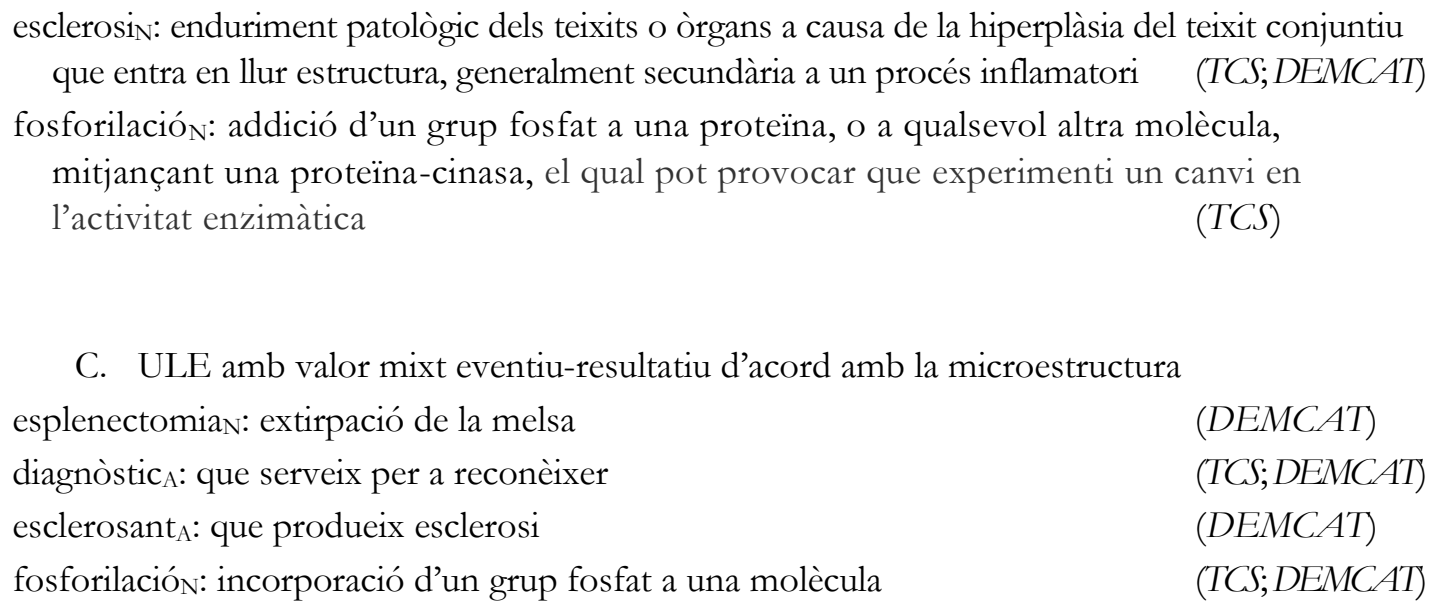

Quadre 2: Reproducció de les definicions de les ULE no neològiques estrictes

El descriptor o transpositor constitueix l'element bàsic per a establir el valor predicatiu. Mostrem la relació d'equivalència sintàctica-semàntica (coincidència respecte al valor predicatiu) entre les ULE no neològiques estrictes i els descriptors o transpositors corresponents a continuació. 


\begin{tabular}{|c|c|c|c|c|}
\hline \multirow[t]{2}{*}{ ULE } & \multicolumn{2}{|c|}{$\begin{array}{l}\text { Presència de marques eventives } \\
\text { en la ULE }\end{array}$} & \multicolumn{2}{|c|}{$\begin{array}{l}\text { Presència de marques eventives } \\
\text { en el descriptor o transpositor }\end{array}$} \\
\hline & Morfologia & $\begin{array}{l}\text { Corpus } \\
\text { textual }\end{array}$ & TCS & DEMCAT \\
\hline esplenectomia $\mathrm{N}_{\mathrm{N}}$ & {$[ \pm]$} & {$[+]$} & & {$[ \pm]$} \\
\hline esplenectòmic $\mathrm{A}_{\mathrm{A}}$ & {$[ \pm]$} & & & \\
\hline esplenectomitzan & {$[+]$} & & & \\
\hline hemopoesi $i_{\mathrm{N}}$ & {$[ \pm]$} & & {$[+]$} & {$[+]$} \\
\hline bemopoètic $c_{\mathrm{A}}$ & {$[ \pm]$} & & & \\
\hline diagnòstic $_{\mathrm{N}}$ & {$[ \pm]$} & {$[+]$} & {$[ \pm][-]$} & {$[ \pm]$} \\
\hline diagnòstic $_{\mathrm{A}}$ & {$[ \pm]$} & & {$[+]$} & {$[+]$} \\
\hline diagnosticar $\mathrm{V}_{\mathrm{V}}$ & {$[+]$} & {$[+]$} & {$[+]$} & {$[+]$} \\
\hline esclerosi $i_{\mathrm{N}}$ & {$[ \pm]$} & {$[+]$} & {$[ \pm]$} & {$[ \pm]$} \\
\hline esclerosant $t_{\mathrm{A}}$ & $\begin{array}{l}{[ \pm]} \\
{[+]}\end{array}$ & & & {$[+]$} \\
\hline naixement $\mathrm{N}$ & {$[ \pm]$} & {$[+]$} & & {$[+]$} \\
\hline néixer & {$[+]$} & {$[+]$} & & {$[+]$} \\
\hline fosforilación & {$[ \pm]$} & {$[+]$} & {$[ \pm]$} & {$[ \pm]$} \\
\hline fosforilatiu $_{\mathrm{A}}$ & {$[ \pm]$} & {$[+]$} & & \\
\hline fosforilar & {$[+]$} & {$[+]$} & & \\
\hline
\end{tabular}

En les ULE nominals, alguns descriptors presenten una predicació mixta eventiva-resultativa, mentre que, en les ULE adjectivals i verbals, els descriptors o els transpositors documentats són eventius. Aquesta distribució permet de mantenir, en general, l'equivalència sintàctica-semàntica entre la ULE i el descriptor o el transpositor corresponent, com es pressuposa en una definició pròpiament terminogràfica (Rebagliato Nadal, 2009).

Per a delimitar el tipus de predicació (eventiva o resultativa), podem analitzar amb més detall el contingut de les definicions. Les definicions il·lustren els dos tipus bàsics de predicació: l'eventivitat lèxica (a partir del descriptor o transpositor) i l'eventivitat oracional. Mostrem les unitats lèxiques que, en la present anàlisi, denoten eventivitat o resultativitat a continuació.

\begin{tabular}{|c|c|c|c|c|c|c|}
\hline \multirow{2}{*}{$\begin{array}{l}\text { Categoria } \\
\text { lèxica }\end{array}$} & \multicolumn{2}{|c|}{ Eventivitat } & \multicolumn{2}{|c|}{ Resultativitat } & \multicolumn{2}{|c|}{\begin{tabular}{|c} 
Eventivitat \\
resultativitat
\end{tabular}} \\
\hline & Lèxica & Oracional & Lèxica & Oracional & Lèxica & Oracional \\
\hline $\begin{array}{r}\text { ULE } \\
\text { nominals }\end{array}$ & $\begin{array}{l}\text { acció } \\
\text { procés }\end{array}$ & a partir de & coneixença & $\begin{array}{l}\text { a causa de } \\
\text { a través de } \\
\text { mitjançant } \\
\text { per } \\
\text { per mitjà de }\end{array}$ & \begin{tabular}{|l} 
addició \\
determinació \\
enduriment \\
extirpació \\
incorporació
\end{tabular} & \\
\hline $\begin{array}{r}\text { ULE } \\
\text { adjectivals } \\
\end{array}$ & & & & & $\begin{array}{l}\text { que produeix } \\
\text { que serveix }\end{array}$ & \\
\hline $\begin{array}{l}\text { ULE } \\
\text { verbals }\end{array}$ & $\begin{array}{l}\text { fer } \\
\text { sortir }\end{array}$ & & & & & \\
\hline
\end{tabular}

Observem que, en absència d'un descriptor o d'un transpositor explícit clarament eventiu (eventivitat lèxica), certs marcadors discursius ens permeten de determinar el grau d'eventivitat del definidor. D’una banda, les preposicions amb valor causal (a causa de) o instrumental (a través de, mitjançant, per, per mitjà de) introdueixen un sintagma nominal eventiu i, per contrast, determinen el 
valor resultatiu de la primera part dels definidors corresponents, que contenen els descriptors. D’altra banda, la preposició locativa a partir de, anteposada a una entitat (predicació resultativa), reforça el valor eventiu del descriptor procés i els complements explícits.

\section{Conclusió}

Tenint en compte les limitacions metodològiques d'aquest estudi respecte a la quantitat de neònims i la selecció de processos neològics, hem detectat algunes tendències objectives respecte a la inclusió i la representació lexicogràfica de les unitats lèxiques especialitzades (ULE).

Hem constatat que les ULE menys neològiques segons el criteri lexicogràfic s'associen a la categoria lèxica nominal, situació que es presenta de manera gairebé sistemàtica en el lemari i en la microestructura dels dos diccionaris analitzats. No disposem de prou dades per a establir relacions entre la neologicitat i el procediment morfològic de les ULE.

Les ULE no neològiques respecten majoritàriament l'equivalència sintàctica-semàntica (categoria lèxica $i$ valor de la predicació) entre el definit i el descriptor o transpositor, fins $i$ tot en els casos de noms amb predicació mixta eventiva-resultativa. Els definidors poden resoldre les ambigüitats detectades mitjançant la inclusió de marcadors discursius.

\section{Bibliografia}

Bernal, Elisenda; CABRÉ, Maria Teresa (2015). «La neologia per conversió sintàctica i per lexicalització». FreIXA, Judit; BERnAL, Elisenda; CABré, Maria Teresa [ed.]. La neologia lèxica catalana. Barcelona: Institut d'Estudis Catalans. 119-131.

BOBNEO = OBSERVATORI DE NEOlOGIA (2018). Cercador OBNEO. [Base de dades amb accés restringit des de la Plataforma OBNEO]. http://obneo.iula.upf.edu/pobneo/index.php.

BREtonnel CoHEN, Kevin; PALMER, Martha; Hunter, Lawrence (2008). «Nominalization and Alternations in Biomedical Language». PLOS ONE 3 (9). 1-21.

CABRÉ, Maria Teresa (1992). La terminologia. La teoria, els mètodes, les aplicacions. Barcelona: Empúries.

CABRÉ, Maria Teresa (1999). La terminología: representación y comunicación. Elementos para una teoría de base comunicativa y otros artículos. Barcelona: Documenta Universitaria; Institut Universitari de Lingüística Aplicada.

CABré, Maria Teresa (2002). «La derivació». SolÀ, Joan; Lloret, Maria-Rosa; MasCaró, Joan; PÉREZ-SALDANYA, Manuel [ed.]. Gramática del català contemporani. Barcelona: Empúries. 731 775.

CABRÉ, Maria Teresa (2004). «La importància de la neologia per al desenvolupament sostenible de la llengua catalana». OBSERVATORI De NeOlogia [ed.]. Llengua catalana i neologia. Barcelona: Meteora. 17-45.

CAÑete, Paola; FernándeZ-SiLva, Sabela; Janer, Francina (2015). «La neologia per composició culta». FreIXA, Judit; BERNAL, Elisenda; CABRÉ, Maria Teresa [ed.]. La neologia lèxica catalana. Barcelona: Institut d'Estudis Catalans. 53-69.

DEMCAT = INSTITUT D’ESTUDIS CATALANS, FUNDACIÓ ACADÈMIA DE CIÈNCIES Mèdiques i de la SAlut de Catalunya i de Balears; EnCiClopèdia Catalana SAU; TERMCAT, Centre de Terminologia; Generalitat de Catalunya - Departament de SALUT (2015-2018). Diccionari enciclopèdic de medicina (DEMCAT): Versió de treball. Barcelona: TERMCAT, Centre de Terminologia. http://www.termcat.cat/ca/Diccionaris En Linia/183.

EsTOPÀ, Rosa (2010). «La neologia especialitzada, repte constant per al mediador lingüístic». Coromina, Eusebi; Mestres, Josep Maria [ed.]. Aspectes de terminologia, neologia i traducció. Barcelona: Societat Catalana de Terminologia; Universitat de Vic. 15-39.

GARCÍA PALACIOS, Joaquín (2009). «La competencia neológica especializada en el estudio y la 
actuación sobre la neología terminológica». Revue française de linguistique apliquée 14 (2). 17-30.

GRÀCIA, Lluïsa (2002). «Formació de mots: composició». SOLÀ, Joan; LLORET, Maria-Rosa; Mascaró, Joan; PÉreZ-Saldanya, Manuel [ed.]. Gramática del català contemporani. Barcelona: Empúries. 777-829.

GRIMSHAW, Jane (1990). Argument Structure. Massachusetts (Estats Units): Massachusetts Institute of Technology.

InstituT D’Estudis CATALANS (2016). Gramàtica de la llengua catalana. Barcelona: Institut d'Estudis Catalans.

KORNFELD, Laura; RESNIK, Gabriela (2003). «Sintagmas terminológicos con adjetivos deverbales». InSTITUTO DE LINGUÍSTICA TEÓRICA E COMPUTACIONAL [ed.]. Terminologia e indústrias da lingua. Actas do VII Simpósio Ibero-Americano de Terminologia. Coïmbra (Portugal): Instituto de Linguística Teórica e Computacional. 545-564.

LORENTE, Mercè (2007). «Les unitats lèxiques verbals dels textos especialitzats. Redefinició d'una proposta de classificació». CABRÉ, Maria Teresa; LORENTE, Mercè; ESTOPÀ, Rosa; FreIXA, Judit; Martí-Olivella, Jaume; Tebé I SORIANO, Carles [ed.]. Estudis de lingüistica i de lingüistica aplicada en honor de M. Teresa Cabré Castellví. Volum 2: De deixebles. Barcelona: Documenta Universitaria; Institut Universitari de Lingüística Aplicada. 365-380.

LORENTE, Mercè; CANTERO, Laura (2015). «La neologia per sufixació». FreIXA, Judit; BERnAL, Elisenda; CABRÉ, Maria Teresa [ed.]. La neologia lèxica catalana. Barcelona: Institut d'Estudis Catalans. 29-51.

MANIEZ, François (2001). «Extraction d'une phraséologie bilingue en langue de spécialité : corpus parallèles et corpus comparables». Meta 46 (3). 552-563.

NAPOLI, Donna Jo (1989). Predication theory. A case study for indexing theory. Cambridge (Regne Unit): Cambridge University Press.

POZUELO-OlLÉ, Òscar (2019). L'eventivitat en els textos i en els diccionaris especialitzats en biomedicina. [Tesi doctoral]. Barcelona: Universitat Pompeu Fabra; Institut de Lingüística Aplicada. http://tdx.cat/handle/10803/667927.

ReBAgliato NADAL, Joan (2009). La definició terminologica. Barcelona: Eumo (Universitat de Vic); TERMCAT, Centre de Terminologia.

RONDEAU, Guy (1981). Introduction à la terminologie. Chicoutimi (Canadà): Gaëtan Morin.

RulL, Xavier (2004). La formació de mots. Qüestions de normativa. Vic: Eumo (Universitat de Vic). SECO, Manuel (1987). Estudios de lexicografía española. Madrid: Paraninfo.

TCS = TERMCAT, CENTRE DE TERMINOLOGIA (2015-2018). Terminologia de ciències de la salut. Barcelona: TERMCAT, Centre de Terminologia. http://www.termcat.cat/ca/Diccionaris En Linia/198.

VENDler, Zeno (1967). Linguistics in Philosophy. Ithaca (Estats Units): Cornell University Press.

WiLLIAMS, Edwin (1994). Thematic Structure in Syntax. Massachusetts (Estats Units): Massachusetts Institute of Technology. 


\title{
El reemplazo de los arabismos en español: remedios curativos medievales
}

\author{
Mihai Enăchescu ${ }^{1}$ \\ Universidad de Bucarest
}

Resumen: Este estudio se propone analizar los movimientos neológicos en el campo de los remedios curativos medievales de origen árabe. El inventario comprende 22 términos, de los cuales 6 han sobrevivido, 3 han desaparecido y otros 13 han sido reemplazados por cultismos de origen latino, palabras patrimoniales, derivados y compuestos; también se da el caso más especial cuando dos arabismos comparten la misma esfera conceptual.

Palabras-clave: arabismos, remedios curativos medievales, pérdida léxica, reemplazo léxico.

Abstract: This study aims to analyze the neological movements within the lexical field of Spanish medieval remedies of Arabic origin. The inventory has 22 terms, from which 6 have survived, 3 have disappeared, and 13 have been replaced by Latinisms, derived and compound words; there is also the special case of two Arabisms that share the same conceptual sphere.

Keywords: Arabisms, medieval remedies, lexical loss, lexical replacement.

${ }^{1}$ Correo electrónico: mihail.enachescu@lls.unibuc.ro. Correo postal: Facultatea de Limbi și Literaturi Straine, Departamentul de Limbi și Literaturi Romanice, Clasice și Neogreacă, str. Edgar Quinet, nr.5-7, sector 1, Bucarest, Rumania. 


\section{Introducción}

En todos los manuales de historia de la lengua española, un capítulo importante lo representa la influencia árabe. El elemento árabe fue la más importante capa del léxico español hasta el siglo XVI, después del elemento latino (cf. Lapesa 1986: 133).

Se pueden distinguir varias etapas en la incorporación de arabismos. Hasta el siglo XI se introducen sin obstáculos, por ser Córdoba el centro cultural de la Península. Durante la Baja Edad Media sigue siendo importante el arabismo, pero empieza ya a competir con el cultismo de origen latino y el extranjerismo europeo. Después comienza el retroceso, que Lapesa (1986: 155-156) atribuye a la decadencia de la influencia cultural musulmana como consecuencia de la expulsión de los árabes, por un lado, y de la influencia del Renacimiento europeo, por otro lado. Tampoco se puede dejar de lado la actitud de rechazo hacia los arabismos, que llevaría a la disminución de este inventario.

No hay que olvidar que desde el Renacimiento se inauguró, al compás de las tendencias renovadoras del humanismo, una campaña de depreciación de arabismos que llevaría a la pérdida de muchos de los que comenzaban por $a$ - o al-, campaña que siguió manteniéndose más o menos agudamente hasta el siglo XIX. (Maíllo Salgado 1998: 305).

Después de la pérdida de la influencia política y cultural árabe, muchos arabismos caen en desuso y son sustituidos por vocablos provenientes en su mayor parte del latín, por vía culta, entre los siglos XV y XVII.

La creciente actitud negativa para con el mundo islámico que caracteriza el tardío Medioevo español acaba por alcanzar el vocabulario de origen árabe. [...] Con los nuevos gustos y modos de la época prerrenacentista muchos aspectos de la cultura material heredada de los vecinos musulmanes quedaron desfavorecidos. En el plano lingüístico se ve el inicio del lento proceso de la eliminación de muchas palabras de origen árabe algunas de las cuales, aunque desechadas de la lengua general, han sobrevivido en dialectos regionales y/o en el judeo-español. (Dworkin 2013: 648-649).

La entrada de latinismos en español se hace masivamente entre los siglos XV-XVII. Así, en el siglo XV se incorporan más del $30 \%$, en el siglo XVI un poco más del $16 \%$, al igual que en el XVII (cf. Reinheimer Rîpeanu 2004: 36). La incorporación de latinismos no supone necesariamente la eliminación de palabras de otros orígenes; muchas veces el latinismo cubre un vacío conceptual o una necesidad de lenguajes especializados. Sin embargo, el recurso al cultismo latino no es la única posibilidad, también se recurre a términos creados por mecanismos internos como la derivación o composición, o bien a préstamos de otros idiomas (cf. Penny 2006: 296).

\section{Remedios curativos medievales}

Hemos elegido estudiar este campo de los remedios curativos medievales dado que presenta cambios muy importantes en cuanto a las palabras de origen árabe. De las 22 palabras que se usaban en la Edad Media para designar distintos remedios, solamente seis se mantienen con el mismo significado, el resto ha sido eliminado o sustituido por otras voces, debido a los cambios experimentados por la sociedad hispánicas de aquellos tiempos.

(...) the loss of much Arabic medical terminology in the early modern period reflects the growing predominance of the newly rediscovered Graeco-Latin medical tradition and its technical vocabulary at the expense of the local Arabic tradition, as well as the Europeanization of early-modern Spanish society. (Dworkin 2012: 111). 
Incluiremos aquí plantas, sustancias minerales, pociones y destilados que tenían algún uso médico o veterinario. El número elevado de arabismos de este campo nos indica por sí mismo "la supremacía alcanzada por la medicina árabe en la Península durante la Edad Media" (Maíllo Salgado 1998: 67).

Para el inventario de los arabismos hemos recurrido a fuentes clásicas, como la Historia de la lengua española de Rafael Lapesa (1986), la Gramática histórica del español de Ralph Penny (2006), o bien el Dictionary of Arabic and Allied Loanwords, escrito por Federico Corriente (2008). La fuente más importante ha sido, sin duda alguna, Los arabismos del castellano en la Baja Edad Media, escrita por Maíllo Salgado (1998).

En primer lugar, haremos una presentación de las voces que se refieren a remedios curativos medievales, indicando el origen, el significado actual según la última edición del DLE y el número de ocurrencias en el CORPES XXI, el corpus que comprende textos del siglo XXI para comprobar su uso en el español actual.

En segundo lugar, analizaremos la supervivencia o la pérdida de estos términos, mencionando el término que ha desplazado el arabismo, o bien los cambios semánticos que ha sufrido a lo largo del tiempo. Separaremos, allí donde sea el caso, los significados del mismo significante en lexemas diferentes. No nos proponemos hacer un análisis pormenorizado de la historia de cada una de estas palabras, sino que intentamos hacer un primer acercamiento al tema, con el propósito de que este trabajo sea un punto de partida para desarrollos posteriores. Incluiremos en el análisis datos estadísticos sacados del Corpus del Nuevo Diccionario bistórico (CDH), un corpus que preferimos a CORDE y a CREA por ser más completo y por permitirnos sacar datos estadísticos más relevantes.

\subsection{Acíbar}

Procede del ár. șibar, con el mismo significado, y su Ia documentación data del 1493 (DCECH I, 37). El DLE nos remite para su definición a la entrada áloe: "Planta perenne de la familia de las liliáceas, con hojas largas y carnosas, de las cuales se extrae un jugo resinoso y muy amargo que se emplea en medicina (...)".

Hay solo 4 ocurrencias con el significado 'áloe' en CORPES XXI, registradas en textos de Chile y Bolivia.

\subsection{Albarraz (abarraz)}

Proviene del ár. hább ar-rás 'granos de la cabeza', documentado por I ${ }^{\mathrm{a}}$ vez en 1325 (DCECH I, 116). El diccionario académico nos indica un sinónimo más actual, estafisagria, donde podemos leer: "Planta herbácea de la familia de las ranunculáceas, (...) Es hierba venenosa, cuyas semillas contienen un alcaloide, y reducidas a polvo sirven para matar los insectos parásitos".

La grana molida servía para matar a los piojos; también se usaba en la cetrería para curar los granos que les salían a los halcones en la garganta; era una purga para los perros y aliviaba el dolor de muelas, según los distintos autores (cf. Maíllo Salgado 1998: 59-60).

Parece estar fuera de uso en el español actual, puesto que se encuentra tan solo un caso en un documento de España en CORPES XXI.

\subsection{Alcarceña}

Su étimo es el ár. karsánna 'yero', y su I' documentación está fechada hacia 1340 (DCECH I, 132). El diccionario académico nos indica, además de su origen árabe, el origen más remoto, o sea el arameo karsannā 'ventrudo', "porque, ingerida en exceso, hincha el vientre" (DLE, s.v).

Para su definición el diccionario nos envía a la entrada yero, donde nos vemos remitidos otra vez a la entrada algarroba. Sin embargo, parece haber una confusión en el diccionario entre el yero (Ervum Ervilia) y la algarroba (Vicia sativa), planta que no incluimos en nuestro estudio, puesto que se utiliza como forraje. 
Esta confusión era frecuente también entre los autores árabes, que confundían a veces la alcarceña, la algarroba y el guisante. La alcarceña se empleaba en solución de agua con miel para desecar los humores groseros del pecho y de los pulmones (cf. Maíllo Salgado 1998: 86-87).

No hay ocurrencias en el corpus analizado.

\subsection{Alcatenes}

Viene del ár. bąr al-kattân 'semilla de lino, linaza', por intermedio de una forma alcatenis del bajo latín, a través de los tratados médicos en bajo latín de la Escuela de Salerno, que sirvieron de base a varios libros de albeitería y cetrería del Medioevo hispánico. Su significado en castellano era: 'medicamento empleado para curar las llagas de los perros y aves de caza'. La I documentación se sitúa alrededor del 1340 (DCECH I, 133).

Según el DLE, es un "medicamento que, mezclado con aceche, se empleaba para curar llagas y úlceras".

Maíllo Salgado (1998: 88-89) añade que se usaba como cataplasma para la maduración de los abscesos; para dolores, irritaciones y úlceras.

No aparecen ocurrencias en el CORPES XXI.

\subsection{AlcohoP}

Proviene del hispanoárabe kuhúl, (árabe clásico kuhl) 'antimonio, galena'. Etimológicamente procede de la misma raíz que 'ákhal 'negro'; su primer testimonio se remonta hacia 1200 (DCECH I, 135).

El DLE ya no registra el significado que nos interesa aquí, pero lo podemos encontrar en el Diccionario histórico (1960-1996): "Polvo generalmente negro, hecho de galena, sulfuro de antimonio u otras sustancias minerales o vegetales, usado como afeite para los ojos y cejas y como colirio". También Neuvonen (1941: 147) indica que el término puede indicar una "galena que se usaba, mezclada con otras sustancias, como remedio para los ojos".

Su presencia en el corpus es impresionante, hay 14437 casos en 5135 documentos, de los cuales 5629 en España. Sin embargo, estas cifras se refieren al uso más actual de este vocablo, el de bebida alcohólica y no son relevantes para nuestro estudio.

\subsection{Algazafán}

Algazafán no aparece en la última edición del DLE, ni tampoco en el DCECH. La última edición del diccionario académico que registra esta voz es la del 1992, donde podemos leer que se trata de la "agalla ${ }^{3}$ del roble o de otros árboles" y procede del ár. al-'assafän, 'las agallas' (NTLLE).

Los árabes utilizaban píldoras de agalla, que era un medicamento muy desagradable de sabor. También se podía utilizar en los colirios. La I documentación está fechada antes de 1428 (cf. Maíllo Salgado 1998: 255).

Su ausencia en los diccionarios, así como la falta de ocurrencias en el corpus del siglo XXI nos indican que se trata de una palabra completamente desusada.

\subsection{Alquermes (variante quermes)}

Proviene del ár. hispánico qármaz (ár. clásico qirmiz), 'cochinilla', que a su vez procede del persa kirm 'gusano', emparentado con el lat. VERMIS. Aparece por primera vez en un documento de 1555 (DCECH, I, 876).

Según el diccionario de la Academia, es una "Especie de electuario en que entraban el quermes animal y varias sustancias excitantes".

No se registran ocurrencias en el corpus.

\footnotetext{
${ }^{2}$ La palabra alcohol aparece analizada desde otro punto de vista en ENĂCHESCU (2017a). Una historia detallada de la evolución semántica de esta palabra en español se podrá leer en ENĂCHESCU (2019).

${ }^{3}$ Por agalla se entiende "Excrecencia redonda que se forma en el roble, alcornoque y otros árboles y arbustos por la picadura de ciertos insectos e infecciones por microorganismos" (DLE, s.v.)
} 


\subsection{Almoraduj}

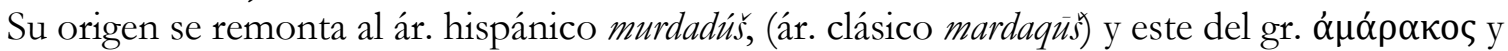
es documentado por primera vez en 1492 (DCECH I, 201-202).

El DLE nos remite para su definición a la entrada mejorana (Hierba vivaz de la familia de las labiadas [...]. Es originaria de Oriente, se cultiva en los jardines por su excelente olor, y suele usarse en medicina como antiespasmódica.)

No hemos encontrado ningún ejemplo en el corpus analizado.

\subsection{Almorí (morí)}

Es una palabra que ha emprendido un largo viaje, ya que, según el DLE, procede del ár. hispánico almurí, este del ár. clásico murrí, este del arameo müryā, y este del lat. MURIA 'salmuera'. El DCECH $(\mathrm{V}, 132)$ indica como fecha de su Ia documentación el siglo XIV, pero Mállo Salgado (1998: 114) indica una fecha más exacta, antes de 1350.

Según el DLE, su significado es "masa de harina, sal, miel y otras cosas, de la cual se hacen tortas que se cuecen en el horno", por lo cual no deberíamos incluirlo en nuestro estudio. Sin embargo, el $\mathrm{DH}$ asegura que se usaba como ingrediente en las comidas y en algunos remedios medicinales. Otro equivalente suyo sería salmuera, según el mismo diccionario.

Usado tanto en la medicina como en la veterinaria, el almorí "da apetito de comer, taja la flema y amansa la cólera" (J. de Aviñón, Sevillana Medicina, apud Mállo Salgado 1998: 114).

No se registran ocurrencias en el corpus.

\subsection{Atíncar}

Su étimo es el ár. tinkâr 'bórax', y aparece documentado por primea vez en un texto fechado hacia 1330 (DCECH I, 397).

El DLE nos remite a otra entrada, bórax ("Sustancia blanca constituida por sal de ácido bórico y sodio, usada en farmacia y en la industria, que se puede encontrar en estado natural"), subrayando su carácter poco usado.

No hemos encontrado ningún ejemplo en el CORPES XXI.

\subsection{Azarote (azarote)}

Podemos encontrar el origen de esta palabra en el ár. 'anzarût 'sarcocola'. Su I' atestiguación data de la I mitad del siglo XIV, bajo la forma anzarote (DCECH I, 433).

El DLE le añade la marca desusado y nos indica un sinónimo más usado, sarcocola, que es una "goma casi transparente que fluye por la corteza de un arbusto de Arabia parecido al espino negro".

Según Maíllo Salgado (1998: 130-131) se usaba para curar heridas, era un cicatrizante; los árabes lo usaban preferentemente como purgante.

No se encuentran ocurrencias en el corpus.

\subsection{Azufaifa}

Viene del ár. hispánico zufáyzafa, diminutivo del ár. zif žuf, zu'zûfa, emparentadas con el gr.

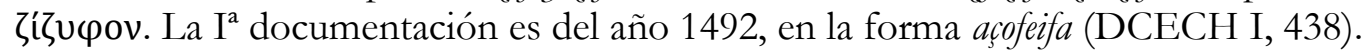

El DLE nos aclara que es "Fruto del azufaifo. [...] encarnada por fuera y amarilla por dentro, dulce y comestible. Se usaba como medicamento pectoral".

No se registran ocurrencias en el corpus.

\subsection{Bezoar}

Proviene del ár. africano bezuwâar, ár. clásico bädizahr, y este del persa pād zahr 'que preserva del veneno'. Se documenta a finales del siglo XVI. (DCECH I, 579).

\footnotetext{
${ }^{4}$ Esta palabra ha sido analizada también en ENĂCHESCU (2017b).
} 
Es, según el diccionario, una "concreción calculosa que suele encontrarse en las vías digestivas y en las urinarias de algunos mamíferos, y a la que se atribuyeron propiedades curativas".

Se utilizaba como antídoto para los venenos.

Hay 7 casos en 6 documentos; en CORPES XXI, y de estos 4 en España.

\subsection{Bórax ${ }^{5}$}

Procede del ár. magr. bauráq, y este del persa búrah, pelvi bōrak 'nitro'. La forma moderna se tomó probablemente del latín BORAX, pero procede del castellano medieval borráx. Su I documentación es de 1438 (DCECH I, 623).

Es, según el DLE, una "sustancia blanca constituida por sal de ácido bórico y sodio, usada en farmacia y en la industria, que se puede encontrar en estado natural".

Parece ser una voz todavía en uso en el español actual, puesto que hemos encontrado 28 ejemplos en 19 documentos, y de estos 11 registrados en España.

\subsection{Jarabe (jarope)}

Su étimo es el ár. hispánico šaráb, ‘bebida, poción', derivado de šarib 'beber'. Se documenta por primera vez hacia 1270, en la forma xarabe (DCECH III, 493).

Siguiendo el DLE es una "bebida que se hace cociendo azúcar en agua hasta que se espesa, añadiéndole zumos refrescantes o sustancias medicinales".

Es una palabra muy usada actualmente, hemos encontrado en el corpus 675 casos en 385 documentos; Del total, 234 aparecen en textos españoles y 162 en México.

La variante más usada en el castellano medieval fue jarope (xarope, axarope), procedente del lat. SIRUPPUS, y a su vez del ár. šaráb. Es dudoso que esta palabra venga directamente del árabe, como defienden otros autores, dice Corominas (DCECH III, 493). Pese a eso, se trata de un doblete etimológico, por lo tanto, lo podemos incluir en este trabajo.

Jarope no tiene ocurrencias en el corpus.

\subsection{Jebe}

Viene del ár. šabb 'vitriolo, alumbre', de la raíz šabb 'encender', y es atestiguado en 1423 en la forma axebe (DCECH III, 503).

Se trata de una voz desusada, nos asegura el DLE, que nos indica un sinónimo más usado, alumbre, donde podemos leer: "Sulfato de alúmina y potasa (...) que se emplea para aclarar aguas turbias, como mordiente en tintorería y como astringente en medicina".

No hay ocurrencias en el corpus.

\subsection{Julepe}

Su étimo es el ár. hispánico ğulláb, que a su vez viene del persa gulāb 'agua de rosas'. Se documenta primero a principios del siglo XV (DCECH III, 537).

El DLE nos indica que se trata de una "poción de aguas destiladas, jarabes y otras materias medicinales".

No se registran ocurrencias en el CORPES XXI con este significado.

\subsection{Quina}

Proviene del ár. qínna, documentado a mediados del siglo XIV. No hay que confundirlo con quina (o quinaquina), voz propagada desde el Perú con este medicamento americano, documentado por $\mathrm{I}^{\mathrm{a}}$ vez en Autoridades. Corominas sugiere que se puede tratar del mismo étimo, aplicado a otra sustancia, y no de una voz quichua (DCECH IV, 730-731).

El DLE subraya su carácter desusado y nos remite a la entrada gálbano, donde podemos aprender que se trata de una "gomorresina de color gris amarillento, más o menos sólida y de olor

\footnotetext{
${ }^{5}$ Esta palabra ha sido analizada también en ENĂCHESCU (2017b).

${ }^{6}$ Esta palabra ha sido analizada también en ENĂCHESCU (2017b).
} 
aromático, que se saca de una planta de la familia de las umbelíferas, espontánea en Siria. Se ha usado en medicina.".

Entraba en la composición de un ungüento para la hemiplejia (cf. Maíllo Salgado 1998: 177178).

No hay ocurrencias con este significado en el corpus.

\subsection{Talco $^{7}$}

Descendiente del ár. hispánico țálq, que designaba el amianto, la mica, el yeso y otros minerales semejantes. El primer testimonio es del 1492 en la forma talque (DCECH V, 386).

La definición del diccionario nos aclara que es un "mineral muy difícil de fundir, (...) muy suave al tacto, lustroso, tan blando que se raya con la uña, y de color generalmente verdoso. (...) en forma de polvo, se utiliza para la higiene y en la industria cosmética".

Es una voz de uso actual, tal y como lo reflejan los 375 casos en 268 documentos del corpus, de los cuales 94 en España.

\subsection{Teliarmín}

Proviene del ár. țin armin̄i 'arcilla de Armenia', documentado antes de 1350, y es sinónimo de bol arménico, o bol de Armenia (cf. Maíllo Salgado 1998: 183-184). El DCECH no registra esta palabra, ni tampoco el DLE.

EL DLE define el bol arménico como "arcilla rojiza procedente de Armenia y usada en medicina, en pintura y como aparejo en el arte de dorar".

Según Mállo Salgado (ídem), se usaba en emplastos para los bubones.

No hay ningún ejemplo en el corpus analizado.

\subsection{Turbit}

Es tomado por vía culta del ár. turbid, con el mismo significado. Aparece por primera vez en un documento de 1386, en la forma turbich (DCECH V, 700).

Según el DLE, el término se puede referir a una planta o a un mineral, con propiedades parecidas. El turbit vegetal es una "planta trepadora asiática, de la familia de las convolvuláceas, [...] y raíces largas, gruesas como el dedo, de corteza oscura, blancas por dentro y resinosas, que se han empleado en medicina como purgante drástico". El turbit mineral es un "sulfato mercurial de propiedades purgantes parecidas a las del turbit vegetal".

La planta es remedio para la epilepsia, el mineral para la caída de las pestañas, según Maíllo Salgado (1998: 366-367).

No se registran ejemplos en el CORPES XXI.

\subsection{Zaragatona}

Se remonta al ár. vulgar zarqațuna, (ár. clásico baær qațuna), con el mismo significado. Aparece atestiguada esta palabra por primera vez en un documento de 1492 (DCECH VI, 85).

Es, según el DLE, una "planta herbácea anual, de la familia de las plantagináceas, [...], fruto capsular con muchas semillas menudas y brillantes que, cocidas, dan una sustancia mucilaginosa, empleada para medicina y para aprestar telas".

Las semillas de esta planta tienen propiedades laxantes, emolientes, antiinflamatorias. (cf. Maíllo Salgado 1998: 368).

En el corpus del siglo XXI aparece un ejemplo en un documento publicado en España.

\section{Arabismos supervivientes}

\footnotetext{
${ }^{7}$ Esta palabra ha sido analizada también en ENĂCHESCU (2017b).
} 
Una parte del listado de arabismo visto arriba (más concretamente 6 de 22) se ha conservado hasta la actualidad sin cambios de significado notables, aunque en algunos casos es posible que ya no se usen en la medicina.

\subsection{Azufaifa}

A pesar de no aparecer en el CORPES XXI, parece que azufaifa es una voz todavía viva. Su ausencia se puede explicar por la rareza de esta fruta, que se cultiva menos.

En el CDH aparecen 73 ocurrencias en 32 documentos a lo largo del tiempo, de los cuales 68 en España; Hay 17 casos en los siglos XIV-XV, 19 durante los Siglos de Oro; decrece su uso en el siglo XVIII (4) y XIX (8), para volver a aumentar en el siglo XX (25).

No parece haber competido con su sinónimo grecolatino yuyuba, ya que este no aparece recogido en los primeros diccionarios. (cf. Maíllo Salgado 1998: 134-135).

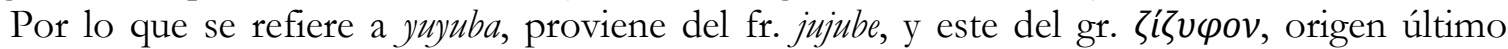
también de azufaifa (DCECH I, 438). Se trata, por lo tanto, de un doblete etimológico.

Parece ser una voz de escaso uso en español a lo largo de las épocas. Hemos encontrado solamente 10 casos en 3 documentos; todos en España. De estos ejemplos, 3 son del siglo XIII, 6 del XV y uno del XVII. Desaparece luego por completo.

\subsection{Bórax}

Es una palabra muy usada en español, una sustancia todavía usada en la medicina. En el CDH se encuentran 594 ejemplos en 52 documentos, de estos 510 en España. No parece muy usado en la Edad Media (29 casos en los siglos XIII-XV), ni durante los siglos XVI-XVII (37). Su uso se dispara en el XIX (399), para llegar a 126 casos en el XX.

Utilizado como cuasi sinónimo del arabismo atíncar, hubo una competición que duró siglos entre estas dos palabras. Atíncar fue más utilizado durante la baja Edad Media, mientras que bórax conservaba un uso culto. Finalmente será esta voz la que prevalecerá, debido en parte a su fisonomía más "romance” (cf. Maíllo Salgado 1998: 305).

\subsection{Jarabe (variante jarope)}

Jarabe es, sin duda, la más usada palabra de este campo y que también ha conservado su significado inicial. En el corpus se registran 2073 ocurrencias en 502 documentos, y 1612 en España. Casi inusitado durante la Edad Media en comparación con jarope (73 casos en el siglo XV comparados con las 754 atestiguaciones de jarope). Su uso se dispara durante los Siglos de Oro (759 ocurrencias frente a 101 de jarope, que ya empieza su retroceso) y se estabiliza a cifras muy altas durante los siglos XIX (341) y XX (832).

Por lo que se refiere a jarope (917 casos en todo el corpus, 913 en España ${ }^{8}$ ), hemos visto que era la palabra más usual durante la Edad Media ( 9 casos en el siglo XIII, 33 en el siglo XIV y 754 en el siglo XV), sigue usual durante los Siglos de Oro (101 ocurrencias), pero su uso se desploma en el XVIII ( 5 casos) y sigue bajísimo hasta la actualidad: 12 casos en el siglo XIX y solamente 3 en el siglo XIX.

\subsection{Talco}

Su I ${ }^{a}$ documentación según el CDH se sitúa alrededor del año 1250, fecha muy anterior a la propuesta por el DCECH (1495), según se puede ver en este ejemplo: "Del .x. grado del signo de capricornio es la piedra a que dizen talc." (Alfonso X, Lapidario).

Según los datos del CDH, talco se registra en 446 casos en 187 documentos, de los cuales un poco más de la mitad (230) en España. Es un vocablo de uso escaso durante la Edad Media (3 casos) o los siglos XVI-XVII (8 casos). Su uso empieza a crecer solo en el XIX (60) y se dispara en el XX (353).

\footnotetext{
${ }^{8}$ Debido al número reducidísimo de ocurrencias fuera de España, podemos deducir que esta palabra no llega a ser conocida en la América Hispánica.
} 
Aparece incluido en el Vocabulario español - latino de Nebrija ('talque, barro para crisoles') y en Autoridades.

\subsection{Turbit}

El CDH incluye 262 ocurrencias en 37 documentos, de los cuales 259 en España y 3 en Argentina. Parece otra voz casi exclusiva del español peninsular.

Usado mucho en el período medieval (2 casos en el siglo XIII, 9 en el XIV y 116 en el XV), sigue con vigor durante los siglos XVI-XVII (109 ejemplos), pero decrece de manera brusca en el siglo XVIII (4 casos), y no vuelve a recuperarse, lo que indica el carácter poco corriente de esta palabra muy específica (8 casos en el siglo XIX y 14 en el siglo XX).

Aparece en Nebrija, Covarrubias y Autoridades (cf. Maíllo Salgado 1998: 366-367).

\subsection{Zaragatona}

Es otra palabra de uso casi exclusivo peninsular, puesto que, del total de 105 ocurrencias en 25 documentos, 103 se registran en España. Hay 7 ejemplos del XIV, 59 de los siglos XVI-XVII, y 26 del XX.

Aparece en Nebrija, Covarrubias, Autoridades. Maillo Salgado (1998: 368) nos indica además un sinónimo, popular y de poco uso, hierba pulguera. En efecto, esta palabra aparece en 5 ocurrencias en 2 documentos, solo de España. De estas, 2 casos son del siglo XIX y 3 del XX.

\section{Arabismos desaparecidos}

Los arabismos que han desaparecido por completo no son muy numerosos. En concreto son tres los que están fuera de uso por motivos extralingüísticos, ya que el referente ha dejado de existir, llevando consigo la palabra que lo designaba.

\subsection{Alcatenes}

Es más bien una voz accidental, sin arraigo en castellano, dado que hemos encontrado solamente 7 casos en 5 documentos, 3 del siglo XIV y 4 del siglo XV.

Se forma por elipsis de bazr al-kattan 'semilla del lino, linaza'. Alfonso Chirino, en Menor daño de la medicina (antes de 1429) nos indica la manera de hacerlo.

El alcatenez es para alinpiar la llaga dela materia almartaq que llaman litargirum que es escoria de plomo \& otros nonbres molido \& çernido vna libra pez media liba çera media libra azeyte \& buen vino de cada vno dos libras cuega todo a fuego manso meçiendo sienpre fasta que sea duro \& prieto.

No aparece en los primeros diccionarios; el DRAE 1925 lo registra por primera vez. (cf. Maíllo Salgado 1998: 88-89)

\subsection{Bezoar}

Hay 121 ocurrencias en 38 textos del CDH, y de estos 82 en España. Se registra un solo ejemplo en el siglo XIII, 55 durante los siglos XVI-XVII, baja el número en el XVIII (17) y se reduce drásticamente en el XIX (2). En el siglo XX hay 46 atestiguaciones; sin embargo, esta cifra es engañosa; 33 proceden de un solo texto, que es una historia de la farmacia. Los demás ejemplos también provienen de textos que hablan sobre el pasado.

Este arabismo, por la rareza del producto que designa, es muy poco utilizado; Nebrija no lo recoge, pero sí Covarrubias y Autoridades. Es término conocido hasta el siglo XVII; en 1674, el médico de la familia real Tomás Murillo Velarde defiende el uso del bezoar: 
Aunque han escrito en nuestros tiempos algunos Apolos de la facultad de Medicina, que las piedras medicinales, como la piedra vezoar y otras no hazen milagors, auiendo tantas experiencias en favor deste alexipharmaco... (apud Maíllo Salgado 1998: 304)

\subsection{Julepe}

Hay 195 ocurrencias en 78 documentos en el corpus, de los cuales 172 se registran en España; así, hay 39 ejemplos del siglo XV, 54 del siglo XVII y 10 del siglo XVIII. En el XIX aparecen 21 casos, pero con otros significados: 'reprimenda, castigo, paliza', mientras que en los 71 ejemplos del siglo XX predomina el significado 'juego de naipes'. Podemos decir que desaparece con este significado en el siglo XVIII.

Este término aparece definido en Autoridades: "término pharmaceutico: bebida dulce, compuesta de aguas destiladas, o licores cocidos o clarificados, y azúcar, que suelen dar para refrescar y confortar los espíritus". Con los adelantos de la medicina caen en desuso pociones como esta, llevando consigo la palabra que las nombraba (cf. Maíllo Salgado 1998: 338).

\section{Arabismos reemplazados por otras voces}

Finalmente, en este apartado vamos a analizar la mayor parte de los términos que componen este campo. Se trata de voces que han sido reemplazadas por palabras de otros orígenes. En ocasiones no se trata de verdaderos reemplazos, puesto que el competidor es una palabra heredada del latín, por lo tanto, anterior al arabismo. En otros casos hemos propuesto dos o más posibles sustitutos, que serán analizados en los apartados correspondientes a su origen.

\subsection{Latinismos}

\subsubsection{Acíbar-áloe}

Acíbar es una voz con muchas ocurrencias en el corpus, a saber 727 casos en 315 documentos y 646 en España. Hay 132 ejemplos durante los siglos XIV-XV, 356 en los Siglos de Oro, 39 casos en el XVIII, 82 en el XIX y 118 en el XX. Estos datos nos podrían llevar a pensar que acíbar es una vOz todavía en uso, pero las ocurrencias del siglo XX están relacionadas con otro significado de esta palabra, 'amargura, disgusto'.

Aparece en Nebrija ("medicina amarga: áloe") y Covarrubias (cf. Maíllo Salgado 1998: 65-66).

Aloe es tomado del lat. ALŎE, y este del gr. ó $\lambda$ ón, documentado por primera vez hacia el año 1300 (DCECH I, 205).

Hay profusa documentación en el corpus analizado, con 563 ejemplos en 139 documentos, y de estos 538 en España. Se convierte en un competidor de acíbar desde su incorporación en la Baja Edad Media, y aparece 319 veces durante los siglos XIII-XV, después hay 93 casos en los siglos XVI-XVII, 4 en el XVIII, 26 en el XIX y 121 en el XX.

\subsubsection{Albarraz - estafisagria}

Albarraz se ha usado poco a lo largo del tiempo, así como nos sugieren las 18 ocurrencias en 6 documentos, de las cuales 4 en el siglo XVI, 4 en el XVII; 2 en el XIX y 8 en el siglo XX. Debido al parecido de las formas, se confunde con albarazo 'lepra', según se puede ver en el siguiente ejemplo, que no es el único: "E el albarraz negra non se cura, por quanto es lepra particular (1495, Traducción de la Cirugía Mayor de Lanfranco)". 60).

No se halla en Nebrija ni en Covarrubias, pero sí en Autoridades (cf. Maíllo Salgado 1998: 59-

Por su parte, estafisagria proviene del lat. STAPHIS AGRǏA, y este del gr. $\sigma \tau \alpha \varphi$ ís á $\gamma \rho i ́ \alpha$; literalmente 'pasa silvestre' (DLE, s.v.).

No parece haber sido jamás una palabra muy usual, puesto que su documentación es escasa. Hay 25 ocurrencias en 12 documentos; solamente de España. Su I atestiguación es de 1381, luego 
aparece 16 veces en el siglo XV, 2 veces durante los siglos XVI-XVII, hay 4 casos en el XIX y tan solo 2 en el siglo XX.

\subsubsection{Alcohol-colirio}

Alcohol se refería antiguamente a un polvo negro, hecho a base de antimonio o galena. Este polvo se empleaba para los colirios, significado que nos interesa aquí, y documentado ya en el Lapidario de Alfonso X (c1250):

Esta piedra a grand fuerça de retener la humidat que no corra; \& de ayuntar las cosas departidas. Et por esso fazen della alcohol pora sanar el albura del del oio que se faz manziella. \& otrossi la ninniella que quiere salir del; por grand dolor.

Se usa con este significado hasta el siglo XV, cuando adquiere un significado de 'colirio en general', no necesariamente a base de galena, según se puede apreciar en el siguiente ejemplo:

\& Alzaraui encomiendan assy como cosa prouada el alcohol fecho de las cortezas de los hueuos frescos de gallinas por diez dias en vinagre temprados \& despues en la sombra desecados \& picados: \& cernidos para que sea fecho alcohol. (Traducción del Tratado de cirugía de Guido de Cauliaco, 1493)

Un buen ejemplo que nos indica la generalización de su significado es la existencia del Libro de los Alcofoles:

E la su cura por umidat fria, las purgas con pilluras auree e alcofolarse con alcofol que dizen besalicon.

E si conpliere; si non, toma la cura del Libro de los Alcofoles. (Tratado de patología, antes de 1500)

Desaparece con este significado a partir del siglo XVI.

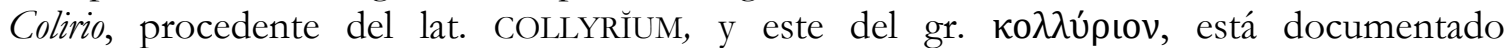
profusamente en el corpus, con 470 ejemplos en 127 documentos, de estos 393 en España. En el siglo XV hay 204 ocurrencias y 103 durante los siglos XVI y XVII. Decrece luego su uso para revitalizarse en el siglo XX con 132 casos.

\subsubsection{Alquermes - electuario}

Alquermes no parece haber gozado de mucha vitalidad en castellano, ya que se registran solamente 21 casos en 14 documentos, todos en España. 9 ejemplos son del XVI, 6 del XVII, para desaparecer luego en el siglo XVIII, cuando aparece una sola ocurrencia. Los 4 ejemplos del siglo XX no indican una revitalización de la palabra, dado que dos aparecen en la Historia de la lengua española de Lapesa, uno en texto que remite a Lapesa y, finalmente, uno en una historia de la farmacia.

Un posible reemplazo podría ser electuario, con la mención de que el alquermes era un tipo especial de electuario en cuya composición entraba el quermes, un insecto. Procede del lat. tardío

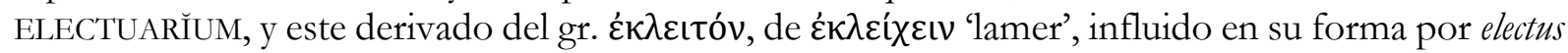
'elegido', 'seleccionado' (DLE, s.v.).

Está muy bien documentado en el corpus, con 509 ejemplos en 87 documentos, de los cuales 503 en España. Parece haber sido medicina muy usual durante la Edad Media (274 ejemplos entre los siglos XIII-XV) y los Siglos de Oro (134 casos), pero su uso se reduce considerablemente más tarde: 4 casos en el XVIII, 69 en el XIX y 28 en el XX.

\subsubsection{Azaro (azarote) - sarcocola}

Azaro(te) es un término raro y poco utilizado, al igual que sarcocola, su sinónimo. Se registran solo 7 casos en 6 documentos, 2 del siglo XV, 2 del siglo XVI y 3 del XVII. 
Aparece mencionado en Autoridades (cf. Maíllo Salgado 1998: 130-131).

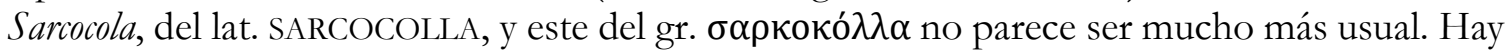
41 ocurrencias en 15 documentos, solo de España. 5 ejemplos son del siglo XIII, 20 del XV; 14 casos podemos encontrar durante los siglos XVI-XVII, y después se vuelve básicamente inusitado, con un solo ejemplo en el XIX otro en el XX.

\subsubsection{Quina - gálbano}

Quina solo tiene 5 ocurrencias en el corpus, todas del siglo XIII; no tuvo uso ni se generalizó, y tampoco aparece en los diccionarios antiguos (cf. Maíllo Salgado 1998: 177-178).

Gálbano, su sustituto, del lat. GALBĂNUM, tiene 137 ocurrencias en 45 documentos, casi todas (135) en España. Atestiguado poco durante los siglos XIII-XIV (12 casos), se vuelve más usual en el siglo XV (53 ejemplos). Sigue siendo bastante usual durante los siglos XVI-XVII (44 casos); su utilización conoce luego una fuerte bajada: 2 casos en el XVIII, 17 en el XIX y 9 en el XX.

\subsection{Palabras patrimoniales (heredadas)}

\subsubsection{Alcarceña - yero (biero)}

Alcarceña tiene 13 ocurrencias en 5 documentos, solo de España. Hay 5 casos en el siglo XIII y 5 en el XVI, uno en el XVII y 2 en el XIX.

Es una palabra de uso restringido, propia del lenguaje médico; no entra en competición con su sinónimo yero y cae en desuso en el siglo XV. Está registrada solo en Autoridades. (cf. Maíllo Salgado 1998: 86-87).

Yero, del lat. vulgar ERUM, y este del lat. ERVUM (DLE; s.v.) tampoco parece voz muy usual, por muy antigua que sea. Hemos encontrado solamente 10 casos en 5 documentos, distribuidos así: 3en el siglo XV, uno en el XVI y 6 en el XX.

\subsubsection{Algazafán - agalla}

Algazafán, sin ocurrencias en el CDH, es un término accidental, que cae pronto en desuso. No aparece en los diccionarios hasta DRAE 1970 (cf. Maíllo Salgado 1998: 255).

Agalla, del lat. GALLA (DLE, s.v.), se encuentra en 122 casos en 66 documentos, más otros 848 casos en 362 documentos en el plural. Como se trata de una palabra muy polisémica (10 acepciones según el DLE), solamente una parte de estos ejemplos se refieren al significado que aquí nos preocupa.

\subsubsection{Almoraduj-mejorana (mayorana)}

Almoraduj, junto con sus variantes almoradux y moradux, aparece en 60 casos en 40 documentos en el corpus; la inmensa mayoría de estos ejemplos (68) aparecen en textos españoles. Hay 2 ejemplos del siglo XIV, 7 del XV; su uso aumenta durante los siglos XVI y XVII, cuando se registran más de la mitad de las ocurrencias totales, es decir 38. Después se documenta esporádicamente: 2 casos en el XVIII, 4en el XIX y 7 en el siglo XX.

Se usaba como remedio en contra de los dolores de cabeza: "Para el dolor de xaqueca \& dolor frio de cabeça loan mucho el moradux para comer \& oler \& en toda manera que vsen dello" (Alfonso Chirino, Menor daño de la medicina, antes de 1429).

Aparece recogido en los diccionarios de Nebrija y Covarrubias (cf. Maíllo Salgado 1998: 276277).

Hay dos variantes de reemplazo, relacionadas etimológicamente.

Mayorana, que viene posiblemente del gr. ó $\mu \alpha \alpha \rho \alpha \kappa o \varsigma$, a través del lat. AMARĂCUS (DCECH I, 201-202), aparece en 71 casos en 14 documentos, 61 de estos en España. 6 ejemplos son del siglo XV, 34 de los siglos XVI-XVII, 10 del XVIII y 21 del XX. 
Mejorana, que proviene de mayorana, con cruces de etimología popular (DLE, s.v.), está mucho más presente en el corpus, con 297 ocurrencias en 119 documentos, y 202 en España. Hay 55 ejemplos en el siglo XV, 66 en los siglos XVI-XVII; 6 en el XVIII, 25 en el XIX y 144 en el XX.

\subsubsection{Almorí- salmuera}

Almorí (o almuri) ha sido un vocablo de uso restringido y conectado con la jerga médica y veterinaria, (cf. Maíllo Salgado 1998: 114-115), como nos lo indican las 30 ocurrencias en 8 documentos, todas de España. No sobrevive a la Edad Media: 9 ejemplos del siglo XIII, 4 del XIV y 16 del XV; después aparece un último ejemplo en el siglo XX.

En el corpus no se registra el significado 'dulce', excepto en los diccionarios, que citan unos textos que no aparecen en el corpus. El DH cita un texto que nos indica las propiedades curativas del almorí: "El almurí purga la flema viscosa y córtala y aprouecha en el dolor de la cólica quando se mezclare en los cristeres con medicinas apropiadas y buenas, y tómase en manjar para el dolor de la sciática [...]".

Será eliminado por salmuera (del lat. SAL MŬRIA), palabra patrimonial bien arraigada en castellano (413 ocurrencias en 159 documentos; 250 en España), pero que no tiene usos médicos.

\subsubsection{Jebe - alumbre}

Jebe compite sin éxito con su sinónimo romance alumbre. No se registra en Nebrija ni en Covarrubias. En Autoridades ya se presenta como anticuado: "xebe: lo mismo que alumbre" y regional "voz usada en Aragón” (cf. Maíllo Salgado 1998: 335-336).

Alumbre proviene del lat. ALUMEN 'sulfato de alúmina', y está registrado en un texto fechado alrededor del año 1295. Es un vocablo muy usado, tal y como lo indican las 1305 ocurrencias en el corpus de 488 documentos.

\subsection{Creación interna (compuestos)}

\subsubsection{Albarraz - bierba piojera}

Otra propuesta de reemplazo para albarraz, además del cultismo estafisagria (v. supra 4.1.2.), es el compuesto popular hierba piojera. Este tampoco parece muy usual, pues solamente se registran 9 ocurrencias en 3 documentos, de los cuales 3 durante el siglo XIX y 6 del siglo XX.

\subsubsection{Teliarmin - bol arménico, bol de Armenia}

Teliarmin no tiene ocurrencias en el CDH. Es, según Maíllo Salgado (1998: 183-184), la típica palabra técnica, un cultismo accidental, que no parece recogido en los diccionarios.

Su reemplazo, bol arménico, aparece 67 veces en 11 documentos, distribuidos así: 4 ejemplos del siglo XIV, 48 del XV, 8 del XVI y 7 del XIX.

La variante bol de Armenia es casi inusual, tal y como lo apuntan las 3 ocurrencias en 2 documentos, una del siglo XIX y 2 del XX.

\subsection{Otros arabismos}

\subsubsection{Atincar-bórax}

Atíncar aparece en 52 casos de 21 documentos, 40 de España. Hay 11 atestiguaciones de los siglos XIV-XV, 26 durante los Siglos de Oro, después hay un fuerte retroceso: 2 ejemplos del XVIII, 12 del XIX y uno solo del siglo XX.

Hay una confusión entre el atíncar y el bórax que dura siglos. El atíncar es el borato de sosa, mientras que el bórax era el nitro de los antiguos. A causa de la confusión de los referentes, atíncar, bórax y el grecolatino crisocola son sinónimos o cuasi sinónimos. Durante la Edad Media, el término más popular y mejor conocido es atíncar, frente a su variante más culta bórax.

La palabra compitió con éxito durante la Edad Media con sus variantes más cultas bórax y crisocola; el último no llegó a ser verdaderamente su competidor, dado su carácter absolutamente 
culto. Durante siglos se usa más atíncar, hasta bien entrado en el siglo XVIII (cf. Maíllo Salgado 1998: 123-124).

\section{Conclusiones}

Nuestro estudio se ha centrado en un número total de 22 términos que designan remedios curativos usados en la medicina medieval.

De este inventario, 6 se conservan sin cambio de significado, 3 desaparecen por completo, y 13 vienen reemplazados. Hay 6 términos reemplazados por cultismos de origen latino, 5 por palabras patrimoniales, 2 por compuestos y un caso más especial, un arabismo (atíncar) reemplazado por otro arabismo (bórax).

\section{Referencias bibliográficas:}

CDH = Instituto de Investigación Rafael Lapesa de la Real Academia Española (2013): Corpus del Nuevo diccionario histórico (CDH) [en linea]. http://web.frl.es/CNDHE [Consulta: 15.10.2018].

CORPES XXI = REAL ACADEMIA ESPAÑOLA: Banco de datos (CORPES XXI) [en línea]. Corpus del Español del Siglo XXI (CORPES). http://www.rae.es [Consulta: 10.10.2018].

CORRIENTE, Federico (2008), Dictionary of Arabic and Allied Loanwords, Leiden, Koninklijke Brill NV.

DCECH = COROMINAS, Joan, PASCuAL, José Antonio (1980-1991), Diccionario crítico etimológico castellano e hispánico, 6 tomos, Madrid, Gredos.

DELR = REINHEIMER RIPEANU, Sanda (coord.) (2004), Dictionnaire des emprunts latins dans les langues romanes, Bucureşti, Editura Academiei Române.

$\mathrm{DH}=$ Diccionario bistórico de la lengua española (1960-1996); disponible en línea http://web.frl.es/DH.html [Consulta: 10.10.2018].

DLE = Diccionario de la Real Academia Española, 23a ed., (2014), Madrid, Gredos, disponible en línea http://www.rae.es/recursos/diccionarios/drae [Consulta: 05.10.2018].

Dworkin, Steven N. (2012), A history of the Spanish lexicon. A linguistic perspective, Oxford, Oxford University Press.

DwOrKIN, Steven N. (2013), «La transición léxica en el español bajomedieval», en CANO, Rafael (coord.), Historia de la lengua española, $\mathrm{I}^{\mathrm{a}}$ ed. 2004, Barcelona, Ariel Letras, pp. 643-656.

ENĂCHESCU, Mihai (2017a), «Pérdida y reemplazo de arabismos en español: metales y productos químicos», Angela Roș CA, Radu MELNICIUC (coord.), Probleme de filologie spaniolă ș $i$ italiană, Chiș inău, CEP USM, pp.61-67.

ENĂCHESCU, Mihai (2017b), «Pérdida y reemplazo de arabismos en español: los nombres de minerales», Studia romanistica, vol.17, nr.1, Caminos del hispanismo. Lingüística, Ostrava, Universitas Ostraviensis, Facultas Philosophica, pp. 41-53.

ENĂCHESCU, Mihai (2019). "Alcohol - historia de una palabra viajera», en Quaestiones Romanicae VII/2. Călători și călătorii. Incursiuni culturale și lingvistice, Szeged, JatePress „Jozsef Attila” Tudomanyi Egyetem Kiado Szeged, pp. 105-113.

LAPESA, Rafael (1986), Historia de la lengua española, 9ª ed. Madrid, Gredos.

MAíllo SAlgADO, Felipe (1998), Los arabismos del castellano en la Baja Edad Media, $3^{\mathrm{a}}$ ed. Salamanca, Ediciones Universidad de Salamanca.

Neuvonen, Eero K. (1941), Los arabismos del español en el siglo XIII, Helsinki, Imprenta de la Sociedad de literatura finesa.

NTLE = Nuevo Tesoro Lexicográfico de la Lengua Española. http://www.rae.es [Consulta: 20.10.2018]. Penny, Ralph (2006), Gramática bistórica del español, $2^{\mathrm{a}}$ ed. Actualizada, Barcelona, Ariel.

REINHEIMER RIPEANU, Sanda (2004), Les emprunts latins dans les langues romanes. Bucureşti, Editura Universităţii din București. 
Diferentes imágenes del medio ambiente se adaptan a diferentes tipos de expresiones. Discurso ambiental: un análisis lingüístico de la metáfora

\author{
Morgan Mok-Won PARK ${ }^{1}$ \\ Universidad de Salamanca
}

Resumen: Este trabajo pretende examinar contrastiva y comparativamente la potencial importancia de las metáforas que se utilizan en el discurso medioambiental, y sus traducciones a través de aplicar la teoría de la relevancia. Se abordarán las perspectivas ecológicas y neológicas del lenguaje para investigar las implicaciones de la traducción de la metáfora.

Palabras clave: metáfora lingüística, discurso medioambiental, modelos de traducción, ecolingüística, neología

Abstract: This paper intends to comparatively and contrastively examine the potential importance of the metaphors that are used in environmental discourse and their translations by applying the theory of relevance. Ecological and neological perspectives of language will be adopted to investigate the implications of the translation of the metaphor.

Keywords: linguistic metaphor, environmental discourse, translation, ecolinguistics, neology

${ }^{1}$ Correo electrónico: morganpark53@gmail.com 


\section{Introducción}

Vivir con el cambio climático no solo sugiere la necesidad de mejorar el conocimiento científico, sino también la demanda de un mejor conocimiento lingüístico, es decir, una mejor comprensión de cómo funciona el lenguaje y la comunicación en nuestra vida. En comparación con el discurso económico, político o periodístico, los textos ambientales no han recibido la debida atención como material lingüístico focal. Sin duda, los problemas ambientales están tan estrechamente relacionados con nuestra vida como la economía y la política.

Cronin (2017:3) discutió las profundas implicaciones de la crisis ambiental para la práctica y el estudio de la traducción e iluminó el papel de la traducción en la construcción de un futuro sostenible. Hoy en día las publicaciones reconocidas se difunden fácilmente en todo el mundo y requieren la traducción como un proceso indispensable. El mismo autor (2017:636) señaló demandas insaciables de datos traducidos en mercados globalizados: los contenidos más globalizados significan más palabras y más traducciones. Samaniego Fernández, Velasco Sacristán y Fuertes Olivera (2005) encarnan la prevalencia de la metáfora y su traducción de una manera fácil: no solo vivimos a través de metáforas, también vivimos a través de traducciones.

A pesar de lo común de la metáfora, todavía presenta muchas dificultades a la hora de su traducción. Sin embargo, Bassnett y Bush (2006) señalaron que la investigación sobre la metáfora se ha centrado principalmente en el lenguaje literario durante gran parte de su historia. Atanasova y Koteyko (2017:72) exigen más investigación comparativa sobre metáforas relacionadas con el cambio climático. Las variedades lingüísticas del inglés y el español tienen un papel sumamente influyente en la conciencia ambiental. Si bien el inglés es considerado y utilizado como lenga franca en la comunicación internacional, el español es el segundo idioma más hablado en el mundo, y siendo uno de los idiomas oficiales de las Naciones Unidas. El interés de investigación sobre inglés y español en el discurso ambiental no podría ser más oportuno y relevante.

\section{Antecedentes teóricos}

\subsection{Enfoque teórico de la relevancia en la metáfora y la traducción}

Los teóricos de la relevancia como Goatly 1997; Steen 2011a; Wilson 2004; Sperber y Wilson 2008 argumentan que hay un continuo de casos entre la conversación literal, la conversación relajada, la hipérbole y la metáfora sin un punto de corte entre ellos. En otras palabras, la distinción entre lo literal y lo metafórico es una cuestión de grado de relevancia. Goatly (1997:15) resume que cuanto mayor sea la brecha entre la proposición expresada y el significado que se pretende, más metafórica será la expresión y viceversa.

Wilson (2010:47-48) explica que la teoría de la relevancia se basa en dos afirmaciones generales: el principio cognitivo de la relevancia y el principio comunicativo de la misma. De acuerdo con el primero, la cognición humana tiende a estar orientada a la maximización de la relevancia, de modo que un oyente entiende la expresión de un hablante haciendo suposiciones interpretativas sobre la intención informativa del hablante. Sobre la base del principio comunicativo, se supone que el comunicador desea que su comunicación tenga éxito, lo que indica que quiere que la audiencia vea su pronunciación lo más relevante posible. Esta tendencia a maximizar la relevancia se resume a continuación: cada acto de comunicación inferencial conlleva una presunción de su propia relevancia óptima (Sperber y Wilson, 2008:104).

Basado en la teoría de la relevancia, Gutt (1993) explica cómo funciona la traducción. La sugerencia de la teoría de la relevancia de que la metáfora expresa una forma de conversación floja se basa en una distinción entre representaciones descriptivas e interpretativas. La traducción cae 
bajo el uso interpretativo del lenguaje. Así es como Gutt (1993) aplica la semejanza interpretativa de la teoría de la relevancia a la traducción. El comunicador en los términos de Wilson y Sperber (2008) se puede representar como traductores, ya que son los que primero leen y entienden los textos originales y luego los traducen con, en la mayoría de los casos, objetivos claros para comunicarse efectivamente con sus lectores.

Smith (2002) afirma que la contribución principal de Gutt (1993) es un mayor derecho otorgado a los traductores para tomar las decisiones correctas asumiendo que el traductor anticipará si el texto de origen a traducir es comunicable en el contexto dado de la audiencia. La contribución secundaria es su aportación a la traducción de información implícita, especialmente el uso del lenguaje figurado. Los textos traducidos deben ser la forma en que los lectores ponen el menor esfuerzo posible para poder disfrutar de la lectura a un costo de procesamiento mínimo sin pensar demasiado en lo que realmente significa. La audiencia en el término de Wilson (2010) se puede interpretar en la traducción como lectores. De acuerdo con la teoría de la relevancia aplicada a la traducción, los lectores cederían su información enciclopédica previamente adquirida para tratar de comprender las nuevas metáforas lingüísticas encontradas en los materiales traducidos. De acuerdo con la regla de relevancia óptima, existe una expectativa por parte del lector de que su intento de interpretación producirá efectos contextuales adecuados.

Es importante abordar que el proceso de metáfora en la lengua de origen (LO) es probablemente diferente en comparación de la lengua de destino (LD). En detalles, las traducciones literales no contienen las mismas suposiciones que las de LO. Aunque el contexto inmediato de una metáfora es el mismo tanto en el texto de origen (TO) como en el texto de destino (TD), los efectos contextuales en las metáforas de TO y TD son probablemente diferentes debido a la influencia de contextos más amplios, como los socioculturales. En estas situaciones, la implicación de una metáfora es difícil de lograr, y la comunicación se debilita o incluso puede llevar a una ruptura. Entonces, el lector objetivo no estará seguro de lo que el autor, a través de la traducción, trata de transmitir, e incluso pensará que la metáfora es irrelevante para los lectores objetivo.

Otro tema que ha sido abordado por los teóricos de la relevancia tiene que ver con la deliberación de las metáforas. Nacey (2013:169-170) escribe que las metáforas pueden juzgarse como deliberadas no solo si se produjeron intencionalmente, sino también si los lectores las perciben como producidas deliberadamente. Debe haber una conciencia por parte del escritor sobre el acto de creación de nuevas metáforas lingüísticas, y también lo mismo se puede aplicar para los lectores de la traducción. Una menor fidelidad puede interpretarse como una creatividad legítima que deja espacio para la creatividad metafórica. La teoría de la relevancia proporciona la validez teórica de la libertad de traducción orientada a objetivos que se sustenta en los siguientes tres fundamentos. Primero, para evitar la ruptura de la comunicación causada por un contexto diferente, se requiere una traducción sensible al contexto y orientada al objetivo. En segundo lugar, las implicaturas débiles, como las características únicas de la metáfora creativa, deben mantenerse mediante una traducción orientada al objetivo. En tercer lugar, la característica interpretativa de la traducción también apoya la práctica de la traducción orientada a objetivos. Así, He Jing (2010) afirma que la preocupación central del traductor no es lograr un estándar fijo de equivalencia, sino más bien hacer posible la comunicación exitosa.

\subsection{Neología y traducción}

La neología ocurre en todos los idiomas como consecuencia de los contactos lingüísticos, y podría decir que la traducción es, en gran medida, responsable de la neología. La neología se puede presentar con diferentes nombres: préstamos, traducción de préstamos, palabras extranjeras, alienismo, exteriorismo y borrowing. En lugar de esta diversidad, el término neología se usará en este estudio para referirse a las unidades léxicas tomadas por LO que pueden ser utilizadas o adaptadas 
en LD. La difusión del inglés y el énfasis puesto en el inglés sugiere que se importará cada vez más neología impulsada por el inglés en otros idiomas.

Núñez Nogueroles (2017) hizo reseñas sobre una serie de artículos sobre anglicismos en una variedad de idiomas: español latinoamericano, europeo y estadounidense. Su colección de las investigaciones relevantes confirma la incorporación generalizada de las expresiones de inglés al español que aparecieron en una amplia gama de campos, desde economía, deportes, publicidad hasta informática. En el estudio sobre la introducción del anglicismo en el español chileno, Gerding, C., Fuentes, M., Gómez l. and Kotz, G. (2014) advierten que los profesores de idiomas y los traductores deben informar a los estudiantes y lectores sobre el impacto que este intercambio lingǘstico tiene en otros idiomas. La relevancia que tiene el anglicismo para la traducción se encuentra en el dilema al que se enfrentan los traductores: elegir unidades anglicizadas para aceptar el flujo del inglés mediante la traducción literal, o bien traducirlas al español para cumplir con los estándares de LD. Un estudio contrastivo de Sanz Vicente (2012) también describe cómo los términos de múltiples palabras en inglés se transfieren al español, y los resultados han demostrado que el mecanismo preferido para transferir los términos de inglés al español se produce en forma de la traducción literal.

En el proceso de traducción, se puede demostrar que otros idiomas, como el español, dependen cada vez más directamente del idioma inglés. Es muy probable que estas nuevas unidades lingüísticas se integren en LD como sus propios componentes y, finalmente, penetren en sus estructuras conceptuales. En otras palabras, nuevos conceptos y términos, por lo tanto, una nueva cognición podría entrar en el sistema lingüístico de LD. Es deseable administrar y monitorear estos intercambios a un nivel particular para asegurar su adaptación correcta dentro del sistema general del lenguaje.

\subsection{Ecolingüística y traducción}

Ecolingüística se refiere a una elección o restricción lingüística que implica la interacción entre el lenguaje y la naturaleza. Denison (2001:80) enfatiza que la ecolingüística implica una jerarquía lingüística implícita, y que en la parte superior de la jerarquía, el inglés es el idioma internacional más utilizado en el mundo. Al describir el estado actual de la ecolingüística europea, Denison (2001:79) despierta la atención sobre el fenómeno en el que la invasión de las fuentes lingüísticas de prestigio, lo que ocurre, en cierta medida, independientemente de las contramedidas, se empeora considerablemente cuando no se realizan tales esfuerzos, y es una fuente de opacidad semántica que no puede ser evitada por los defensores de las actitudes lingüísticas del laissez-faire. Denison (2001:80) nos recuerda que debemos tener en cuenta el efecto acumulativo de dicha influencia. Cronin (2017:2304) pide que se tomen decisiones trascendentales en vista de posibles consecuencias futuras o en su mayoría inocentes e innumerables ramificaciones individuales que la traducción podría producir.

Cronin $(2017: 162,186)$ explica el término eco-traducción como un concepto que abarca todas las formas de pensamiento y la práctica de la traducción que se involucran en los desafíos del cambio ambiental inducido por el ser humano. Cronin (2017:2303-2304) responde a la pregunta de cómo ver la traducción en la perspectiva ecolingüística: tenemos que pensar en la traducción como una parte esencial para resolver todos los motivos equivocados y revisar una gran cantidad de suposiciones fundamentales sobre lo que es el ser humano y lo que es vivir y ser parte del mundo por medio de la traducción. Se han realizado varias investigaciones sobre la diversidad lingüística y los peligros de su desaparición o aspectos gramaticales del discurso ambiental, pero muy pocas se publicaron en el área del lenguaje de la ecología y la traducción. En otras palabras, falta la investigación sobre el multilingüismo desde un punto de vista contrastivo de la interacción. Teniendo en cuenta que los traductores son una parte importante del ecosistema en el que 
contribuyen a las lenguas traducidas y su entorno, Fill (2001:51) solicita estudios de lenguajes individuales con respecto a la ecolingüística con posibilidad de enfoques contrastivos.

\section{Metodología}

\subsection{Colección del corpus}

El Consejo de Administración del Programa de las Naciones Unidas para el Medio Ambiente (PNUMA), que es un organismo de las Naciones Unidas, adoptó una estrategia a largo plazo para involucrar a la población joven en actividades ambientales. Uno de los productos secundarios importantes de esta estrategia es la revista TUNZA que se publicó desde 2002 hasta 2014 con la visión de fortalecer la conciencia ambiental de los jóvenes. El corpus compilado consta de 25 números de la revista inglesa de 2007 a 2014, a la que se agregan las versiones traducidas correspondientes en español. Por lo tanto, el corpus para análisis comprende 50 volúmenes con un total de 698,693 palabras: 322,524 palabras en inglés y 376,169 palabras en español.

\subsection{Identificación de metáforas lingüísticas}

El método Pragglejaz fue elegido como un medio para encontrar formas lingüísticas de metáfora en uso, dado que Steen (2007:91) indica la posible utilidad de emplear este procedimiento para validar metáfora. En primer lugar, el texto completo debe leerse detenidamente para establecer una comprensión general del corpus y, luego, las unidades léxicas se determinen según las pautas establecidas por Steen y sus colegas (2010:27). El siguiente paso es estudiar su significado contextual. Steen (2007:97) escribe que decidir si un significado metafórico particular es convencionalizado puede hacerse consultando un registro público disponible, actualizado y producido de forma independiente, más específicamente, un diccionario como una norma de referencia concreta. Para el análisis de las unidades léxicas en inglés, se seleccionó el Diccionario de Inglés Macmillan (MED), ya que se trata de un diccionario basado en corpus, según lo recomendado por el Grupo Pragglejaz.

\subsubsection{Un caso de no ser metafórico}

El significado contextual de la unidad léxica potencialmente metafórica debe compararse con su significado básico que requiere tres etapas. En primer lugar, se debe consultar el significado básico. En segundo lugar, el significado básico de la unidad léxica debe contrastarse con el significado contextual. En tercer lugar, en el caso de global, no hay contraste entre el significado contextual y el significado básico. Como no hay contraste entre el significado contextual y el significado básico global no es metafórico.

(Ej) Besides, trees produce oxygen and help prevent global warming by absorbing carbon dioxide.

(a) El significado básico de global que se encuentra en MED es:

- incluyendo o afectando a todo el mundo

- complete, incluyendo todas las partes de algo

(b) El significado básico de global se refiere a:

- afectando a todo el mundo

(c) Metaphorical? No 


\subsubsection{Un caso de ser metafórico}

Para encontrar ejemplos de uso metafórico, la investigadora tiene que buscar manualmente las pistas contextuales. La forma en que se aplica un procedimiento de identificación de metáforas a la unidad léxica environmental se presenta a continuación.

(Ej) Now, the world is wrestling with a financial and economic crisis, a crisis of indebtedness. The discussions, bowever, are largely about the short term rather than about our reliance on fossil energy sources, our diminishing resources and overconsumption, which are building up massive environmental debts.

(a) El significado básico de environmental que se encuentra en MED es:

1. relacionado con el mundo natural y efecto que la actividad humana tiene sobre él (a) destinado a ayudar o proteger el medio ambiente

(b) El significado contextual de environmental combinado con debts se refiere a:

- La unidad lexica environmental in Ej no es completamente comprensible por sí misma sin las claves contextuales. En otras palabras, environmental debts por sí solas no son lo suficientemente explícitas. Con la ayuda del contexto, solo entonces, se puede entender en comparación con su significado básico 'el efecto que la actividad humana tiene en él'.

(c) ¿Metafórico? Sí

\subsection{Procedimiento extendido de identificación de metáforas para la traducción}

Dado que el otro pilar importante de este estudio es la traducción, se requieren dos pasos adicionales en el procedimiento de identificación de metáforas extendido. El primer paso es identificar las traducciones de las metáforas lingüísticas de origen al alinear TO con TD. El siguiente paso requiere investigar si los equivalentes de traducción son metafóricos mediante el uso de diccionarios de referencia en español, y, de ser así, cómo se realizan. El Diccionario de Lengua Española de la Real Academia Española (DRAE) se eligió como referencia, ya que está preparado por la Real Academia Española, que es la institución oficial responsable de supervisar la lengua española.

\section{Resultados: palabra clave metáfora lingüística}

Tabla 1 se muestra los resultados de las palabras clave identificadas como metáforas lingüísticas y su frecuencia después de pasar el procedimiento de identificación de metáforas. Estas palabras clave muestran claramente los valores y puntos de dirección del PNUMA. Las tres palabras clave más destacadas son: MUNDO, PERSONA y MEDIO AMBIENTE. La palabra clave que resulta ser la más metafórica es JUVENTUD con un abrumador $96 \%$. Con una diferencia considerable, el segundo lugar es SOSTENIBLE con 54\% seguido de CARBONO (28\%) y MUNDO (14\%). La palabra clave con la menor posibilidad de ser metafórica es PERSONA. 
Tabla 1. Resultados de la identificación de la metáfora lingüística

\begin{tabular}{|c|c|c|c|c|}
\hline No & $\begin{array}{c}\text { Potenciales palabras clave } \\
\text { metáforas }\end{array}$ & $\begin{array}{c}\text { Frecuencia } \\
\text { general } \\
\text { (No) }\end{array}$ & $\begin{array}{l}\text { Metáfora } \\
\text { lingüística } \\
\text { (No) }\end{array}$ & $\begin{array}{c}\text { Metáfora } \\
\text { porcentaje } \\
(\%)\end{array}$ \\
\hline 1 & $\begin{array}{l}\text { WORLD / WORLD'S / WORLDS' / } \\
\text { UNDERWORLD / WORLDWIDE / } \\
\text { THE WORLD }\end{array}$ & 309 & 44 & 14.2 \\
\hline 2 & PEOPLE / PEOPLES & 283 & 2 & 0.7 \\
\hline 3 & $\begin{array}{c}\text { ENVIRONMENT / } \\
\text { ENVIRONMENTAL / } \\
\text { ENVIRONMENTALLY / } \\
\text { ENVIRONMENTALISM }\end{array}$ & 238 & 16 & 6.7 \\
\hline 4 & CARBON / DECARBONIZE & 113 & 32 & 28.3 \\
\hline 5 & $\begin{array}{l}\text { WASTE / WASTES / } \\
\text { WASTFEULLNESS }\end{array}$ & 94 & 6 & 6.3 \\
\hline 6 & CLIMATE & 88 & 12 & 13.6 \\
\hline 7 & $\begin{array}{c}\text { SUSTAINABLE / } \\
\text { UNSUSTAINABLE / } \\
\text { SUSTAIN / } \\
\text { STAINABLY / } \\
\text { SUSTAINABILITY }\end{array}$ & 87 & 47 & 54.0 \\
\hline 8 & YOUTH / YOUTHFUL & 80 & 77 & 96.2 \\
\hline 9 & GLOBAL / GLOBALLY & 73 & 6 & 8.2 \\
\hline 10 & PLANET / THE PLANET & 58 & 5 & 8.6 \\
\hline & TOTAL & 1,423 & 247 & 17.3 \\
\hline
\end{tabular}

\section{Análisis: patrones de traducción}

Las traducciones de palabras clave identificadas como metáforas lingüísticas pueden clasificarse en función de su grado relativo de metaforización. Inicialmente, se dividieron en dos grupos principales según si las metáforas lingüísticas se mantienen o no en TD. Estos dos grupos 
superiores pueden clasificarse en dos subgrupos, respectivamente, según su nivel de relevancia metafórica.

Tabla 2. Patrones de traducción (PT) de metáforas lingüísticas

\begin{tabular}{|l|c|l|l|}
\hline \multicolumn{2}{|l|}{ Metáfora no lingüística } & \multicolumn{2}{l|}{ Metáfora lingüística } \\
\hline PT 1 & PT 2 & PT 3 & PT 4 \\
\hline Omitido & Explicativo & Literal & No-literal \\
\hline
\end{tabular}

PT 1 implica una simple exclusión de las metáforas lingüísticas de origen en TD, que se sitúa en el extremo de la continuidad de la metáfora. PT 2 presenta casos en los que se omite una metáfora lingüística de origen en TO y se sustituye por una explicación en TD. Ambos PT 3 y 4 incorporan una metáfora lingüística en TD. En PT 3, una metáfora lingüística se conserva siguiendo de cerca la forma de LO que exhibe un alto grado de relevancia, mientras que PT 4 adopta una expresión lingüística metafórica diferente en LD.

\subsection{Patrón de traducción 1: Omitido}

Si la metáfora es redundante o no tiene un propósito práctico, hay pocos casos para PT 1. Sin embargo, no está claro si esto fue una omisión consciente por parte del traductor o si fue un error. Es dudoso que haya sido un error porque tanto la traducción general de la revista como el texto cercano a las partes omitidas se traducen casi palabra por palabra. Supuestamente, fue una omisión consciente por parte del traductor. Tabla 3 muestra extractos de la concordancia paralela de PT 1. La palabra clave metáfora lingüística world no se traduce en TD bajo la decisión del traductor de ser menos importante mientras se evita que el TD sea largo. La palabra clave metáfora lingüística climate tampoco se encuentra en TD, lo que presumiblemente se puede deducir del contexto cercano, y se percibe el intento del traductor de hacer que la longitud de TD sea equivalente a la de TO.

Tabla 3. Extractos de la concordancia paralela de PT 1

\begin{tabular}{|l|l|l|}
\hline Ej & \multicolumn{1}{|c|}{ Texto de origen } & \multicolumn{1}{c|}{ Texto de destino } \\
\hline 1 & $\begin{array}{l}\text { Nobody likes invasions of rats, but } \\
\text { islanders have more reason than most to } \\
\text { fear them. Blamed for half the } \\
\text { extinctions since the 1600s, they wreak } \\
\text { especial havoc when they arrive at } \\
\text { islands where they have no natural } \\
\text { predators. }\end{array}$ & $\begin{array}{l}\text { A nadie le gustan las invasiones de ratas, } \\
\text { pero los habitantes de una isla tiene más } \\
\text { razones que la mayoría para temerlas. } \\
\text { Culpadas por la mitad de las extinciones } \\
{[\phi] \text { desde los años 1600, causan estragos }} \\
\text { severos cuando llegan a islas en las cuales } \\
\text { no tienen predadores. }\end{array}$ \\
\hline 2 & $\begin{array}{l}\text { Since it was founded last year, the Project } \\
\text { has taught over 1,500 people from } \\
\text { around the world (including Australia, } \\
\text { Mexico, Puerto Rico, Thailand, Uganda } \\
\text { and the United States) abeut climate } \\
\text { isstes, and sent them home to deliver 10 } \\
\text { or more of their own presentations. }\end{array}$ & $\begin{array}{l}\text { Desde su fundación el año pasado, el } \\
\text { Proyecto ha entrenado a 1.500 personas } \\
\text { Australia, los Estados Unidos de América, } \\
\text { México, Puerto Rico, Tailandia y Uganda } \\
{[\phi] . \text { Todas volvieron a su propio país para }} \\
\text { dar otras diez presentaciones más. }\end{array}$ \\
\hline
\end{tabular}




\subsection{Patrón de traducción 2: Explicativo}

PT 2 no conserva una metáfora lingüística de TO, en cambio, proporciona la incorporación de una explicación por parte del traductor. Una expresión metafórica environmental activism en Ejemplo 4 se expande aún más en la traducción. La palabra clave metáfora lingüística world en Ejemplo 4 no se traduce literalmente en TD, en cambio, la frase se representa de una manera no metafórica con una explicación guiada. A diferencia de PT 1, lo que está implícito en TO se hace explícito en TD. Aunque no hay una metáfora lingǘstica conservada en TD, la intervención de explicación del traductor no solo cumple su propósito de entregar el mensaje intacto, sino que también mantiene un flujo natural de la lectura en LD.

Tabla 4. Extractos de la concordancia paralela de PT 2

\begin{tabular}{|l|l|l|}
\hline Ej & \multicolumn{1}{|c|}{ Texto de origen } & \multicolumn{1}{c|}{ Texto de destino } \\
\hline 3 & $\begin{array}{l}\text { For his environmental activism, like his } \\
\text { film stardom, is well over a decade old, } \\
\text { even though he is still only 33. }\end{array}$ & $\begin{array}{l}\text { ha sido activista dedicada a asuntos } \\
\text { ambientales desde casi dos décadas, } \\
\text { aunque solo tiene 33 años de edad. }\end{array}$ \\
\hline 4 & $\begin{array}{l}\text { So how can humanity possibly hope to } \\
\text { produce what it is going to need in an } \\
\text { increasingly water-constrained world? }\end{array}$ & $\begin{array}{l}\text { ¿cómo puede esperar la humanidad que } \\
\text { será posible producir lo que hará falta en } \\
\text { el futuro, dado que el agua ya es cada } \\
\text { vez más escasa hoy día? }\end{array}$ \\
\hline
\end{tabular}

\subsection{Patrón de traducción 3: Literal}

Por medio de PT 3, las traducciones conservan los mismos efectos estilísticos que el original. Hay una lista sumamente larga de traducciones palabra por palabra sin intentar realizar cambios en la forma. Las expresiones de metáforas lingüísticas traducidas en TD no tienen una entrada en DRAE y, por lo tanto, se han inventado claramente para que coincidan con las expresiones en LO. Estas expresiones son difíciles de decodificar sin el conocimiento del contexto. Tabla 5 muestra cómo se practica PT 3 con las palabras clave metáforas lingüísticas world y sustainable.

Tabla 5. Extractos de la concordancia paralela de PT 3a: World, Sustainable

\begin{tabular}{|c|c|c|}
\hline $\mathbf{E j}$ & Texto de origen & Texto de destino \\
\hline 5 & $\begin{array}{l}\text { 'Feeding the world must remain } \\
\text { humanity's top priority.' }\end{array}$ & $\begin{array}{l}\text { "Alimentar al mundo debe seguir } \\
\text { siento la prioridad absoluta de la } \\
\text { humanidad." }\end{array}$ \\
\hline 6 & Pizza Earth - the world on a plate & Planeta-pizza - el mundo en un plato \\
\hline 7 & $\begin{array}{l}\text { We are often encouraged to eat more fish to } \\
\text { support a sustainable lifestyle. }\end{array}$ & $\begin{array}{l}\text { A menudo nos alientan a comer más } \\
\text { pescado para apoyar un estilo de vida } \\
\text { sostenible. }\end{array}$ \\
\hline
\end{tabular}


Tabla 6 presenta los extractos de la concordancia paralela para la palabra clave metáfora lingüística environment, en los cuales las unidades léxicas environmental wellbeing, environmentalism, environmental age y environmental thinking no son completamente comprensibles por sí mismas sin el contexto que las rodea.

Tabla 6. Extractos de la concordancia paralela de PT 3b: Environment

\begin{tabular}{|c|c|c|}
\hline Ej & Texto de origen & Texto de destino \\
\hline 8 & $\begin{array}{l}\text { Tourism and environmental well- } \\
\text { being rarely go hand in hand, and the } \\
\text { pressures are particularly great on } \\
\text { islands. }\end{array}$ & $\begin{array}{l}\text { El turismo y el bienestar del medio } \\
\text { ambiente rara vez van de la mano, y las } \\
\text { presiones son especialmente fuertes en las } \\
\text { islas. }\end{array}$ \\
\hline 9 & $\begin{array}{l}\text { 'We must move environmentalism } \\
\text { from being the philosophy of a } \\
\text { passionate minority to a way of life that } \\
\text { automatically integrates ecology into } \\
\text { governmental policy and normal living } \\
\text { standards. }\end{array}$ & $\begin{array}{l}\text { "Es necesario que cambiemos el } \\
\text { ambientalismo para que deje de ser la } \\
\text { filosofía de una minoría apasionada y se } \\
\text { convierta en un modo de vida que } \\
\text { automáticamente integre la ecología a la } \\
\text { política gubernamental y a los estándares } \\
\text { de vida normales." }\end{array}$ \\
\hline 10 & $\begin{array}{l}\text { We are entering an environmental } \\
\text { age whether we like it or not.' }\end{array}$ & $\begin{array}{l}\text { Queramos o no, estamos entrando en } \\
\text { una edad medioambiental." }\end{array}$ \\
\hline 11 & $\begin{array}{l}\text { He made } 11^{\text {th }} \text { Hour }- \text { which he } \\
\text { produced, co-wrote and narrated - to try } \\
\text { to move environmental thinking into } \\
\text { the mainstream. }\end{array}$ & $\begin{array}{l}\text { El deseo de llevar el pensamiento } \\
\text { medioambiental a la corriente } \\
\text { dominante fue lo que motivó a DiCaprio } \\
\text { a filmar La Ultima Hora, que él produjo, y } \\
\text { cuyo guión también fue coescrito y } \\
\text { narrado por él mismo. }\end{array}$ \\
\hline
\end{tabular}

En particular, para la palabra clave metáfora lingüística carbon en Tabla 7 hay una lista larga de metáforas lingüísticas novedosas que se traducen literalmente a carbono en LD. Si bien la palabra clave carbon es metafórica, sus traducciones tienden a ser muy literales, y al hacerlo, crean metáforas lingüísticas novedosas en LD.

Tabla 7. Extractos de la concordancia paralela de PT 3c: Carbon

\begin{tabular}{|r|c|c|}
\hline $\mathbf{E j}$ & \multicolumn{1}{|c|}{ Texto de origen } & Texto de destino \\
\hline 12 & $\begin{array}{l}\text { a typical TV on standby has a s big as } \\
\text { a carbon footprint over the year as a } \\
\text { typical person in Burundi. }\end{array}$ & $\begin{array}{c}\text { un aparato de TV típico en } \\
\text { standby deja una pisada de carbono } \\
\text { tan grande a través de un año como } \\
\text { una persona típica en Burundi. }\end{array}$ \\
\hline 13 & $\begin{array}{l}\text { the high-carbon infrastructure is } \\
\text { perpetuated for the many decades of its } \\
\text { future useful life. }\end{array}$ & $\begin{array}{l}\text { la infraestructura de alto } \\
\text { carbon es perpetuada por los muchos } \\
\text { decenios de su futura vida útil. }\end{array}$ \\
\hline
\end{tabular}




\begin{tabular}{|r|r|r|}
\hline 14 & $\begin{array}{c}\text { What practical things can everyone } \\
\text { do to kick the carbon habit? }\end{array}$ & $\begin{array}{r}\text { ¿Qué cosas prácticas puede hacer } \\
\text { cualquier persona para dejar el hábito } \\
\text { del carbono? }\end{array}$ \\
\hline 15 & $\begin{array}{l}\text { Imagine a zero-carbon city with all } \\
\text { its power provided by the sun, the wind } \\
\text { and recycled waste - }\end{array}$ & $\begin{array}{l}\text { Imaginen una ciudad de cero- } \\
\text { carbono en que toda la energía es } \\
\text { proporcionada por el sol, el viento y } \\
\text { residuos reciclados, }\end{array}$ \\
\hline
\end{tabular}

La tendencia continúa en Ejemplos 16 manteniendo los efectos estilísticos e irónicos de LO como waste siendo la palabra clave el nombre propio. Continuamente, Ejemplo 17 con climate, se tradujo literalmente en LD. Además, la palabra clave y el nombre propio planet se traduce literalmente en Ejemplo 18 y 19. Se puede deducir que PT 3 ocurre más frecuentemente con nombres propios, lo que implica la práctica de traducción automática y habitual del traductor.

Tabla 8. Extractos de la concordancia paralela de PT 3d: Waste, Climate, Planet

\begin{tabular}{|r|c|c|}
\hline $\mathbf{E j}$ & Texto de origen & Texto de destino \\
\hline 16 & $\begin{array}{c}\text { Their project 'Useful Waste for a } \\
\text { Better Future' has won the } \$ 10,000 \text { first } \\
\text { prize: 'In our small way, we have tried to } \\
\text { change perceptions and improve our local } \\
\text { environment.' }\end{array}$ & $\begin{array}{c}\text { Su proyecto "Basura útil para un } \\
\text { futuro mejor" acababa de ganar el } \\
\text { primer premio: "En nuestra modesta } \\
\text { manera hemos tratado de cambiar las } \\
\text { percepciones de la gente y mejorar } \\
\text { nuestro medio ambiente local," } \\
\text { agregaron. }\end{array}$ \\
\hline 17 & $\begin{array}{l}\text { UNEP has also started the Climate } \\
\text { Neutral Network to help countries, cities } \\
\text { and corporations }\end{array}$ & $\begin{array}{c}\text { el PNUMA inició la creación de la } \\
\text { Red de Clima Neutral para ayudar a } \\
\text { países, ciudades y corporaciones }\end{array}$ \\
\hline 18 & $\begin{array}{l}\text { The 2006 Living Planet Report } \\
\text { identifyed it as my home, Cuba. }\end{array}$ & $\begin{array}{c}\text { El Informe Planeta Vivo 2006 lo } \\
\text { identifi co como mi patria: Cuba. }\end{array}$ \\
\hline $\begin{array}{l}\text { It is his third environmental } \\
\text { locumentary, preceded by two short fi } \\
\text { lms a web audience: Global Warming in } \\
\text { 2001 and Water Planet in 2004, both still } \\
\text { available on his site. }\end{array}$ & $\begin{array}{l}\text { Ya había producido dos cortos } \\
\text { para una audiencia en la web: El } \\
\text { Calentamiento de la Tierra en 2001 y } \\
\text { Planeta de Agua en 2004, que ambas } \\
\text { todavía pueden verse en su sitio. }\end{array}$ \\
\hline
\end{tabular}

Se encontró que al tratar con nombres propios con metáforas lingüísticas incluidas, los traductores tienen tendencia a la traducción literal sin intentar adaptar al LD. Tabla 9 muestra los casos en los que se ha elegido la traducción para conservar las expresiones de LO. En Ejemplo 20, la expresión de LO se pega y copia, junto con la traducción literal a LD escrita entre paréntesis. De igual modo, se ha elegido la traducción para conservar LO, poniendo la versión en español entre paréntesis como en Ejemplo 21. A continuación, Ejemplo 22 incluye sustain como palabras clave metáfora lingüística y muestra que no se ha intentado traducir a LD. 
Tabla 9. Extractos de la concordancia paralela de PT 3f: Climate, Sustain

\begin{tabular}{|c|c|c|}
\hline $\mathrm{Ej}$ & Texto de origen & Texto de destino \\
\hline 20 & $\begin{array}{l}\text { The concept of creating } \\
\text { environmentally educated and empowered } \\
\text { communities led Al Gore to create The } \\
\text { Climate Project. }\end{array}$ & $\begin{array}{l}\text { El concepto de crear } \\
\text { comunidades ambientalmente } \\
\text { educadas y potenciadas llevó a Al Gore } \\
\text { a Crear The Climate Project (E1 } \\
\text { Proyecto Clima). }\end{array}$ \\
\hline 21 & $\begin{array}{l}\text { Dr Caroline Bailie, however, sees them } \\
\text { as a way of tackling poverty. A professor of } \\
\text { materials engineering at Queen's University } \\
\text { in Canada, she is the brains behind Waste } \\
\text { for Life, a network of people seeking } \\
\text { solutions that help the environment and } \\
\text { empower local people. }\end{array}$ & $\begin{array}{l}\text { Sin embargo, la Dra Caroline } \\
\text { Baillie las ve como una manera de } \\
\text { tratar de resolver el problema de la } \\
\text { pobreza. Profesora de ingeniería de } \\
\text { materiales en la Universidad de } \\
\text { Queen's en Canadá, Caroline Baillie es } \\
\text { el cerebro detrás de "Waste for Life" } \\
\text { (basura-por-vida), una red de } \\
\text { personas que buscan soluciones que } \\
\text { ayudan al medio ambiente y habilitan a } \\
\text { los habitantes locales. }\end{array}$ \\
\hline 22 & $\begin{array}{l}\text { 'We can act as a moral conscience,' } \\
\text { said Richard Graves, of SustainUS, a US } \\
\text { youth organization. }\end{array}$ & $\begin{array}{l}\text { "Podemos asumir el papel de } \\
\text { conciencia moral," afirma Richard } \\
\text { Graves, de SustainUS, una } \\
\text { organizacion juvenil estadounidense. }\end{array}$ \\
\hline
\end{tabular}

\subsection{Patrón de traducción 4: No-literal}

A través de PT 4, las metáforas lingüísticas en TO se ajustan a LD manteniendo su metaforicidad, pero describiéndola de una manera orientada a LD. Tabla 10 muestra cómo pueden ser posibles las orientaciones de $\mathrm{LD}$, pero al mismo tiempo las traducciones conservadas de metáforas lingüísticas de origen con la palabra clave carbon.

Tabla 10. Extractos de la concordancia paralela de PT 4a: carbon

\begin{tabular}{|r|c|c|}
\hline Ej & Texto de origen & Texto de destino \\
\hline 23 & Counting carbon & La cuenta del carbono \\
\hline 24 & $\begin{array}{c}\text { How high is your carbon } \\
\text { awareness? }\end{array}$ & $\begin{array}{c}\text { ¿Cuán correcto es tu hábito de } \\
\text { carbono? }\end{array}$ \\
\hline
\end{tabular}

Con la palabra clave metáfora lingüística people en Tabla 11, PT 4 se puede aplicar. En Ejemplo 25, PEOPLE MOVERS es la subtitular de un artículo cuyo título es Green cities, y trata sobre los vehículos de la ciudad, como automóviles tradicionales, automóviles eléctricos, bicicletas y autobuses en diferentes ciudades del mundo. El subtítulo se ha traducido de una manera orientada 
a LD. También en Ejemplo 26, se puede observar que se aplica la traducción guiada para el destinatario.

Tabla 11. Extractos de la concordancia paralela de PT 4b: people, waste

\begin{tabular}{|r|c|c|}
\hline $\mathbf{E j}$ & \multicolumn{1}{|c|}{ Texto de origen } & Texto de destino \\
\hline 25 & PEOPLE MOVERS & MOVIENDO A LA GENTE \\
\hline 26 & $\begin{array}{l}\text { Birds are like people. They stick to } \\
\text { TV, not to miss the news. Actually, } \\
\text { animals have adapted to human } \\
\text { circumstances and use equipment that is } \\
\text { left over by us. }\end{array}$ & $\begin{array}{c}\text { Los pájaros actúan como la } \\
\text { gente. Viven pegados a la TV para no } \\
\text { perderse las noticias de la tarde. En } \\
\text { efecto, los animales se han adaptado a } \\
\text { circunstancias humanas y usan el } \\
\text { equipo que nosotros desechamos. }\end{array}$ \\
\hline
\end{tabular}

\section{Conclusiones}

Tabla 12 muestra que el patrón de traducción aplicado de manera más recurrente es el PT 3 con una frecuencia abrumadora, lo que da la primera indicación de que los traductores tienen una mayor tendencia hacia la traducción literal. Con un margen considerable, el segundo lugar es para PT 2, seguido por PT 4. La estrategia menos común que los traductores optan por es PT 1.

\section{PT $3>>>$ PT $2>>$ PT $4>$ PT 1}

Tabla 12. Frecuencia de P'T 1, PT 2, PT 3, PT 4

\begin{tabular}{|l|l|c|c|c|c|c|c|r|r|r|}
\hline \multirow{2}{*}{ No } & \multirow{2}{*}{ KW } & Total & \multicolumn{2}{|c|}{ PT 1 } & \multicolumn{2}{|c|}{ PT 2 } & \multicolumn{3}{|c|}{ PT 3 } & \multicolumn{2}{|c|}{ PT 4 } \\
\cline { 5 - 12 } & & N & N & \% & N & \% & N & \% & N & \% \\
\hline 1 & WORLD & 44 & 1 & 2.2 & 3 & 6.8 & 40 & 90.9 & 0 & 0 \\
\hline 2 & PEOPLE & 2 & 0 & 0 & 1 & 50.0 & 0 & 0 & 1 & 50.0 \\
\hline 3 & ENVIRONMENT & 16 & 0 & 0 & 1 & 6.2 & 15 & 93.7 & 0 & 0 \\
\hline 4 & CARBON & 32 & 0 & 0 & 1 & 3.1 & 29 & 90.6 & 2 & 6.2 \\
\hline 5 & WASTE & 6 & 0 & 0 & 1 & 16.6 & 5 & 83.3 & 0 & 0 \\
\hline 6 & CLIMATE & 12 & 1 & 8.3 & 1 & 8.3 & 10 & 83.3 & 0 & 0 \\
\hline 7 & SUSTAINABLE & 47 & 0 & 0 & 3 & 6.3 & 44 & 93.6 & 0 & 0 \\
\hline 8 & YOUTH & 77 & 0 & 0 & 28 & 36.3 & 50 & 64.9 & 0 & 0 \\
\hline 9 & GLOBAL & 6 & 0 & 0 & 0 & 0 & 6 & 100 & 0 & 0 \\
\hline 10 & PLANET & 5 & 0 & 0 & 0 & 0 & 5 & 100 & 0 & 0 \\
\hline & TOTAL & 247 & 2 & 0.8 & 39 & 15.7 & 204 & 82.5 & 3 & 1.2 \\
\hline
\end{tabular}


Al ser PT 1 el patrón menos destacado significa que los traductores en general buscan fidelidad y se practica principalmente por dos razones: evitar la repetición o la longitud. A continuación, el propósito de PT 2 puede explicarse por el principio comunicativo de la teoría de la relevancia, según la cual se supone que los traductores desean que su comunicación tenga éxito aunque la información explicativa adicional tiende a crear oraciones más largas, lo que indica que quiere que los lectores vean su pronunciación lo más relevante posible, incluso si se trata de obviar metáforas lingüísticas de TO.

En ausencia de las expresiones equivalentes en TD, los traductores tienden a considerar PT 3 más accesible y, sin embargo, potencialmente consecuente. Es importante recordar que todas las metáforas lingüísticas convencionales deben haber sido nuevas e innovadoras en algún momento de la historia. Estos usos literales del lenguaje, que, si se repiten con la frecuencia suficiente, pueden resultar en el establecimiento de correspondencias sistemáticas, como sostienen Samaniego Fernández, Velasco Sacristán y Fuertes Olivera (2005:62). Por lo tanto, es fundamental tener en cuenta que al hacer un uso intencional o no intencional de PT 3, los traductores introducen de hecho nuevas expresiones metafóricas en el idioma y la cultura de destino, y al final afectan la forma de pensar sobre el medio ambiente y los problemas ambientales.

Como demuestra Sanz Vicente (2012), la influencia que tiene el inglés en la formación española de estas unidades debe ser vigilada, porque esta preferencia por las traducciones literales significa que debemos considerar en qué medida actúan como un elemento innovador y enriquecedor en el lenguaje de la formación secundaria de palabras. Cronin (2017:2311) pide que los traductores tomen decisiones prudentes en vista de las posibles consecuencias futuras de la traducción de metáforas sin control.

Además, es importante resaltar que la traducción está dirigida a los jóvenes, y por lo tanto, TD debe guiarse por la orientación del destinatario. Sobre todo para los lectores jóvenes, la práctica de palabra por palabra puede imponer una posibilidad significativa en la que los lectores de LD no pueden inferir las implicaturas de manera que hacen los lectores de LO entender el texto, ya que el contexto de LO y LD son diferentes y el resultado del procesamiento de la teoría de relevancia podría ser diferente de TO.

Si bien la traducción literal o la neología en la traducción pueden mostrar diferentes grados de adaptación al idioma de destino, desde un grado de asimilación cero hasta una asimilación casi total, se recomienda la libertad o predisposición a la adaptación del traductor. En este sentido, el pequeño intento de practicar PT 4 deja mucho que desear. Se puede deducir que PT 4 se utiliza como un medio para esforzarse por preservar la presencia metafórica de TO mientras se exploran las expresiones idealistas que son relativamente cómodas y comprensibles para los lectores objetivo. La teoría de la relevancia apoya la validez de la traducción creativa y orientada a objetivos. Por lo tanto, PT 4 puede servir como un indicador útil para las habilidades de los traductores y la legibilidad de TD, y sugerir que se debe alentar un enfoque más abierto y realista en la traducción. Esto se debe a que las diferentes imágenes del entorno se tienen que adaptar a diferentes tipos de expresiones lingüísticas.

\section{Referencias}

ATANASOva, Dimitrinka \& KOTEYKO, Nelya (2017) «Metaphors in Online Editorials and OpEds about Climate Change», The Role of Language in the Climate Change Debate, ed. (Kjersti, Flottum), Routledge.

BASSNETT, Susan \& Bush, Peter (2006) «The Translator as Writer», London \& New York: Continuum. 
Cronin, Michael (2017) «Eco-Translation Translation and Ecology in the Age of the Anthropocene», Routledge.

DENISON, Norman (2001) «Ecosystems: Language World Systems and Other Metaphors», The

Ecolinguistics Reader: Language, Ecology and Environment, eds. (Fill, Alwin \& Mühlhäusler, Peter), London and New York: Continuum.

FILL, Alwin \& MÜHLHÄUsler, Peter (2001) «The Ecolinguistics Reader: Language, Ecology and Environment», London and New York: Continuum.

GERDing, C. \& Fuentes, M. \& GÓmEZ, L., KotZ, G. (2014) «Anglicisms: An active wordformation mechanism in Spanish», Colombian Applied Linguistics Journal 16(1), p.40-54.

GOATLY, A. (1997) «A response to Schleppegrell: what makes a grammar green?», Journal of Pragmatics 28, p.249-51.

GOTTI, Maurizio (2014) «Reformulation and reconceptualization in popularization discourse», Ibérica 27, p.15-34.

GuTT, E.-A. (1993) «Translation and Relevance: Cognition and Context», Oxford: Blackwell.

HE, Jing. (2010) «The Translation of English and Chinese Puns from the Perspective of Relevance Theory», The Journal of Specialized Translation 13, p.81-99.

NÚÑEZ NOGUEROLES, E. E. (2017) «An up-to-date review of the literature on Anglicisms in Spanish», Diálogo de la Lengua IX, p.1-54.

SAmaniego Fernández, Eva, Marisol Velasco Sacristán and Pedro Fuertes Olivera (2005) «Translations we live by: The impact of metaphor translation on target system», Lengua y Sociedad: Investigaciones recientes en Lingüistica Aplicada ed. (Pedro A., Fuertes Olivera), Valladolid, Servicio de Publicaciones, p.61-81.

SANZ VICENTE, M.L. (2012). «Searching for patterns in the transfer of multiword units: a corpus-based contrastive study on secondary term formation», ed. (Gornostay, T.), Proceedings of CHAT 2012. The 2nd Workshop on the Creation, Harmonization and Application of Terminology Resources. Co-located with TKE 2012. Linköping Electronic Conference Proceedings 72, Linköping: Linköping University Electronic Press p.11-18.

SMITH, K. (2002) «Translation as Secondary Communication: The Relevance Theory Perspective of Ernst-August Gutt», Acta Theologica Supplementum 2.

Sperber, D \& Wilson D. (2008) «A Deflationary Account of Metaphors», The Cambridge Handbook of Metaphor and Thought, ed. (R.W. Gibbs,Jr.), Cambridge: Cambridge University Press, p.85-105.

STEEN, Gerard J. (2007) «Finding Metaphor in Grammar and Usage: A Methodological Analysis of Theory and Research», Amsterdam: John Benjamins.

SteEn, Gerard J., L., Herrmann, B., Kaal, A., Krennmayr, T., \& Pasma, T. (2010) «A Method for Linguistic Metaphor Identification: From MIP to MIPVU», Amsterdam/Philadelphia: John Benjamins.

STEEN, Gerard J. (2011a) «From Three Dimensions to Five Steps: The Value of Deliberate Metaphor», Metaphorik de 21, p.83-110.

NACEY, Susan. (2013) «Metaphors in Learner English», Amsterdam and Philadelphia: John Benjamins Publishing Company.

WiLSON, D. (2004) «Parallels and Differences in the Treatment of Metaphor in Relevance Theory and Cognitive Linguistics», Studies in Pragmatics 11, p.42-60.

WILSON, Deirdre, and Sperber, Dan. (2004) «Relevance Theory», The handbook of pragmatics, eds. (L. Horn \& G. Ward), Oxford: Blackwell, p.607-632. 


\title{
Detección de neologismos semánticos: Una aproximación estadística y de aprendizaje automático que combina corpus generales y especializados
}

\author{
Andrés Torres Rivera, Rosa Estopà Bagot, Juan Manuel Torres-Moreno \\ Universidad Pompen Fabra - IULA / Université d'Avignon et des Pays de Vaucluse - LIA
}

Resumen: En este artículo se presenta un acercamiento metodológico para la detección y extracción de neologismos semánticos mediante el sistema DENISE, creado para desarrollar estos dos procesos. Concretamente el sistema analiza aquellos neologismos que tienen su origen como unidades de conocimiento especializado en el campo de la informática y que posteriormente se introducen en la lengua general (en este caso: español y francés) con un nuevo significado distinto a los ya registrados en diccionarios de referencia. Para este fin, se expone la metodología empleada en este estudio y una comparativa de las distintas medidas de distancia que fueron evaluadas. Finalmente, se presentan los resultados obtenidos a partir de las pruebas realizadas con el coeficiente de correlación de Pearson y el coeficiente kappa de Cohen.

Palaras claves: procesamiento del lenguaje natural, neología semántica, terminología, minería de texto, aprendizaje automático, lenguas romances.

\begin{abstract}
This article presents a methodological approach for the detection and extraction of semantic neologisms through the DENISE system, created to carry out these two processes. Specifically, the system analyzes those neologisms that have their origin as units of specialized knowledge in the field of information technology and that are subsequently introduced into the general language (in this case: Spanish and French) with a new word meaning different from those already registered in the reference dictionaries. For this purpose, the methodology used in this study and a comparison of the different distance measures that were evaluated are explained. Finally, the results obtained from the tests carried out with the Pearson correlation coefficient and Cohen's kappa coefficient are presented.
\end{abstract}

Keywords: Natural language processing, semantic neology, terminology, text mining, machine learning, romance languages. 


\section{Introducción}

El presente estudio describe el sistema DENISE ${ }^{1}$, un sistema de detección y extracción semiautomática de neologismos semánticos (en adelante NS) que provienen de campos de conocimiento especializado. Este sistema emplea estrategias de aprendizaje automático no supervisado para evaluar la existencia de candidatos a NS en un texto. Para llevar a cabo este proceso, el usuario introduce un término que cree que pueda ser un candidato a NS para obtener contextos de lengua general, posteriormente el sistema realiza los cálculos correspondientes para determinar si dicho contexto es neológico y así llevar a cabo un proceso de validación del candidato como NS.

En los apartados siguientes se describen el objeto de estudio específico y el referente teórico en el que se enmarca el estudio; los objetivos generales y específicos tanto del sistema como del estudio; el funcionamiento de DENISE, acompañado de la descripción de los métodos empleados y los resultados que se espera obtener en la evaluación; la descripción de la evaluación del sistema e interpretación de los resultados así como la correlación de Pearson y el coeficiente de kappa de Cohen para comparar el nivel de efectividad del sistema.

Finalmente, en la sección de conclusiones se detallan las fortalezas y debilidades de esta metodología acompañadas de una nueva propuesta metodológica, dado que se observó una leve correlación (tanto en Pearson como en kappa) en los sistemas de cálculo de neologicidad. Esta nueva metodología busca dar respuesta las debilidades del sistema actual mediante la implementación de modelos neuronales de desambiguación semántica con word embedding en conjunto con etiquetas gramaticales.

\section{Objeto de estudio}

En esta investigación definimos el concepto de neologismo semántico de acuerdo con la metodología de trabajo del Observatorio de Neología (OBNEO) ${ }^{2}$ de la Universitat Pompeu Fabra. Según Cabré \& Estopà (2004), un NS es un neologismo formado por una modificación del significado de la base léxica. Con el propósito de obtener una clasificación cuya organización permita la detección de NS desde una perspectiva informática, se utiliza la tipología propuesta por Cabré (2009), cuyo primer nivel establece cinco tipos principales de neologismos: formales, sintácticos, semánticos, préstamos y otros (donde se incorporan fenómenos menos frecuentes). Como se observa en la Tabla 1, los NS pueden surgir mediante tres procesos distintos: reducción de significado, ampliación de significado y cambio de significado. Dado que detectar esta distinción no forma parte de los objetivos del proyecto, nos enfocamos solamente en el nivel de cambio semántico sin especificar el mecanismo que permite dicho cambio.

\begin{tabular}{|c|c|c|c|c|}
\hline \multicolumn{5}{|c|}{ Categoría (FCONV) } \\
\hline \multicolumn{5}{|c|}{ Subcategoría } \\
\hline Proceso & Formación & $\begin{array}{l}\text { Cambio } \\
\text { gramatical }\end{array}$ & $\begin{array}{l}\text { Cambio } \\
\text { semántico }\end{array}$ & $\begin{array}{l}\text { Reducción } \\
\text { de significado } \\
\text { Ampliación } \\
\text { de significado } \\
\text { Cambio } \\
\text { de significado }\end{array}$ \\
\hline
\end{tabular}

Tabla 1: Fragmento de la tabla de clasificación multivariable (Cabré, 2009, p.35)

\footnotetext{
${ }^{1}$ Detector de neologismos semánticos por sus iniciales en sus lenguas de trabajo: catalán, español y francés.

2 Observatori de Neologia: https://www.upf.edu/web/obneo/
} 
El alcance del sistema DENISE ${ }^{3}$ se limita a NS que provienen de unidades terminológicas del campo de la informática y analiza la inclusión de los mismos en la lengua general empleando corpus de prensa en español y francés.

\section{Objetivos}

Por una parte, el objetivo principal de este estudio es comprobar si el sistema DENISE es capaz de detectar de forma semiautomática candidatos a NS utilizados en la lengua general y que provienen del campo de la informática. Por otra parte, esta investigación tiene como objetivo específico comprobar si el cálculo de similitudes se realiza exitosamente, es decir, si determina que una palabra es un candidato válido a NS.

Como método de comprobación de las funciones del sistema, se evaluará si existe correlación y concordancia entre los candidatos a NS detectados por el sistema y aquellos obtenidos manualmente por especialistas. Con este propósito, se emplearán los contextos extraídos de la base de datos del OBNEO que contienen un NS detectado y etiquetado manualmente. De esta forma, se comprobará el número de casos que puede evaluar correctamente el sistema propuesto.

\subsection{Recursos para desarrollar un sistema de detección semiautomática de neologismos semánticos}

Una de las características principales del diseño de esta aplicación consiste en que los elementos de trabajo de DENISE deben ser flexibles, de forma que puedan ser reemplazados como piezas intercambiables. Actualmente, el sistema funciona en español, pero se contempla incorporar el catalán y el francés. Asimismo, también existe la posibilidad de añadir cualquier lengua de trabajo, siempre y cuando se cuente con todos los elementos requeridos por esta metodología.

Los elementos usados por el sistema son los siguientes:

- Corpus generales para realizar consultas y obtener contextos para ser analizados.

- Corpus especializados para construir campos semánticos que delimiten las temáticas que pueden ser analizadas.

- Diccionarios de referencia para obtener definiciones.

- Listas de términos y neologismos para realizar evaluaciones.

En la Tabla 2 se muestran los corpus de trabajo con los que se cuenta y su tamaño bruto en palabras. Los corpus generales sirven para extraer contextos de los términos que son consultados. Se espera que estos contextos tengan información diferente a la recogida en las definiciones de los diccionarios de referencia, es decir, un término informático puede ser candidato a NS si su concordancia en los corpus de lengua general da cuenta de una realidad diferente a la documentada en los diccionarios. Por otra parte, los corpus especializados sirvieron para realizar la extracción de términos de informática para crear un campo semántico que contiene los términos más representativos e informativos de este campo del conocimiento.

\begin{tabular}{llll}
\hline Corpus & Lengua & Tipo & Tamaño \\
\hline PC Word & ES & Especializado & $36,397,039$ \\
Wiki. Informática & ES & Especializado & $79,748,494$ \\
Wiki. Informática & FR & Especializado & $56,408,978$ \\
Jornada & ES & General & $723,528,525$ \\
El Financiero & ES & General & $230,111,744$ \\
\hline
\end{tabular}

${ }_{3}^{3}$ Detector de neologismos semánticos por sus iniciales en sus lenguas de trabajo: catalán, español y francés. 


\begin{tabular}{llll}
\hline Wikipedia & FR & General & $3,713,159,148$ \\
L'Observateur & FR & General & $1,300,687,386$ \\
L'Est Républicain & FR & General & $790,616,360$ \\
Le Monde & FR & General & $347,531,455$ \\
VSD & FR & General & $65,408,978$ \\
\hline \multicolumn{2}{l}{ Tabla 2: Extensión en palabras de los corpus de trabajo }
\end{tabular}

Los diccionarios de referencia que se usan corresponden al Diccionario del español de México ${ }^{4}$, del colegio de México; el Diccionario de la lengua española ${ }^{5}$ de la Real Academia Española; y el Wikcionario ${ }^{6}$ en español. Las acepciones de estos diccionarios sirven para determinar si los elementos consultados están documentados y, en caso de estarlo, si sus definiciones son similares a la concordancia de corpus general.

\section{Métodos de análisis}

Para cumplir con los objetivos mencionados anteriormente, DENISE combina dos métodos: el uso de medidas de similitud y la representación de textos en espacios vectoriales. El empleo de espacios vectoriales permite crear una matriz de documentos que representen los textos que serán evaluados mediante la función coseno. Esta matriz consiste en una transformación de los textos en valores de punto flotante, donde cada palabra representa un elemento de un vector y cada elemento evaluado (campo semántico, acepción y contexto de entrada) corresponde a un vector de la matriz de similitud.

Estas dos metodologías también son empleadas para calcular el índice de neologicidad de un candidato. Cuando dicho índice tiende hacia un valor cercano a 1, una palabra tiene mayor probabilidad de ser un candidato a NS. En cambio, cuando este índice tiende a 0 o menos, la palabra analizada no se considera un candidato viable.

\subsection{TFIDF: frecuencia de términos y frecuencia inversa de documento}

Definimos TFIDF (también denominado tf-idf; ver Ecuación 1) como el método empleado en sistemas de resumen automático, minería de texto y recuperación de información que permite hallar la frecuencia de término por la frecuencia inversa de documento, es decir, determina estadísticamente la relevancia de una palabra en un documento o en una colección de documentos (Jones, 1972; Salton, Fox, \& Wu, 1983; Salton, Wong, \& Yang, 1975; Salton \& McGill, 1984; Wu, Luk, Wong, \& Kwok, 2008).

En este caso, definimos documento como un texto de entrada, es decir, como una concordancia de un corpus o una definición de un diccionario. Con este método se evita evaluar tokens comunes para dar mayor importancia a tokens más informativos.

$$
t f i d f=(t, d, D)=t f(t, d) \cdot i d f(t, D)
$$

Ecuación 1: frecuencia de término - frecuencia de documento inversa

\subsection{Función coseno}

La función coseno (Ecuación 2) es una medida de similitud basada en espacios vectoriales. En el caso de sistemas dedicados al procesamiento del lenguaje natural, estos espacios vectoriales constituyen representaciones numéricas de textos; en el caso de este estudio las representaciones vectoriales están constituidas por los elementos de entrada del sistema: concordancia, definiciones

\footnotetext{
4 http://dem.colmex.mx

5 http://dle.rae.es

${ }^{6}$ https://es.wiktionary.org
} 
de diccionario y campo semántico (Baeza-Yates \& Ribeiro-Neto, 1999; Singhal, 2001; Tan, Steinbach, \& Kumar, 2005).

$$
\cos (\theta)=\frac{A \cdot B}{\|A\|\|B\|}=\frac{\sum_{i=1}^{n} A_{i} B_{i}}{\sqrt{\sum_{i=1}^{n} A_{i}^{2}} \sqrt{\sum_{i=1}^{n} B_{i}^{2}}}
$$

Ecuación 2: Función coseno para cálculo de similitud entre vectores.

Los elementos de entrada son textos simples (o cadenas de caracteres) que se transforman en espacios vectoriales de forma que la regla de coseno Euclideano pueda ser usada para determinar la similitud entre vectores. Un resultado de 1 en este cálculo indica que la similitud entre vectores es exacta, por ejemplo, la similitud de un vector consigo mismo, mientras que un resultado igual o menor a 0 indica que los vectores son opuestos y, por tanto, no existe similitud entre los elementos que están siendo analizados. En la Figura 1 se puede observar cómo se construye una matriz de similitud.

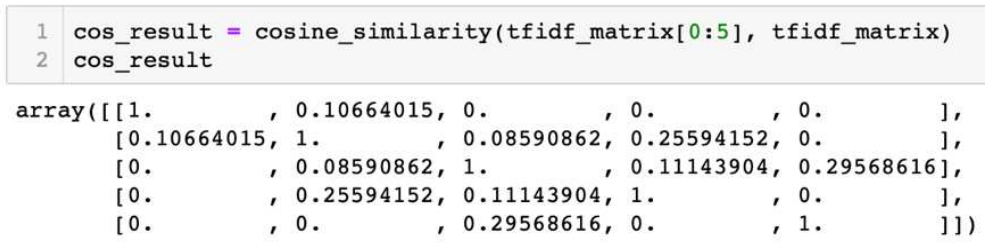

Figura 1: Ejemplo de matriz de similitud tf-idf.

\subsection{Descripción del sistema DENISE}

El sistema que proponemos (ver Figura 2) toma como entrada una palabra o lista de palabras y permite la selección por parte del usuario de la lengua de trabajo y de los campos semánticos disponibles, en este caso, el referido a la informática. A continuación, DENISE lleva a cabo un primer proceso de filtrado: si la palabra ingresada no existe en los diccionarios de referencia, se interrumpe el proceso y se presenta como candidato a neologismo formal para ser revisado por el usuario. En el caso contrario, se extraen las acepciones existentes de la palabra que ha sido consultada. 


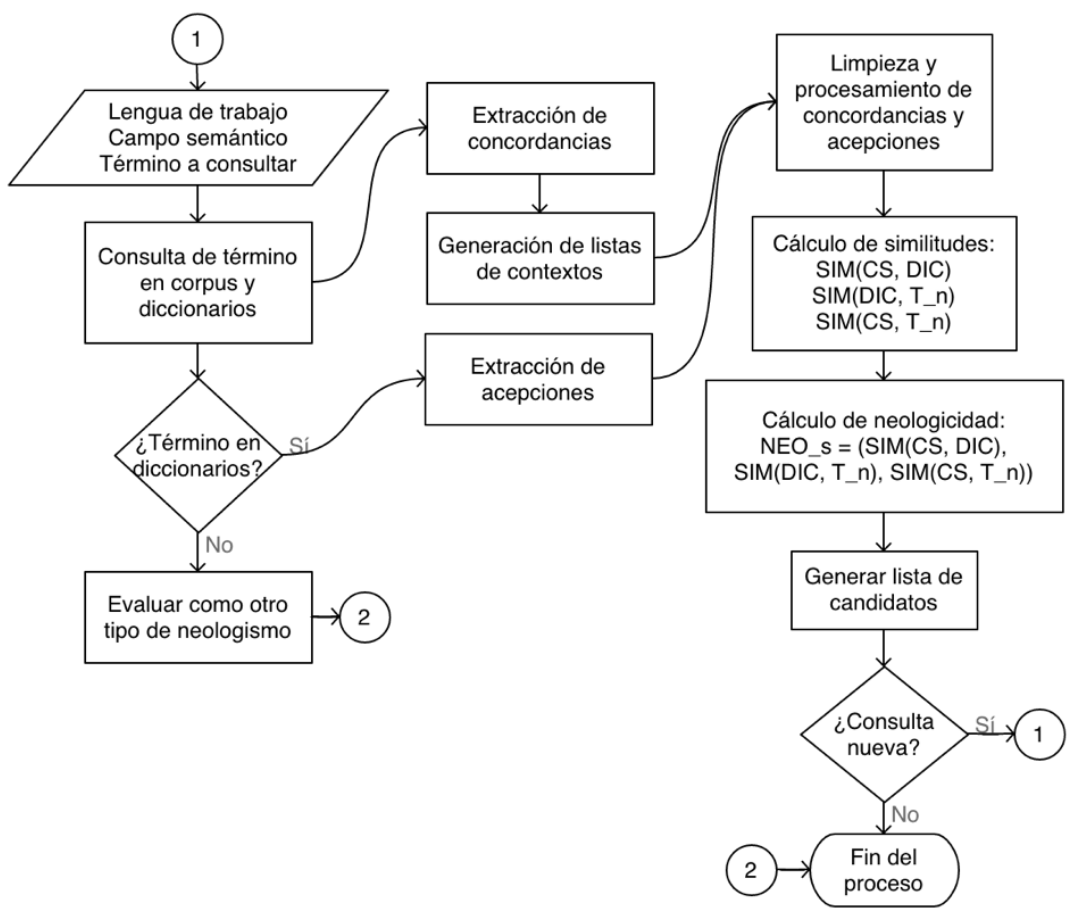

Figura 2: Diagrama de flujo del sistema DENISE

Paralelamente a los procesos mencionados, se extraen concordancias de los corpus generales para cada elemento de la lista y posteriormente, se realizan las siguientes tareas de preprocesamiento: limpieza y normalización del texto, tokenización, eliminación de stopwords, segmentación de textos con el módulo segmentador de Cortex (Torres-Moreno, VelázquezMorales \& Meunier, 2001) y stemming. Una vez procesados los textos de entrada, estos son transformados en representaciones vectoriales y se calculan las siguientes similitudes:

- Similitud entre la acepción del diccionario y el campo semántico: SIM(CS, DIC)

- Similitud entre la acepción del diccionario y el contexto: SIM(DIC, T_n)

- Similitud entre el contexto ingresado y el campo semántico: SIM(CS, T_n)

El proceso de análisis final (el análisis de neologicidad) toma en cuenta los resultados de los cálculos de la matriz de similitud para determinar si alguno de los tokens de las concordancias analizadas puede ser un candidato válido a NS. Un candidato ideal a NS es aquel que cumple con las siguientes condiciones: tiene mayor similitud con el campo semántico seleccionado, presenta menor similitud con las acepciones de los diccionarios y a su vez el campo semántico del que forma parte tiene poca similitud con la acepción.

Estas condiciones indican que un token del contexto ingresado tiene un significado novedoso, distinto a los ya documentados en las acepciones que contemplan los diccionarios. Sin embargo, el caso opuesto indicaría que el elemento consultado ya cuenta con una acepción en diccionarios, la concordancia es similar a esta acepción y, por lo tanto, se considera un token no neológico.

\section{Evaluación y análisis del sistema}

La evaluación consistió en realizar un proceso de validación de los contextos de la base de datos de OBNEO. Estos contextos cuentan con neologismos previamente detectados que el sistema debe evaluar como candidatos válidos. Además, se lleva a cabo un segundo proceso de 
validación, con contextos nuevos obtenidos de los corpus generales, que sirve para medir la eficacia con contextos que el sistema no ha analizado.

Se ingresaron en el sistema 35 NS (ver Figura 3) seleccionados manualmente de la base de datos de OBNEO. Estos neologismos ya cuentan con acepciones en nuestros tres diccionarios de referencia ${ }^{7}$ y se busca comprobar que son evaluados como neológicos frente a las acepciones de lengua general, pero como no neológicos frente a las acepciones informáticas.

Estos 35 NS presentan las siguientes características:

- Han sido evaluados manualmente en OBNEO.

- Cuentan con definiciones en los tres diccionarios de referencia.

- Pertenecen todos ellos al campo de la informática.

- Disponen de contextos en los corpus generales que serán usados en la segunda evaluación.

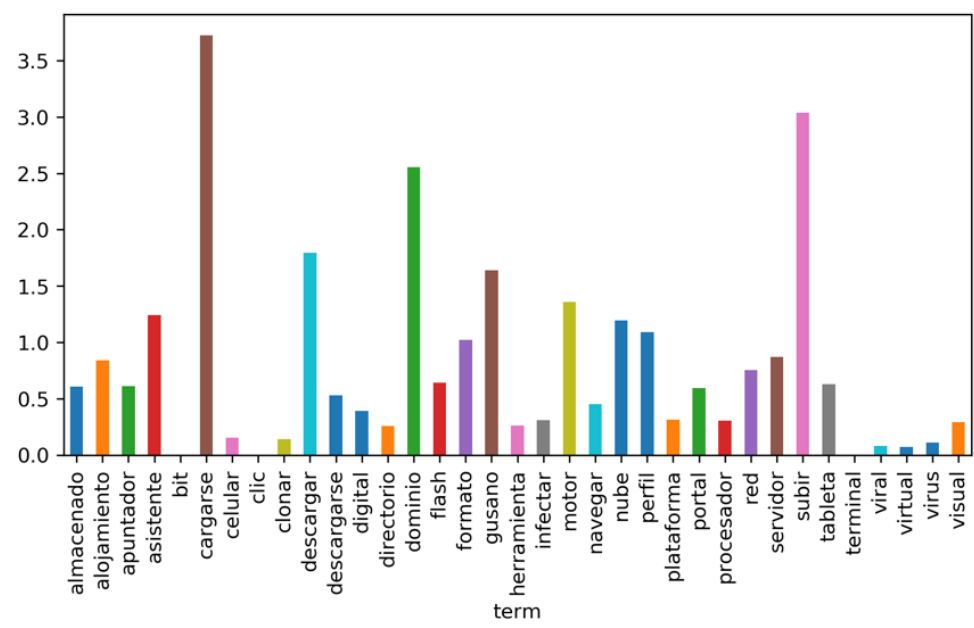

Figura 3: Similitud acumulada por término entre concordancias y campo semántico.

En la Figura 3 podemos ver el listado de los 35 términos y su similitud acumulada con el campo semántico, lo que nos ayuda a visualizar rápidamente los posibles términos que tienen más similitud con el campo semántico. En la Figura 4 podemos ver el listado de los 35 términos y la similitud acumulada del campo semántico y las acepciones.

En la Figura 5 se muestra el listado de los 35 NS y la similitud acumulada de los contextos obtenidos para cada NS y las acepciones de los diccionarios. Estos datos muestran de forma resumida la relación que existe entre los elementos que son analizados. Sin embargo, son poco informativos, ya que no podemos observar frente a qué acepciones un candidato es neológico o si todos los diccionarios cuentan con la misma cantidad de acepciones.

\footnotetext{
${ }^{7}$ En consecuencia, se consideran no neológicos en la actualidad. No obstante, dado que la finalidad de este estudio es corroborar la eficacia del sistema, nos interesa tener elementos estables en la lengua para comprobar que los cálculos de similitud se realizan de forma correcta y que el sistema es capaz de determinar si un contexto de entrada es novedoso y distinto a los significados de las acepciones recogidas en los diccionarios.
} 


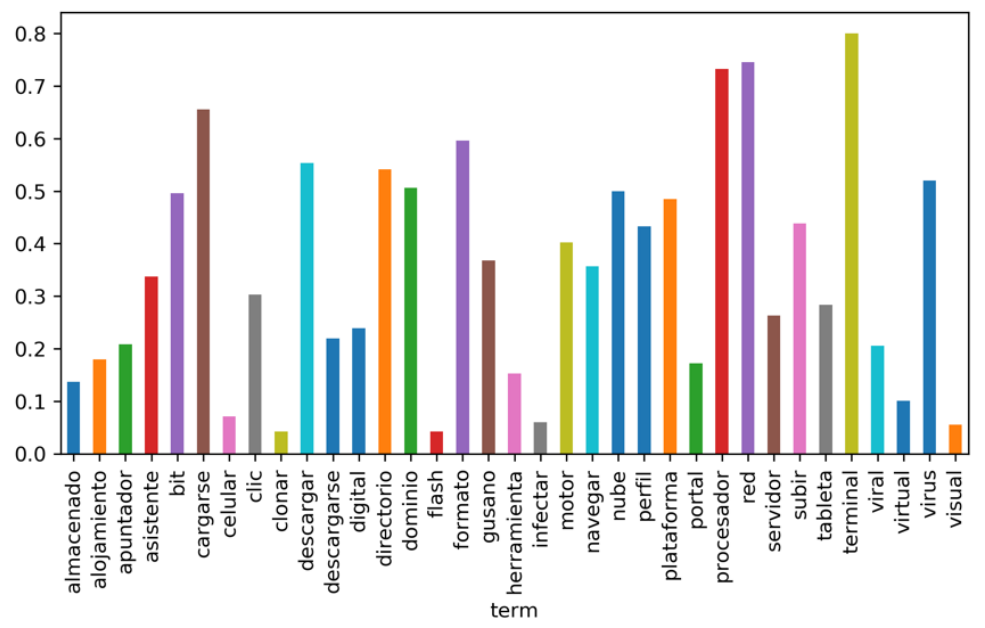

Figura 4: Similitud acumulada por término entre acepciones de los diccionarios de referencia y campo semántico.

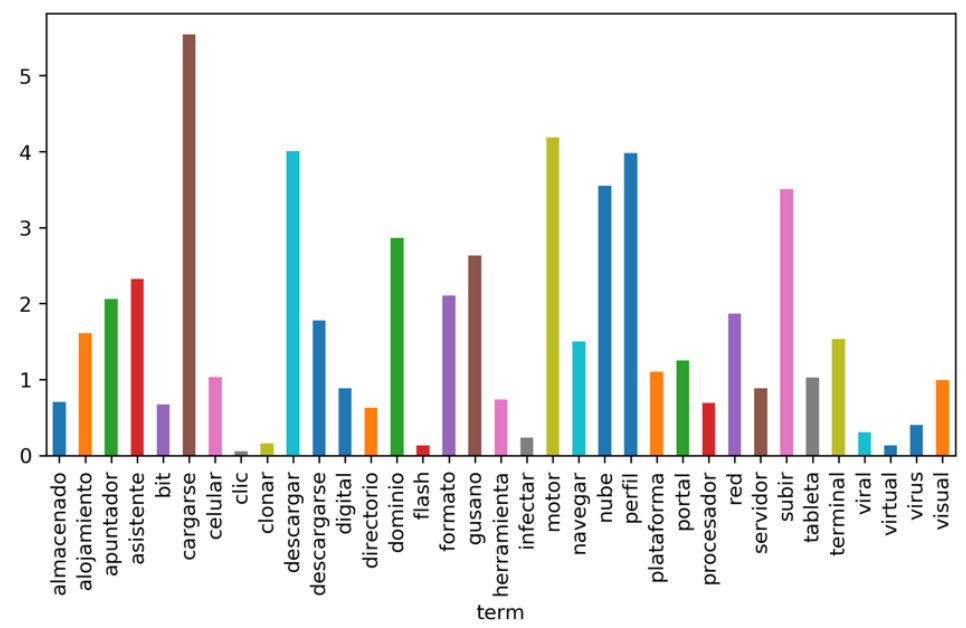

Figura 5: Similitud acumulada por término entre concordancias y acepciones de los diccionarios de referencia.

Los 35 términos, que ya han sido clasificados manualmente como NS, generaron 563 casos para ser analizados y, por lo tanto, se espera que frente a las acepciones informáticas tengamos un resultado de falso (o de 0 booleano) en la evaluación de neologicidad y frente a las acepciones no neológicas un 1 o verdadero.

Las métricas empleadas para el cálculo de la neologicidad toman en cuenta los resultados del cálculo de la similitud coseno, y dan un resultado booleano de verdadero si un contexto es considerado neológico o falso si un contexto es evaluado como no neológico.

Se diseñaron tres ecuaciones que se describen a continuación:

- ns_AT: medida que da preferencia a las diferencias entre similitudes.

- ns_JM: medida que da preferencia a la similitud con el campo semántico.

- cond: medida que da preferencia a condiciones lógicas de la evaluación.

\section{Resultados}

Para validar los resultados obtenidos con las fórmulas para el cálculo de neologicidad se emplearon el coeficiente kappa de Cohen y la correlación de Pearson, además de las medidas de 
precisión, recall, f-score y support para obtener una visión más clara de la efectividad del sistema. Para calcular estos últimos índices se compararon los resultados con los casos que fueron evaluados manualmente (los contextos obtenidos de la base de datos de OBNEO). En la Figura 6: Fragmento de resultados de la evaluación.Figura 6 se puede observar un fragmento de la tabla generada por el sistema, donde se pueden ver los contextos analizados y los valores obtenidos.

\begin{tabular}{|c|c|c|c|c|c|c|c|c|c|c|c|c|c|c|}
\hline & term_id & term & context & dic & dic_id & definition & man_cond & CS_Tn & CS_DIC & DIC_Tn & ns_AT & ns_JM & shape & cond \\
\hline 0 & 0 & almacenado & $\begin{array}{r}\text { esta transmisión } \\
\text { de conocimiento } \\
\text { dentro de la ... }\end{array}$ & dle & 0 & $\begin{array}{r}\text { poner o guardar en } \\
\text { almacén }\end{array}$ & 1 & 0.128628 & 0.000000 & 0.053410 & 0.075218 & 0.110825 & $\begin{array}{r}(3, \\
128)\end{array}$ & 1 \\
\hline 1 & 0 & almacenado & $\begin{array}{r}\text { esta transmisión } \\
\text { de conocimiento } \\
\text { dentro de la ... }\end{array}$ & dle & 0 & $\begin{array}{r}\text { registrar información } \\
\text { en la memoria de un } \\
\text { orde... }\end{array}$ & 0 & 0.110489 & 0.099474 & 0.245637 & -0.234622 & 0.061768 & $\begin{array}{r}(3, \\
127)\end{array}$ & 0 \\
\hline 2 & 0 & almacenado & $\begin{array}{r}\text { esta transmisión } \\
\text { de conocimiento } \\
\text { dentro de la ... }\end{array}$ & dle & 0 & $\begin{array}{r}\text { reunir o guardar } \\
\text { muchas cosas }\end{array}$ & 1 & 0.127808 & 0.000000 & 0.000000 & 0.127808 & 0.127808 & $\begin{array}{r}(3, \\
129)\end{array}$ & 1 \\
\hline 3 & 0 & almacenado & $\begin{array}{r}\text { esta transmisión } \\
\text { de conocimiento } \\
\text { dentro de la ... }\end{array}$ & dem & 1 & $\begin{array}{r}\text { que está guardado en } \\
\text { un lugar o espacio, } \\
\text { gener... }\end{array}$ & 1 & 0.130315 & 0.000000 & 0.084513 & 0.045802 & 0.102144 & $\begin{array}{r}(3, \\
137)\end{array}$ & 1 \\
\hline 4 & 0 & almacenado & $\begin{array}{r}\text { esta transmisión } \\
\text { de conocimiento } \\
\text { dentro de la ... }\end{array}$ & wiki & 2 & $\begin{array}{l}\text { participio de } \\
\text { almacenar. }\end{array}$ & 1 & 0.108840 & 0.037733 & 0.321765 & -0.250658 & 0.014162 & $\begin{array}{r}(3, \\
126)\end{array}$ & 0 \\
\hline
\end{tabular}

Figura 6: Fragmento de resultados de la evaluación.

En la Tabla 3 señalamos en negrita el resultado de correlación de Pearson que existe entre los valores que fueron evaluados manualmente (man_cond) y la métrica ns_AT. Dicho resultado representa la correlación más alta entre las fórmulas implementadas. A pesar de que se obtuvo un valor inferior a 0.5 , cifra que se toma como referencia para determinar que existe correlación, sigue siendo el más alto en comparación con los demás valores obtenidos.

\begin{tabular}{llllll}
\hline & ns_JM & ns_AT & cond & man_cond & CS_Tn \\
\hline ns_JM & 1.000 .000 & 0.768107 & 0.655538 & -0.050428 & 0.619765 \\
ns_AT & 0.768107 & 1.000 .000 & 0.716360 & 0.226924 & 0.212741 \\
cond & 0.655538 & 0.716360 & 1.000 .000 & 0.154894 & 0.365848 \\
man_cond & -0.050428 & 0.226924 & 0.154894 & 1.000 .000 & 0.143995 \\
CS_Tn & 0.619765 & 0.212741 & 0.365848 & 0.143995 & 1.000 .000
\end{tabular}

Tabla 3: Correlación de Pearson entre métricas y contextos evaluados manualmente.

Por otra parte, el coeficiente kappa de Cohen denota la concordancia que existe entre evaluadores, en este caso, las métricas cond y man_cond. Se obtuvo un resultado de 0.05122 , lo que indica que existe una leve correlación entre resultados. En términos de kappa un resultado inferior a 0 indica que no existe concordancia entre evaluadores, mientras que un valor de kappa entre 0 y 0.2 sirve como referencia de leve concordancia.

Dado que nuestra métrica cond depende de condiciones lógicas (tener mayor similitud con el campo y menor similitud con las acepciones del diccionario), da como resultado un valor booleano verdadero (1) o falso (0), se usaron estos resultados para realizar los cálculos de precisión, recall, f-score y support, los resultados se pueden encontrar en la Tabla 4.

\begin{tabular}{lll}
\hline & man_cond & cond \\
\hline Precision & 0.1007 & 0.9931 \\
Recall & 0.9767 & 0.2788 \\
F-score & 0.1826 & 0.4354 \\
Support & 43 & 520 \\
\hline
\end{tabular}

Tabla 4: Precisión, recall, f-score y support entre valores etiquetados manualmente y valores etiquetados automáticamente por el sistema. 
La precisión es la habilidad que tiene el sistema para clasificar de forma correcta los elementos ingresados. Sin embargo, esta habilidad no necesariamente se corresponde con resultados correctos. Nuestro sistema tiene un .99 (entendido como un 99\%) de precisión; en cambio, el resto de los índices muestra que este no es un resultado que pueda ser empleado como referencia.

El recall indica la cantidad de verdaderos positivos evaluados correctamente. A pesar de que el sistema obtuvo una precisión de .99, se consiguió un .27 de recall, lo que equivale a un $30 \%$ de casos de verdaderos positivos evaluados correctamente.

El $f$-score representa el promedio ponderado de la precesión y el recall toma en cuenta todos los resultados, tanto los falsos positivos como los verdaderos positivos. En nuestro caso obtuvimos un f-score de .43 .

Si se analizan los casos de verdaderos positivos (ver Tabla 5) se puede comprobar que los índices de neologicidad de la fórmula ns_AT tienen las correlaciones esperadas. El resultado tiende hacia 1 cuando se evalúa frente a acepciones de lengua general y tiende hacia -1 cuando se evalúa frente a una definición informática. Al existir un índice que tiende a -1, el candidato es descartado.

\begin{tabular}{llllll}
\hline & ns_JM & ns_AT & cond & man_cond & CS_Tn \\
\hline ns_JM & 1.000 .000 & 0.622360 & 0.466675 & 0.466675 & 0.879583 \\
ns_AT & 0.622360 & 1.000 .000 & 0.885224 & 0.885224 & 0.465579 \\
cond & 0.466675 & 0.885224 & 1.000 .000 & 1.000 .000 & 0.434686 \\
man_cond & 0.466675 & 0.885224 & 1.000 .000 & 1.000 .000 & 0.434686 \\
CS_Tn & 0.879583 & 0.465579 & 0.434686 & 0.434686 & 1.000 .000
\end{tabular}

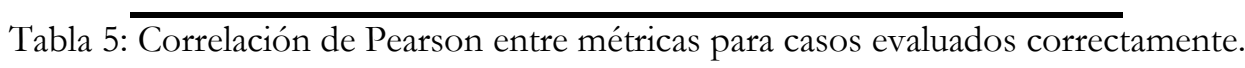

La correlación de Pearson para casos de verdaderos positivos muestra que el cálculo de ns_AT se incrementa frente a los índices evaluados tanto automática como manualmente. Por lo tanto, se puede concluir que esta fórmula ha sido la más eficaz para realizar el análisis de neologicidad.

\section{Conclusiones, limitaciones y líneas futuras de investigación}

Como se puede observar en la Figura 7, el Diccionario de la lengua española desequilibra los resultados, ya que muchas de sus definiciones son tautológicas, sinonímicas o referencias a otras entradas del diccionario. Este tipo de definiciones son poco informativas y provocan un crecimiento exponencial de los falsos negativos, ya que las matrices de similitud tienen muy pocas palabras en común en comparación con la concordancia que está siendo analizada.

Una posible solución a este problema podría ser ajustar la muestra de acepciones de cada diccionario, dado que el DLE cuenta un mayor número de acepciones en comparación con los demás diccionarios de referencia utilizados y como se ha mencionado anteriormente, no todas las acepciones son lo suficiente informativas o son definiciones tautológicas. Este ajuste implicaría determinar un número de acepciones por entrada y determinar una longitud mínima en palabras para cada acepción. Sin embargo, estas soluciones conllevan otros problemas, por ejemplo, eliminar acepciones que solamente están registradas en un diccionario de referencia o eliminar acepciones de los tres diccionarios, por lo tanto, tampoco es una solución viable. 


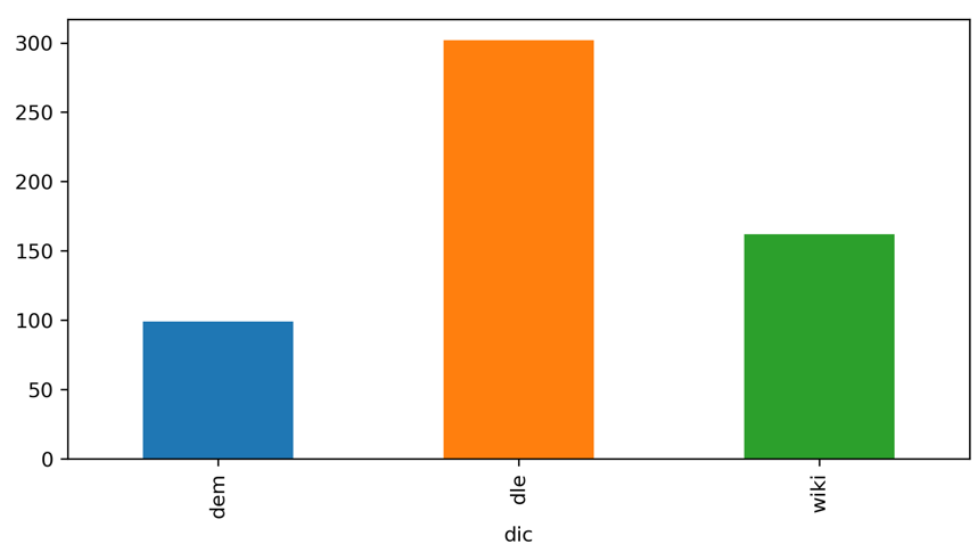

Figura 7: Distribución de acepciones por diccionario de referencia.

Con respecto a las métricas para el cálculo de la neologicidad, las fórmulas propuestas dependen del cálculo de similitud de coseno, pero solamente en un nivel estrictamente formal, es decir, solamente se está evaluando la similitud palabra por palabra entre las acepciones de los diccionarios de referencia, campo semántico y contexto de entrada. Como mejora a este cálculo, se podría considerar agregar pesos adicionales, por ejemplo, distribución de la matriz de similitud, fuente de las acepciones y contextos de entrada, longitud de la definición, entre otros elementos formales que aporten más información.

En resumen, los resultados obtenidos con el sistema DENISE tienden a positivos, aunque solo moderadamente. Las mejoras y cambios propuestos podrían mejorar los resultados, la depuración de las acepciones debería incrementar las cifras observadas en recall y $f$-score, pero solamente serían soluciones parciales ya que la interacción del usuario se limita a validar que una palabra observada en un texto puede ser un candidato a NS.

\subsection{Detección de neologismos semánticos mediante extracción automática de palabras claves y redes neuronales}

En función de los resultados observados en este estudio, se ha optado por un cambio de enfoque conservando las ideas fundamentales que se exponen en este artículo (la similitud y los espacios vectoriales), pero aplicadas con metodologías distintas: un sistema de detección automática de temas que determine, mediante similitud de espacios vectoriales y un modelo de regresión logística, la temática de un texto de entrada.

También se añaden dos elementos nuevos: extracción automática de palabras claves con filtros de etiquetas gramaticales mediante aprendizaje automático no supervisado (Barrios, López, Argerich, \& Wachenchauzer, 2016; Li \& Wang, 2014; Mihalcea \& Tarau, 2004; Pay, Lucci, \& Cox, 2018) y un método de desambiguación semántica por word embedding con etiquetas gramaticales (Trask, Michalak, \& Liu, 2015) para extraer candidatos a NS desde un texto de entrada, sin el supuesto de validar un candidato, sino de descubrir automáticamente si existen palabras candidatas en el texto de entrada.

El modelo de desambiguación semántica se basa en el algoritmo word2vec (Mikolov, Chen, Corrado, \& Dean, 2013), ya que también es un modelo de desambiguación semántica mediante modelos neuronales pero expande el trabajo de Huang, Socher, Manning, \& Ng (2012), dado que emplea un etiquetado gramatical supervisado y no clusters detectados automáticamente. De esta forma, el flujo de proceso del sistema DENISE cambiaría como se muestra en la Figura 8. 


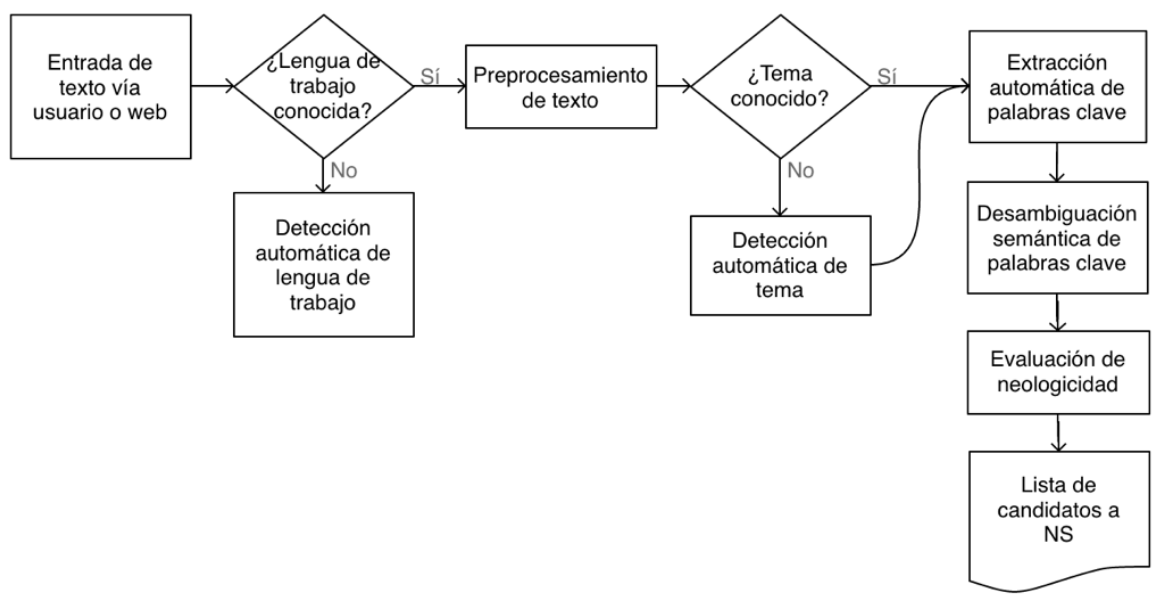

Figura 8: Diagrama de flujo de DENISE 1.1

Este modelo simplifica los pasos a seguir, gracias a la implementación de estrategias más robustas. Actualmente el proyecto se encuentra en la fase de entrenamiento y análisis, se ha completado el etiquetado gramatical de los corpus de trabajo para la generación de modelos neuronales y se están haciendo pruebas con unigramas. A diferencia del diseño del sistema anterior, se cuenta con una maquetación simple en las tres lenguas de trabajo. El siguiente paso es completar el entrenamiento de modelos neuronales con bigramas y trigramas, para proceder a evaluarlos.

Los modelos neuronales toman el rol de los diccionarios como método de desambiguación, ya que abren la posibilidad a encontrar relaciones semánticas en la totalidad de un corpus de lengua general y no solamente en lo contenido en las definiciones de los diccionarios. Por lo tanto, se espera poder diferenciar entre los significados comunes ya conocidos y los nuevos significados que pertenecen a un campo especializado de conocimiento.

\section{Bibliografía}

Baeza-Yates, R., \& Ribeiro-Neto, B. (1999). Modern Information Retrieval. New York (Vol. 9). New York: ACM Press. https://doi.org/10.1080/14735789709366603

Barrios, F., López, F., Argerich, L., \& Wachenchauzer, R. (2016). Variations of the Similarity Function of TextRank for Automated Summarization. CoRR, abs/1602.0.

Cabré, Maria Teresa, \& Estopà, R. (2004). Metodología del trabajo en neología : criterios, materiales y procesos. Universitat Pompeu Fabra. Institut Universitari de Lingüística Aplicada. Recuperado de https://repositori.upf.edu/handle/10230/1307

Cabré, Maria Teresa. (2009). La classificació dels neologismes: una tasca complexa. En María Teresa Cabré \& R. Estopà (Eds.), Les paraules noves: criteris per detectar i mesurar els neologismes (pp. 11-37). Vic, Barcelona: Eumo Editorial, Universitat Pompeu Fabra.

Huang, E. H., Socher, R., Manning, C. D., \& Ng, A. Y. (2012). Improving Word Representations via Global Context and Multiple Word Prototypes. En Proceedings of the 50th Annual Meeting of the Association for Computational Linguistics: Long Papers - Volume 1 (pp. 873-882). Stroudsburg, PA, USA: Association for Computational Linguistics.

Jones, K. S. (1972). A Statistical Interpretation of Term Specificity and Its Application in Retrieval. Journal of Documentation. https://doi.org/10.1108/eb026526

Li, G., \& Wang, H. (2014). Improved Automatic Keyword Extraction Based on TextRank Using Domain Knowledge. En Natural Language Processing and Chinese Computing (pp. 403-413). https://doi.org/10.1007/978-3-662-45924-9_36

Mihalcea, R., \& Tarau, P. (2004). TextRank: Bringing Order into Text. En Proceedings of the 2004 Conference on Empirical Methods in Natural Language Processing. 
Mikolov, T., Chen, K., Corrado, G., \& Dean, J. (2013). Efficient Estimation of Word Representations in Vector Space. CoRR, abs/1301.3.

Pay, T., Lucci, S., \& Cox, J. (2018). An Ensemble of Automatic Keyphrase Extractors : TextRank, RAKE and TAKE, (August). https://doi.org/10.13140/RG.2.2.13961.70243/1

Salton, G., Fox, E. A., \& Wu, H. (1983). Extended Boolean Information Retrieval. Commun. ACM, 26(11), 1022-1036. https://doi.org/10.1145/182.358466

Salton, G., \& McGill, M. (1984). Introduction to Modern Information Retrieval. McGraw-Hill Book Company.

Salton, G., Wong, A., \& Yang, C. S. (1975). A vector space model for automatic indexing. Communications of the ACM, 18(11), 613-620. https://doi.org/10.1145/361219.361220

Singhal, A. (2001). Modern Information Retrieval: A Brief Overview. IEEE Data Engineering Bulletin, 24.

Tan, P.-N., Steinbach, M., \& Kumar, V. (2005). Introduction to Data Mining, (First Edition). Boston, MA, USA: Addison-Wesley Longman Publishing Co., Inc.

Torres-Moreno, J. M., Velázquez-Morales, P., \& Meunier, J.-G. J.-G. (2001). Cortex: un algorithme pour la condensation automatique de textes. En ARCo'2001.

Trask, A., Michalak, P., \& Liu, J. (2015). sense2vec - \{A\} Fast and Accurate Method for Word Sense Disambiguation In Neural Word Embeddings. CoRR, abs/1511.0.

Wu, H. C., Luk, R. W. P., Wong, K. F., \& Kwok, K. L. (2008). Interpreting TF-IDF term weights as making relevance decisions. ACM Transactions on Information Systems, 26(3), 1-37. https://doi.org/10.1145/1361684.1361686 


\title{
Commentaires épilinguistiques et sentiment néologique : évaluation comparative de quelques néologismes par deux groupes d'étudiants
}

\author{
Hélène Favreau
}

UCO Angers, LICLA

Résumé : L'objectif de cet article est d'appréhender la façon dont s'opèrent chez deux populations d'étudiants (français natifs vs. allophones) la catégorisation et l'acceptation ou le rejet de néologismes en français, ce qui permet à la fois d'apprécier une ambivalence de positionnement entre les deux groupes et également de mettre en évidence certaines représentations que les locuteurs se font de cette langue.

Mots-clés : sentiment néologique, normes perceptives, création morphologique, discours épilinguistique.

Abstract: This paper aims at examining, through the analysis of speeches from French students and from foreign students, how they categorize and accept (or reject) neologisms in French, which is a way to perceive both ambivalent and typical positions in each group, as well as to bring out specific representations speakers have about this language.

Keywords: neological feeling, perceptive norms, morphological innovation, epilinguistic speech. 


\section{Introduction}

«La langue n'est pas un répertoire immobile [...] Elle est en elle-même le lieu d'un travail incessant » (Benveniste 1966 : 155). Le néologisme linguistique, qu'il soit volontaire ou involontaire, qu'il reste un hapax ou s'installe dans la langue, est sans doute le marqueur privilégié d'une telle dynamique permettant de désigner ce qui n'a, jusqu'alors, pas encore pu être nommé. Tantôt réponse évidente à des besoins langagiers nouveaux, tantôt élément fondateur du pacte colludique (Vorger 2011) entre locuteur et récepteur, le néologisme relève quoi qu'il en soit en partie de la sphère subjective et affective du langage en ce qu'il est fréquemment source de discussions intersubjectives qui font état, le plus souvent, de désaccords manifestes quant au statut à lui accorder. Ce dernier est d'ailleurs difficile à apprécier. En effet, quels critères président à sa définition ? Un terme nouveau acquiert-il le statut de néologisme sur la simple base de sa reconnaissance comme tel ? de sa morphologie ? de son sens ? de sa propagation ? de sa temporalité ?, ces deux derniers éléments s'avérant être des "propriétés fondamentales du néologisme » (Bouzidi 2010 : 29).

L'on est alors à même de constater que ces interrogations, si elles intéressent tout particulièrement le linguiste, débordent le champ strictement scientifique pour trouver une place dans les discours ordinaires des locuteurs non-spécialistes. Ceux-ci s'emparent en effet de plus en plus des questions linguistiques, notamment lexicales, pour exercer leur activité métalinguistique, voire épilinguistique (Canut, 2007a). Comment de tels commentaires transparaissent-ils dans leurs propos et que nous révèlent-ils de la perception du phénomène néologique (abordé ici seulement du point de vue morphologique) et, plus largement, des représentations que les locuteurs se font de l'objet-langue?

Afin de tenter de répondre à ces questions qui se trouvent au croisement de la lexicologie/lexicographie, de la sociolinguistique, et de la linguistique populaire, notre propos, après avoir rappelé des éléments des cadres théorique et méthodologique qui sous-tendent cette recherche, prendra appui sur l'analyse de discours épilinguistiques sollicités auprès de deux groupes d'étudiants (français et allophones) pour tenter d'appréhender la façon dont s'opèrent chez ces deux populations la catégorisation et l'acceptation (ou non) du néologisme en français à partir d'exemples lexicaux qui leur sont présentés.

\section{Distinctions terminologiques}

\subsection{Propriétés fondamentales du néologisme}

Ce premier point, qui se veut relativement concis, pose le cadre dans lequel nous situons cette recherche en revenant sur quelques précisions terminologiques utiles pour la suite. Le terme néologisme renvoie étymologiquement à la notion de nouveauté. Sans revenir sur la distinction nouveau/récent qui n'est pas toujours clairement établie, ce terme renvoie à trois aspects : la nouveauté peut en effet être d'ordre morphologique, d'ordre sémantique, ou liée à des emplois syntaxiques particuliers (associations inhabituelles de termes). Sans occulter ces dimensions distinctes, nous avons pour notre part circonscrit ce travail autour de la néologie formelle, définie comme «l'apparition de mots/lexies qui n'existaient pas dans un état antérieur de la langue et qui sont obtenus, pour la plupart, par dérivation ou composition » (Sablayrolles 2000 : 43). Cette définition induit deux caractéristiques liées à l'idée de nouveauté : sa durée, difficile, voire impossible à établir ; sa relativité, car quelque chose ne peut être qualifié de nouveau qu'en relation/opposition avec du « déjà existant ».

On opposera également, à la suite de plusieurs travaux (Guibert, Mortureux, entre autres), les néologismes qui s’intègrent à la langue car ils correspondent à des créations à vocation 
essentiellement dénominative associant une forme à un contenu " plein » supposé entretenir un rapport étroit au monde et, en cela, nécessaires dans le processus logique d'évolution de la langue en tant que reflet de nouvelles réalités, aux néologismes résultant d'une démarche créatrice à vocation plus stylistique et étant, par définition, beaucoup plus ponctuels. Se pose alors le problème -ou au moins la question- du critère permettant d'apprécier l'intégration (ou non) à la langue : bien souvent (chez les non-spécialistes en tout cas et c'est ce qui nous intéresse ici), cela se résume à savoir si la lexie en question est présente dans les dictionnaires avec tous les biais que cela suppose. On sait notamment qu'il est très rare que l'installation d'un mot dans le dictionnaire coïncide avec son année d'attestation. Et pour aller plus loin, en termes de datation, il est rare d'être sûr de la première occurrence du néologisme, et encore moins de sa création ${ }^{1}$.

\subsection{Sentiment linguistique et discours spontanés sur le lexique}

Parmi les niveaux de l'analyse linguistique, le lexique est peut-être celui sur lequel se concentre le plus naturellement l'affect des locuteurs (ne parle-t-on pas de sentiment linguistique ?), à partir du moment où l'on considère, à plus ou moins juste titre, qu'il apparait comme la dimension de la langue la plus immédiatement palpable par eux. Ainsi, il peut fréquemment faire l'objet de débats, notamment en ce qui concerne son évolution ou en ce qui concerne l'utilisation qui en est faite dans la sphère publique comme privée. Pour s'en convaincre, s'il en était besoin, il suffit d'observer les commentaires nombreux et les discussions parfois houleuses qu'il suscite aussi bien chez ses observateurs avisés (linguistes, enseignants, journalistes, écrivains et autres professionnels de la langue) que chez ses locuteurs-lambda. Les discours, gloses, observations métalinguistiques sont la trace de ces manifestations subjectives, affectives, sentimentales vis-à-vis du lexique.

Pour ce qui nous concerne, nous écarterons les discours savants sur le lexique pour nous situer davantage dans le champ de la linguistique populaire afin de nous intéresser au(x) sentiment(s) linguistique(s) des locuteurs non spécialistes au travers de discours sollicités. L'objectif est de recueillir, de façon empirique, des éléments d'observation sur les relations entre le social et le linguistique ; sur le rapport -jamais neutre- du locuteur à sa langue ; sur une perception du changement (de l'évolution) linguistique.

Le choix que nous avons fait pour avoir accès aux perceptions du sentiment néologique entretenues par les locuteurs est de passer par leurs discours méta-/épilinguistiques. Il convient donc de s'arrêter sur cette notion. Depuis Canut (2000), on sait en effet que les deux adjectifs se chevauchent, le second englobant le premier, la différence résidant essentiellement dans le fait que les discours méta- portent sur des pratiques et font appel à une réflexivité (soit par la prescription (discours normatif) soir par l'objectivation (discours des linguistes)) tandis que l'activité épilinguistique, à un niveau moins conscient, peut comporter en plus des discours subjectifs, que ces derniers soient évaluatifs, appréciatifs (descriptifs), normatifs (prescriptifs). De façon très schématique, les discours métalinguistiques sont des manifestations dans l'acte d'énonciation des attitudes des locuteurs face à la langue et ses pratiques. En d'autres termes, le discours métalinguistique, «c'est le discours sur le langage et les langues (philosophie du langage, linguistique générale) ou sur une langue particulière, métalangage A sur langue B ; ou réflexif, métalangage A sur langue A (dictionnaires, grammaires, chroniques de langage, etc.). Il est aussi bien écrit que parlé. » (Rey-Debove 1997 : 321). Parallèlement, le discours épilinguistique relève d'une sphère englobant « tout type de discours autonome sur les langues ou les pratiques » (Canut 2007a : 50).

\section{Méthodologie du recueil de données}

\subsection{Genèse et objectifs de l'enquête}

\footnotetext{
${ }_{1}$ «La néologicité s’inscrit et s'étale dans le temps. Il y a des néologismes qui naissent et disparaissent aussi vite qu'ils sont venus ; d'autres attendent très longtemps pour connaître la gloire. » (Bouzidi 2010 : 31).
} 
La genèse de cette enquête remonte un peu au hasard, comme c'est souvent le cas en recherche. Elle est née suite à une discussion animée lors d'un cours de sociolinguistique de Licence 3e année entre certains étudiants français du groupe et certains étudiants d'échange qui manifestaient leur désaccord (de façon parfois passionnée, voire véhémente) quant au statut à accorder au mot divulgâcher ${ }^{2}$. (" ça se dit? ça se ditpas en français? ?). Nous nous sommes alors attachée à vouloir comprendre certaines perceptions que nos étudiants pouvaient avoir de la langue française en général et ce, à travers l'évolution -inévitable- de son lexique, question qui apparaissait assez clivante entre les deux groupes. Ce que nous présentons ici constitue donc une sorte de pré-enquête (avec les biais que cette étape suppose), pouvant/devant donner lieu à une recherche plus structurée par la suite. Dans ces conditions, et pour des raisons matérielles aussi, nous n'avons pas constitué un échantillon de locuteurs selon « les règles de l'art ", et l'élaboration du corpus de mots testés a été réalisé de façon assez arbitraire et intuitive. Une priorité méthodologique a cependant guidé le recueil des données : surmonter l'insécurité linguistique (plus ou moins marquée, a fortiori chez le groupe allophone) des apprenants en créant des conditions favorables à l'expression de ces commentaires méta- voire épilinguistiques. Ainsi, même si on peut raisonnablement estimer que la méthode de l'entretien semi-directif aurait sans doute été plus appropriée et plus enrichissante en termes d'approfondissement des propos, le questionnaire écrit se prêtait davantage à une expression plus juste et réfléchie, de par l'effacement de la contrainte temporelle inhérente à une conversation en face à face et de par la possibilité de formuler au plus juste leurs perceptions. De plus, le questionnaire écrit présente l'avantage de pouvoir avoir accès à des données aussi bien quantitatives que qualitatives.

L'objectif est de tester un certain nombre d'hypothèses posées au préalable quant à la perception chez nos étudiants de plusieurs types de néologismes qui leur sont présentés et de découvrir, à travers elles, quelles représentations linguistiques inhérentes à chacun des groupes testés ces perceptions permettent de mettre au jour.

\subsection{Constitution du corpus}

Comme évoqué précédemment, le corpus n’a pas obéi à un échantillonnage systématique de lexies néologiques. Ceci étant, les termes présentés aux étudiants sont des lexies néologiques récoltées pendant l'été 2017 dans divers médias écrits (presse quotidienne, périodiques, et, plus occasionnellement, publicités ${ }^{3}$ ). Il s'agissait plus d'une veille que d'une récolte systématique car le but n'était pas d'établir un relevé exhaustif de néologismes sur une période donnée (si tant est que cela soit possible !) mais plutôt de susciter les commentaires des étudiants à partir de quelques exemples contemporains. La passation du test a eu lieu en octobre 2017. Seize items ont été sélectionnés dans le corpus de 72 néologismes relevés, sur la base de plusieurs critères :

- D’un point de vue morphologique, nous avons tenté de fournir des exemples répondant à des matrices lexicogéniques distinctes (cf. Sablayrolles 2000 : 245) et ce, afin de tester l'hypothèse selon laquelle certaines formations sont plus ou moins bien perçues en tant que néologismes. De même, pour des raisons de durée de passation de l'enquête, il était exclu de tester les 72 mots. Ainsi, il a été retenu 4 exemples par catégorie (la dimension intuitive a joué ici un rôle dans l'incorporation de tel ou tel mot...) : 4 créations par dérivation, 4 par composition, 4 mots-valises et 4 emprunts.

- Du point de vue de l'usage et de la diffusion, et compte tenu des limites posées plus haut par la temporalité du caractère néologique, nous avons tout de même souhaité présenter à nos participants, et sans que cette précision ne leur soit donnée d'emblée, autant de termes «officiellement» attestés (au sens 'présents dans l'un et/ou l'autre des 2 usuels') que de

\footnotetext{
${ }^{2}$ Équivalent de l'anglicisme spoiler.

${ }^{3}$ Liste des titres principaux : Le Monde, L’Express, Le Point, Le Nouvel Obs, Libération, Télérama, HuffPost, etc.

${ }^{4}$ Les deux usuels ayant servi à notre référencement sont le Petit Robert (PR) et le Petit Larousse (PL).
} 
termes non « officiellement » attestés dans ces mêmes recensements à la date de passation du test et ce, afin d'observer d'éventuelles différences de perception ${ }^{5}$.

\begin{tabular}{|l|l|l|}
\hline & \multicolumn{1}{|c|}{ Attestés dans les usuels } & \multicolumn{1}{c|}{ Non attestés dans les usuels } \\
\hline \multirow{2}{*}{ Emprunts } & $\begin{array}{l}\text { selfie (PL/PR 2016) } \\
\text { émoticône (PL 2017) }\end{array}$ & $\begin{array}{l}\text { fashionista (PR 2019) } \\
\text { punchline }\end{array}$ \\
\hline Mots-valises & $\begin{array}{l}\text { burkini (PL/PR 2018) } \\
\text { bistronomie (PR 2018) }\end{array}$ & $\begin{array}{l}\text { trouple } \\
\text { démocrature (PR 2019) }\end{array}$ \\
\hline Composition & $\begin{array}{l}\text { antisystème (PL 2017/PR 2019) } \\
\text { post-vérité (PR 2018) }\end{array}$ & $\begin{array}{l}\text { cybersécurité (PR 2019) } \\
\text { grossophobie (PR 2019) }\end{array}$ \\
\hline \multirow{2}{*}{ Dérivation } & $\begin{array}{l}\text { ubérisation (PL/PR 2018) } \\
\text { googliser (PL/PR 2018) }\end{array}$ & $\begin{array}{l}\text { dégagisme (PR 2019) } \\
\text { rageux (PR 2019) }\end{array}$ \\
\hline
\end{tabular}

À ces seize items, nous avons ajouté une dix-septième lexie, créée pour l'occasion par nos soins, afin de voir ce qui motive à classer (ou pas) dans les «(im)possibles» de la langue un terme totalement inédit (on en est sûr pour cet exemple) : *ventrinal.

\subsection{Le questionnaire}

Chaque lexie a fait l'objet d'un court questionnaire organisé en deux temps et sur lequel nous allons revenir dans l'exploitation des résultats. Cela nous a permis de récolter des données aussi bien quantitatives que qualitatives. Pour le premier temps de passation du test, 4 questions étaient posées pour chacun des néologismes présentés de façon isolée :

- Question 1: Avez-vous déjà rencontré ce mot?

- Question 2: D’après vous, ce mot peut-il exister en français ?

- Question 3: Pourquoi/pourquoi pas?

- Question 4: Si oui, quelle est sa signification, d'après vous ? Si non, pourriez-vous imaginer une définition?

Ensuite, les exemples étaient présentés en contexte. Puis, la présence/l'absence de termes dans les dictionnaires était révélée. Une autre question étaient alors posée :

- Question 5 : Quel(s) commentaire(s) cela vous inspire-t-il ?

\subsection{Les participants}

Encore une fois, ce travail s'apparente davantage à une étude exploratoire qu'à une recherche aboutie et pour des raisons de commodité, le questionnaire a été remis à quelques étudiants de notre université. Deux groupes ont été constitués : des étudiants de langue maternelle française ; des étudiants allophones. Les caractéristiques de composition des groupes sont les suivantes :

Groupe de 20 étudiants français (F1 à F20)

\begin{tabular}{|c|c|c|c|c|c|c|c|c|}
\hline \multicolumn{2}{|c|}{ Sexe } & \multicolumn{5}{|c|}{ Compétence linguistique } & \multicolumn{2}{c|}{ Filière d'études } \\
\hline $\mathrm{M}$ & $\mathrm{F}$ & natif & $\mathrm{C} 1$ & $\mathrm{~B} 2$ & $\mathrm{~B} 1$ & $\mathrm{~A} 2$ & Sciences & Langues \\
\hline 6 & 14 & 20 & 0 & 0 & 0 & 0 & 10 & 10 \\
\hline
\end{tabular}

Groupe de 20 étudiants étrangers (E1 à E20)

\begin{tabular}{|c|c|c|c|c|c|c|c|c|c|c|c|c|c|c|}
\hline \multicolumn{2}{|c|}{ Sexe } & \multicolumn{5}{|c|}{ Compétence linguistique } & \multicolumn{8}{|c|}{ Langue maternelle } \\
\hline $\mathrm{M}$ & $\mathrm{F}$ & natif & C1 & B2 & B1 & A2 & 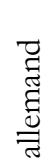 & 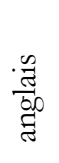 & 氖 & 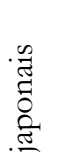 & 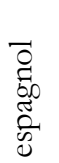 & 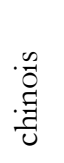 & 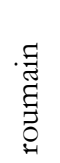 & 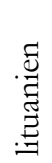 \\
\hline 12 & 8 & 0 & 4 & 12 & 2 & 2 & 6 & 5 & 2 & 2 & 2 & 1 & 1 & \\
\hline
\end{tabular}

${ }^{5} \mathrm{Il}$ est intéressant d'observer que sur les 8 entrées « non attestées » officiellement au moment de la passation, 6 ont fait, depuis, leur apparition dans l'édition 2019 du Petit Robert (publiée en mai 2018). 
Nous n'analyserons les réponses obtenues qu'à travers le prisme de l'opposition français comme langue maternelle vs. français comme langue étrangère, sans prendre en compte les autres variables de l'analyse car elles font l'objet de notre travail actuel ${ }^{6}$.

Nous avons recueilli (et limité à) 40 questionnaires. Il était important que les deux échantillons soient de taille égale pour tenter de vérifier l'hypothèse selon laquelle le sentiment néologique est perçu différemment selon les deux groupes.

\section{Exploitation des résultats}

Il est ici difficile, dans l'espace imparti, de présenter les résultats de manière exhaustive. Nous n'évoquerons donc que les traits saillants à partir des résultats globaux, c'est-à-dire sans rentrer dans le croisement des différentes variables, même si celles-ci permettent d'affiner certaines des analyses déjà esquissées par les résultats globaux.

\subsection{Reconnaissance des néologismes}

À la question «avez-vous déjà rencontré ce mot ? ", voici les résultats globaux obtenus, ainsi que par sous-groupe (indépendamment des différentes variables).

\begin{tabular}{|c|c|c|c|c|c|c|c|c|c|c|c|c|c|c|}
\hline & \multicolumn{7}{|c|}{ Attestés dans les usuels } & \multicolumn{7}{|c|}{ Non attestés dans les usuels } \\
\hline & & \multicolumn{2}{|c|}{$\begin{array}{l}\text { étudiants } \\
\text { français }\end{array}$} & \multicolumn{2}{|c|}{$\begin{array}{l}\text { étudiants } \\
\text { étrangers }\end{array}$} & \multicolumn{2}{|c|}{ Global } & & \multicolumn{2}{|c|}{$\begin{array}{l}\text { étudiants } \\
\text { français }\end{array}$} & \multicolumn{2}{|c|}{$\begin{array}{l}\text { étudiants } \\
\text { étrangers }\end{array}$} & \multicolumn{2}{|c|}{ Global } \\
\hline & & Oui & Non & Oui & Non & Oui & Non & & Oui & Non & Oui & Non & Oui & Non \\
\hline \multirow{2}{*}{ Emprunts } & selfie & 20 & 0 & 20 & 0 & 40 & 0 & fashionista & 14 & 6 & 14 & 6 & 28 & 12 \\
\hline & émoticône & 20 & 0 & 20 & 0 & 40 & 0 & punchline & 17 & 3 & 14 & 6 & 31 & 9 \\
\hline \multirow{2}{*}{ Mots-valises } & burkini & 16 & 4 & 13 & 7 & 29 & 11 & \multirow{2}{*}{$\begin{array}{l}\text { trouple } \\
\text { démocrature }\end{array}$} & 0 & 20 & 0 & 20 & 0 & 40 \\
\hline & bistronomie & 10 & 10 & 7 & 13 & 17 & 23 & & 1 & 19 & 0 & 20 & 1 & 39 \\
\hline \multirow{2}{*}{ Composition } & antisystème & 18 & 2 & 9 & 11 & 27 & 13 & cybersécurité & 18 & 2 & 15 & 5 & 33 & 7 \\
\hline & post-vérité & 3 & 17 & 4 & 16 & 7 & 33 & grossophobie & 11 & 9 & 4 & 16 & 15 & 25 \\
\hline \multirow{3}{*}{ Dérivation } & ubérisation & 12 & 8 & 5 & 15 & 17 & 23 & \multirow{2}{*}{$\begin{array}{l}\text { dégagisme } \\
\text { rageux }\end{array}$} & 12 & 8 & 1 & 19 & 13 & 27 \\
\hline & googliser & 13 & 7 & 10 & 10 & 23 & 17 & & 9 & 11 & 0 & 20 & 9 & 31 \\
\hline & & & & & & & & *ventrinal & 20 & 0 & 20 & 0 & 40 & 0 \\
\hline
\end{tabular}

On remarque d'emblée plusieurs choses. Premièrement, les résultats, assez nets dans l'ensemble, permettent de mettre en évidence deux niveaux de « reconnaissance » de la lexie envisagée : des mots très connus de tous (cases blanches) et des mots pas du tout (ou presque pas) connus (cases grises). C'est évidemment cette dernière catégorie qui nous intéressera davantage dans l'optique de la question suivante.

Deuxièmement, on constate que la catégorie des emprunts n'est absolument pas questionnée et les termes lui appartenant sont à l'unanimité bien reconnus (qu'ils soient attestés ou non). En revanche, les procédés où les termes sont le moins reconnus sont les mots-valises (cela peut s'entendre puisqu'ils correspondent à des créations hybrides ponctuelles, et partant, peut-être moins diffusées que les procédés classiques et donc sujettes à un travail interprétatif plus important) et la création par dérivation (là, le résultat est un peu plus curieux).

Troisièmement, on note également que la catégorie des mots non attestés (même si cette précision n'a pas été donnée d'emblée à nos enquêtés) est celle qui concentre le plus de mots méconnus chez nos sujets (6 contre 3$)$.

\footnotetext{
${ }^{6}$ Elles ne sont toutefois pas à négliger. Il en va ainsi de la répartition par sexe ; par niveau de compétence en français (le sentiment néologique est-il partagé indépendamment du degré de compétence en français ?) ; par filière d'étude (dans le groupe d'étudiants français, nous avons veillé à avoir une répartition équitable entre étudiants de sciences dures, et de langues (dont on peut supposer qu'ils ont une conscience métalinguistique plus aiguë)) ; par nationalité (pour les étudiants étrangers) : on peut notamment supposer que des différences de perception quant aux néologismes du français puissent se faire jour en fonction de la langue maternelle (famille des langues romanes ou non, par exemple); ces variables pouvant entraîner des différences de perception quant aux commentaires sollicités, même s'il est bien évident que d'autres critères sociologiques interviennent sur les attitudes linguistiques (ex : disparité des origines sociales). Telle est, en tout cas, notre intuition à ce stade.
} 


\subsection{Critères de reconnaissance ou de rejet des néologismes}

À la question 2 « d'après vous ce mot peut-il exister en français ? ", nous ne donnons ici les résultats que sur les 9 mots déclarés comme « inconnus ».

\begin{tabular}{|c|c|c|c|c|c|c|c|c|c|c|c|c|c|c|}
\hline & \multicolumn{7}{|c|}{ Attestés dans les usuels } & \multicolumn{7}{|c|}{ Non attestés dans les usuels } \\
\hline & & \multicolumn{2}{|c|}{$\begin{array}{l}\text { étudiants } \\
\text { français }\end{array}$} & \multicolumn{2}{|c|}{$\begin{array}{l}\text { étudiants } \\
\text { étrangers }\end{array}$} & \multicolumn{2}{|c|}{ Global } & & \multicolumn{2}{|c|}{$\begin{array}{c}\text { étudiants } \\
\text { français }\end{array}$} & \multicolumn{2}{|c|}{$\begin{array}{l}\text { étudiants } \\
\text { étrangers }\end{array}$} & \multicolumn{2}{|c|}{ Global } \\
\hline & & Oui & Non & Oui & Non & Oui & Non & & Oui & Non & Oui & Non & Oui & Non \\
\hline \multirow{2}{*}{ Mots-valises } & & & & & & & & trouple & 9 & 11 & 12 & 8 & 21 & 19 \\
\hline & bistronomie & 10 & 10 & 13 & 7 & 23 & 17 & démocrature & 5 & 15 & 4 & 16 & 9 & 31 \\
\hline \multirow{2}{*}{ Composition } & & & & & & & & & & & & & & \\
\hline & post-vérité & 17 & 3 & 18 & 2 & 35 & 5 & grossophobie & 14 & 6 & 13 & 7 & 27 & 13 \\
\hline \multirow{3}{*}{ Dérivation } & ubérisation & 14 & 6 & 10 & 10 & 24 & 16 & dégagisme & 17 & 3 & 15 & 5 & 32 & 8 \\
\hline & & & & & & & & rageux & 17 & 3 & 11 & 9 & 28 & 12 \\
\hline & & & & & & & & *ventrinal & 15 & 5 & 14 & 6 & 29 & 11 \\
\hline
\end{tabular}

À l'exception de démocrature, ils sont tous globalement qualifiés comme étant tout de même susceptibles d'être des termes appartenant à la langue française (cases grises).

Outre les résultats quantitatifs, les commentaires qualitatifs reçus en réponse à la question 3 permettent de mesurer la diversité des raisons invoquées pour justifier de telles catégorisations. Il n'est pas possible de faire figurer tous les commentaires ici, mais ceux choisis sont représentatifs car ils apparaissent dans plusieurs des réponses données. Ainsi sont avancés, entre autres, l'argument de la compréhension immédiate après décomposition de la formation du mot: « [postvérité] on peut comprendre assez facilement post (après) + vérité » (F2) ; l'argument esthéticosubjectif : " [grossophobie] ça a la musique d'un mot français, alors oui, ça pourrait faire partie » (E9) ; l'argument de la logique du système : « [dégagisme] c'est construit comme un mot qui pourrait exister en français » (F5).

Des différences de positionnement sont toutefois à noter entre les deux sous-groupes sur les termes bistronomie et ubérisation où la tendance est sensiblement différente (ubérisation semble plutôt bien reconnu par les étudiants français, le résultat est plus mitigé pour les étudiants étrangers ; pour bistronomie, c'est l'inverse qui se produit), mais surtout sur le terme trouple qui, selon les étudiants français, ne peut pas faire partie du lexique français là où la tendance s'inverse pour les étudiants étrangers. Ainsi, pour rejeter une occurrence que les étudiants étrangers acceptent, eux, plus volontiers, sont invoquées par les locuteurs français les notions de concurrence (souvent liée à une méconnaissance) : " [démocrature] il y a déjà le terme démocratie donc on a pas besoin de ce nouveau terme » (F14); de difficulté articulatoire : «[trouple] je ne trouve pas ça très facile à prononcer » (F8) ; de perception d'une faute : " [trouple] en fait c'est une mauvaise prononciation/orthographe de trouble »(F13) ; et d'absence du sacro-saint dictionnaire : « [trouple] ça m'étonnerait que ce soit dans le dictionnaire » (F20).

\subsection{Mécanismes d'inférence du sens}

Nous passons rapidement l'analyse de la question 4 qui demandait d'expliquer les différentes lexies car outre un certain nombre de définitions erronées -voire cocasses ! - sur les termes inconnus, cette question avait plus vocation à observer les mécanismes mis en place pour émettre des hypothèses quant au sens de certains mots. On observe ainsi que, sans l'aide d'un contexte d'emploi, pour inférer le sens d'un néologisme inconnu, les étudiants ont recours à plusieurs types de mécanismes. Ils font intervenir les ressemblances formelles : «[trouple] je ne sais pas quelle définition donner mais il ressemble à trouble avec un 'p' donc peut-être que c'est un sens proche » (E6), « [googliser] c'est curieux, je sais ce que ça veut dire mais c'est pas le terme que j'utilise donc je pense que ça doit avoir un sens différent de "faire une recherche sur Google" » (F1). C'est, 
dans d'autres cas, la dérivation classique qui est utilisée au service de l'émission d'hypothèses quant au sens de ces mots inconnus : " [*ventrinal] ça doit être un adjectif (comme matinal) en rapport avec le ventre ? » (F10), " [ubérisation] c'est peut-être une action de faire quelque chose car ça termine en -tion» (E19).

Cette question a aussi eu le mérite de mesurer la coïncidence ou l'écart (parfois important) entre le fait de déclarer « je connais, j’ai déjà rencontré tel terme » et la capacité à lui attribuer un sens correct. Cette remarque vaut particulièrement pour fashionista où seuls $40 \%$ des participants ont donné une définition correcte ; idem pour antisystème où seule la moitié de ceux ayant déclaré avoir rencontré le terme ont été en réalité capables de le définir correctement.

\subsection{Part des jugements de valeur dans les discours}

Une fois ces premiers commentaires recueillis, le deuxième temps de l'enquête consistait à montrer aux étudiants les termes en contexte afin qu'ils en saisissent le sens, le cas échéant, et à leur « révéler» la présence (ou non) de ces lexies dans «le » dictionnaire en leur demandant leur sentiment par rapport à cela. Pour la plupart des étudiants français, les réponses qualitatives ainsi sollicitées ont fait état de jugements de valeur : sur les 280 commentaires laissés, plus de la moitié (183, soit $65,3 \%$; contre $41,7 \%$ chez le groupe d'étudiants étrangers) contiennent des remarques à caractère évaluatif (principalement à connotation négative).

C'est sur cette question que nous avons recueilli la plus grande densité de données, aussi bien en termes quantitatifs que qualitatifs. De façon générale, il semblerait que les locuteurs oscillent la plupart du temps entre des commentaires de nature épi- et métalinguistique. On peut en effet comprendre que les remarques métalinguistiques à propos de ces néologismes soient fréquentes puisque nous les avons sollicitées. En revanche, elles laissent souvent place, dans notre corpus, à des jugements de valeur, quand bien même ceux-ci ne sont pas explicitement sollicités.

Ce recours assez systématique par le groupe «français » aux commentaires d'ordre épilinguistique dénote une assez forte tendance à l'intériorisation de normes ou en tout cas de conceptions " traditionnelles » de la langue. Ainsi, on peut dégager et identifier des unités de contenu des occurrences épilinguistiques qui peuvent être regroupées dans des catégories thématiques renvoyant aux attitudes évaluatives-prescriptives-descriptives mentionnées par Canut (2007a: 52) ${ }^{7}$.

\subsubsection{Conceptions traditionnelles de la langue chez les étudiants français}

L'analyse des réponses nous permet de distinguer plusieurs éléments renvoyant à des conceptions assez traditionnelles de la langue.

\subsubsection{Discours à forte portée évaluative}

Cette dimension évaluative se manifeste, dans notre corpus, de trois façons. Tout d'abord, on remarque des jugements généraux sur la langue. Il est par exemple difficile pour nombre d'étudiants français de considérer les emprunts (à l'exception peut-être d'émoticône) comme étant intégrés au système de la langue. Beaucoup de discours les dépeignent comme étant encore perçus comme des nouveautés bien qu'abondamment utilisés : " [selfie] je suis le 1er à l'utiliser mais pour moi, il ne devrait pas être comptabilisé dans le vocabulaire français parce que ça vient de l'anglais quand même ; c'est pas du français » (F5). Ensuite, on perçoit une certaine nécessité de hiérarchiser des emplois concurrentiels sur la base de critères le plus souvent subjectifs, qu'ils soient esthétiques, préférentiels, etc. : " [selfie] je crois qu'il existe un équivalent : égoportrait. Je suis sûre qu'il est utilisé au Québec et je l'aime mieux que selfie parce qu'il fait plus français et qu'il est plus «poétique » je trouve ». Enfin, la dimension évaluative se résume parfois à s’interroger sur le

${ }^{7}$ Ces regroupements thématiques font également écho aux caractéristiques repérées par Samuel Vernet (2012) dans une étude menée sur les discours spontanés des forums de discussion Internet. 
caractère opportun/inopportun du néologisme : «[*ventrinal] c'est normal qu'il ne soit présent dans un aucun dictionnaire vu qu'il ne renvoie à aucun objet ni à aucun concept. Même si on peut penser qu'il fait français, je ne l'accepte pas car il ne signifie rien » (F18). On juge ici de la raison d'être du néologisme en la reliant à son efficacité : il doit servir à quelque chose, en l'occurrence remplir une fonction référentielle.

\subsubsection{Discours à forte portée prescriptive}

Dans ces discours, apparaissent systématiquement les notions de mauvais usage et de rapport à la faute : « [rageux] j’ai du mal à voir la différence avec rageur ce qui fait que j’aurais du mal à l'utiliser, par peur de faire une faute » (F6), attitude sans doute à mettre en lien avec l'intériorisation de normes linguistiques. Par ailleurs, on observe également une référence assez automatique au dictionnaire : « [googliser] je ne comprends pas que ce soit dans le dictionnaire. Pas parce que je ne sais pas ce que ça veut dire, mais parce que moi j'utilise une autre forme : googler. Et la plupart des gens autour de moi aussi. J'ai jamais entendu/lu googliser un terme. Donc je trouve que là, le dictionnaire ne reflète pas du tout l'usage actuel. » (F12). Ce dernier exemple fait d'ailleurs émerger une autre thématique présente dans notre corpus : celle de la référence à l'expérience personnelle qui, en tant que telle, dénote moins un discours à portée prescriptive qu'à vocation descriptive, ce qui tend à montrer -et il importe de le rappeler- que les catégories thématiques ne sont pas étanches et que peuvent affleurer au sein d'un même discours plusieurs positionnements.

\subsubsection{Commentaires plus réflexifs chez les étudiants étrangers}

Les remarques des étudiants étrangers sont, sur les mêmes sujets, moins enclines à l'évaluation et reposent davantage sur des constats descriptifs, le plus souvent neutres et réflexifs ${ }^{8}$. Il est, dans ce groupe, beaucoup plus fréquemment fait référence aux expériences personnelles, en utilisant d'ailleurs souvent leur propre langue à titre de comparaison. Par exemple : " [googliser] ce terme est un peu bizarre pour moi parce que le verbe anglais est google, donc là, le français ajoute un suffixe qu'on n'a pas en anglais »(E11). Les étudiants étrangers tendent également à faire davantage montre de capacités métalinguistiques. C'est le cas notamment lorsqu'ils rapprochent, à plusieurs reprises, les néologismes observés des jeux de mots, dans une optique de constat neutre du fonctionnement linguistique : « [grossophobie] je comprends comment est formé le mot et un peu son sens parce qu'en allemand, on peut faire aussi comme ça des mots nouveaux super longs juste en faisant comme les jeux de Légo : mettre des morceaux les uns avec les autres. En fait, avec des certains nouveaux mots, on s'amuse » (E4).

Suite à la révélation de l'inexistence du terme *ventrinal, un commentaire d'un étudiant étranger (le seul à avoir réagi sur ce terme) nous semble être un écho parfait à l'idée mentionnée plus haut de " raison d'être » d'un néologisme : " mais en fait si, il existe, puisque l'enquête le fait exister ! » (E7). Il n'y a finalement pas besoin d'un prétendu « manque » à combler dans le système linguistique pour prêter vie à une forme inédite. Un néologisme peut exister en lui-même et pour lui-même.

\subsection{Commentaires}

Il a été démontré, dans plusieurs travaux antérieurs (Sablayrolles 2000 : 406) que "les néologismes appellent des jugements de valeur -pas uniquement ceux qui opposent le point de vue « puriste » et le point de vue « laxiste » pour schématiser à l'extrême- qui portent sur leur esthétique, leur opportunité, les indications qu'ils apportent sur leur émetteur, le rôle qu'ils jouent dans

8 Attention : elles ne sont toutefois pas exemptes de commentaires appréciatifs... mais dans une moindre mesure, très nettement. 
l'interlocution ». Nous retrouvons, dans une large mesure, ces éléments au travers de cette enquête à la nuance près que ces jugements de valeur sur les néologismes dénotent un positionnement beaucoup plus normatif chez nos étudiants français ${ }^{9}$ qui mettent facilement en avant les poncifs et autres idées reçues ${ }^{10}$ bien connu(e)s dans la tradition prescriptiviste française par rapport à nos étudiants étrangers qui, loin de pouvoir être taxés de laxistes (ne caricaturons pas non plus!), semblent faire porter davantage leurs remarques sur des éléments objectifs. Le fait qu'ils soient allophones explique sans doute en partie cette plus grande distanciation vis-à-vis de ce qui constitue pour l'autre groupe, une, sinon « la » langue maternelle, avec tout l'attachement que cela suppose.

Ces discours épilinguistiques et l'ambivalence des positionnements quant au sentiment néologique chez ces deux populations non-spécialistes donnent un aperçu des représentations et de l'imaginaire qui entourent la langue et contribuent à l'éclairage d'une facette de la linguistique populaire.

\section{Remarques conclusives}

Cette expérience, quoi qu'imparfaite à bien des titres, a tout de même le mérite de nous livrer quelques enseignements. Le premier -plus un rappel qu'un véritable enseignement- est que le curseur servant à catégoriser/accepter un néologisme comme tel reste un élément subjectif, donnant en cela au lexique de chacun une véritable singularité.

Le deuxième est que les discours épilinguistiques analysés sollicités (par opposition à "spontanés ») véhiculent un certain nombre de perceptions quant au phénomène de néologie et, par lui, semblent perpétuer des représentations/attitudes à propos de la langue française ("purisme spontané »).

Le troisième est que les réponses des deux groupes d'étudiants envisagés semblent corroborer l'hypothèse selon laquelle il existe des attitudes linguistiques typiques chez ces deux populations (natifs vs. allophones) : la première ayant plutôt recours à des attitudes épilinguistiques, la seconde à un positionnement plus réflexif et neutre (méta-), même si cela reste à nuancer et à approfondir.

Ce qui conduit au quatrième enseignement qui est que les étudiants interrogés se sont prêtés de bonne grâce à cette enquête et à en croire les commentaires enjoués laissés par certains dans la section du questionnaire prévue à cet effet, elle pourrait être/sera renouvelée, en y apportant les améliorations significatives, à commencer par des entretiens indispensables avec les informateurs pour affiner le rapport de ces locuteurs « ordinaires » avec le lexique français dans sa dimension néologique.

Cette tentative montre en tout cas que les données des analyses lexicales formelles ne sont pas inutiles lorsqu'on cherche à explorer les pratiques linguistiques ou, comme ici, les représentations qu'ont spontanément « les gens » à propos de la langue, qui devrait rester un moment encore objet de tous les fantasmes et de tous les imaginaires pour reprendre l'expression chère à Anne-Marie Houdebine.

\section{Bibliographie sélective}

BENVENISTE, Émile (1966), Problèmes de linguistique générale (tome 2), Paris, Gallimard.

BOUZIDI, Boubakeur (2010), « Néologicité et temporalité dans le processus néologique », Synergies Algérie, ${ }^{\circ} 9$, p. 27-36.

CANUT, Cécile (1998), "Pour une analyse des productions épilinguistiques ", Cabiers de praxématique, n³1, p. 69-90.

CANUT, Cécile (2000), "Subjectivité, imaginaires et fantasmes des langues : la mise en discours 'épilinguistique' », Langage et société, n93, p. 71-97.

CANUT, Cécile (2007a), «L'épilinguistique en question », dans Siouffi, G. \& Steuckardt, A. (éds), Les linguistes et la norme, Berne, Peter Lang, p. 49-72.

\footnotetext{
${ }^{9}$ Ce qui était assez inattendu chez cette population.
}

${ }^{10}$ Cf. Marina Yaguello (1988). 
CANUT, Cécile (2007b), Une langue sans qualité, Limoges, Lambert-Lucas.

HOUDEBINE-GRAVAUD, Anne-Marie (1995), «L'Unes langue », dans Eloy, Jean-Michel (éd.), La qualité de la langue? Le cas du français, Paris, Honoré Champion, p. 95-121.

LAFONTAINE, Dominique (1986), Le parti pris des mots. Normes et attitudes linguistiques, Liège, Mardaga.

MORTUREUX, Marie-Françoise (1984), "La dénomination, approche socio-linguistique », Langages, $\mathrm{n}^{\circ} 76$, p. $95-112$.

PAVEAU, Marie-Anne (2006), Les prédiscours. Sens, mémoire, cognition, Paris, Presses Sorbonne Nouvelle.

PAVEAU, Marie-Anne (2007), «Les normes perceptives de la linguistique populaire », Langage et Société, n¹21, p. 93-109.

REY-DEBOVE, Josette (1997), Le métalangage. Étude linguistique du discours sur le langage, Paris, Armand Colin.

SABLAYROLLES, Jean-François (2000), La néologie en français contemporain, Paris, Honoré Champion.

SABLAYROLLES, Jean-François (2002), "Le sentiment néologique », dans Sablayrolles, J.-F. (éd.), L'innovation lexicale, Paris, Honoré Champion, p. 279-295.

SIOUFFI, Gilles \& Agnès STEUCKARDT (éds.) (2007), Les linguistes et la norme. Aspects normatifs du discours linguistique, Berne, Peter Lang.

TABOURET-KELLER, Andrée (éd.) (1997), Le nom des langues I. Les enjeux de la nomination des langues, Louvain-la-Neuve, Peeters.

VERNET, Samuel (2012), Rapport à la norme. Discours métalinguistique spontané sur des forums anglophones et francophones, Mémoire sous la direction de Marinette Matthey, Université de Grenoble.

VORGER, Camille (2011), Poétique du slam : de la scène à l'école. Néologie, néostyles et créativité lexicale, Thèse sous la direction de Francis Grossmann et Dominique Abry, Université de Grenoble.

WINTER-FROEMEL, Esme \& ZIRKER, Angelika (éds.) (2015), Enjeux du jeu de mots : perspectives linguistiques et littéraires, Berlin, De Gruyter.

YAGUELLO, Marina (1988), Catalogue des idées reçues sur la langue, Paris, Seuil.

\section{Usuels}

Le Petit Larousse (2018), Paris, Larousse.

Le Petit Robert, dictionnaire alphabétique et analogique de la langue française (2018), Paris, le Robert. 
«Ma si può dire architetta e avvocata? Non sono errori?». Un'indagine sull'accettabilità dei neologismi per i nomi femminili delle professioni da parte degli studenti in Italia

\author{
Paolo Nitti \\ Università degli Studi dell'Insubria
}

Résumé : L'essai illustre une recherche concernant l'acceptation des néologismes connectés aux noms italiens féminins, utilisés pour les professionnels, par les étudiants italiens des niveaux scolaires différents. L'enquête est conçue dans la continuité des études de Sabatini (1987), Petralli (1996), Palermo (2005), Fusco (2012) et Robustelli (2017). La recherche s’inscrit dans les études de la didactique des langues (Nitti 2018c) et la méthodologie concerne l'analyse de données obtenues à travers un questionnaire sociolinguistique.

Mots clés: sexisme ; langue italienne ; morphologie ; néologismes.

Abstract: This essay offers an investigation about the acceptance of neologisms describing feminine Italian job-titles by native Italian students with different levels of education. This work is in continuity with that of Sabatini (1987), Petralli (1996), Palermo (2005), Fusco (2012) and Robustelli (2017). My research fits within the educational language studies (Nitti 2018c), and its methodology includes a sociolinguistic questionnaire survey and data analysis.

Keywords: sexism; Italian language; morphology; neologisms. 


\section{Introduzione}

Nel corso degli ultimi anni e attraverso un processo politico e sociale molto complesso, avviato a partire dalle dichiarazioni della Presidente della Camera dei Deputati, Laura Boldrini, il mondo istituzionale italiano ha ripreso a interrogarsi in merito agli usi sessisti e discriminanti della lingua italiana. Sono numerosi, infatti, i tentativi da parte delle amministrazioni pubbliche italiane di ricercare delle modalità comunicative inclusive e non discriminatorie.

È opportuno, ai fini della trattazione, stabilire che la lingua italiana non è, come ogni sistemalinguistico, sessista a priori e fornisce le opportunità espressive per rispettare le differenze di genere e utilizzare forme non discriminatorie (Fusco 2012).

Uno dei settori particolarmente delicati rispetto alla questione degli usi sessisti della lingua riguarda l'accettazione o il rifiuto dei neologismi, soprattutto per quanto concerne i nomi connessi con le professioni.

Un neologismo, in effetti, «si forma principalmente per il bisogno di denominare un nuovo oggetto o un nuovo concetto: si tratta della capacità che il lessico di una lingua ha di adeguarsi ai mutamenti storici, culturali, sociali e alle innovazioni scientifiche e tecnologiche» (Adamo, Della Valle 2017: 7). Nel caso dei nomi di professione declinati al femminile, il neologismo non riguarda tanto un nuovo oggetto quanto un nuovo concetto (Geiger 2015): la presenza delle donne all'interno del panorama professionale per quanto concerne professioni tradizionalmente svolte da uomini (Klemens 2007).

Sul piano grammaticale, la questione è particolarmente discussa rispetto alle lingue romanze, la cui impostazione tradizionalmente concepisce il maschile come forma non marcata (Yaguello 1978).

Un aspetto significativo in merito agli usi sessisti della lingua è che il dibattito è cominciato negli Stati Uniti verso la fine degli anni Sessanta (Martyna 1980) ed è stato esteso al contesto europeo e alle lingue romanze in seguito (Robustelli 2017), sottolineando elementi problematici di lingue che, a differenza dell'inglese, possiedono una morfologia in cui l'opposizione di genere è determinante (Cardona 2006).

Alcuni neologismi tendono a risultare estranei rispetto al sistema linguistico; infatti, se si considera l'orecchio del parlante in merito a una nuova parola, «si prova in genere un certo disagio, provocato dall'iniziale difficoltà a percepirla come familiare» (Adamo, Della Valle 2017: 7).

I nomi di professione declinati al femminile «possono sembrare strani, e per questo suscitare dubbi sulla loro correttezza, ma nella maggior parte dei casi ciò avviene solo perché si tratta di forme con cui non si ha ancora familiarità» (Robustelli 2017: 88).

Una differenza notevole rispetto al passato, per quanto concerne i neologismi connessi con i nomi di professione, declinati al femminile, riguarda l'atteggiamento delle accademie e dei centri di ricerca: da un sostanziale disinteresse - se non addirittura da un rifiuto (Lepschy 1988) - si è passati a un atteggiamento tendenzialmente accogliente, volto soprattutto a sensibilizzare l'opinione pubblica a proposito delle possibilità espressive della lingua e della sua grammatica (Sabatini 2008; Robustelli 2017).

Quest'ultima riflessione pare rilevante rispetto ad alcune dichiarazioni del mondo politico e istituzionale per quanto concerne l'utilizzo dei nomi di professione declinati al femminile; molti politici, in effetti, a partire dal Presidente della Repubblica italiana, Giorgio Napolitano, hanno dichiarato queste forme come scorrette o, addirittura, abominevoli ${ }^{1}$.

Il fatto che sono generalmente le fasce più vecchie della popolazione a essere maggiormente conservative sul piano linguistico è noto all'interno della letteratura scientifica (Marello 1996; Lorenzetti 2002; Berruto 2004), tuttavia ci si è interrogati riguardo al livello di accettazione di alcuni nomi di professione declinati al femminile e di usi non sessisti della lingua, anche a livello

1 https://www.corriere.it/cronache/17 gennaio 04/sgarbi-contro-laura-boldrini-l-uso-femminile-sindaca-ministra-cruscarisponde-80a1d26e-d2aa-11e6-af42-cccac9ae7941.shtml (ultima consultazione 15/11/2018). 
morfosintattico, da parte degli studenti di diversi ordini di istruzione, valutando le eventuali differenze di età e di contesto socio-culturale.

Queste parole sono soggette a dinamiche linguistiche e sociolinguistiche, come accade a tutti i neologismi, ma presentano anche il fatto di descrivere una condizione che identifica un cambiamento sociale significativo.

Come osservano Serianni e Castelvecchi, «le incertezze della grammatica su questo punto dipendono da ragioni extra-linguistiche: ossia dal processo di trasformazione sociale compiutosi in questo secolo, e tutt'ora in pieno sviluppo, che ha visto le donne affermarsi in campi e attività un tempo loro preclusi» (2016: 118).

L'assenza di certezze sul piano grammaticale si intuisce anche dalla presenza, nella lingua scritta, di elementi grafici e dell'interpunzione che spesso accompagnano i nomi di professione declinati al femminile (come le parentesi, le virgolette e il corsivo); segnali di una presa di distanza «da un'espressione avvertita ancora come stravagante, troppo estrosa o eccessivamente alla moda» (D’Adamo, Della Valle 2017: 15), basti pensare all'ipergeneralizzazione del morfema $\{-\mathrm{a}\}$ per i nomi di professione ai fini di scherno e di derisione ${ }^{2}$.

La ricerca si inquadra all'interno degli studi di linguistica percezionale (Bazzanella 2014), utilizzando una modalità caratteristica dell'indagine in sociolinguistica: il questionario per la rilevazione di dati linguistici (Johnstone 2000; Tagliamonte 2006).

Le implicazioni della ricerca da un lato contribuiscono a chiarire alcuni processi relativi alla formazione e alla fissazione dei neologismi allinterno del patrimonio lessicale dell'italiano e del repertorio del parlante, giacché «non sempre il processo di adeguamento linguistico alle nuove realtà professionali è stato uniforme» (Serianni, Castelvecchi 2016: 118), dall'altro si inseriscono negli studi di linguistica educativa e di glottodidattica (Vedovelli 2003), per quanto concerne il livello di consapevolezza dei parlanti rispetto al sistema linguistico utilizzato.

Risulta particolarmente complesso separare la ricerca nel campo della neologia rispetto agli studi di lessicologia e alle implicazioni sulle diverse branche della linguistica che se ne servono. Per quanto concerne la tradizione accademica italiana, la neologia fatica a delinearsi come settore di ricerca autonomo e la considerazione trova conferma in merito alla mancanza di differenziazione degli ambiti di indagine all'interno delle grammatiche di lingua italiana, sensibili per tradizione ai meccanismi di produzione e di formazione delle parole (Grossman, Rainer 2004; Adamo, Della Valle 2017).

Il lessico rappresenta lo strato più esterno della lingua e risente di influenze esterne; nel lessico, infatti, si fondono due aspetti: «la conoscenza del mondo e la conoscenza della lingua» (Laudanna, Voghera, 2006: 130).

\section{La ricerca}

A partire dalle premesse descritte in precedenza, si è deciso di valutare l'accettabilità di alcuni neologismi, per lo più di carattere morfologico, da parte di un campione di studenti di età e gradi di istruzione differenti.

La ricerca è stata suddivisa a seconda di fasi diversificate: da una disamina della letteratura scientifica in merito alla linguistica percezionale, alle caratteristiche dei neologismi e della produzione delle parole per quanto concerne l'italiano e alle specificità metodologiche della ricerca in sociolinguistica, si è passati all'individuazione dei termini da proporre all'interno del questionario. Si sono valutati 30 nomi di professione declinati al femminile (Tabella 1), secondo le indicazioni riportate da Sabatini (1986), Robustelli (2017) e Nitti (2018a). 


\begin{tabular}{|l|l|l|l|}
\hline Architetta & Direttrice/Direttora & Ministra & Questrice/Questora \\
\hline Assessora & Gastroenterologa & Otorina & Rettrice/Rettora \\
\hline Avvocata & La giudice & Politica & Senatrice/Senatora \\
\hline Chirurga & Ingegnera & Prefetta & Sindaca \\
\hline Consigliera & Magistrata & La presidente & Storica \\
\hline Critica & Medica & Primaria & La vigile \\
\hline
\end{tabular}

Tabella 1 - I neologismi proposti al campione

Alma Sabatini (1987) ha individuato la presenza di alcune disparità linguistiche, definendole «dissimmetrie» e suddividendole sulla base della semantica e della grammatica. Le dissimmetrie grammaticali sono connesse con l'uso del genere e, in particolare, del maschile come forma non marcata o generale. La classificazione proposta da Sabatini si è rivelata preziosa ai fini dell'indagine, poiché ha permesso di concentrare la ricerca su un tipo di dissimmetria grammaticale: il femminile dei nomi di professione.

Tutte le parole sono state valutate sulla base dell'assenza di una proposta di declinazione al femminile, all'interno di alcuni vocabolari di lingua italiana (Marello 1996). La ricerca dei lemmi nei vocabolari è volta a confermarne lo statuto di neologismo, infatti

«un vocabolario non può tenere conto di tutta la produttività della lingua in termini di neoformazioni e di prestiti: molte parole vengono introdotte o create continuamente dai parlanti ed è necessario che trascorra un po' di tempo affinché le forme incontrino fortuna e si attestino definitivamente nella lingua» (Nitti 2018b: 34).

Tutte le parole proposte, inoltre, sono attestate nelle produzioni contemporanee - e talvolta anche di epoche più lontane (Robustelli 2017) - dei parlanti, come confermato da un'osservazione della presenza delle parole su alcuni dei principali motori di ricerca in Internet: Bing, Google e Yahoo Search.

È necessario, a proposito dell'utilizzo di Google ai fini della ricerca linguistica, ricordare l'analisi proposta da Robustelli (2017: 82) sulla forte disparità numerica rispetto al numero di citazioni di forme declinate al maschile e al femminile in merito ai nomi di professione.

Pare opportuno riferirsi anche alla variabilità diamesica della lingua: mentre il parlato presenta un grado di accettabilità maggiore delle neoformazioni, lo scritto risulta maggiormente resistente: «l'italiano scritto, infatti, è stato per molto tempo identificato con l'autorità del suo modello letterario, che per secoli aveva rappresentato la norma grammaticale lessicografica» (D'Adamo, Della Valle 2017: 20). Le nuove modalità comunicative rese possibili - e fruibili - dal progresso tecnologico hanno determinato forti cambiamenti sul piano linguistico in relazione alla dimensione diamesica (Lorenzetti 2002; Berruto 2004; D’Achille 2010): la lingua utilizzata all'interno della messaggistica istantanea e nei social media è infatti caratterizzata da affinità significative con l'oralità e la presenza dei neologismi non sembra sanzionata come accade nelle altre varietà scritte (Fusco 2012).

Come emerge dalla Tabella 1, i nomi di professione sono stati scelti, sulla base di processi di derivazione morfologica diversificati a seconda dei suffissi e, talvolta, in relazione alla morfosintassi, nel caso dell'aggiunta dell'articolo determinativo. La base delle formazioni ottenute mediante derivazione è costituita da una matrice, generalmente percepita dai parlanti come produttiva (Dardano 1978: 10). Alcuni nomi presentano due possibilità di suffissazione, essendo i suffissi identici sul piano semantico e grammaticale, ma appartenenti a tradizioni di trasmissione diverse (Migliorini 1957). 
Per la proposta di neologismi agli informanti, si è tenuto conto del femminile dei nomi di professione che sono oggetto di dibattito politico, istituzionale e accademico-divulgativo, raggruppandoli in diverse categorie morfologiche e morfosintattiche:

1) Nomi che presentano un maschile singolare in $\{-o\}$ e il cui femminile singolare, di norma è rappresentato dal morfema $\{-\mathrm{a}\}$;

2) Nomi che presentano un maschile singolare in \{-tore\}; in questi casi la formazione del femminile singolare prevede tradizionalmente l'inserimento del suffisso \{-trice\}, tuttavia, come già discusso da Serianni e Castelvecchi, «nel suffisso -trice la desinenza -e non reca un esplicito contrassegno al femminile e, di conseguenza la lingua popolare tende ad utilizzare il maschile -tore, mutandone la terminazione in -a. Si ha in questi casi un'opposizione -tore/tora, più regolare e immediata» (2016: 123). L’alternanza \{-trice\}/\{-tora\} è relativa ai soli nomi agentivi, in cui risulta evidente il genere femminile della persona che esercita la funzione, mentre per i sostantivi non riferiti a persone, si utilizza la sola formazione con \{trice\}. La differenza fra i due suffissi riguarda la tradizione dotta o popolare; mentre \{-tora\} risulta popolare e, quindi, antiquato, \{-trice $\}$ non ha avuto una vera diffusione popolare ed è stato recepito sovente, nella storia letteraria dell'italiano, come maschile (Cortelazzo 1972: 110).

3) Nomi che presentano un maschile singolare in $\{$-sore $\}$, generalmente di natura deverbale; il femminile singolare si forma con il suffisso \{-itrice\} in aggiunta al radicale dell'infinito o, più raramente, in \{-sora $\}$. Il caso di «assessora» è particolare perché il verbo di origine non appare più trasparente nella lingua comune;

4) Nomi che presentano un maschile singolare in $\{-\mathrm{e}\}$ e che al femminile singolare assumono il morfema $\{-\mathrm{a}\}$;

5) Nomi «semplici» (Robustelli 2017: 90) che presentano un maschile singolare in $\{-\mathrm{e}\}$, il cui femminile singolare è espresso con l'anteposizione di un articolo concordato al femminile.

Al fine della sistematizzazione tassonomica delle forme si è scelto di comprendere le trasformazioni flessive e quelle derivazionali nella stessa categoria, poiché non è sempre semplice distinguere i processi di derivazione da quelli di flessione (Rainer in Grossmann, Rainer 2004; D’Adamo, Della Valle 2017; Nitti 2017).

Per quanto concerne il suffisso \{-essa\}, si è ritenuto di non inserire la forma all'interno dell'elenco di nomi perché non più produttiva in italiano per la formazione dei femminili (Sabatini 1987; Serianni, Castelvecchi 2016; Dardano 2017; Robustelli 2017).

Individuate le forme, è stato strutturato il questionario sociolinguistico (Johnstone 2000; Tagliamonte 2006), suddiviso in tre sezioni e corredato di un'intestazione introduttiva. Per la compilazione da parte degli studenti minorenni è stato richiesto ai genitori o ai tutori di firmare il consenso informato e l'autorizzazione al trattamento dei dati, mentre per gli studenti maggiorenni è stato predisposto un campo apposito all'interno del questionario.

I quesiti sono stati semplificati al massimo, al fine di non prevedere una diversificazione dei questionari e di garantirne la possibilità di compilazione anche da parte di informanti molto giovani, caratterizzati da una bassa competenza testuale. Si è scelto di adottare un registro informale privilegiando l'uso della seconda persona singolare per le domande (es.: «pensi che la parola sia corretta al femminile?», «Pensi sia sessista o discriminatorio l'uso solamente al maschile di questa parola?», «Pensi che questa sia una parola nuova nella lingua?»). Il questionario ha previsto un'introduzione relativa al trattamento dei dati, al rispetto della privacy degli informanti e alle 
modalità di divulgazione. La prima sezione, di carattere generale ha riguardato alcuni campi relativi alle caratteristiche degli informanti, in particolare il comune di residenza, il sesso, l'ordine di istruzione e l'eventuale possesso di altre lingue oltre a quelle inserite nell'offerta didattica dell'agenzia formativa.

La seconda parte del questionario ha indagato la considerazione degli usi sessisti della lingua attraverso un quesito che prevedeva risposte a scelta multipla, graduate a seconda dell'intensità. All'interno della terza parte del questionario si è proposta una batteria di nomi di professione declinati morfologicamente o sintatticamente al femminile e si è richiesto di valutarne l'accettabilità in termini di produzione linguistica. I quesiti riportavano anche uno spazio libero per le note, da esprimere, eventualmente in forma aperta, al fine di apprezzare le considerazioni degli informanti rispetto alle domande e agli argomenti inseriti nel questionario. Ogni domanda prevedeva anche di indicare se la parola fosse ritenuta un neologismo e se l'eventuale uso univoco al maschile costituisse un atteggiamento sessista e discriminatorio.

Il tempo per la compilazione del questionario, variabile a seconda delle caratteristiche degli informanti, è stato indicato all'interno dell'introduzione e oscillava fra i 15 e i 20 minuti. La proposta dei questionari è avvenuta una volta identificato il campione, nel periodo compreso fra ottobre e dicembre del 2017, in forma elettronica, attraverso l'applicazione Moduli Google. Mentre agli studenti maggiorenni è stato inviato direttamente il link con le istruzioni per la compilazione, via posta elettronica, gli studenti minorenni hanno compilato il questionario nei laboratori informatici, con il supporto degli insegnanti presenti. La presenza degli insegnanti è un fattore da considerare ai fini dell'analisi dei dati, sebbene sia stato esplicitamente richiesto di non fornire risposte e di limitarsi alla spiegazione eventuale dei quesiti e alla soluzione di problemi connessi con la compilazione: apparecchiature, connessione a internet e contingenze del gruppo classe.

\section{Il campione}

Il campione è composto da 600 studenti di ordini e cicli di istruzione diversi: 150 frequentano la scuola primaria e sono compresi fra il quarto e il quinto anno, 150 la secondaria di primo grado, 150 la secondaria di secondo grado e 150 l'università (lauree triennali). La valutazione dell'età dell'informante ai fini della compilazione è risultata significativa per quanto concerne la scuola primaria, in quanto si è evitato che alunni troppo piccoli e non in pieno possesso delle competenze di lettoscrittura accedessero al questionario.

Non si è ritenuto di diversificare il questionario in relazione al tipo di apprendente al fine di non viziarne le risposte e i dati della ricerca (Berruto 2004; Hulstijn 1997). 


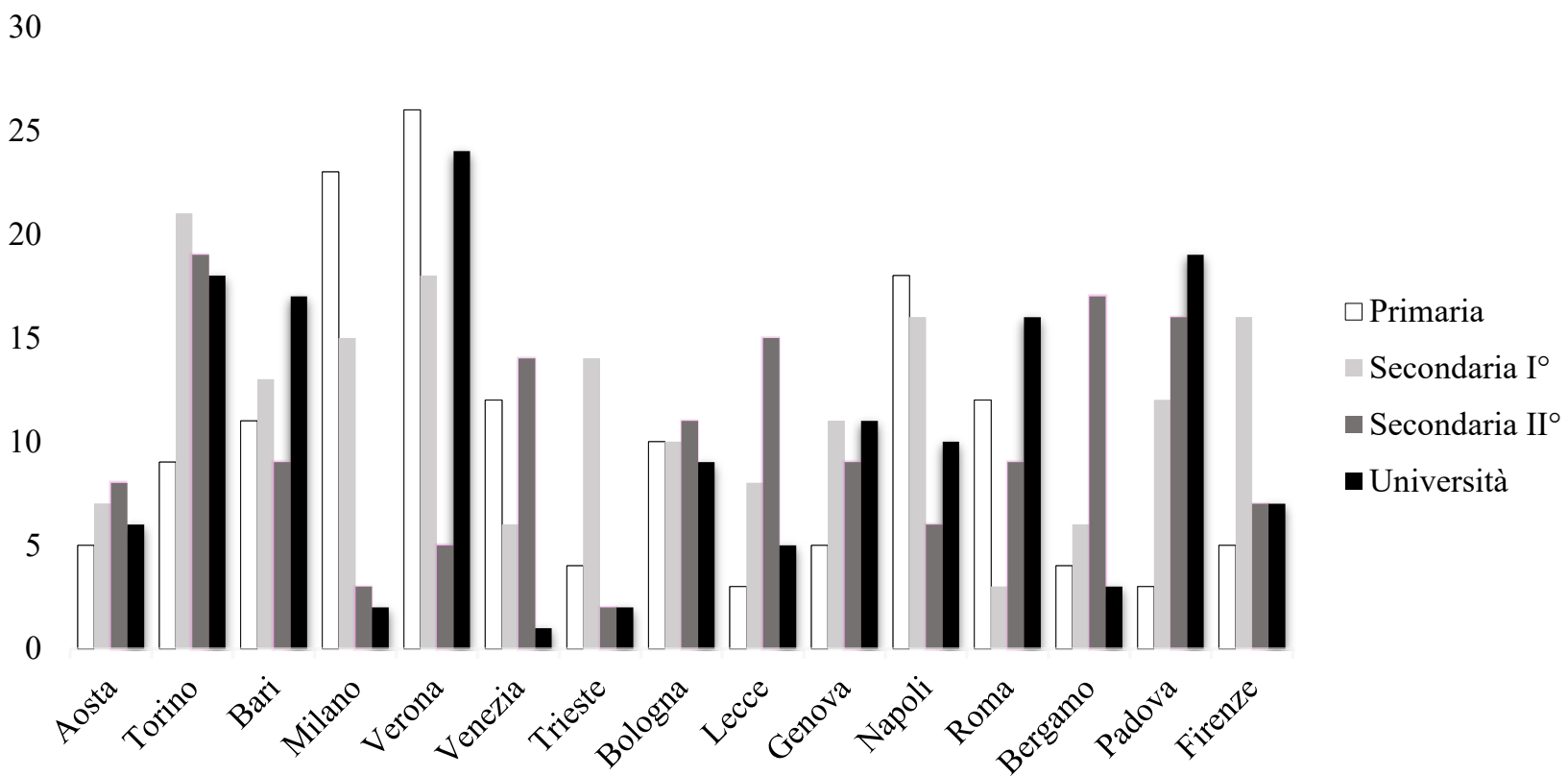

Grafico 1 - La distribuzione degli informanti in base alla città di residenza

Il Grafico 1 mostra la distribuzione degli informanti rispetto ai contesti territoriali di residenza; le città maggiormente rappresentate sono relative al Nord, mentre il Centro e il Sud sono meno presenti. In effetti, la scelta di analizzare i dati provenienti solamente da alcune città e non da altre è relativa alla quantità di risposte ricevute, rispetto alla richiesta di compilazione. Nel corso della prima fase di ricerca, infatti, sono state contattate 100 agenzie formative, distribuite su 25 città italiane, collocate in maniera bilanciata rispetto alla geografia italiana. Il contesto urbano o provinciale degli informanti non è stato indicativo rispetto all'analisi dei dati, in quanto le risposte sono state fornite in maniera uniforme e la variabile non è risultata significativa per la ricerca.

Per quanto riguarda il sesso, sono state considerate le risposte di 296 maschi e 304 femmine e la variabile, ritenuta particolarmente importante ai fini della ricerca, si è rivelata poco significativa, essendo le risposte omogenee fra maschi e femmine.
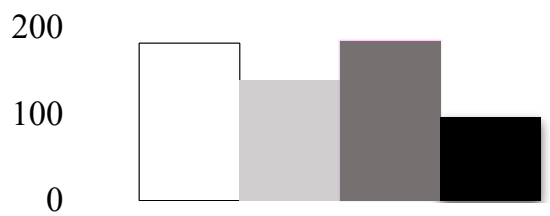

Grafico 2 - L'età degli informanti

$$
\begin{aligned}
& \square 9-12 \text { anni } \\
& \text {-13-15 anni } \\
& \text { - 16-20 anni } \\
& \text { - 21-25 anni }
\end{aligned}
$$

L'età degli informanti, rappresentata all'interno del Grafico 2, è abbastanza variegata, con una prevalenza di informanti fra i 16-20 e fra i 9-12 anni. La fascia di età meno rappresentata, come auspicabile in merito alla suddivisione in base ai diversi ordini di istruzione va dai 21 ai 25 anni. L'indicazione dell'età dell'informante si è dimostrata fondamentale in merito all'analisi dei dati, costituendo una variabile significativa ai fini della ricerca.

\section{Analisi dei dati}




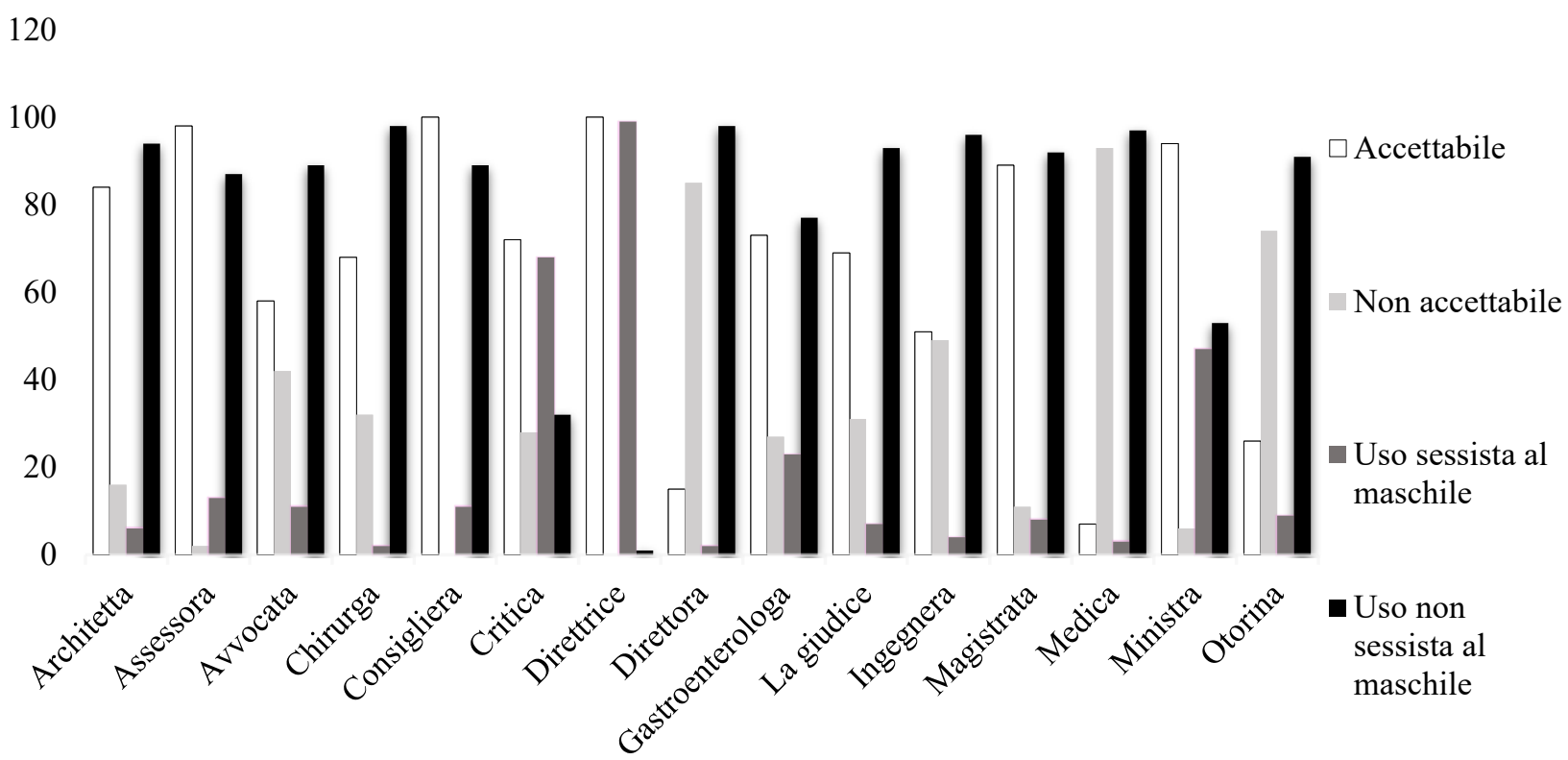

Grafico 3 - L'accettabilità dei nomi femminili di professione secondo il campione

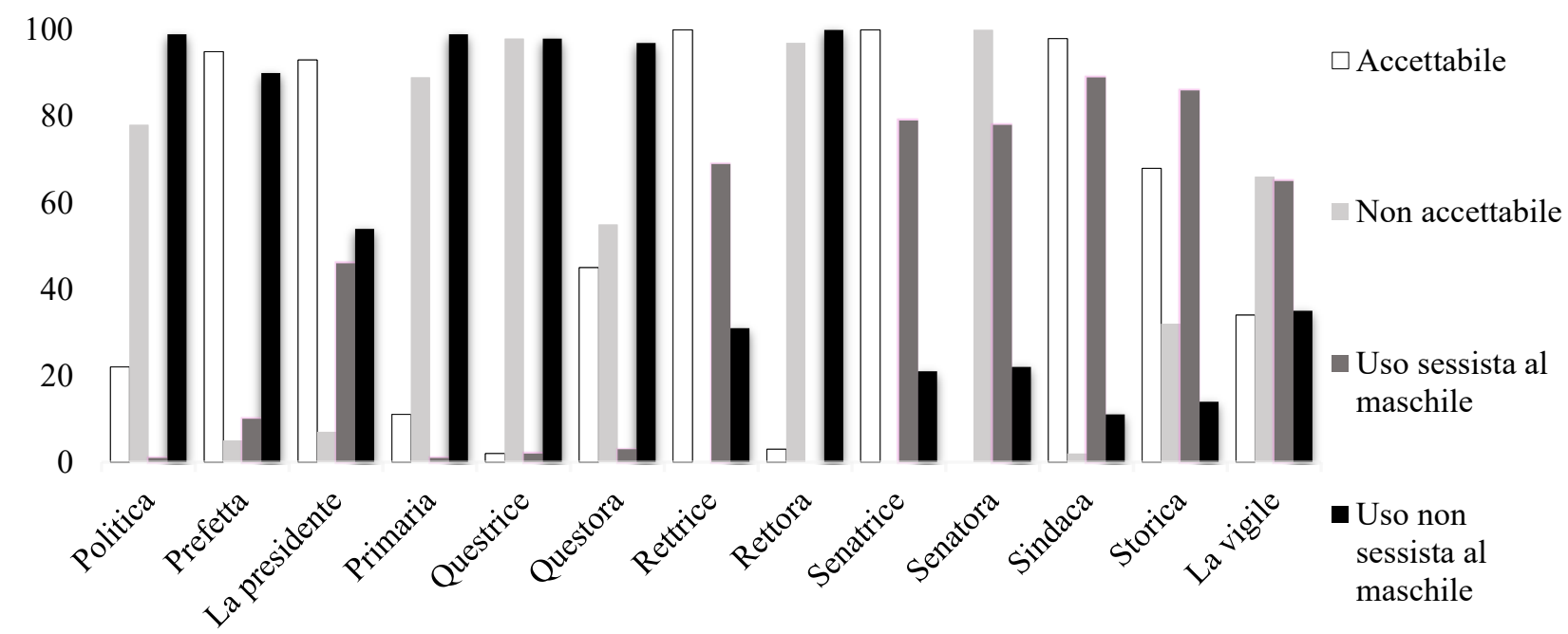

Grafico 4 - L'accettabilità dei nomi femminili di professione secondo il campione

Osservando il Grafico 3 e il Grafico 4 emerge chiaramente che il campione, in linea tendenziale, accoglie i nomi femminili legati alle professioni, seppur con alcune discrepanze in merito alla presenza di forme doppie («senatora pare inaccettabile rispetto a «senatrice»e lo stesso accade alle coppie «direttora» / «direttrice», «questora» / «questrice» e «rettora» / «rettrice»), confermando che nella lingua raramente possono coesistere forme in perfetta sovrapposizione, in virtù del principio di economicità della lingua (Nitti 2017).

Nei processi di derivazione, infatti, si distinguono due dispositivi di segno opposto: uno tende $a^{2}$ scoraggiare la formazione di parole e l'altro a incoraggiarla (Dardano 1978: 99). Il primo dispositivo è relativo all'esistenza di una parola o di una formazione suffissata di valore uguale a quella che si desidera formare, mentre il secondo riguarda il principio di analogia, il parallelismo con altre formazioni e parole simili (D’Adamo, Della Valle 2017: 27). 
È interessante notare che i neologismi «sindaca» e «ministra» sono notevolmente più accettati nei contesti in cui l'amministrazione comunale è governata da donne, come confermato dalle ricerche sull'argomento (Nitti 2018a). Il tipo di suffisso non sembra esercitare un'azione favorevole o sfavorevole alla misura dell'accettabilità del neologismo: mentre «storica» è tendenzialmente accettato, non si può osservare lo stesso parere per «medica». Anche l'ambito professionale sembra essere poco rilevante ai fini dell'accettabilità: per quanto concerne il settore della medicina e il lavoro nel campo sanitario, gli informanti sono favorevoli all'utilizzo di «chirurga» e di «gastroenterologa», e decisamente sfavorevoli al neologismo «otorina». All'interno delle note alcuni informanti hanno segnalato che «politica», «critica», «primaria» e «storica» si riferiscono all'aggettivo o alla materia in oggetto (negli ultimi casi con qualche perplessità), escludendo l'estensione a nomi di professione declinati al femminile. Per quanto riguarda «architetta», «critica» e «medica», lo stesso presunto conflitto si verificherebbe in relazione ai verbi che condividono la stessa radice, alla terza persona singolare dell'indicativo presente.

I neologismi rifiutati dalla maggioranza del campione sono «direttora», «medica», «otorina», «politica», «primaria», «questrice», «questora», «rettora», «senatora», «la vigile», mentre quelli accettati sono: «architetta», «assessora», «avvocata», «chirurga», «consigliera», «critica», «direttrice», «gastroenterologa», «la giudice», «magistrata», «ministra», «prefetta», «la presidente», «rettrice», «senatrice», «sindaca» e «storica». Il neologismo «ingegnera» rappresenta un caso quasi in bilico rispetto all'accettabilità, sebbene i pareri favorevoli superino, di poco, i contrari. La percezione degli usi sessisti pare, in generale, piuttosto bassa; gli informanti tendenzialmente confermano un'estensione del maschile alle forme non marcate o a quelle che indicano la professione generica, senza determinarla in relazione al genere delle persone, e la considerazione, seppur espressa con parole diverse e all'interno di item differenti, sembra essere rappresentativa nelle note $(11 \%$ del campione). Serianni e Castelvecchi, a questo proposito, notano che «la qualifica professionale enunciata con un maschile tende a stemperare, a mettere in secondo piano il sesso del suo portatore» (2016: 121). La considerazione sembra paradossale dal momento che la presunta genericità e l'assenza di marcatezza avverrebbero proprio utilizzando un maschile, come già osservato da Sabatini (1987).

100

50

0

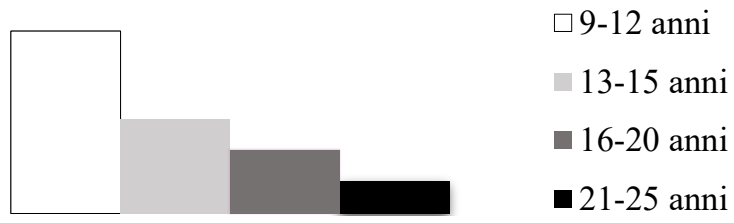

Grafico 5 - La percezione degli usi sessisti a seconda delle età

100

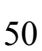

0

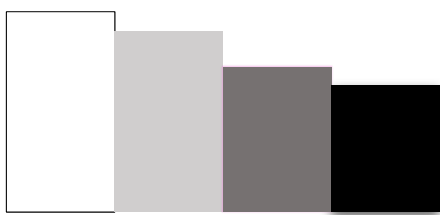

$\square 9-12$ anni

13-15 anni

- 16-20 anni

-21-25 anni

Grafico 6 - I livelli di accettabilità dei neologismi rispetto al campione

Il sesso degli informanti pare non costituire una variabile significativa in relazione alle risposte, ma lo stesso non accade rispetto all'età. Gli informanti più giovani, infatti, tendono a percepire più chiaramente un uso sessista in merito all'esclusività del maschile per le professioni (Grafico 5) e lo stesso accade in relazione al grado di accettabilità dei neologismi (Grafico 6). 


\section{Conclusioni}

Attraverso l'analisi dei dati è stato possibile chiarire che i neologismi per identificare i nomi femminili connessi con le professioni sono soggetti a diverse variabili, in relazione all'accettabilità, da parte dei parlanti. L'accettabilità del lessico è uno dei parametri per distinguere un occasionalismo da un neologismo; «una parola nuova che si candida a entrare nel patrimonio lessicale di una lingua grazie alla fortuna che incontrerà nella sua circolazione» (D'Adamo, Della Valle: 26).

In linea generale, la collocazione geografica del parlante non risulta una variabile significativa, tuttavia, la presenza di donne ai vertici delle istituzioni, come accade per le sindache, le assessore e le consigliere, incide notevolmente sul grado di accettabilità, a causa delle forme linguistiche che rientrano nell'italiano comune, quotidiano, in maniera frequente, sebbene occorra approfondire con uno studio ulteriore, la ricorrenza delle forme all'interno di corpora di parlato e scritto, circoscritti agli ambiti territoriali considerati.

L'analisi delle risposte fornite a Roma e a Torino, infatti, mostra livelli significativamente positivi sia per l'accettabilità dei nomi di professione al femminile $(97-99 \%$ per il neologismo «sindaca») che per il riconoscimento di usi sessisti (74-85\%). La differenza di sesso degli informanti non ha prodotto differenze significative rispetto alle risposte: femmine e maschi hanno fornito tendenzialmente le stesse indicazioni. Un aspetto decisamente rilevante ai fini dell'indagine - e a conferma della letteratura scientifica (Grossman, Rainer 2004; Ježek 2011) - riguarda l'età degli informanti: più sono giovani, più i neologismi tendono a essere dichiarati accettabili, sebbene raramente le innovazioni linguistiche prodotte dalle fasce sociali più giovani tendano a fissarsi nel sistema linguistico (Berruto 2004). In questo caso, tuttavia, occorre indicare che il neologismo non è prodotto a livello diastratico, non rientrando esclusivamente nei gerghi giovanili. Gli informanti più giovani hanno accettato il neologismo manifestando una tendenza accogliente rispetto alle innovazioni sul piano linguistico, dettata dalle caratteristiche sociali, psico-evolutive e, naturalmente, dall'assenza di una piena maturità linguistica. Occorre distinguere fra la maturità linguistica, raggiunta da un parlante adulto e la consapevolezza, ottenuta per mezzo dello studio metalinguistico (D’Odorico 2005). Il ruolo della scuola è rilevante perché il processo di istruzione tende a fissare le forme standard della lingua, rigettando le varietà e le neoformazioni (Berruto 2004).

Le note all'interno del questionario hanno permesso di mettere in rilievo il valore formativo dell'indagine; molti informanti, infatti, si sono interrogati, come emerge dal titolo del contributo, sull'appropriatezza delle forme linguistiche rispetto alla lingua, concepita come sistema, e alla sua grammatica.

\section{Bibliografia}

Alvar EzQUerra Manuel (1999), La formación de palabras en español, Madrid, Arco Libros.

ANDORNO Cecilia (2003), La grammatica italiana, Milano, Bruno Mondadori.

BAZZANELLA Carla (2014), Linguistica cognitiva, Roma-Bari, Editori Laterza.

Berruto Gaetano (2004), Prima lezione di sociolinguistica, Roma-Bari, Editori Laterza.

BusINARO Chiara (2008), «Buone prassi per la creazione di materiali didattici non sessisti: il caso di Nove Passì, Quaderni del CIRSIL, p. 1-15.

CACCIARI Cristina, PADOVANI Roberto (2007), «Further evidence of gender stereotype priming in language: Semantic facilitation and inhibition in Italian role nouns», Applied Psycholinguistics, 28(2), p. $277-293$.

CAPECCHI Saveria (2006), Identità di genere e media, Roma, Carocci editore.

CARDONA Giorgio Raimondo (2006), Introduzione all'etnolinguistica, Novara, UTET. 
CARDINALETTI Anna, GiUsti Giuliana (1991), «Il sessismo nella lingua italiana. Riflessioni sui lavori di Alma Sabatini», Rassegna Italiana di Linguistica Applicata, 23, p. 169-189.

CASTELVECCHI Alberto, SERIANNI Luca (1988), Grammatica italiana. Italiano comune e lingua letteraria. Suoni, forme, costrutti, Torino, UTET.

CAVAGNOLI Stefania (2013), Linguaggio giuridico e lingua di genere: una simbiosi possibile. Alessandria: Edizioni dell'Orso.

Corbisiero Fabio, MATURi Pietro, Ruspini Elisabetta (2015), Genere e linguaggio. I segni dell'uguaglianza e della diversità, Milano, FrancoAngeli.

CORRÀ Loredana (2016), Sviluppo della competenza lessicale. Acquisiżione, apprendimento, insegnamento, Ariccia (Roma), Aracne editrice.

CORNERO Loredana (2012), La tigre e il violino, Roma, Rai Eri.

Cortelazzo Manlio (1972), Avviamento critico allo studio della dialettologia italiana. III. Lineamenti di italiano popolare, Pisa, Pacini.

D’Achille Paolo (2010), L'italiano contemporaneo, Bologna, Il Mulino.

D'ACHILle Paolo (2004), Breve grammatica storica dellitaliano, Roma, Carocci editore.

D’Odorico Laura (2005), Lo sviluppo linguistico, Roma-Bari, Laterza.

DARDANO Maurizio (1978), La formazione delle parole nellitaliano di oggi, Roma, Bulzoni.

DARDANo Maurizio, TRIFOne Pietro (1997), La nuova grammatica della lingua italiana, Bologna,

Zanichelli.

De Mauro Tullio (2003), Guida all'uso delle parole, Roma, Editori Riuniti.

Dossi Carlo (1981), La desinenza in A, Torino, Einaudi.

ECKert Penelope, MCConneL-Ginet Sally (2003), Language and Gender, Cambridge, Cambridge University Press.

FASCHILLI Claudio (2014), Come comprendiamo le parole, Milano, Mondadori Università.

FRESU Rita (2008), «Il gender nella storia linguistica italiana (1988-2008)», Bollettino di italianistica, 1, p. $86-11$.

FusCo Fabiana (2012), La lingua e il femminile nella lessicografia italiana tra stereotipi e (in)visibilità, Alessandria, Edizioni dell'Orso.

GEIGER Grazia (2015), Il linguaggio delle donne. La comunicazione al femminile, Milano, Tecniche Nuove. Grossman Maria, Rainer Franz (ed.) (2004) La formazione delle parole in italiano, Tübingen, Max Niemeyer Verlag.

Guerrero Ramos Gloria (1995), Neologismos en el español actual, Madrid, Arco Libros.

HulstijN Jan (1997), «Second Language Acquisition Research in the Laboratory: Possibilities and Limitations», Studies in Second Language Acquisition, 19(2), p. 131-143.

JEŽEK Elisabetta (2011), Lessico. classi di parole, strutture, combinaz̧ioni, Bologna, Il Mulino.

JoHnstone Barbara (2000), Qualitative Methods in Sociolinguistics, Oxford, OUP.

KLEMENS Nadine (2007), Cultivating Stereotyped Gender Roles: Sexism in Language, MünchenRavensburg, Grin Verlag.

LAUDANNA Alessandro, BuRANi Cristina (1993), Il lessico: processi e rappresentazioni, Roma, Carocci editore.

Laudanna Alessandro, Voghera Miriam (2006), Il linguaggio. Strutture linguistiche e processi cognitivi, Bari, Editori Laterza.

LAUFER Batia (1992), How much lexis is necessary for reading comprehension?, London, Macmillan.

LEPSCHY Giulio Ciro (2008), Parole, parole, parole e altri saggi di linguistica, Bologna, Il Mulino.

LEPSCHY Giulio Ciro (1988), «Lingua e sessismo», L'Italia dialettale, 51, p. 7-37.

LEPSCHY Anna Laura, LEPSCHY Giulio Ciro (1981), La lingua italiana, Milano, Bompiani.

Lo DuCa Maria Giuseppa (2013), Lingua italiana ed educazione linguistica. Tra storia, ricerca e didattica, Roma, Carocci editore.

LORENZETTI Luca (2002), L'italiano contemporaneo, Roma, Carocci editore.

LuRAgHi Silvia, Olita Anna (2006), Linguaggio e genere, Roma, Carocci editore. 
MARCONi Diego (1999), La competenza lessicale, Roma-Bari, Laterza.

MARELlo Carla (1999), Riflettere sulla lingua, Firenze, La Nuova Italia.

MARELlo Carla (1996), Le parole dell'italiano, Lessico e dirionari, Bologna, Zanichelli.

MARTYNA Wendy (1980), «Beyond the 'He/Man' approach: The Case for Nonsexist Language», Signs, 5(3), p. 482-493.

MARTYNA Wendy (1978), «What Does He Mean? Use of the Generic Masculine», Journal of Communication, 28(1), p. 131-138.

MCCONnEL-GINET Sally, BARKER Ruth, FurMAN Nelly (1980), Women and Language in Literature and Society, New York, Praeger Publishers.

Michard-Marchal Claire, Ribery Claude (1982), Sexisme et Sciences Humaines, Lille, Presse Universitaire de Lille.

Migliorini Bruno (1957), Saggi linguistici, Firenze, Le Monnier.

Miller Casey, SwIFT Kate (1981), The Handbook of Nonsexist Writing for Writers, Editors and Speakers, Cambridge-New York, Barnes and Noble Books-Harper and Row.

Migliorini Bruno (1948), «A proposito dei nomi in -trice», Italica, 25(2), p. 99-103.

Mills Sara (2008), Language and Sexism, Cambridge, Cambridge University Press.

Nagpal Tooher, Dominique (2009), Cultivating Stereotyped Gender Roles: Sexism in Language?, München-Ravensburg, Grin Verlag.

NiTTI Paolo (2018a), «La vigile e la sindaca. Uno studio sul sessismo nella lingua italiana», Educational Reflective Practices, 8(1), p. 122-141.

NiTTI Paolo (2018b), La didattica della lingua italiana per gruppi disomogenei, Brescia, Editrice La Scuola. NiTTI Paolo (2017), La grammatica nell'insegnamento dell'italiano per stranieri, Saarbrücken, EAI.

NuZZO Elena, RASTELLI Stefano (2011), Glottodidattica sperimentale. Nozioni, rappresentazioni e processing nell'apprendimento della seconda lingua, Roma, Carocci editore.

O’NEIL Judy, MARSICK Victoria (2009), «Peer Mentoring and Action Learning», Adult Learning, 20 (1\&2), p. 19-24.

PALERMO Massimo (2005), «La percezione dei neologismi tra vecchi e nuovi media», in LO PIPARO Franco, RufFino Giovanni (Eds.), Gli italiani e la lingua, Palermo, Sellerio, p. 165-181.

Petralli Alessio (1996), Neologismi e nuovi media. Verso la "globalizzazione multimediale" della comunicazione?, Bologna, CLUEB.

Presson Nora, MACWhinNey Brian, TOKOWICZ Natasha (2014), «Learning grammatical gender: The use of rules by novice learners», Applied Psycholinguistics, 35(4), p. 709-737.

Pruvost Jean, SABlayrolles Jean-François (2003), Les néologismes, Paris, Presses Universitaires de France.

RAELIN Joe (2000), Work-based Learning: The New Frontier of Management Development, Upper Saddle NJ, Prentice-Hall.

ROBUSTELLI Cecilia (2017), Sindaco e sindaca: il linguaggio di genere, Roma, GEDI.

RoBustelli Cecilia (2014), Donne, grammatica e media, Roma, GiULiA giornaliste.

RoBustelli Cecilia (2012), Linee guida per l'uso del genere nel linguaggio amministrativo, Firenze, Comitato pari opportunità, Comune di Firenze.

Rossi Rosa (1978), Le parole delle donne, Roma, Editori Riuniti.

SABATini Alma (1987), Il sessismo e la lingua italiana, Roma, Presidenza del Consiglio dei Ministri.

SABATINi Alma (1986), Raccomandazioni per un uso non sessista della lingua italiana. Per la scuola e l'editoria scolastica, Roma, Presidenza del Consiglio dei Ministri.

SABATINi Francesco (2008), La tempesta delle lingue, Firenze, Cesati.

SALVI Giampaolo, VANELLI Laura (2004), Nuova grammatica italiana, Bologna, Il Mulino.

SAPEGNO Maria Serena (2014), La differenza insegna, Roma, Carocci editore.

SAPEGNO Maria Serena (2010), Che genere di lingua? Sessismo e potere discriminatorio delle parole, Roma, Carocci editore.

SCALISE Sergio, BISETTO Antonietta (2008), La struttura delle parole, Bologna, Il Mulino. 
SCOTTI Morgana Silvia (1981), Le parole nuove, Bologna, Zanichelli.

SERIANni Luca (2016), Parola, Bologna, Il Mulino.

SERIANNI Luca, CASTELVECCHI Alberto (2016), Grammatica italiana. Italiano comune e lingua letteraria, Novara, UTET.

SPENDER Dale (1980), Men Made Language, London-Boston, Routledge-Keagan Paul.

Tagliamonte Sali (2006), Analysing Sociolinguistic Variation, Cambridge, CUP.

TAYLOR Edward (2010), «Fostering Transformative Learning», in MEZIROW Jack, TAYLOR Edward (Eds.), Transformative Learning in Practice: Insights from Community, Workplace, and Higher Education, San Francisco, Jossey-Bass, p. 3-17.

VEDOVELLI Massimo (2003), «Note sulla glottodidattica italiana oggi: problemi e prospettive», Studi Italiani di Linguistica Teorica e Applicata, 32, p. 173-197.

Violi Patrizia (1986), L’infinito singolare. Considerazioni sulla differenza sessuale nel linguaggio. Verona: Essedue.

VygotSKij Semënovič Lev (1962), Thought and Language, Chicago, The MIT Press.

Wenger Etienne (1999), Communities of Practice: Learning, Meaning, and Identity, Cambridge, Cambridge University Press.

Wenger Etienne, MCDermotT Richard, SNyder William (2002), Cultivating Communities of Practice: A Guide to Managing Knowledge, Cambridge, Harvard Business School Press.

YAGuello Marina (1978), Les mots et les femmes, Paris, Payot.

ZoLli Paolo (1999), Come nascono le parole italiane, Cambridge, Cambridge University Press. 


\title{
Mots, couleurs et néologie : analyse des dénominations de couleur en français contemporain
}

\author{
Claudio Grimaldi ${ }^{1}$ \\ Università degli Studi di Napoli "Parthenope"
}

\begin{abstract}
Resumé: Sur le plan linguistique les couleurs représentent un champ d'investigation particulièrement intéressant qui peut être abordé sous plusieurs points de vue (entre autres, comparatif, cognitif, psycholinguistique, évolutif). Dans ce domaine de recherche une attention particulière a été portée au fil des dernières années sur les termes chromatiques (voir, à ce propos, les Dictionnaires des mots et expressions de couleur de Mollard-Desfour publiés entre 1998 et 2015), notamment en ce qui concerne les dénominations de couleur dans le domaine de la mode qui témoignent du caractère évolutif et novateur - d'ailleurs, très significatif - de ce champ linguistique d'études (voir, Krysolova, 2005). Les textes du secteur de la mode (magazines, pages web, catalogues, journaux) s'avèrent être, en effet, une source non négligeable de nouvelles structures linguistiques de termes chromatiques qui sont fortement influencées par les évolutions sociales et, donc, par des facteurs extralinguistiques.
\end{abstract}

Mots-clés: néologie chromatique ; couleurs ; mode ; mots de couleur ; dénominations de couleur

\begin{abstract}
Linguistically, colours represent a particularly interesting field of study, which can be approached from several different points of view (including comparative, cognitive, psycholinguistic, evolutive). In this field of research, particular attention has been paid to terms for colours (see Mollard-Desfour's Dictionnaires des mots et expressions de couleur published between 1998 and 2015), notably regarding the colour denominations in the field of fashion which show an evolutive and novel character - which is significant - of this field of linguistic study (see Krysolova 2005). Texts in the field of fashion (magazines, webpages, catalogues, newspapers) constitute a non-negligible source for new linguistic structures of colour terms which are highly influenced by societal changes, and thus, by extralinguistic factors.
\end{abstract}

Keywords: chromatic neology, colour, fashion, colour words, colour names

${ }_{1}^{1}$ Adresse électronique : claudio.grimaldi@uniparthenope.it 


\section{Introduction}

Le concept de couleur a été depuis toujours au carrefour de plusieurs domaines d'étude tels que, entre autres, la physique, la psychologie, la physiologie et la linguistique. Des siècles de réflexions et de recherches ont amené dans la seconde moitié du $\mathrm{XX}^{\mathrm{e}}$ siècle à une nouvelle conception des couleurs, selon laquelle celles-ci ne résident pas dans le monde extérieur, comme le soutenait la théorie classique, mais sont construites par le cerveau. Comme l'indique Rey (2005: s.v. couleur), les couleurs n'existent donc pas en tant que qualité des objets au même titre que la masse, la forme ou la texture : elles sont une construction du cerveau humain et de certaines espèces animales seulement.

Si le concept scientifique de couleur lié aux longueurs d'onde des rayonnements lumineux (voir les travaux de Thomas Young, Hermann von Helmholtz et Edwald Hering) et à la physiologie humaine (voir, à ce propos, les découvertes scientifiques d'Edwin Land et Semir Zeki), est très récent dans l'histoire des cultures, en revanche la notion de catégorisation des couleurs est très ancienne et a imposé depuis longtemps d'autres termes tels que teinte ou nuance. C'est grâce à ces concepts que les différentes cultures, au moyen de leurs langues, ont construit des axes continus pour découper des zones, des champs spécifiés et des tonalités de couleurs.

Cette contribution vise à analyser le lexique des couleurs en français contemporain à partir d'un corpus de textes constitué d'une cinquantaine d'articles disponibles en ligne concernant les nouvelles tendances de la mode de 2018. Étant donné l'ampleur du domaine d'étude traité, notre réflexion ne prétend pas à l'exhaustivité, mais elle est censée repérer quelques procédés néologiques récents concernant le lexique chromatique au moins par rapport aux typologies de textes pris en examen et au champ d'investigation retenu. Le repérage des phénomènes néologiques dans le lexique chromatique présent dans le corpus a été possible grâce à la réalisation d'un modèle d'analyse proposant une catégorisation des dénominations des couleurs selon les éléments linguistiques composant ces mêmes dénominations (\$3.1).

Avant de présenter notre cas d'étude, une prémisse méthodologique s'avère nécessaire puisque plusieurs conceptions concernant la catégorisation des couleurs ont été proposées au fil du $\mathrm{XX}^{\mathrm{e}}$ siècle. Dans un premier temps, il nous semble donc impératif de présenter brièvement les études de renom concernant le concept de couleur en linguistique et en psycholinguistique, qui constituent les jalons théoriques de notre réflexion. Nous délimiterons ensuite notre champ d'application de l'analyse du lexique chromatique choisi afin de proposer les résultats de notre étude et des pistes de travail futures.

\section{La notion de couleur : quelques prémisses théoriques}

Dans les recherches en psycholinguistique et en anthropologie la parution de l'ouvrage Basic color terms: their universality and evolution (1969) de Berlin et Kay a imposé pendant plusieurs années la conception de l'existence d'une liste de noms de couleurs élémentaires, appelées basic color terms. Ces couleurs sont communes à toutes les langues, sont au nombre de onze (blanc, noir, rouge, jaune, vert, bleu, brun/marron, gris, orange, violet, rose) et leur construction morphologique se base sur un seul morphème. Les deux linguistes américains ont également mis en évidence une hiérarchie de couleurs correspondant à six stades définissant la distribution universelle des termes de couleur (Golka 2014).

Outre la présence d'universels liés à la dénomination des couleurs et à leur hiérarchie, Berlin et Kay ont aussi décrit ce qu'ils ont appelé les focal colors, à savoir des nuances de la couleur considérées comme le meilleur exemple de cette couleur par les locuteurs d'une langue donnée. Ce concept a été ensuite repris par Rosch Heider (1972,1973) pour ses expériences concernant l'universalité dans la dénomination des couleurs. Ses expériences ont mené à la célèbre théorie des prototypes selon laquelle les couleurs focales sont plus expressives et marquées, ce qui conduit à

J. C. de Hoyos, C. Veleanu, C. Poix, A. Renwick, Les défis de la néologie / Desafíos de la neología, EDITUM, Murcia, 2020 
leur donner le statut de prototypes. Les études de Rosch Heider, qui se sont successivement intéressées aux catégories sémantiques, analysées, entre autres, par Kleiber (1990), ont été partiellement mises en question par Wierzbicka (1996, 2005), qui, contrairement à ce que proposaient Berlin et Kay, ne considère pas les couleurs en tant que concepts universaux. Le concept de couleur est, d'ailleurs, absent dans la liste des primitifs sémantiques construite par Wierzbicka puisqu'il existe des langues qui ne possèdent aucun terme de couleur. Selon la théorie de Wierzbicka, le concept de prototype appliqué à la couleur est partiellement réévalué non pas en tant que meilleur exemple d'une couleur, mais comme l'objet ou le phénomène naturel qui l'exemplifie le mieux (e.g., bleu-ciel et blanc-jour).

Ces recherches menées notamment dans la sphère de la psycholinguistique ont démontré que, certes, la façon de percevoir les couleurs est universelle, mais le langage illustre la conceptualisation du monde et non pas la façon exacte de dénommer l'univers chromatique adoptée par les locuteurs.

Dans le domaine de la linguistique cognitive contemporaine, les études de Dubois (2006a, 2006b ; Dubois, Cance 2012) ont souligné que les travaux de Berlin et Kay étaient incapables de rendre compte de la richesse et de la diversité des processus de conceptualisation et de dénomination des phénomènes liés à la couleur. En effet, selon Dubois, la restriction des analyses de Berlin et Kay aux seuls termes chromatiques de base a empêché de considérer une représentation cognitive de la couleur plus large. Les recherches de Berlin et Kay étaient, en effet, restreintes à un échantillon de formes lexicales limité et à une représentation matérielle des couleurs qui n'était pas exhaustive. Les études conduites par Dubois ont, donc, permis d'explorer des dispositifs techniques différents en tant que support de l'analyse des dénominations des couleurs (nuanciers impliqués dans de multiples pratiques telles que, entre autres, les peintures pour artistes, les peintures décoratives pour un grand public, les teintures de cheveux et de vernis à ongles), en élargissant ainsi l'éventail des conceptualisations des phénomènes colorés. Du côté de la langue, nous partageons la considération de Dubois et Grinevald (2003 : 82), selon lesquelles « une analyse proprement linguistique des termes de couleur de base en français, dans une perspective à la fois synchronique et diachronique, peut également permettre de préciser la dynamique des processus de création, d'évolution et de fixation de tels termes, en même temps que le développement des conceptualisations de la couleur».

L'approche adoptée par Dubois permet de prendre en considération de manière complète la dimension culturelle de la couleur (Mollard-Desfour 2007, 2008, 2011 ; Mollard-Desfour, Krysolova, Schindler 2010 ; Silvestre, Cardeira, Villalva 2006), ainsi que la pluralité des objets culturels et les conceptualisations différentes de la couleur. Voilà pourquoi les réflexions que nous proposons dans cette contribution s'insèrent dans la lignée des travaux de Dubois. La prise en considération de la diversité des champs d'application pratiques de la couleur permet, en effet, de mieux cerner les relations entre catégories cognitives et catégories lexicales, ainsi que la variété des modes de représentation et d'expression de la couleur d'un point de vue linguistique (Molinier 2001, 2006 ; Krysolova 2005 ; Rodríguez Pedreira 2002 ; Kristol 1978 ; Grimaldi 2020).

\section{Méthodologie adoptée et choix du corpus pour une étude des dénominations de couleur dans le domaine de la mode vestimentaire}

Si l'on accepte le cadre théorique exposé auparavant, il en résulte que les locuteurs encadrent la compréhension des processus complexes d'un point de vue psychologique et linguistique de la catégorisation dans une réalité mouvante et productrice de catégories et de formes langagières adaptées à des pratiques différentes. En d'autres termes, pour ce qui concerne le phénomène de la couleur, il faut inscrire l'étude de sa dénomination dans la diversité des pratiques qui lui donnent sens. En effet, comme l'indiquent Dubois et Grinevald (1999 : 14) : 
La diversité des formes et niveaux d'abstraction de la couleur (ou des couleurs) dépendrait de la diversité de l'expérience sensible à travers la diversité des pratiques de la couleur, celle-ci se trouvant ainsi plus ou moins autonomisée de celle des objets colorés, dans les diverses cultures. La COULEUR au singulier ne serait pas une primitive perceptive mais une abstraction résultant d'un long processus historique étroitement associé aux diverses pratiques culturelles, en particulier sans doute celles liées à la production d'artefacts, comme la teinture, la production de pigments pour la peinture d'objets, voire des corps.

Notre perspective se fonde sur la diversité des connaissances construites dans les pratiques, dans notre cas d'étude cette pratique étant celle de la mode vestimentaire. En particulier, nous avons choisi d'analyser les modalités de construction des dénominations des couleurs dans la présentation des saisons des collections de la mode vestimentaire pour l'année 2018, à savoir les saisons printemps/été 2018 et automne/hiver 2018. Notre corpus se compose d'une cinquantaine d'articles de revues de mode telles que Vogue, Elle, Grazia, Marie Claire, présentant les nouvelles collections des saisons examinées, ainsi que des articles sur les défilés des semaines de la mode contenus dans des blogues sur la mode. Nous avons analysé les articles composant notre corpus en sélectionnant les dénominations de couleur et en les partageant par la suite entre formes monolexémiques et polylexicales correspondant aux termes de base de Berlin et Kay, formes monolexémiques et polylexicales autres que les termes de base, compositions lexicales, pour en explorer, finalement, leur sémantique. Notre attention s'est attardée en particulier sur la présence éventuelle de nouveaux procédés néologiques de dénominations de couleur.

De ce point de vue, une prémisse concernant la présence de standards internationaux du système des couleurs dans la mode vestimentaire s'impose. Nous avons vérifié l'existence de standards internationaux pour indiquer les différentes couleurs utilisées pour la création des vêtements et des accessoires par les maisons de mode. La société chargée d'indiquer les couleurs dans le domaine de la mode est la société américaine Pantone, qui propose un langage universel pour les couleurs censé faciliter les décisions et la communication entre les marques et les fabricants. La technologie X-Rite utilisée par la société Pantone assure, en effet, la régularité des couleurs sur les différents matériaux et finitions dans le graphisme, la mode et l'industrie. En plus, chaque année le Pantone Color Institute publie des prévisions de tendance dans son annonce "Color of the Year », ainsi que des rapports sur les tendances de couleur dans les défilés de mode. Ces rapports et prévisions sont repris très fréquemment dans les articles de presse en français concernant les défilés de mode et les tendances vestimentaires de chaque saison.

\section{Pantone 2017-2018}

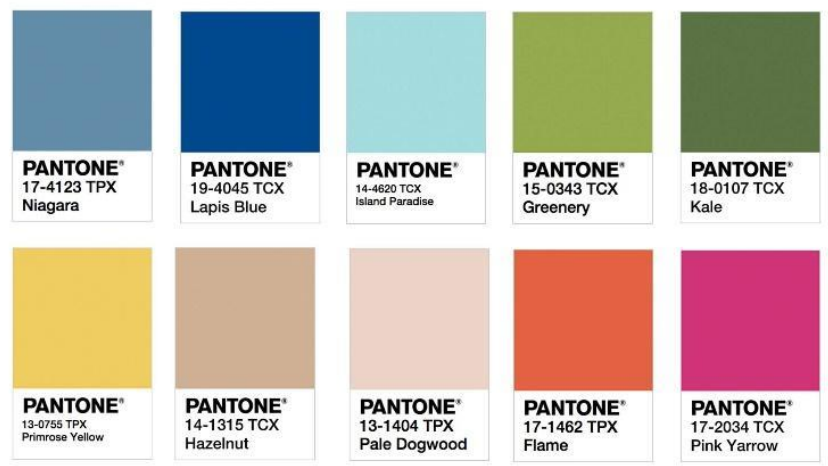

Fig. 1 - Exemple de maquette concernant l'association de couleurs, codes de couleur et dénomination en langue anglaise des couleurs de l'année selon Pantone

La transformation en mots du code couleur sous forme d'initiales et chiffres et de la nuance spécifique Pantone est faite en langue anglaise, ce qui, à notre avis, influence de manière 
significative le lexique chromatique en langue française. Nous verrons par la suite qu'en effet la recherche d'équivalents en français ou la traduction en français des couleurs de tendance annuelles proposées par Pantone pose de nombreux problèmes, étant donné que les dénominations de couleurs indiquées par la société américaine n’ont pas d'équivalents standardisés en langue française.

\subsection{Dénominations de couleur dans le corpus créé}

Pour ce qui concerne l'analyse de notre corpus, dans un premier temps nous avons vérifié toutes les occurrences des formes correspondant aux termes de base, en particulier les formes monolexémiques apparaissant seules sur l'ensemble des articles et des onze couleurs. Celles-ci apparaissent toutes dans notre corpus selon des occurrences différentes, en raison notamment du fait que - nous y reviendrons par la suite - le violet a été choisi par la société Pantone comme la couleur de 2018.

Il s'agit ensuite d'étudier la présence des formes monolexémiques ou polylexicales autres que les termes de base, en particulier les formes lexicales simples, et les compositions lexicales souvent construites à partir d'un des termes de base. Le tableau n. 1 présente les compositions lexicales trouvées dans notre corpus et permet d'analyser la diversité des désignations des couleurs pour la mode vestimentaire dans l'échantillon textuel retenu. Afin de permettre une lecture plus aisée des données, nous avons regroupé les constructions lexicales selon leur structure linguistique en indiquant par Tc le terme de couleur.

\begin{tabular}{|c|c|c|c|}
\hline & Tc + adjectif & & Tc + nom commun \\
\hline 1. & beige poudré & 1. & blanc coquillage \\
\hline 2. & blanc cassé & 2. & bleu ciel \\
\hline 3. & bleu clair & 3. & bleu denim \\
\hline 4. & bleu électrique & 4. & bleu lavande \\
\hline 5. & bleu foncé & 5. & bleu layette \\
\hline 6. & bleu vif & 6. & bleu marine \\
\hline 7. & fuchsia éclatant & 7. & bleu tie \& dye \\
\hline 8. & gris clair & 8. & bleu turquoise \\
\hline 9. & gris foncé & 9. & brun seigle \\
\hline 10. & jaune acidulé & 10. & gris souris \\
\hline 11. & jaune anisé & 11. & jaune canari \\
\hline 12. & jaune délicat & 12. & jaune citron \\
\hline 13. & jaune vitaminé & 13. & jaune moutarde \\
\hline 14. & menthe acidulée & 14. & jaune poussin \\
\hline 15. & orange vitaminé & 15. & rose barbie \\
\hline 16. & prune violacée & 16. & rose dragée \\
\hline 17. & rose cramoisi & 17. & rose pastel \\
\hline 18. & rose flashy & 18. & rose pastèque \\
\hline 19. & rose pâle & 19. & rouge coquelicot \\
\hline 20. & rose poudré & 20. & rouge flamme \\
\hline 21. & rose shocking & 21. & rouge pop \\
\hline 22. & rouge éclatant & 22. & rouge rouille \\
\hline 23. & rouge flamboyant & 23. & rouge vermillon \\
\hline 24. & rouge foncé & 24. & vert bouteille \\
\hline 25. & rouge incandescent & 25. & vert olive \\
\hline
\end{tabular}




\begin{tabular}{|c|c|}
\hline $\begin{array}{ll}26 . & \text { rouge orangé } \\
27 . & \text { rouge sensuel } \\
28 . & \text { rouge vif } \\
29 . & \text { sienne brûlée } \\
30 . & \text { vert fluo } \\
\text { 31. } & \text { violet flamboyant } \\
\text { 32. } & \text { violet osé } \\
33 . & \text { violet satiné }\end{array}$ & $\begin{array}{ll}\text { 26. } & \text { vert pastel } \\
\text { 27. } & \text { vert poireau } \\
\text { 28. } & \text { vert pomme }\end{array}$ \\
\hline $\begin{array}{l}\text { Tc }+ \text { adjectifs } \\
\text { 1. gris clair subtil et lumineux, } \\
\text { voire irisé ou scintillant } \\
\text { beige trendy et délicat }\end{array}$ & $\begin{array}{ll} & \text { Tc }+ \text { Tc } \\
\text { 1. } & \text { rose fuchsia } \\
\text { 2. } & \text { bleu gris } \\
\text { 3. } & \text { vert bronze }\end{array}$ \\
\hline $\begin{array}{l}\text { Tc }+ \text { nom commun complexe }+ \\
\text { adjectif }\end{array}$ & $\begin{array}{l}\text { Tc }+ \text { de }+ \text { nom commun } \\
\text { 1. vert d'eau }\end{array}$ \\
\hline $\begin{array}{l}\text { Tc }+ \text { nom commun }+ \text { adjectif } \\
\text { 1. } \quad \text { bleu turquoise pastel } \\
\text { 2. } \quad \text { bleu turquoise flashy }\end{array}$ & $\begin{array}{l}\text { Tc }+ \text { nom propre } \\
\text { bleu klein }\end{array}$ \\
\hline & $\begin{array}{l}\text { Nom commun }+\mathbf{T c} \\
\text { 1. ocre jaune }\end{array}$ \\
\hline
\end{tabular}

Tableau n. 1 - Liste des constructions lexicales dans le corpus

Le recensement des formes polylexicales met en valeur que nous avons pu identifier une grande variété de constructions différentes, incluant une grande diversité d'expansions, cette diversité se manifestant tant dans le nombre des expansions que dans les types de constructions aussi bien morphologiques que syntaxiques. Les deux structures terme de couleur + nom commun et terme de couleur + adjectif représentent la quasi-totalité des formes polylexicales.

Une étude détaillée des dénominations des couleurs utilisées dans la mode vestimentaire révèle un certain nombre de principes d'arrangement des catégories fonctionnelles qui les composent, ces mêmes catégories fonctionnelles pouvant être réalisées par des éléments variés. Les termes de couleurs sont, en majorité, des termes basiques de l'inventaire de Berlin et Kay (1969), sauf pour les cas de beige dans beige poudré, fuchsia dans fuchsia éclatant, menthe dans menthe acidulée, prune dans prune violacée et sienne dans sienne brûlée. Les qualificatifs qui déterminent la nuance de ces termes de couleur sont de nature diverse et différente, tant en termes de sémantique que de catégorie: ils comprennent notamment des noms communs (souris, ciel, poireau, etc.) et des adjectifs sémantiquement divers, y compris des adjectifs de couleur (orangé, violacé, etc.). La spécification de la nuance d'une couleur de base se réalise parfois à travers une information relative au degré d'intensité de cette couleur exprimée sous forme adjectivale (clair, foncé, pâle, etc.). Une seule occurrence de la spécification réalisée à travers des noms propres (bleu klein) et des noms communs accompagnés d'une préposition (vert d'eau) est présente.

Quant à la structure des dénominations des couleurs, la syntaxe des dénominations est généralement linéaire, le substantif Tc pouvant être suivi d'éléments spécificateurs de diverses natures. Il existe également la possibilité qu'un terme général, renvoyant à un vêtement ou à un accessoire, puisse être placé en position initiale, la dénomination de la couleur toute entière étant 
ainsi une spécification de ce terme. Dans ce cas, le terme de couleur est un adjectif qui suit les règles d'accord des adjectifs de couleur dans la langue française.

Avant d'aborder la sémantique des formes lexicales retenues, nous proposons dans le tableau n. 2 la liste des désignations monolexémiques autre que les termes de base ${ }^{2}$.

\begin{tabular}{|l|l|l|l|l|}
\hline ardoise & camel & dragée & ocre & taupe \\
\hline argent & caramel & doré & panne & terre de sienne \\
\hline beige & cerise & flashy & pistache & tomette \\
\hline bonbon & chocolat & framboise & sable & \\
\hline bordeaux & citron & kaki & safran & \\
\hline brique & daim & lilas & sépia & \\
\hline burgundy & denim & mauve & tartan & \\
\hline
\end{tabular}

Tableau n. 2 - Désignations monolexémiques autres que les termes de couleur de base

\subsection{La sémantique des dénominations de couleur}

Une analyse sémantique des désignations proposées dans le tableau n. 2 permet de mettre en évidence des données intéressantes. Pour les formes monolexicales qui ne correspondent pas à des termes de base et qui s'observent massivement dans notre corpus, celles-ci renvoient majoritairement à des référents qui sont des objets concrets dont la teinte est considérée comme typique pour la nuance. C'est le cas, entre autres, de caramel, chocolat, pistache, sépia, sable, citron, kaki. Aucune référence particulièrement abstraite, telle que nuage, océan, et symboliquement emblématique, ne semble s'imposer. La plupart des références aux objets concrets renvoient à l'univers des animaux et de la nature, sous forme de plantes, fleurs et fruits.

Les formes composées, quant à elles, sont en général construites à partir de la désignation de sources typiques associées aux termes de couleurs : il s'agit de structures lexicales enracinées dans la langue française, où le nom commun inséré dans la construction lexicale est souvent employé seul dans la désignation des couleurs. C'est le cas, par exemple, des tonalités de rouge, comme rouille dans rouge rouille, flamme dans rouge flamme, coquelicot dans rouge coquelicot, ou de la tonalité de vert pour poireau dans vert poireau. Pour ce qui est des constructions lexicales du type terme de couleur + adjectif, les aspects renvoyant à l'intensité et à la brillance occupent une place centrale grâce à l'utilisation d'adjectifs tels que vif, foncé, clair, flamboyant, acidulé, foncé, satiné, et de l'apocope fluo.

\subsection{Phénomènes néologiques dans le corpus créé}

Afin d'analyser les phénomènes néologiques dans la dénomination des couleurs par rapport au secteur de la mode vestimentaire, nous avons vérifié la présence des désignations monolexémiques et des formes polylexicales lexicalisées dans les dictionnaires de référence de la couleur (Guillemard 1998 ; Adams 2017). Il en résulte que la plupart d'entre elles sont recensées dans les dictionnaires consultés et, quant aux constructions lexicales, celles-ci forment dans la plupart des cas des structures particulièrement figées et typiques dans l'indication des couleurs de la mode vestimentaire. Toutefois, nous relevons que certains noms communs utilisés dans les constructions lexicales du type terme de couleur + nom commun ne sont pas lexicalisés dans les ressources lexicographiques consultées. C'est le cas, par exemple, de coquillage, barbie, denim, seigle, pop, pastèque, tie \& dye. Certains de ces noms communs suivent les principes indiqués auparavant (renvoyer aux sources typiques associées aux termes de couleur) et font donc référence à des objets concrets dont la teinte est considérée comme typique pour la nuance (seigle, coquillage, pastèque). En

${ }^{2}$ Camel et burgundy sont en italiques dans le corpus consulté. 
revanche, pour barbie, pop et tie \& dye la référence avec un objet concret est bien évidemment moins forte et la véracité perceptive de la couleur n'est que partiellement garantie. De ce point de vue, ces noms communs, qui ne peuvent pas être considérés comme les prototypes d'une nuance, sauf partiellement barbie, renvoient à une sphère de perception des couleurs s'appuyant sur des connaissances encyclopédiques et culturelles plus ou moins partagées par les lecteurs, qui vont audelà des univers animal ou botanique généralement utilisés dans la dénomination des couleurs. De plus, pour ce qui est de $p o p$, la référence à la couleur n'est pas explicite puisque le nom renvoie au pop art, dont le prototype de couleur n'est pas évident.

Quant aux constructions polylexicales du type terme de couleur + adjectif, il en résulte qu'une bonne partie des adjectifs utilisés dans ce type de constructions dans notre corpus ne renvoient pas à l'intensité de la coloration. Ils évoquent plutôt d'autres sensations généralement associées au toucher (comme délicat, incandescent, poudrê) ou à une sphère sensorielle plus charnelle et évocatrice d'un plaisir autre que celui du regard (sensuel, osê). Quant à anisé et cassé, ces adjectifs, bien qu'ils ne soient pas recensés dans les ouvrages lexicographiques consultés, sont souvent utilisés dans la sphère de la coloration des vêtements puisque anisé renvoie à une couleur verte légèrement jaunâtre typique des boissons alcoolisées fabriquées à partir de la plante connue sous le nom d'anis vert, et cassé est très employé en association au blanc pour indiquer la couleur blanche légèrement teintée de jaune et de gris. En revanche, vitaminé est un adjectif utilisé de manière figurée pour renvoyer à la dimension énergétique et, dans la sphère de la coloration, son association à des couleurs comme orange et jaune permet de renvoyer à une intensité vive, presque fluo. Le néologisme flashy, emprunt à la langue anglaise, est particulièrement fréquent dans notre corpus pour indiquer une couleur très vive et acidulée, cet adjectif étant aussi à la base d'un phénomène de conversion qui fait qu'il est utilisé comme nom (le flashy).

Des emprunts à la langue anglaise sont également recensés dans les constructions monolexémiques burgundy et camel: il s'agit ici d'un emprunt qui n'est pas nécessaire en raison de la présence d'équivalents en langue française bien stabilisés dans le lexique de la couleur (par exemple, bourgogne pour burgundy). Quant aux formes monolexicales qui ne correspondent pas à des termes de base, nous signalons la présence seule des noms communs citron, bonbon et dragée qui, d'après les sources lexicographiques consultées, ne sont utilisés qu'avec d'autres termes de couleur, et l'utilisation des formes monolexicales daim et denim en tant que couleur prototypique renvoyant à une certaine nuance.

Une dernière réflexion concernant les phénomènes néologiques dans la désignation des couleurs relève d'une première recherche faite sur la traduction en français des noms des couleurs de l'année proposées par la société Pantone. Nous schématisons dans le tableau n. 3 les résultats d'une première enquête menée sur les tentatives de traduction en français des noms de couleur anglais.

\begin{tabular}{|l|l|l|}
\hline Nom et code PANTONE & \multicolumn{1}{|c|}{ Traduction française 1 } & \multicolumn{1}{c|}{ Traduction française 2 } \\
\hline Emperador (18-1028) & marron impérial & marron chocolat \\
\hline Almost Mauve (12-2103) & mauve en devenir & mauve très pâle \\
\hline Spring Crocus (17-3020) & fuchsia d'un crocus flamboyant & rose fuchsia flamboyant \\
\hline Lime Punch (13-0550) & jaune vert au parfum citronné & jaune citron vert \\
\hline Meadowlark (13-0646) & jaune rayonnant et ensoleillé & jaune brillant et ensoleillé \\
\hline Cherry Tomato (17-1563) & rouge d'un fruit d'été & rouge tomate très vif \\
\hline Little Boy Blue (16-4132) & bleu des écoliers & bleu clair/bleu ciel azur \\
\hline Chili Oil (18-1440) & bordeaux des sauces pimentées & rouge bordeaux qui tire sur le brun \\
\hline Pink Lavender (14-3207) & violet rosé des lavanderaies & rose lavande doux et romantique \\
\hline Blooming Dahlia (15-1520) & rose crevette d'un dahlia en fleur & rose dahlia très doux et féminin \\
\hline Arcadia (16-5533) & vert d'un printemps verdoyant & vert printanier rétro et moderne \\
\hline Ultra Violet (18-3838) & violet ultra vivifiant & violet vif \\
\hline
\end{tabular}

Tableau n. 3 - Noms de couleurs proposées par Pantone et équivalents en langue française 
Le tableau montre de manière évidente que pour ne pas recourir au terme en langue anglaise, qui d'une certaine manière semble s'apparenter presque à un nom de marque (Altmanova 2016 [2013]), puisqu'il identifie un produit sur le marché créé par une entreprise, le choix est d'interpréter la couleur en présentant le terme de couleur et en lui associant un adjectif (marron impérial, mauve très pâle, rose fucbsia flamboyant, jaune rayonnant et ensoleillé, jaune brillant et ensoleillé, bleu clair/bleu ciel azur) ou une spécification pouvant expliciter la nuance de ce même terme (bleu des écoliers, violet rosé des lavanderaies, rose crevette d'un dablia en fleur, rouge bordeaux qui tire sur le brun). Cette tendance est aussi évidente lorsque nous prenons en considération uniquement la couleur de l'année 2018, à savoir la couleur ultra violet, pour laquelle nous avons trouvé un nombre élevé de résultats, tels que violet ultra vivifiant, violet vif ou incontournable ultra violet, bien que la traduction en français, ultra-violet, soit la plus simple et la plus adéquate pour rendre l'intensité de cette variante de couleur de base.

\section{Conclusion}

Cette première étude exploratoire des catégorisations des couleurs dans la mode vestimentaire permet de tirer des considérations partielles. Nous avons remarqué que pour cette pratique et par rapport aux typologies de textes analysés, le système de catégorisation repose sur plusieurs stratégies et modes de désignations (compositions lexicales, constructions monolexémiques, constructions polylexicales, etc.) s'appuyant aussi bien sur les termes de base que sur des termes de couleurs autres que les termes de base. Nous avons aussi mis en relief que la manière la plus fréquente pour identifier une nuance est celle d'associer une couleur à un objet concret ou naturel qui est censé fonctionner en tant qu'élément prototypique de cette nuance même. Dans cette perspective, l'adjectivation joue un rôle qui n'est pas du tout anodin puisqu'elle permet de spécifier une couleur en apportant des informations sur son intensité.

Enfin, pour ce qui concerne les aspects linguistiques liés à la dénomination des couleurs, le modèle d'analyse que nous avons exploité dans cette contribution permet de classer les nombreuses structures linguistiques des dénominations de couleur et d'en percevoir rapidement la distribution à l'intérieur d'un corpus donné. La prise en considération d'un corpus de référence d'ouvrages lexicographiques permet ensuite de relever les cas les plus intéressants de néologie, ainsi que les phénomènes les plus remarquables relatifs à la sémantique des termes de couleur.

En particulier, notre attention s'est attardée notamment sur le recours à une adjectivation peu fréquente dans la désignation des couleurs. La catégorisation des couleurs se base sur le recours à des adjectifs qui ne concernent pas l'intensité ou à des adjectifs renvoyant à l'aspect visuel, mais qui sont utilisés de manière métaphorique (vitaminé pour symboliser l'énergie, incandescent pour renvoyer à la force). Nous avons également remarqué l'emploi de quelques emprunts à la langue anglaise dans les structures monolexicales. D'autres utilisations intéressantes ont concerné les constructions du type terme commun + nom commun, telles que rose barbie, blue denim, bleu tie \& dye, qui, dans les années à venir, pourront se lexicaliser et enrichir l'ensemble des structures déjà recensées dans les ouvrages lexicographiques consultés.

Pour conclure et pour souligner le rôle linguistique et culturel de la néologie dans le secteur de la mode, nous aimerions citer Barthes qui dans une étude sur les unités signifiantes dans la mode vestimentaire (1960) rappelait que :

Il suffirait de construire une mémoire mathématique (sous forme d'une machine à faire la mode), pour que la mode, même à l'échelle d'une micro-diachronie, apparaisse comme un ordre de formes limité et essentiellement computable : vérité choquante pour un commerce fondé entièrement sur l'exaltation d'une néologie incessante, mais précisément utile pour comprendre comment une idéologie retourne le réel. 


\section{Références bibliographiques}

ADAMs Sean (2017), Le dictionnaire de la couleur. À l'usage de tous ceux qui veulent comprendre et utiliser la couleur, Paris, Pyramid éditions.

Altmanova Jana (2016 [2013]), Du nom déposé au nom commun. Néologie et lexicologie en discours, Milano, EDUCatt.

BARTHES Roland (1960), " "Le bleu est à la mode cette année”. Notes sur la recherche des unités signifiantes dans le vêtement de mode ", Revue française de sociologie, n 1-2, p. 147-162.

BERLIN Brent, KAY Paul (1969), Basic color terms: their universality and evolution, Berkeley, University of California Press.

Dubois Danièle (2006a), "Les "mots" et les catégories cognitives du sensible : des rapports problématiques », Cabiers du LCPE, n ${ }^{\circ}$, p. 23-47.

DuboIs Danièle (2006b), « De l'expérience subjective des catégories de couleurs à l'objectivité de la couleur : approches cognitives », Cabiers du LCPE, nº 7, p. 67-78.

Dubois Danièle, GRINEVALD Colette (1999), « Pratiques de la couleur et dénominations », Faits de langues, $\mathrm{n}^{\circ} 14$, p. 11-25.

Dubois Danièle, Grinevald Colette (2003), «En voir de toutes les couleurs : processus de dénomination des couleurs et constructions cognitives ». VANDELOISE Claude (éd.), Langues et cognition, Paris, Lavoisier, p. 79-113.

Dubors Danielle, CANCE Caroline (2012), «Vers une sémiotique du sensible : des couleurs en discours et en pratiques ", Histoire Épistémologie Langage, tome 34, fascicule 1, p. 63-95.

GolKA Maria H. (2014), « La catégorisation linguistique des couleurs : niveaux d'élémentarité des noms de couleurs français », Cognitive Studies/Études cognitives, n 14, p. 131-147.

Grimaldi Claudio (2020), "La variabilité des références dans les dénominations de couleur françaises", $7^{e}$ Congrès Mondial de Linguistique Française, doi: https://doi.org/10.1051/shsconf/20207805010, <https://www.shsconferences.org/articles/shsconf/pdf/2020/06/shsconf_cmlf2020_05010.pdf>, dernière consultation : $01 / 10 / 2020$.

Guillemard Colette (1998), Le dico des mots de la couleur, Paris, Éditions du Seuil.

KLEIBER Georges (1990), La sémantique du prototype, Paris, Presses Universitaires de France.

KRISTOL Andres (1978), Color. Les langues romanes devant le phénomène de la couleur, Berne, Francke.

KRYSOLOVA Svetlana (2005), Contribution à l'étude lexico-sémantique des dénominations chromatiques en russe et en français, Thèse de doctorat, Université Nancy 2.

MOLINIER Christian (2001), «Les adjectifs de couleur en français. Éléments pour une classification », Revue Romane, n³6/2, p. 193-206.

MOLINIER Christian (2006), «Les termes de couleur en français. Essai de classification sémanticosyntaxique », Cabiers de Grammaire, n 30, p. 259-275.

Mollard-Desfour Annie (2007), «Les couleurs dans la mode. Phénomènes lexicaux et données sociologiques ». ARGOD-DUTARD Françoise (dir.), Le français : des mots de chacun, une langue pour tous. Des français parlés à la langue des poètes, Rennes, Presses Universitaires de Rennes, p. 113-121.

Mollard-Desfour, Annie (2008), "Les mots de couleur : des passages entre langues et cultures », $<$ https://gerflint.fr/Base/Italie4/mollarddesfour.pdf>, dernière consultation : 06/10/2020.

MOLLARD-DeSFOur Annie (2011), «Le lexique de la couleur : de la langue à la culture... et aux dictionnaires », Revue d'études françaises, $\mathrm{n}^{\circ} 16, \mathrm{p} .89-109$.

Mollard-Desfour Annie, Krylosova Svetlana, Schindler Verena M. (2010), «From red bordeaux to absinthe green, from hot chocolate to cappuccino: Beverages, their referential 
colour terms and reflections on cultural differences », Interim Meeting «Color and Food: From the Farm to the Table » of the International Colour Association, Actes du Colloque (12-15 octobre 2010, Mar del Plata, Argentina), Buenos Aires, Grupo Argentino del Color and Nobuko, p. 200-205.

REY Alain (2005), Dictionnaire culture en langue française, Paris, Le Robert.

Rodriguez Pedreira Nuria (2002), «Recherches sur les adjectifs de couleur. Description et référenciation », L'information grammaticale, $\mathrm{n}^{\circ}$ 95, p. 27-30.

ROSCH HEIDER Eleanor (1972), « Universals in color naming and memory », Journal of Experimental Psychology, n 93(1), p. 10-20.

ROSCH HEIDER Eleanor (1973), «On the internal structure of perceptual and semantic categories ». MoOrE Timothy E. (ed.), Cognitive development and the acquisition of language, New York-San Francisco-London, Academic Press, p. 111-144.

Silvestre João Paulo, CARDEIRA Esperança, VilLalva Alina (éds.) (2006), Colour and colour naming: crosslinguistic approaches, Lisboa, Centro de Linguística da Universidade de LisboaUniversidade de Aveiro.

WIERZBICKA Anna (1996), Semantics: primes and universals, Oxford, Oxford University Press.

WIERZBICKA Anna (2005), "There are no "Color Universals" but there are universals of visual semantics », Anthropological Linguistics, vol. 47, n 2, p. 217-244. 


\title{
La néologie wallonne aujourd'hui. Étude d'un concours de néologismes subventionné : la Bate dès noûmots
}

\author{
Matthieu Balthazard \\ Université de Liège
}

Résumé : On s'intéresse à l'un des quatre foyers néologiques principaux des dialectes romans belges : Lès noûmots. Après une description globale de ce concours de néologismes, on l'envisage comme un moyen d'institutionnalisation lexicale et on en étudie des formations lauréates, en filigrane desquelles s'observe une vue standardisante pour le devenir des dialectes, en apparence détachée du français. Enfin on expose succinctement les pro et contra de la standardisation pour la conservation des dialectes.

Mots-clés : dialectologie, néologie, standardisation, wallon.

\begin{abstract}
We are interested in one of the four main neological sources of the Belgian dialects: Lès noûmots. After a global description of this competition of neologisms, it is considered as a way of lexical institutionalization and we study some laureate formations, behind which we can see a standardizing view for the future of dialects, apparently detached from French. Finally, we outline the pro and contra of standardization for the conservation of dialects.
\end{abstract}

Keywords: dialectology, neology, standardization, Walloon. 
Aujourd'hui, de nombreux dialectes (au sens de systèmes linguistiques qui ne jouissent pas d'un statut de langue officielle ${ }^{1}$ ) sont en danger. Face à cette situation, l'Europe et ses états engagent une série de mesures, selon des degrés divers. À un niveau plus régional, des actions de promotion des dialectes sont également organisées çà et là, avec plus ou moins de vigueur et de succès. Cellesci peuvent viser l'apprentissage et l'étude de la langue (au sens de système linguistique), mais aussi sa défense, son illustration et son développement face à un monde en changement perpétuel. C'est dans cette dernière optique que se situe l'entreprise que nous étudions aujourd'hui, celle d'un concours de néologismes dialectaux belgoromans : la Bate dès Noûmots (littéralement, «le combat, le concours des néologismes »).

D’abord, nous décrirons la situation linguistique de la Belgique romane (1). Puis, nous présenterons les foyers néologiques dialectaux qui naissent du besoin dénotatif (2), avant de nous attarder avec plus de détails sur le concours de néologismes qui nous concerne (3). Nous l'aborderons d'un point de vue externe en décrivant son organisation globale et en nous demandant si cette entreprise peut être vue comme une tentative d'institutionnalisation du lexique dialectal (3.1.), ainsi que d'un point de vue interne en questionnant des créations lauréates issues des éditions passées (3.2.). Nous mettrons ensuite ces études de cas en perspective en mettant en évidence la vision du devenir des dialectes belgoromans sous-jacente à ces productions, et donc, au concours (3.3.). Enfin, nous ferons dialoguer les pro et contra de la standardisation mise au service de la conservation des dialectes en général, des dialectes belgoromans en particulier (4).

\section{Situation linguistique belgoromane}

La Belgique possède trois langues officielles : le néerlandais, parlé au Nord, le français, parlé au Sud, et l'allemand, parlé dans une fine bordure à l'Est't . Dans la partie romane de la Belgique, la partie sud donc, le français chevauche les dialectes romans (qui, pour rappel, sont des continuateurs du latin au même titre que le français) : le picard, le wallon, le champenois et le gaumais ${ }^{3}$.

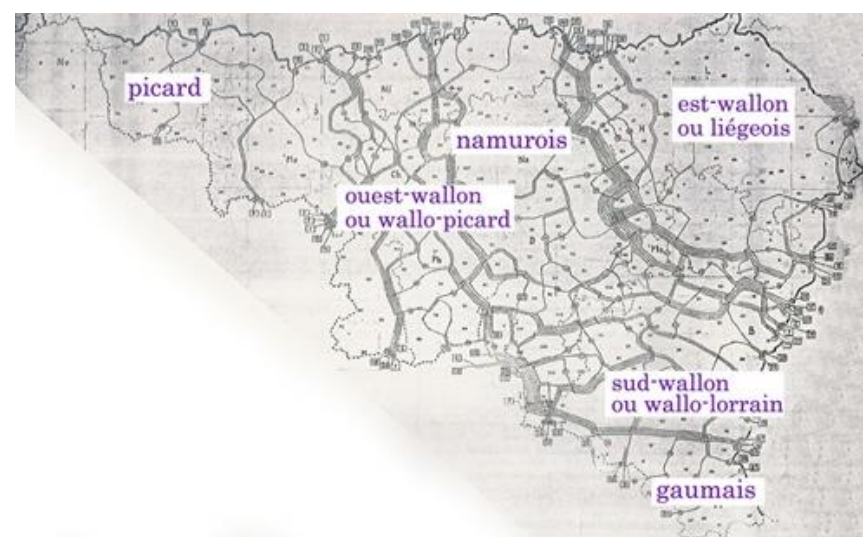

Figure 1. La segmentation dialectale selon L. Remacle et adaptée par Baiwir $2008: 5^{4}$.

Sur l'axe des relations langue-dialecte, le rapport français-wallon ${ }^{5}$ est caractérisé, jusqu'à la fin de l'Ancien Régime, par une période de « coexistence pacifique » (Boutier 2009 : 109). Durant cette

\footnotetext{
${ }^{1}$ C'est dans ce sens que nous utiliserons dialecte, de même qu'à l'occasion, langue régionale.

2 À la description, il faut ajouter Bruxelles, enclave bilingue français-néerlandais dans la partie néerlandophone du pays.

${ }^{3}$ Ceci est une représentation schématique, car des zones de chevauchement entre le français, langue officielle, et des dialectes germaniques existent également, dans l'est et dans le sud du pays (pour une présentation plus détaillée des dialectes de la partie méridionale du pays, v. par ex. Baiwir 2008).

4 Soulignons les zones de transition entre les variétés wallonne et picarde et entre les variétés wallonne et lorraine (le gaumais est en fait la variété belge du lorrain). Ce que l'on nomme habituellement le wallo-picard est un wallon empreint de traits considérés comme picards, tandis que le wallo-lorrain est un wallon mâtiné de traits lorrains (pour une présentation détaillée du panorama dialectal, v. Francard 2013, Baiwir 2008).

5 Comme d'autres, par commodité, nous rassemblons sous wallon les différents dialectes belgoromans. Si nous nous référons au wallon stricto sensu, nous le précisons.
} 
période, tous les autochtones wallons ont pour langue usuelle orale le wallon, dans toutes les couches de la société. Puis, à partir du XIX ${ }^{\mathrm{e}}$ siècle, se fait voir une «période de lutte du français pour l'hégémonie » (Boutier 2009 : 109-111). Entre 1800 et 1950, on passe progressivement d'une situation où le nombre d'unilingues français était très réduit, à une situation où la plupart des locuteurs wallons cultivés renoncent à faire connaitre le wallon à leurs enfants. Vers 1950, le wallon est combattu par l'école et c'est tendanciellement le français qu'on décide de transmettre à la génération suivante (Boutier 2009 : 114).

Aujourd'hui, les dialectes belgoromans ne sont plus transmis (sauf dans le cas de très - très rares exceptions). L'UNESCO décrit le wallon comme « en danger» (Moseley 2010) et le contexte linguistique belgoroman est perçu, ressenti et défini comme monolingue français (étiquette reprise à Martin 2017a : 180). Si le wallon est en danger, on ne peut cependant pas le qualifier de langue morte, étant donné qu'il est encore utilisé, bien qu'en des milieux retreints, wallonophones ou wallonisants ${ }^{6}$. Les représentations théâtrales dialectales sont par exemple bien présentes en Wallonie, même si ces types de démarche sont sûrement à estimer, au moins en partie, comme des démarches à caractère nostalgique ou patrimonial.

\section{Face au besoin dénotatif, des foyers néologiques}

Face au besoin dénotatif, quatre foyers néologiques principaux peuvent être mis au jour : les deux premiers présentés ci-après relèvent des interventions dites «in vivo », c'est-à-dire celles des pratiques sociales spontanées, tandis que les deux suivants procèdent d'une logique en laboratoire, « in vitro » (Calvet 1997 : 179-180, Blanchet $2013: 75)$.

$\left(1^{\circ}\right)$ Le premier foyer néologique identifié est composé par les locuteurs qui, dans leurs pratiques individuelles en discours, répondent au besoin immédiat de la communication : des enquêtes (que nous espérons étendre) nous ont montré que c'est généralement l'emprunt à la langue-toit (le français) qui est de mise, ou encore la paraphrase en discours (par opposition à la langue). Leurs choix posés pour former des mots ou des discours métalinguistiques ne semblent pas empreints d'un fondement idéologique militant, sauf si ces enquêtes sont menées auprès de personnes dont l'engagement wallon (linguistique) est déclaré : en ces cas, ces personnes reprennent régulièrement des mots issus des foyers dits in vitro (Balthazard 2017).

$\left(2^{\circ}\right)$ Le deuxième foyer est constitué des scripteurs du wallon qui, à un niveau individuel, décident de former des mots nouveaux dans leurs textes, que ces derniers poursuivent une fonction poétique (au sens de Jakobson 1960) ou non. A priori, il semble complexe d'envisager leurs productions néologiques tant elles sont diverses d'un point de vue morphologique (emprunts aménagés, néologie sémantique, mots tout à fait neufs, reprises aux foyers in vitro...) et tant elles peuvent relever de l'hapax scriptural (Pruvost et Sablayrolles 2003 : 60). Nous espérons mener plus tard, sur la base d'un corpus large, une étude approfondie de cette instance néologique.

Par ailleurs, nous relèverons deux autres foyers, in vitro, dont les organisations sont plus identifiables en ce qu'elles sont collectives.

$\left(3^{\circ}\right)$ D'abord, le foyer desdits refondeurs du wallon est à identifier. Ces derniers désirent «standardiser et normaliser les variétés existantes du wallon pour les fondre en une sorte de langue supra-régionale appelée rfondou walon, littéralement "wallon refondu" (Francard 2013: 81) et capable de nommer la modernité. Nous comptons analyser leur activité néologique, car elle est concrète, organisée et bien documentée, mais nous ne le ferons pas ici ${ }^{7}$.

$\left(4^{\circ}\right)$ En effet, pour l'heure, nous nous pencherons avec attention sur un foyer qui donne lieu à des créations collectives dépendant plus ou moins directement, par l'entremise d'un concours subventionné, d'une structure de l'État (la Fédération Wallonie Bruxelles, qui est l'organe en charge

\footnotetext{
${ }^{6}$ Nous entendons par là des personnes impliquées dans des milieux wallophiles ou participant régulièrement et activement à des activités de promotion de la langue wallonne, de la pièce de théâtre villageoise aux activités éditoriales wallonnes.

7 Pour une première découverte des formations et des matrices de formation proposées par les refondeurs, le lecteur intéressé pourra consulter le site tenu par leur figure de proue (Mahin 1994).
} 
des affaires culturelles en Wallonie et à Bruxelles) : la Bate dès Noûmots, que nous décrirons selon un point de vue externe, puis interne.

\section{La Bate dès noûmots}

\subsection{Point de vue externe}

\subsubsection{Description générale}

Lès noûmots est un concours de néologismes, il est ouvert à tous et est tenu à l'occasion de la Fête aux Langues de Wallonie. Cette dernière, subventionnée par la Fédération Wallonie Bruxelles (FWB), est organisée annuellement dans le but de "promouvoir le développement et la diffusion des langues régionales de Wallonie » (Service des langues régionales endogènes $s . d$.) et est jonchée, durant un mois, d'activités, qui peuvent changer selon les éditions (affichage de phrases en patois, pièces de théâtre, stages de sensibilisation à la langue, etc.). Le concours néologique est lui toujours présent: cette réitération montre l'attachement des organisateurs pour ce concours et, plus généralement, pour le développement du fonds lexical dialectal. C'est d'ailleurs certainement là qu'il faut chercher la justification de ce concours : « [u]ne langue, pour que son avenir soit assuré, doit être employée dans les secteurs où se joue l'avenir de la société. Cela présuppose que son vocabulaire soit adapté à ces secteurs et s'enrichisse de nouveaux mots pour désigner des réalités nouvelles » (Service des langues régionales endogènes s.d.), affirment les organisateurs en empruntant les mots de Francard (2016:3).

Concernant le fonctionnement du concours, un appel est d'abord lancé : les organisateurs proposent un thème (par exemple, en 2018, celui du voyage), accompagné d'une liste de mots français (souvent des termes) à transposer en wallon. Ensuite, les participants communiquent au jury leurs créations, lesquelles doivent toujours être incluses dans un petit cotexte, ainsi qu'être accompagnées d'un commentaire relatif à leur configuration ${ }^{8}$. Puis, le jury, composé de personnes formées à la linguistique dans un cadre universitaire, délibère et proclame les résultats du concours lors d'une journée festive consacrée aux langues de Wallonie. Les lauréats du concours sont pour finir l'objet d'une publication dans un trimestriel consacré aux langues romanes de moindre expansion (MicRomania), laquelle est souvent relayée par des périodiques dialectaux à diffusion régionale (Cocorico, Singuliers, etc.) ${ }^{9}$.

\subsubsection{La Bate, un moyen d'institutionnalisation de la langue à petits frais?}

Le français, et bien d'autres langues avec lui aujourd'hui, se dote d'un appareil officiel d'institutionnalisation lexicale (par exemple, l'Office québécois de la langue française au Québec, ou la Commission d'enrichissement de la langue française en France). Quant au wallon, il ne bénéficie évidemment pas d'une instance officielle de cette trempe. Toutefois, le concours de néologismes dont nous parlons pourrait être considéré comme un moyen d'institutionnalisation de la langue (ou plutôt des variétés belgoromanes) à petits frais. Il nous semble en effet que les différentes étapes du concours peuvent être comparées à celles qui prévalent dans les processus décisionnels des commissions de terminologie officielles, par exemple celles de la France, dont voici la description de l'organisation :

Les experts de dix-neuf collèges implantés dans les différents ministères ont pour mission de proposer à la Commission d'enrichissement les termes et expressions nécessaires apparaissant dans des langues étrangères et de les accompagner de leur définition. Une fois validés par l'Académie française, les termes sont publiés au Journal officiel de la République française (Ministère français de la Culture s.d.).

\footnotetext{
${ }^{8}$ La configuration d'un mot est « l'analyse de celui-ci en ses éléments constitutifs (essentiellement des morphèmes [...]) et la matrice lexicale qui l'a produite » (Pruvost et Sablayrolles 2003 : 98-99). La matrice lexicale est le procédé de création (Pruvost et Sablayrolles $2003: 96)$

${ }_{9}^{9}$ La liste des lauréats des années 2015-2017 est disponible sur le site du concours (Service des langues régionales endogènes s.d.).
} 
Tout bien pesé, les participants audit concours jouent un peu le même rôle que ces collèges d'experts qui « propose[nt] à la Commission d'enrichissement les termes et expressions nécessaires apparaissant dans des langues étrangères [...] ». Le jury dès Noûmots donne son aval pour la publication dans MicRomania, un peu comme l'Académie française, par sa validation, permet que les termes «so[ie]nt publiés au Journal officiel de la République française ». Il nous semble dès lors que le wallon se donne, par ce biais et par la bande, quelque moyen d'institutionnalisation.

On pourrait nous rétorquer que ce concours est avant tout ludique et qu'il n'est pas à comparer avec les organes officiels évoqués plus haut. Nous ne pourrons pas donner complètement tort à ces personnes, mais nous ne pourrons pas non plus leur donner tout à fait raison. De fait, le wallon n'est en rien muni d'une armée ni d'une marine, pour filer la métaphore de Weinreich (1945), de sorte qu'il n'a peut-être d'autre choix que d'allier à ce but d'enrichissement un peu de légèreté. De plus, ludisme n'implique pas non-nécessité, selon nous : la néologie n'a de fait jamais été bien loin du ludisme, dans la mesure où la recherche d'expressivité (via la métaphore par exemple) est d'un des moteurs du changement linguistique, qu'on pense au mot tête, venu de testa "pot, cruche en terre cuite », ou encore à urina, issu de *aurina, formé d'après aurum « or ».

\subsection{Point de vue interne ${ }^{10}$}

\subsubsection{Principes de création lexicale}

Sur le site du concours, les organisateurs fournissent les critères d'évaluation pour les unités nouvelles et, par là, les principes de création lexicale qui sont à suivre. Ainsi, le concours impose le recours à des matrices internes de formation (Service des langues régionales endogènes s.d.) :

[c]ette forme d'enrichissement [(celle faite par l'emprunt à d'autres langues)] de la langue n'est pas celle que le concours « Noûmots » souhaite privilégier, parce qu'elle ne fait pas appel à des ressources propres de nos langues régionales. [...] Il convient en particulier [...] de puiser dans l'inventaire des préfixes et suffixes disponibles [dans les langues régionales de Wallonie].

De plus, les mots nouveaux proposés sont appréciés à l'aune des «atouts » qu'ils présentent «quant à l'accueil de la forme par le public (compréhension par un maximum de Wallons, adaptabilité aux différentes formes régionales, facilité de mémorisation) » (Service des langues régionales endogènes $s . d$.). Autrement dit, quant à leur chance d'intégrer le système linguistique concerné, de quitter le discours pour la langue.

\subsection{2. "Des ressources propres de nos langues régionales »}

Comme dit, les participants au concours sont tenus de puiser au fonds morphologique wallon. Ce but est majoritairement atteint par les lauréats du concours (c'est d'ailleurs pour cette raison qu'ils remportent la mise). Pourtant, nous remarquons en plusieurs cas que les mots primés restent, de façon plus ou moins masquée, tributaires du français, langue-toit du wallon - sans doute en raison de la démarche essentiellement traductrice qui est utilisée (et vers laquelle les participants sont poussés, car leur est soumise une liste, dont ils peuvent sortir ou non selon les années, de mots français à transposer en wallon). Par exemple, la locution verbale fé do ₹ûna (littéralement, « faire du bourdonnement»), "faire le buzz», premier prix en 2015, témoigne de cette dépendance. En français, la combinatoire correspondante est faire le buzz ou faire du buzz, où buzz est un emprunt à l'anglais, qui ne possède en revanche pas le développement syntagmatique correspondant *to do

${ }^{10}$ Une partie des réflexions développées dans cette section est inspirée d'un papier commis pour un périodique non scientifique (Balthazard 2018). 
buг: Ainsi, alors que le calque ${ }^{11}$ zuna («bourdonnement»), par traduction, de bu₹そ, montre une volonté de puiser à l'anglais plus qu'au français, l'expression envisagée d'un point de vue syntagmatique montre une dépendance au français (l'expression wallonne est un calque structurel de fr. faire du burz vu que * to do burz n'existe pas, v. Balthazard 2018). En somme, au niveau paradigmatique, la morphologie wallonne est sauvegardée (les affixes utilisés sont wallons), mais, au niveau syntagmatique, le français, langue-toit, joue un rôle influent dans les développements syntactiques (sans qu'il n'y en ait forcément une prise de conscience déclarée).

En plus d'être syntagmatique, cette dette peut être culturelle, ainsi que le montre le premier prix de cette année (2018), natacha (pour hôtesse de l'air), du nom du célèbre personnage de la bande dessinée éponyme de Walthéry. Ainsi, certes la situation est-elle isotopique et isoculturelle de telle sorte que les langues sont en contact et s'influencent, mais l'ouverture à la francité semble tout de même plus grande qu'annoncée, sûrement car le second critère de choix du jury est celui de l'acceptabilité par les locuteurs. Nous y reviendrons.

\subsubsection{Forme unique vs plusieurs variantes}

Former un mot nouveau, c'est aussi poser un choix quant à la vision des langues et de leur devenir ; ce choix est d'autant plus fort que la langue est nettement différenciée dans l'espace, au sein de ce que les linguistes ont identifié comme une seule et même variété (par exemple, le wallon au sens strict, qui se divise en wallon namurois, wallon liégeois, etc.), ou bien au sein d'un groupe de plusieurs variétés unies par une même langue-toit ou un espace politique commun (le picard, le wallon, le champenois, le gaumais dans la Wallonie politique) : cherchera-t-on une forme pour un sens, ou plusieurs variantes pour un même sens?

Fréquemment, les participants forment plusieurs réalisations différenciées sur le plan diatopique, à l'instar des variantes moute voye (pic.), mousse voye ou moustère voye (wallo-pic., ou ouestw.), mostère vôye (w. namurois, ou centre-w.), mostère voye (w. liégeois, ou est-w.), mostère vôye (wallonlorrain, ou sud-w.) et montère èl tchèmin (gaum.), littéralement «montre voie » ou "montre le chemin », pour «GPS » $»^{12}$. Aussi, généralement, la variation qui touche l'espace belgoroman tend à être respectée.

Cependant, les mots primés ne permettent pas toujours cette déclinaison morphologique. Il en est ainsi pour le substantif féminin natacha, dont on parlait, mais également pour le mot masculin guigne djins (littéralement « surveille gens »-2015), composé du verbe guignî conjugué à la troisième personne de l'indicatif présent et du nom masculin pluriel djins. Si le morphème lexical djins n'est pas vraiment problématique car répandu dans l'espace belgoroman, nous ne pouvons en dire autant de guigne, dont le type lexical est surtout présent en wallo-lorrain et en picard, mais pas vraiment ailleurs (le liégeois possède par exemple rilon̂kî̀ à ou rîwètî - Baiwir 2011 : 124-125). Notons néanmoins que le type guigne a l'avantage, contrairement aux autres, d'être compris par tous (grâce à sa proximité avec le verbe français guigne) et, ainsi, de jouir d'un des atouts décrits dans le règlement du concours (la « compréhension par un maximum de Wallons »).

En tous les cas, cette situation pose question, tant pratiquement qu'idéologiquement. Au moment d'utiliser ce néologisme, le Liégeois, le Namurois ou le Bastognard décidera-t-il de le reproduire tel quel, ou bien de l'adapter à son parler (wête djins...) ? Plus largement, la néologie wallonne contemporaine doit-elle se soumettre à la « force d'intercourse » ou bien suivre un « esprit de clocher », pour reprendre l'opposition saussurienne ${ }^{13}$ ?

\footnotetext{
${ }^{11}$ Le calque, une des variantes de l'emprunt, « consiste soit à emprunter un emploi, c'est-à-dire un signifié, sans que le signifiant luimême soit emprunté, soit à traduire littéralement dans la langue d'accueil une expression de la langue source » (Apothéloz 2002 : 16-17).

${ }^{12}$ Un autre exemple est fourni par la néologie sémantique touchant clignète et ses variantes, qui prennent le sens d'« émoticône » (en plus de « clin d'œil ») : clongnète (pic.), clignète (wallo-pic., w. namurois, w. liégeois, wallo-lorr., gaum.).

13 «En un mot, [la force d'intercourse] est un principe unifiant, qui contrarie l'action dissolvante de l'esprit de clocher. C'est à l'intercourse qu'est due l'extension et la cohésion d'une langue »(Saussure 1972 : 281-282).
} 


\subsection{Mise en perspective : une vision du devenir des parlers en filigrane des choix lexicaux et morphologiques}

Il s'agit en réalité de répondre à cette question: ces développements lexicaux et morphologiques imposent-ils une vision particulière pour les devenirs des parlers du point de vue d'une standardisation, le choix d'une langue standardisée pour qu'elle survive ? Après une mise au point terminologique, tentons de débrouiller cette question.

\subsubsection{Mise au point terminologique (standardisation, normalisation, koinéisation, standardisation pluricentrique)}

Nous employons standardisation en un sens très large, celui d'« uniformisation du corpus d'une langue » (Robillard 1997 : 266), de l'émergence d'une variété régionale. Faute de temps, nous ne la distinguons donc pas ici des concepts de normalisation ou de koinéisation, ces concepts n'étant de toutes manières pas pleinement opposés car ils se situent au sein d'un même continuum (Baggioni 1997, Robillard 1997, Lodge 2010). Une langue est par ailleurs dite pluricentrique lorsqu'elle a plusieurs variétés standard ; c'est le cas du catalan, qui possède la variété proprement catalane ainsi que celle du Pays valencien (Sumien 2006). Une standardisation pluricentrique est donc, pour nous, un processus de standardisation plurielle (une standardisation par variété) qui se réalise régionalement ou autour de centres, mais au sein d'une langue polynomiquement une ${ }^{14}$; on a donc affaire à des standards régionaux, qui se forment autour d'une région ou d'un noyau dialectal. C'est ce qu'il semble se passer pour le sud du domaine d'oc (avec le languedocien, le provençal, etc.), mais aussi pour le cas corse (Tacke 2015 : 235). Au contraire, quand cette uniformisation se fait à l'aune d'une seule référence (existante ou reconstruite), nous parlerons ici de standardisation unique.

\subsubsection{Vision: standardisation pluricentrique et standardisation unique}

Concernant cette vision pluricentrique, le type <montre-voie $>$ (v. supra) et ses variantes nous semblent être représentatifs. De fait, les formes proposées sont propres à une zone assez large, à un régiolecte (une forme pour le namurois, une pour le liégeois, etc.), un peu de la même manière que, dans le cas occitan, les "programmes d'enseignement de 2010 se différencient en quatre variétés régionales, à savoir le languedocien, le provençal, le gascon et le limousin » (Tacke 2015 : 234). Le jury du concours prime donc des mots qui permettent cette différenciation régiolectale.

Cependant, cette standardisation peut couvrir tout l'espace belgoroman (qui comprend quatre variétés) : guigne djins et natacha sont ainsi proposés comme formes uniques. Mais, sur la base de ces deux exemples, on observe que cette standardisation lexicale est permise par un savoir commun qu'ont tous les locuteurs belgoromans, à savoir la langue française en Belgique (cas de guigne djins) ou la culture franco-belge (cas de natacha).

En se basant sur les lauréats des années 2015 et $2016^{15}$, on compte neuf formes accompagnées de leurs variantes principales (et donc allant vers une standardisation pluricentrique) et onze formes présentées de façon isolée (et donc allant vers une standardisation unique, mais ayant possiblement un potentiel morphologique - non présenté par les organisateurs sur leur site - permettant une différenciation diatopique par régiolecte). La vision promue par le concours semble être, du reste, à mi-chemin entre la standardisation pluricentrique et la standardisation unique.

\footnotetext{
${ }^{14}$ Marcellesi (1984 : 314) parle de langues polynomiques comme « langues dont l'unité est abstraite et résulte d'un mouvement dialectique et non de la simple ossification d'une norme unique, et dont l'existence est fondée sur l'affirmation massive de ceux qui la parlent, de lui donner un nom particulier et la déclarer autonome des autres langues reconnues ».

15 Pour établir ces statistiques, nous n'avons pu tenir compte des données 2017-2018. La présentation des lauréats de 2017 dont nous disposons nous semble peu claire sur l'existence, oui ou non, de variantes. Quant aux lauréats de 2018, nous n'en connaissons que le premier prix, natacha.
} 


\subsubsection{Pourquoi cette vision?}

Cette vision plutôt standardisante, qu'elle soit pluricentrique ou non, est sans doute liée à la volonté de transmission et de maintien de la vie des parlers belgoromans. Le concours se tient d'ailleurs dans un contexte de lente extinction des vernaculaires, de sorte qu'il nous semble être, face au déclin dialectal, une des réponses données par le Service des Langues régionales endogènes et, donc par la FWB, et donc, en définitive, par l'État. Choisir un concours de néologismes pour nommer les nouvelles choses du monde est d'ailleurs un acte clair allant dans le sens d'une volonté de maintien en vie des vernaculaires (v. la citation des organisateurs en 3.1.1.).

Par ailleurs, cette vision standardisante peut remplir des fonctions identitaires. Selon Didier de Robillard, la fonction identitaire d'une langue standard comprend une fonction unificatrice, une fonction de prestige et une fonction séparatrice. Dans notre cas, la standardisation remplit des fonctions unificatrice (du point de vue des dialectes) et séparatrice (du point de l'opposition dialectes $v$ français) : de fait, la «langue est utilisée par des locuteurs pour se positionner dans le monde en affirmant leur appartenance à un groupe (=fonction unificatrice), [...] ce qui implique la différenciation par rapport à d'autres, exclus du même coup (=fonction séparatrice). » (Robillard $1997: 68)$.

Enfin, cette standardisation peut ne pas être pluricentrique quand les formes proposées sont uniques. En de tels cas, il semble que la vision de la standardisation témoigne d'une prise en compte d'une dimension sociolinguistique (et donc, réaliste) de la standardisation, à savoir que le locuteur « n'obéit pas toujours aux règles matricielles du corpus d'une langue » (Robillard 1997 : 267) : les organisateurs priment de fait des mots potentiellement plus aptes à s'intégrer dans l'esprit des locuteurs et donc en langue.

Au total, les choix et actes des organisateurs semblent souligner l'importance du recours aux ressources internes de la langue (pour des raisons identitaires et de conservation notamment), mais aussi témoigner d'un réalisme sociolinguistiquement orienté : il parait préférable d'élire des mots qui ont une chance de passer le stade de la proposition, de quitter le discours pour la langue.

\section{Standardisation et conservation des dialectes. Mise en questions et en problèmes du cas des parlers belgoromans}

Pour plusieurs, la survie des parlers dialectaux devra passer par la standardisation, par cette union qui fait la force. Il est vrai qu'en première analyse, on peut se dire que plus une langue compte de locuteurs, plus elle est forte. Cela va un peu de pair avec le stéréotype selon lequel «les seules langues véritables sont les langues standardisées» (Lüdi 1990 : 317). Cette uniformatisation peut en tous les cas faire émerger des questions et des débats dans le contexte de la disparition des dialectes et de la volonté de leur maintien. Les interrogations et problèmes sont tant de nature idéologique et générale que pratique et particulière.

\subsection{Des questionnements idéologiques, généraux}

Une question se pose: dans une perspective de conservation des dialectes, convient-il d'uniformiser ou bien de maintenir la diversité ? Uniformiser signifie peut-être une perte du foisonnement et de la diversité locale des parlers ; maintenir la diversité est peut-être une perte de force. Que l'on choisisse l'une ou l'autre solution, il est en tout cas bien difficile de prédire l'avenir (l'histoire a montré que divination linguistique et réalité ne se rejoignaient que bien rarement), mais donnons quelques réflexions alimentant (bien humblement) ce débat.

En faveur de l'esprit de clocher, de la non-standardisation, nous pourrions faire nôtre une réflexion picarde de Martin : "une absence de standardisation peut être "vécue" [...] comme une "liberté assumée" » contre la standardisation, de sorte que ces langues peuvent se définir comme 
des «langue[s] de liberté » (Martin 2017b : 4). Pour elle, il n'y a pas « de contradiction formelle entre la non-standardisation du [dialecte] à l'échelle du domaine linguistique [dialectal], la présence de la variation et la question de la vitalité littéraire du [dialecte]. C'est peut-être, ajoute-t-elle, ce particuralisme de la non-standardisation qui évite de poser un "carcan" trop rigide revendiquant ainsi par la variation une forme de liberté ». (Martin 2017b : 5). Dans cette optique, le concept de polynomie, développé par Marcellesi (1984), nous semble puissant ; c'est d'ailleurs ainsi que semble se vivre la diversité en Corse (Tacke 2015). En outre, nous noterons que standardiser, c'est peutêtre encore renforcer cette attitude volontariste, dont l'histoire du français est marquée au coin, qui accentue le rôle d'une certaine politisation linguistique, qui voit l'histoire des langues comme « une longue série d'interventions politico-administratives» (Lodge 2010:9), et non comme une évolution « naturelle ».

Enfin, dans l'hypothèse d'une standardisation qui permet le maintien par la force de l'union, il faut encore se demander s'il est préférable d'agir de façon consciente, de standardiser au sens de Lodge, c'est-à-dire d'unifier par des institutions, "par le haut» (Lodge 2010) ou bien, toujours en suivant les définitions de Lodge, de koéniser, c'est-à-dire unifier par le locuteur, "par le bas » (Lodge 2010, v. aussi Baggioni 1995 et1997).

\subsection{Des questionnements pratiques, particuliers}

Une difficulté liée à notre cas est que quatre systèmes sont présents sur le territoire de la Wallonie. Et ceux-ci sont à cheval sur deux pays (France, Belgique) de manière que la question linguistique est conditionnée par la question politique. D'un point de vue exclusivement linguistique, les problèmes découlant de ce chevauchement pourraient être rapidement écartés ; chaque variété pourrait s'occuper d'elle-même : les locuteurs picards forment des mots picards, les locuteurs wallons, des mots wallons, etc. Toutefois, cela revient à oublier deux choses. Premièrement, le fait que des zones de transition existent, que des points partagent à la fois des caractéristiques picardes et wallonnes, par exemple (les habitants de Soignies disent capia et ceux de Chimay tchapiô, Pierret 1998 : 25). En ces cas, les isoglosses devraient-elles alors quitter leur statut originel de "fictions méthodologiques" (Lodge 2010 : 14) pour aller composer la base d'un discours standardisant faisant un départ net entre les variétés en présence en oubliant ces zones de transition ? Deuxièmement, le fait que des realia différentes sont à nommer de part et d'autre de la frontière (systèmes politique, éducatif... différents). D'ailleurs, si l'on pense à des concours tels que celui subventionné par la FWB, saute aux yeux qu'il touche les langues de la Wallonie politique, et non les langues de la Wallonie linguistique. Si l'on considère ce qui vient d'être dit, faudrait-il alors proposer un concours divisé en plusieurs sous-concours (un pour le picard, un pour le wallon, etc.) $?^{16}$

\section{Conclusion}

Plusieurs foyers néologiques existent dans le domaine dialectal belgoroman. Il serait intéressant d'étudier chacun d'eux en profondeur. Mais, pour l'heure, nous nous sommes intéressé à l'un d'eux seulement : la Bate dès noûmots. Ce concours de néologismes témoigne d'un certain souci de la part du politique pour le devenir des dialectes et reflète des aspects d'institutionnalisation par la bande du lexique dialectal belgoroman.

\footnotetext{
${ }^{16}$ Le domaine picard semble, du côté français, considérer l'extension binationale picarde. Rey et Martin, de l'Université de Picardie ont ainsi formé une Commission de néologie et de terminologie pour le picard, qui inclut le picard belge. De même, un projet dirigé par Baiwir (Lille 3) a pour but de construire un atlas informatisé dit " panpicard » (APPI, pour Atlas PanPicard Informatisé). Enfin, notons que les outils dialectologiques nous invitent malgré nous à considérer les différences de façon plus politique que linguistique. L'Atlas linguistique de Wallonie, même s'il comprend quelques points en France, est avant tout un atlas des dialectes de la Wallonie politique. Les Atlas linguistiques de France sont encore plus profondément marqués par cette segmentation administrative : les départements et régions continuent à découper les aires linguistiques. À ce sujet, soulignons encore l'intérêt du projet APPI, fondé sur des critères strictement linguistiques.
} 
Cette entreprise fait preuve d'un certain purisme dans la mesure où elle souhaite respecter la morphologie des dialectes, en recourant avant tout aux matrices internes de formation. Mais cette volonté initiale est tempérée par un réalisme sociolinguistique : le but premier est que ces mots proposés s'enracinent dans l'esprit des locuteurs, c'est-à-dire en langue.

À cet exercice néologique et à cette situation est immanquablement liée une vision du devenir des dialectes, vision qui semble tendre vers la standardisation, que celle-ci soit vécue de façon pluricentrique ou unique. Entre esprit de clocher et force d'intercourse, où se situe la voie à suivre ? Les langues régionales de Wallonie ne semblent pas encore avoir choisi (pour autant qu'elles le doivent), contrairement à d'autres telles que le provençal ou le corse, qui, notamment dans le but d'édifier des programmes d'enseignement, ont dû trancher (norme pluricentrique, polynomie, etc.).

\section{Bibliographie}

ApOTHELOZ Denis (2002), La construction du lexique français, Paris-Gap, Ophrys.

BAGGIONI Daniel (1995), "Normalisation/standardisation des langues nationales dans l'espace européen ", Archives et documents de la Société d'bistoire et d'épistémologie des sciences du langage, 11, La genèse de la norme, Colloque de la SHESL, janvier 1994.

BAGGIONI Daniel (1997), "Normalisation-standardisation », dans MoreAu Marie-Louise (éd.), Sociolinguistique : les concepts de base, p. 215-217.

BAIWIR Esther (2008), «Les dialectes de Wallonie : présentation et illustration », Revue Roumaine de Linguistique, 53, 1-2, p. 187-204.

BAIWIR Esther (2011), Atlas linguistique de Wallonie, 17 : Famille, ville et relations sociales, Liège, Faculté de Philosophie et Lettres de l'Université de Liège.

BALTHAZARD Matthieu (2017), «La néologie wallonne aujourd'hui, entre formation lexicale spontanée et formation lexicale organisée », communication présentée à la $8^{\mathrm{e}}$ journée du Traitement des Sources Galloromanes, Liège, le 4 mai 2017.

BALTHAZARD Matthieu (2018), "Quelques remarques sur Lès noûmots, à propos du concours de création de néologismes ", Wallonnes, chronique trimestrielle de la Société de Langue et Littérature Wallonnes, 1, p. 18-22.

Blanchet Philippe (2013), "Politique linguistique et diffusion du français dans le monde », dans Thierry Bulot et Philippe BLANCHET (éds.), Une introduction à la sociolinguistique. Pour l'étude des dynamiques de la langue française dans le monde, Paris, Éditions des archives contemporaines, p. 73-111.

BOUTIER Marie-Guy (2009), «Variétés linguistiques en concorde et en conflit : wallon et français en Wallonie », Travaux de linguistique, 59, 2, p. 105-121.

CAlvet Louis-Jean (1997), "In vitro vs. in vivo", dans Moreau Marie-Louise (éd.), Sociolinguistique : les concepts de base, p.179-180.

FRANCARD Michel (2013), Wallon, picard, gaumais, champenois. Les langues régionales de Wallonie, Bruxelles, De Boeck.

FRANCARD Michel (2016), «La création néologique en langue régionale : des mots pour dire la Wallonie d'aujourd'hui », MicRomania, 97, 2, p. 3-23.

JAKOBSON Roman (1960), «Closing statements : Linguistics and Poetics », Style in langage, NewYork, T.A. Sebeok.

LÜDI Georges (1990), «Diglossie et polyglossie », dans G. Holtus, M. METZELTIN et C. SHMitT (éds.), Lexikon der Romanistischen Linguistik, Tübingen, Niemeyer, 5, 1, p. 307-334.

LODGE Anthony (2010), «Standardisation, koinéisation et l'historiographie du français », Revue de linguistique romane, 74 , p. 5-25.

MAHIN Lucien (1994), «La création de néologismes en wallon », Aberteke. [consulté le 7 novembre 2018 sur http://lucyin.walon.org/diccionairaedje/waldim1 7.html]. 
MARCELLESI Jean-Baptiste (1984), "La définition des langues en domaine roman; les enseignements à tirer de la situation corse ", Actes du Congrès de Linguistique et de Philologie Romanes, vol. 5 (Sociolinguistique), Aix-en-Provence, p. 307-314.

MARTIN Fanny (2017a), «Espaces et lieux de la langue en Picardie au XXIème siècle. Retour sur un travail de thèse de doctorat ", Bien dire et bien aprandre, 32, p. 177-186.

MARTIN Fanny (2017b), "Le projet RESTAURE, un tremplin pour le picard ", La Bretagne linguistique, 21, p. 2-14.

MINISTERE FRANÇAIS DE LA CULTURE, FranceTerme [consulté le 9 juin 2018 sur http://www.culture.fr/Ressources/FranceTerme/Le-dispositif-d-enrichissement-de-lalangue-francaise].

MoselEy Christopher (éd.) (2010), Atlas des langues en danger dans le monde, $3^{e}$ éd., Paris, Éditions UNESCO [version en ligne consultée le 5 mars 2018 sur http://www.unesco.org/culture/en/endangeredlanguages/atlas]

Moreau Marie-Louise (éd.) (1997), Sociolinguistique. Les concepts de base, Sprimont, Pierre Mardaga.

OTTAVI Pascal (2010), «Langue corse et polynomie. Retour sur un processus langagier dans l'enseignement secondaire », Cabiers de sociolinguistique, 15, 1, p. 87-96.

Pierret Jean-Marie (1998), «Les dialectes de la Wallonie », La revue générale, 5, p. 21-36.

Pruvost Jean et SABlayrolles Jean-François (2003), Les néologismes, Paris, Presses universitaires de France.

REMACLE Louis (1972), «La géographie dialectale de la Belgique romane », dans STRAKA Georges (éd.), Les dialectes de France au Moyen Agge et aujourd'bui : domaines d'öl et domaine franco-provençal, Paris, Klincksieck, p. 310-355.

REY Christophe (2007), «Néologie et langues régionales : l'exemple du picard », diaporama projeté lors des Journées du dictionnaire, 23 mars 2007, Alliance française-Université de CergyPontoise.

RobILlARD Didier de (1997), «Standardisation», dans MOREAU Marie-Louise (éd.), Sociolinguistique : les concepts de base, p. 266-269

SABLAYROLLES Jean-François (2000), La néologie en français contemporain, Paris, Honoré Champion.

SAussure Ferdinand de (1972), Cours de linguistique générale, Paris, Payot.

Service des langues Regionales endogenes, Fête aux langues de Wallonie. Service des langues régionales endogènes. Fédération Wallonie-Bruxelles [consulté le 22 janvier 2018 sur http://www.languesregionales.cfwb.be/index.php?id=feteauxlanguesdewallonie].

Sumien Domergue (2006), La standardisation pluricentrique de l'occitan: nouvel enjeu sociolinguistique, développement du lexique et de la morphologie, Turnhout, Brepols.

TACKE Félix (2015), «Aménagement linguistique et défense institutionnalisée de la langue : les français régionaux et les langues des minorités », dans Polzin-HaumanN Claudia et SCHWEICKARD Wolgang (éds.), Manuel de linguistique française, Berlin/Boston, Walter de Gruyter, p. 216-241.

WEINREICH Max (1945), Yivo-bleter, p. 13. 
Guerre des isotopies dans la conceptualisation de la néologie d'emprunt : le « quantitative easing » de la BCE et sa figuralité à l'épreuve du discours de presse francophone

\author{
Danio Maldussi ${ }^{1}$ \\ Dipartimento di Interpretażione e Traduæione, Università di Bologna, Campus di Forlì
}

Résumé : Cet article propose une première analyse de la figuralité qui entoure le terme « quantitative easing », un exemple prototypique de néologisme d'emprunt opaque qui appelle une cohorte de formulations métasémiques dans le discours de presse. Il traite d'abord les raisons de son opacité et de sa complexité. Il aborde ensuite le rôle des métaphores et des métonymies en tant que catalyseurs de camps de pensée fédérateurs et opposés, reflet de différentes visions de l'Europe. Mots-clés : assouplissement quantitatif, BCE, métaphore, métonymie

Abstract: This contribution proposes a preliminary analysis of the figures of speech surrounding the term "quantitative easing", a prototypical example of an opaque borrowed neologism, which generates a proliferation of accompanying figures of speech in the press. It first deals with the reasons for the term's opacity and complexity. It then discusses the role of metaphor and metonymy as catalysts of federating lines of thought, however different these may be, a reflection of opposing visions of Europe.

Keywords: quantitative easing, ECB, metaphor, metonymy

${ }^{1}$ Adresse électronique danio.maldussi@unibo.it 


\section{Introduction}

Cet article constitue une première exploration, en vue d'ultérieurs approfondissements sur des corpus plus amples, de la figuralité associée aux mesures de politique monétaire dites de quantitative easing (dorénavant QE). Notre recherche est une démonstration d'un phénomène peu étudié, à savoir la cohorte métasémique (métaphores et métonymies) susceptible d'accompagner un néologisme d'emprunt opaque et son fonctionnement. En particulier, nous nous occupons des figures associées à la réalisation européenne des mesures de $\mathrm{QE}$ de la part de la Banque centrale européenne (dorénavant BCE) pour la distinguer de celle de l'américaine Federal Reserve (dorénavant FED) et dont les distinctions tiennent aux différents statuts des deux institutions. QE, exemple prototypique de néologisme d'emprunt qui oriente (dans notre cas diversement) le lecteur, est une notion opaque au vu de la constellation de notions corrélées et du traitement dans le discours de presse. Notre objectif est double : d'un côté, repérer les figures statistiquement plus significatives associées à $\mathrm{QE}$, considérées ici en tant que tentatives de la part de la presse d'en appréhender le concept et reflet d'orientations idéologiques; de l'autre côté, mettre en évidence la capacité de la figuralité à orienter des visions fédératrices et parfois à produire des mystifications. La figuralité, comme l'écrit Bonhomme est « un fait de langue à part entière » (2005 : 7). Loin d'une conception qui la considère en tant qu'ornementation de la langue ou en tant que transgression des conventions de langage, voire des « détours de communication » (ibid. : 23), elle est analysée ici en tant que «schèmes discursifs balisant les productions verbales » (ibid.).

Pour ce qui est de l'approche méthodologique, notre point de départ est la subdivision en différents types de métaphores proposée par Rossi (2017) et la notion d'« essaim métaphorique » introduite par Prandi et Mattera (2012). En ce qui concerne l'argumentation métaphorique et l'argumentation métonymique, nos ouvrages de référence sont respectivement le volume de Bonhomme, Paillet et Wahl (2017), le volume de Bonhomme (2005) et celui de Plantin (1996). Quant au rôle de la métaphore dans la création néonymique et de sa fonction structurante nous faisons appel respectivement aux apports théoriques de Rossi (2017) et d'Oliveira (2010). Quant à ses aspects idéologiques, nous nous inspirons des réflexions de Gaudin (2003).

Dans un premier temps, nous introduisons les raisons de l'opacité intrinsèque et du caractère polémique du QE. Dans un deuxième temps, nous illustrons le choix de nos sous-corpus comparables de presse généraliste et spécialisée francophone et les aspects méthodologiques. Dans un troisième temps, après avoir établi quelques points de repères, nous nous penchons sur le repérage des isotopies statistiquement significatives qui animent le discours sur le QE, menant une réflexion sur les aspects idéologiques - que Gaudin qualifie parfois de «malversations idéologiques » (2003 : 219) — qui caractérisent le débat autour du QE. Pour terminer, nous nous tournons brièvement sur les profondes dissensions au sujet de la nature même du QE et de ses enjeux, reflet de visions opposées de l'Europe que la figuralité suractive dans la trame du discours.

\section{QE : un concept opaque et polémique}

Les mesures de politique monétaire dites de QE suscitent depuis toujours des débats et des polémiques dans la presse généraliste et spécialisée. Des polémiques et des débats qui sont attribuables au caractère essentiellement opaque des mesures de QE et cela pour deux raisons : conceptuelles et linguistiques. Du point de vue notionnel, il s'agit d'une mesure de politique monétaire "non conventionnelle», selon la dénomination utilisée par Mario Draghi, ancien Président de la BCE, qui prévoit que l'institut de Francfort, et ce déjà à partir de mars 2015, achète des actifs auprès des banques commerciales, telles que les obligations. Comme le confirme la BCE dans son Communiqué de presse du 22 janvier 2015, l'objectif de ces rachats est celui de : 
[fournir] un soutien monétaire à l'économie dans un contexte de taux d'intérêt directeurs de la BCE se situant à leur niveau plancher. [Les achats d'actifs] constituent un nouvel assouplissement des conditions monétaires et financières, réduisant le coût de l'accès au financement des entreprises et des ménages. Cela tend à soutenir l'investissement et la consommation et contribue, in fine, à un retour de l'inflation vers des niveaux proches de $2 \%$.

L'opacité du concept de QE tient également à l'ample constellation d'informations corrélées de type notionnel qui constituent autant de préalables à sa compréhension : politique monétaire expansionniste, taux directeurs, monnaie scripturale, stimulation du crédit.

La présente étude se situe dans le sillage de notre article précédent dans lequel nous avons analysé la stratégie de communication institutionnelle de la BCE et souligné que la richesse des balises méta discursives et des gloses entourant la dénomination de QE, tout comme l'hésitation dans la presse entre assouplissement quantitatif, assouplissement monétaire et l'emprunt intégral, constituent autant d'indices non seulement de son caractère néologique présumé mais aussi de son haut degré d'implicite. QE est un terme relationnel qui indique un procès et de ce fait représente la nominalisation d'un concept dérivé d'un prédicat d'action. Possédant une structure claire, il constitue une action condensée. Son opacité serait attribuable aussi à des facteurs concomitants, tels que son assimilation, par analogie, dans le discours de presse à la politique de la BCE alors que Draghi ne fait que s'en démarquer préférant à l'expression QE, celle de assetpurchase program ${ }^{2}$. À tel point que nous avons supposé une dénomination qui relève presque de l'euphémisme (Maldussi 2019).

Nous qualifions QE de néologie d'emprunt selon la définition donnée par Loubier : «création déjà réalisée dans une autre langue par une communauté linguistique donnée » (2003: 24) ${ }^{3}$. Présent dans la Banque de données IATE, dans le Grand Dictionnaire terminologique de l'Office québécois et dans le Dictionnaire multilingue du FMI, qui proposent tous comme équivalent assouplissement quantitatif, ce syntagme, suite à notre recherche précédente, s'apparenterait, à maints égards, à une formule conventionnelle qui masque la structure actancielle des schémas d'arguments, et cela malgré l'apparente transparence du calque littéral ${ }^{4}$ (ibid.). L'origine de QE, un calque du japonais 量的緩, par translittération ryöteki kanwa (littéralement « quantitative easing ») ${ }^{5}$ est des plus controversées, voire mystérieuses ${ }^{6}$. Or, comme en témoignent nos sous-corpus, le syntagme QE est utilisé jusqu'à fin 2014 en référence à la politique de la FED et, au moment du lancement de la politique de Draghi, en début 2015, en référence à celle-ci. Le recours à QE dans la presse en référence à l'activité du Président de la BCE, tout comme l'absence de ce syntagme dans les réponses officielles de Draghi, constituent autant d'indices polémiques. Cette confusion conceptuelle, qui ajoute à la complexité du concept, unie à sa charge sémantique, finit par générer un foisonnement de figures qui répondent à une double fonction: d'une part, une fonction heuristique, dans la mesure où elles constituent autant de tentatives de saisir et de structurer ce concept grâce par exemple à l'analogie avec l'arme (Cf. 4.1, Figures 5 et 6); d'autre part, la mise en récit aidant, elles ajoutent à la spectacularisation de cette mesure, avec le risque de mystifications, comme dans le cas de l'analogie avec la planche à billets (Cf. 4.1, Figures 7 et 8).

\footnotetext{
2 «programme d'achat d'actifs »

${ }^{3}$ D'après Best et Cosmai (2018 :169), le terme QE fait sa première apparition dans un document de l'UE en langue italienne en 2010. Dans la version française, il est traduit par mesures d'assouplissement monétaire quantitatif. D'après ces auteurs, l'utilisation de deux adjectifs souligne l'incertitude quant à la meilleure solution traductologique à adopter.

${ }^{4}$ La fiche terminologique établie par la Commission d'enrichissement de la langue française qui a été publiée au Journal officiel $\mathrm{du}$ 07/12/2018 propose comme équivalent politique d'expansion monétaire et indique que le terme assouplissement quantitatif n'est pas recommandé.

${ }^{5}$ Nous tenons à remercier Motoko Ueyama, Professeure de langue japonaise auprès de l'Université de Bologne, siège de Forlì, pour son aide en la matière.

${ }^{6}$ Pour la reconstruction de l'origine du terme quantitative easing, nous renvoyons au site Business Insider.
} 
De plus, l'ample recours de la part des médias aux figures représente un indice supplémentaire de complexité (Maldussi 2019 : 96), les concepts complexes étant à l'origine d'un nombre accru de métaphores dont la fonction primaire est la compréhension (Lakoff et Johnson 1980 : 36). S’il est vrai, comme l'affirme Oliveira en référence à la culture scientifique, que l'une des principales fonctions de la métaphore néonymique « consiste à combler certaines lacunes de dénomination, à appréhender une nouvelle perception de la réalité, mais également à la structurer » (2010), il est tout aussi vrai, comme l'écrit Rossi se rattachant à l'essai Socioterminologie de Gaudin (2003), que les figures peuvent en même temps générer « de nouvelles connaissances tout comme des manipulations idéologiques frauduleuses » $(2017: 155)$.

\section{Choix du corpus de presse et questions méthodologiques}

Notre recherche précédente a montré que l'ajout de la traduction littérale en français, tout comme l'utilisation de l'emprunt intégral en italien, ne dissipent pas l'opacité qui entrave l'appréhension du concept (Maldussi 2019: 94-96). Or, si d'une part la spécificité du discours journalistique, comme écrit Bang Nielsen à propos de la représentation des mouvements migratoires, consiste dans le « droit de prendre la parole pour les autres » $(2017: 361)$, d'autre part ce fait "implique que le journaliste doit manier un contenu parfois fortement argumentatif» et " polémique ». Le discours journalistique se révèle donc « un espace de reproduction de discours persuasifs $[\ldots]$ par sa polyphonie $[. .$.$] » qui « reflète des points de vue et des motifs divers par la$ reprise du discours des acteurs sociaux [...] (ibid. : 363). QE est un thème tout aussi polémique et argumentatif qui est empreint de figuralité, ce qui confirme l'intuition de Boulanger selon qui « [1]a complexité de la finance rend la simplification par la métaphore d'autant plus attrayante aux yeux des lecteurs et des journalistes aussi » (2016 : 151). Une métaphore, nous le rappelons, ne fournit qu'une compréhension partielle, masquant d'autres aspects du concept (Lakoff et Johnson 1980 : 12-13). Les figures sont donc « au cœur de l'énonciation schématisante ». En effet, "produire des figures, c'est activer des schèmes discursifs qui modélisent certaines variations de la langue en vue d'augmenter la pertinence de la communication » (Bonhomme 2005 : 41). Les figures s'avèrent donc fonctionnelles dans l'écriture journalistique, lieu privilégié de leur cristallisation, où elles finissent par s'ériger en tant que « focalisations langagières » (ibid.).

Aux fins de notre recherche, nous avons analysé quatre sous-corpus tirés des journaux suivants : La Tribune (678.014 mots) et Les Échos (760.376 mots) pour ce qui est de la presse spécialisée et Le Figaro (306.208 mots) et Le Monde (349.616 mots) pour ce qui est de la presse généraliste, couvrant un laps de temps qui va de 2012 au mois d'octobre 2018. Au niveau méthodologique, notre analyse s'est focalisée uniquement autour de l'équivalent littéral assouplissement quantitatif car sa fréquence est nettement supérieure à celle de l'emprunt intégral et des deux variantes assouplissement monétaire et assouplissement monétaire quantitatif (Maldussi 2019 : 92). Ensuite, à travers la fonction «Information Mutuelle $»^{7}$ de AntConc, nous avons repéré les collocations à visée métaphorique prenant garde de ne retenir que les contextes pertinents grâce à l'élargissement des contextes à la phrase, voire à l'article dans sa totalité ${ }^{8}$. Nous avons ensuite compté les occurrences des figures pour chaque sous-corpus et calculé leur fréquence.

Les graphiques comptabilisent les occurrences des isotopies considérées, divisées par le nombre de mots des sous-corpus. Le calcul a été effectué par an pour les graphiques qui illustrent le pourcentage atteint par chaque journal ; tout l'intervalle (2012-octobre 2018) est en revanche pris en compte pour les graphiques qui comparent la presse spécialisée et la presse généraliste ( $L a$ Tribune + Les Echos; Le Monde + Le Figaro). Afin de faciliter la lecture des données, nous présentons

\footnotetext{
${ }^{7}$ La fonction « Mutual Information » est une mesure probabiliste du degré de dépendance de deux mots.

${ }^{8} \mathrm{La}$ fréquence minimale des figures a été établie à deux occurrences, ce qui nous a permis de repérer les collocations moins fréquentes.
} 
les résultats sous forme de pourcentage en nombre décimal (deux ou trois décimales, si nécessaire). Ce pourcentage figure sur l'axe $\mathrm{Y}$ des graphiques à suivre. Dans les graphiques en secteurs (Figures $2,4,6,8)$ la représentation des points de données est sous forme de pourcentage du graphique entier.

\section{Guerre des figures de style : quelques points de repère}

Avant d'aborder l'exploration des collocations et des dynamiques discursives qui caractérisent le discours autour du QE, nous introduisons brièvement le point de départ de notre analyse, à savoir la distinction opérée par Rossi qui envisage trois cas de figures. Cette distinction, parfois poreuse, s'articule ainsi : 1) la métaphore créative, 2) la métaphore dénominative isolée, 3) les métaphores en débats. Pour ce qui est du premier type, il s'agit « d'une métaphore qui joue sur un rapprochement conceptuel inattendu, souvent inédit, pour orienter la vision d'une nouvelle notion» et qui est "utilisée pour légitimer la découverte et en même temps pour légitimer la renommée du chercheur ». Le deuxième type est « le fruit d'une énonciation collective, anonyme » [dont le but est de] véhiculer des notions spécialisées par des dénominations simples et facilement accessibles ». Le troisième type représente «[...] une isotopie fondatrice dans un domaine spécialisé. Il s'agit d'une métaphore diffuse, à fonction structurante » dont la fonction est «de produire un réseau de concepts et de termes cohérents » et qui « ne présente pas un énonciateur primaire » (2017 : 153-170). Â leur tour, les métaphores en débat cristallisent des positionnements dominants générant des "essaims métaphoriques», à savoir des "réseaux complexes de métaphores entrelacées », engendrés par « un principe générateur» (Prandi et Mattera 2012 : 405). Ce dernier peut être une métaphore créative ou un concept métaphorique embryonnaire institué par une expression linguistique. Bien conscients que la focalisation de Rossi repose sur la fonction heuristique de ces figures dans les découvertes scientifiques, nous pensons également que cette distinction puisse être appliquée, sous plusieurs aspects, à la figuralité médiatique.

Le discours journalistique sur le QE, reprenant les mots de Bang Nielsen, est un espace de reproduction de discours persuasifs et polémiques, reflet de différents points de vue : experts et économistes au sens large, journalistes spécialisés dans le domaine économique et financier, leaders politiques des pays membres, gouverneurs des banques centrales. Dans les cas que nous étudierons ici, les créations métaphoriques, appartenant aux types 1 et 3 , apparaissent comme autant de tentatives d'appréhender un concept controversé et comme autant de catalyseurs de positions dominantes. Observées dans leurs contextes amples, elles découlent parfois d'isotopies fondatrices de fond, aux nombreuses filiations, parfois de métaphores dénominatives isolées, donnant lieu à de véritables positionnements idéologiques amplifiés par la médiatisation de l'univers financier. Comme l'écrit Gaudin, citant Lakoff et Johnson, « [1]a validation d'une métaphore est trouvée non dans sa vérité » (2003 : 206), mais plutôt dans « les perceptions et les inférences qui s'autorisent d'elle, ainsi que les actions qu'elle sanctionne (Lakoff et Johnson 1985 : 168).

\subsection{Analyse des résultats}

La première isotopie que nous avons isolée est celle qui est reconductible à l'isotopie fondatrice du domaine des finances «L'argent est un liquide », qui rentre dans la typologie des "métaphores en débat ». Comme l'écrit Rossi, cette métaphore, qui « ne présente pas de marques évidentes de la présence d'un premier énonciateur [...] » exerce la fonction « de produire un réseau de concepts et de termes cohérents, offrant une charpente figurée au domaine et une source de production de nouvelles terminologies » (2017: 158-159). Font partie de cette isotopie, amplement présente dans tous les sous-corpus considérés, le verbe injecter et le substantif injection. Nous avons observé que ce dernier, en raison de sa répétitivité, se mue en formules stéréotypées: sur un total de 260 occurrences de la tête de syntagme injection, tous sous-corpus considérés, les formules injection* de 


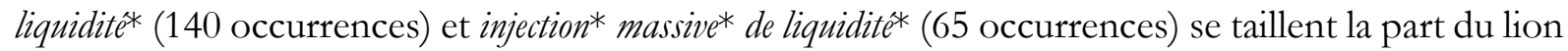
avec 205 occurrences, le reste relevant pour la plupart de métaphores telles que injection mesurée, géante, artificielle ou tout simplement monétaire. Notre exploration montre que la presse généraliste présente une fréquence légèrement plus élevée de ces formules stéréotypées par rapport à la presse spécialisée. La même isotopie donne lieu à des terminologies lexicalisées cohérentes à forte charge idéologique telles que celles exprimées par le verbe inonder et le substantif inondation, qui font état d'une dimension polémique, leur représentation simpliste, voire stéréotypée ${ }^{9}$, du fonctionnement du QE ne faisant qu'amplifier la dimension polémique de contextes déjà négatifs : "Les marchés financiers adulent Mario Draghi, [...] qui les inonde de liquidités gratuites » mais, se demande Robin, «à quoi sert-il d'arroser une prairie déjà gorgée d'eau comme il s'apprête à le faire le 3 décembre? » (2015).

Comme le montre la Fig. $1^{10}$, c'est Le Monde qui atteint le pic des fréquences de l'isotopie «L'argent est un liquide » en 2013 au moment du lancement, de la part de la FED, de ses mesures de politique monétaire. En outre, sur l'intervalle considéré (2012-octobre 2018), cette isotopie affiche une fréquence plus haute dans les deux sous-corpus généralistes par rapport à la presse spécialisée (Fig. 2).

L'analyse des contextes contenant la métaphore de l'« injection de liquidités » nous a permis de repérer la métaphore créative de la «monnaie-hélicoptère ». D’après la définition qu'en donne Wikipedia, elle consiste :

pour une banque centrale, à créer de la monnaie et de la distribuer directement aux citoyens, à la manière d'un dividende citoyen. L'idée est devenue célèbre grâce à l'économiste américain Milton Friedman en 1969. À partir de 2012, certains économistes ont rebaptisé l'idée « quantitative easing pour le peuple ».

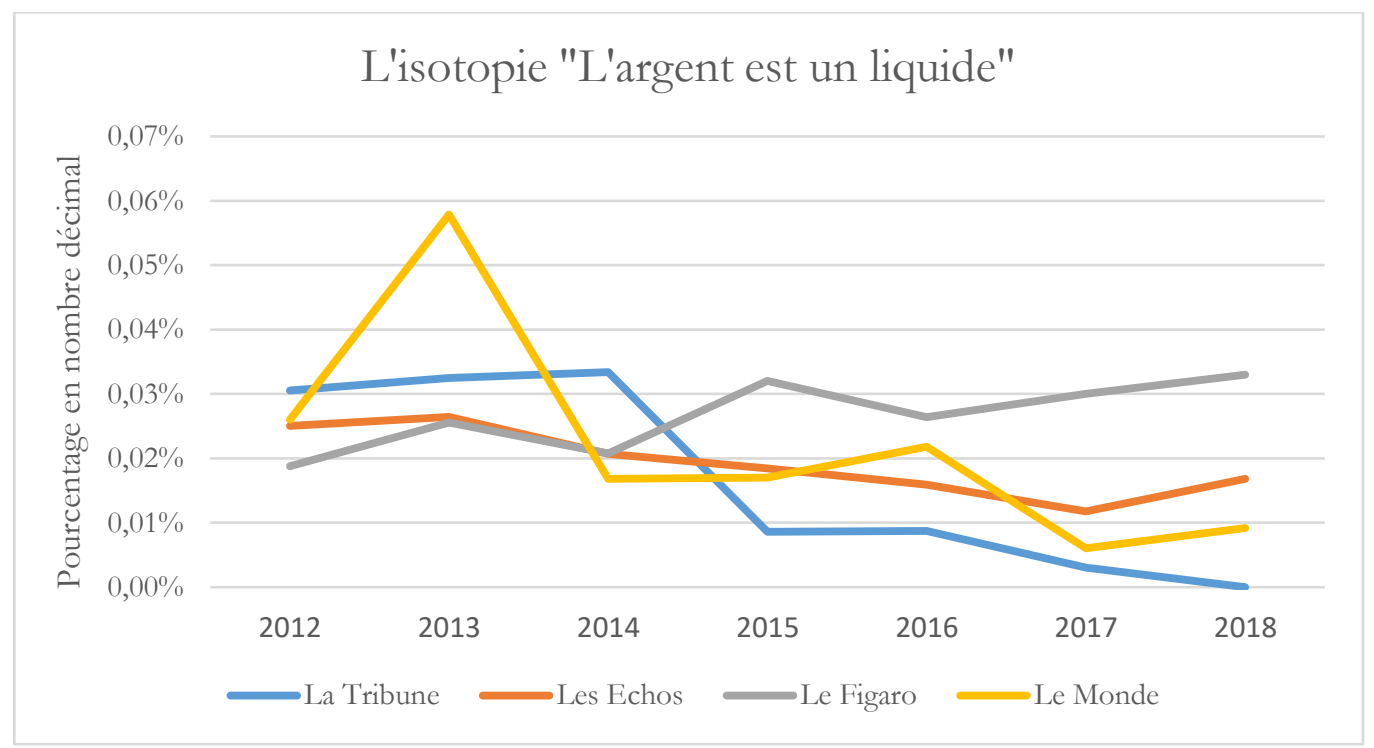

Fig. 1

\footnotetext{
${ }^{9}$ Le journaliste Lemasson constate que nombre d'économistes sont « incapables d'expliquer le "quantitative easing” autrement que par la formule convenue de "l'inondation des marchés en liquidités" » (2017).

${ }^{10}$ Cette isotopie réunit les occurrences des formules stéréotipées tout comme des verbes injecter et inonder (en particulier à l'infinitif, à la troisième personne du singulier et du pluriel de l'indicatif présent, au participe passé), des substantifs injection et inondation. Toutes les occurrences sont en référence aux liquidités dégagées par les mesures de QE.
} 


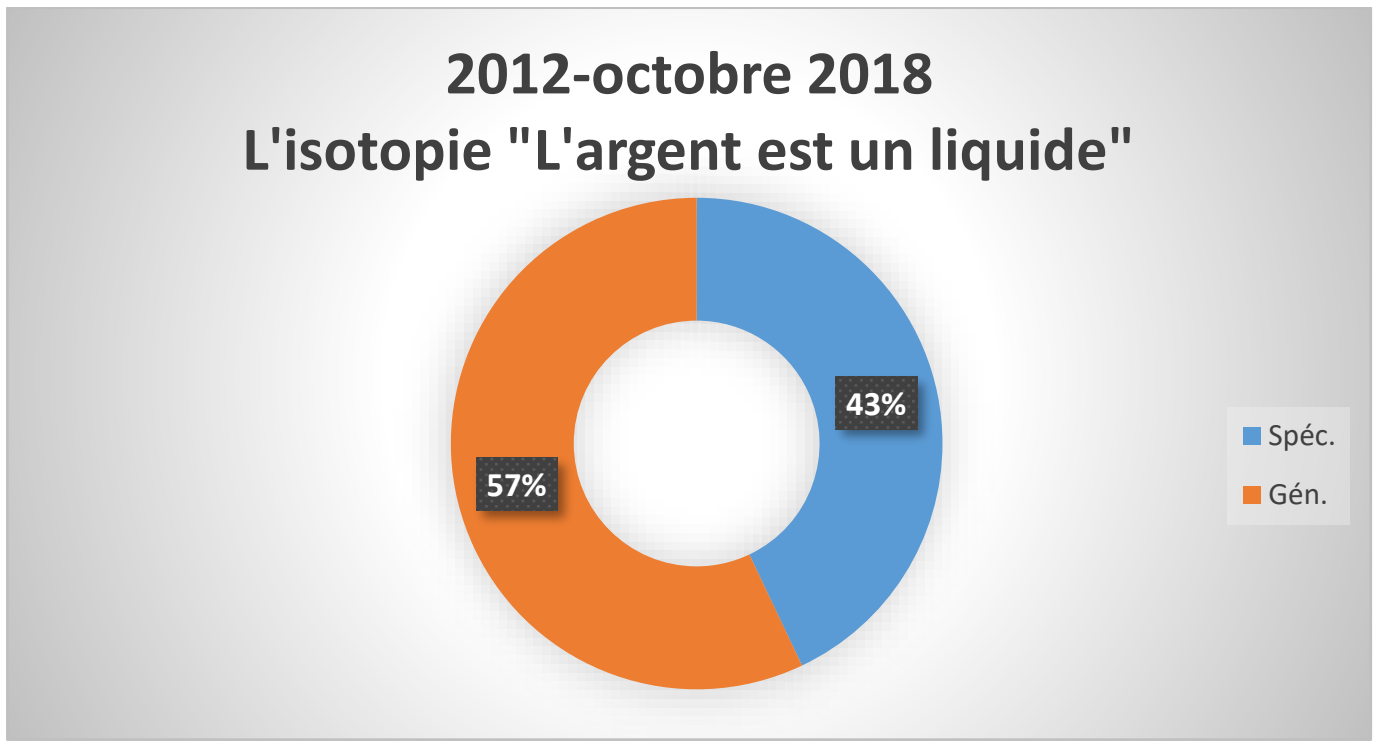

Fig. 2

Arme figurée et donc reconductible à l'isotopie ample «Le QE est une arme », que nous analyserons par la suite, la monnaie-hélicoptère, contrairement aux isotopies perçues comme des concepts partagés, a donc un énonciateur primaire en la personne de Milton Friedman. Nous précisons que le rapport entre bélicoptère et monnaie intervient en deux phases : 1) l'bélicoptère est métonymique en tant qu'instrument qui irrigue un liquide ; 2) Le liquide métaphorique est la monnaie. Pour rester bref, non parlons de métonymie pour l'bélicoptère et de métaphore pour la monnaie-hélicoptère. Plus périphériques et plus techniques par rapport à la métaphore centrale de l' arme non conventionnelle de Draghi, la métonymie de l'hélicoptère et, en particulier, la métaphore de la monnaie-hélicoptère deviennent représentatives d'une théorie économique qui prévoit un financement aux ménages, sans l'entremise des banques. Nous avons choisi d'analyser uniquement les fréquences de la métonymie « condensée » de l'hélicoptère (Cf. Figures 3 et 4) car de loin plus fréquente par rapport à la métaphore « explicite » de la monnaie-hélicoptère.

La Fig. 3 montre que le pic des fréquences de la métonymie de l'hélicoptère pour Le Monde et Les Echos est atteint en 2016, Le Figaro affichant une fréquence presque nulle sur toute la période considérée. La Tribune, par contre, présente la fréquence la plus haute en 2013. L'analyse des contextes montre que l'année 2016 marque à la fois le début, suite à l'ouverture de crédit de la part de Draghi, et la fin du débat sur cette mesure extrême. Or, il est intéressant de constater que $L a$ Tribune anticipe en 2013 le recours à cette métonymie, lors du lancement de la part de la BCE du programme OMT (opérations monétaires sur titres). Après avoir déclaré, en juillet 2012, qu'il aurait fait tout ce qu'il faut ("Whatever it takes ») pour sauver l'euro, Draghi lance une mesure de rachat d'obligations qui est partiellement assimilable à celle qui constitue l'objet de cet article. L'analyse des contextes montre également que l'opposition de la part de l'Allemagne à cette mesure de politique monétaire commence à pointer en filigrane. La presse spécialisée (Fig. 4) affiche pour cette métonymie issue du domaine financier et plus opaque par rapport aux autres isotopies, une fréquence significativement plus élevée par rapport à la presse généraliste. 


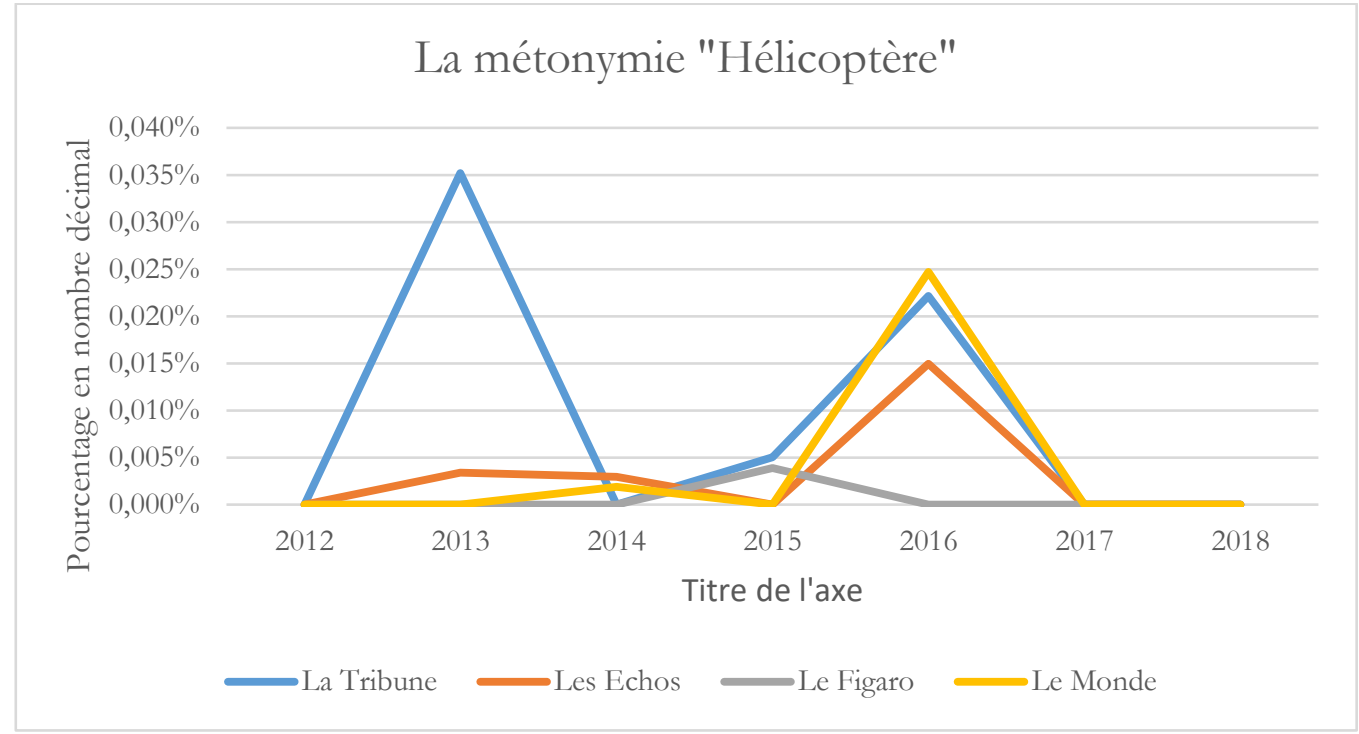

Fig. 3

\section{2-octobre 2018 La métonymie "Hélicoptère"}

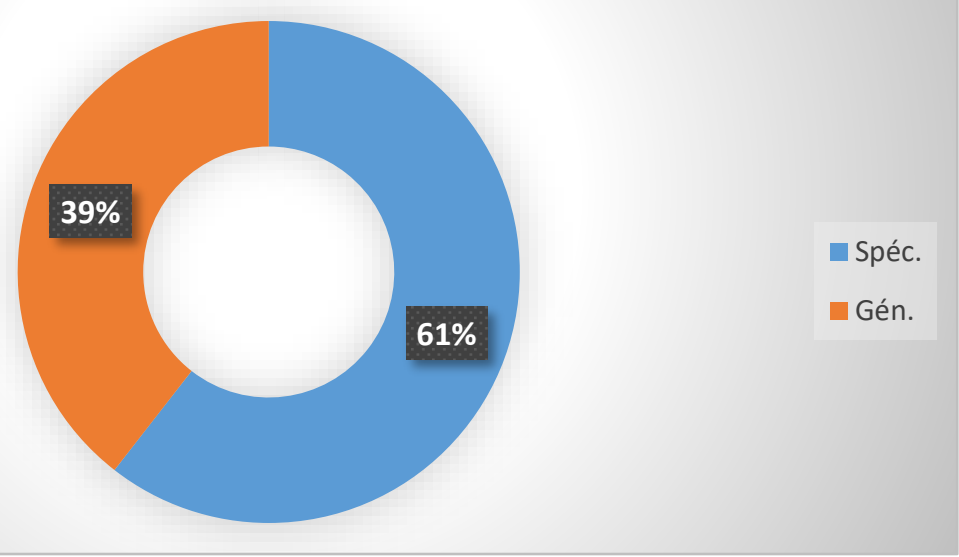

Fig.4

Penchons-nous maintenant sur «Le QE est une arme », une isotopie possédant une position heuristique forte et qui appartient au scénario plus vaste de la métaphore structurale de la " guerre » qui classe l'activité financière et ses leviers comme des armes. Étiquetés comme «non conventionnels » par Trichet et Draghi, les rachats de titres de la part de la BCE produisent, par analogie, la métaphore de l'arme, une métaphore par projection où tous les jugements de valeur sur l'arme sont projetés sur la mesure du QE alimentant une constellation d'expressions de forme différente. Or, l'essaim métaphorique se produit au moment où ces projections agissent en réseau : à côté de la phraséologie guerrière (la BCE « dégaine l'arme nucléaire », "fourbit ses armes » ou "active son arme ») coexistent en effet les constructions $\mathrm{N} 1+$ de $+\mathrm{N} 2$ (arme de réserve, arme des liquidités, les constructions $\mathrm{N}+$ adj. : le QE est alors arme suprême, arme budgétaire, arme monétaire, arme nucléaire, arme destructrice, arme blanche et leurs variantes, comme par exemple arme de la monétisation ou les armes de destruction massive. Or, à côté des armes non conventionnelles comme arme nucléaire, en 
parfaite adéquation avec le caractère non conventionnel des mesures de Draghi, coexistent des armes conventionnelles «classiques", telles que arme blanche ou bazooka. Ces phores, qui focalisent respectivement la puissance tranchante, voire perforante, et la puissance de destruction, présentent un caractère inédit et donc, à notre avis, plus inventif. Nous ajoutons enfin la métaphore du parefeu, laquelle, en vertu de son caractère " passif », fait toujours partie de l'essaim métaphorique généré par l'isotopie de l'arme mais avec une structure actancielle renversée.

L'isotopie de l' "arme », à son tour, génère un essaim métaphorique rattaché à une palette de types d'armes. Dans l'article de Godin (2014), par exemple, "[1]'arme blanche » est « la baisse des taux de 15 points de base », "[]'arme de poing : réduire les réserves obligatoires », " []e canon de $75 »$ : la fin de la stérilisation des achats de titres », « [1]'artillerie lourde : un nouveau LTRO ${ }^{11}$ », « [1]a "Grosse Bertha" : un taux de dépôt négatif » et pour terminer " []'arme nucléaire : un Quantitative Easing à l'européenne » que Godin définit à travers la métonymie de la "planche à billets », un rachat de titres «à l'image de ce que la FED a fait» et que nous étudierons par la suite. Comme on peut le remarquer, la "qualité argumentative» de ces métaphores se caractérise par "une argumentation rapide et efficace, parfaitement adaptée à certains genres, qu'ils soient polémiques, médiatiques ou doxologiques» (Bonhomme et al., 2017 : 8). La "logique emphatique » qui caractérise les différents comparants a pour objectif non pas « de susciter une conviction raisonnée, mais seulement de provoquer une adhésion de circonstance au message transmis » (ibid.). "À la différence de la métonymie » écrit Bonhomme, «la métaphore constitue une zone de suractivation de l'encyclopédie ou une figure d'expansion catégorielle propre à enrichir indéfiniment le discours, même si elle se sclérose parfois dans des formations stéréotypées [...]» (2005:126). Si arme blanche est un hapax qui ne figure que dans le sous-corpus La Tribune, au contraire, les métaphores de l'artillerie lourde et du bazooka monétaire sont répandues dans tous les sous-corpus considérés. Comme le montre la Fig. $6^{12}$, c'est la presse généraliste qui affiche la fréquence la plus haute sur la période considérée (2012-octobre 2018), avec un pic en 2016 pour Le Figaro (Fig. 5), ce qui prouve que la qualité argumentative de cette isotopie se révèle plus adaptée aux contextes moins spécialisés, plus médiatiques et plus polémiques.

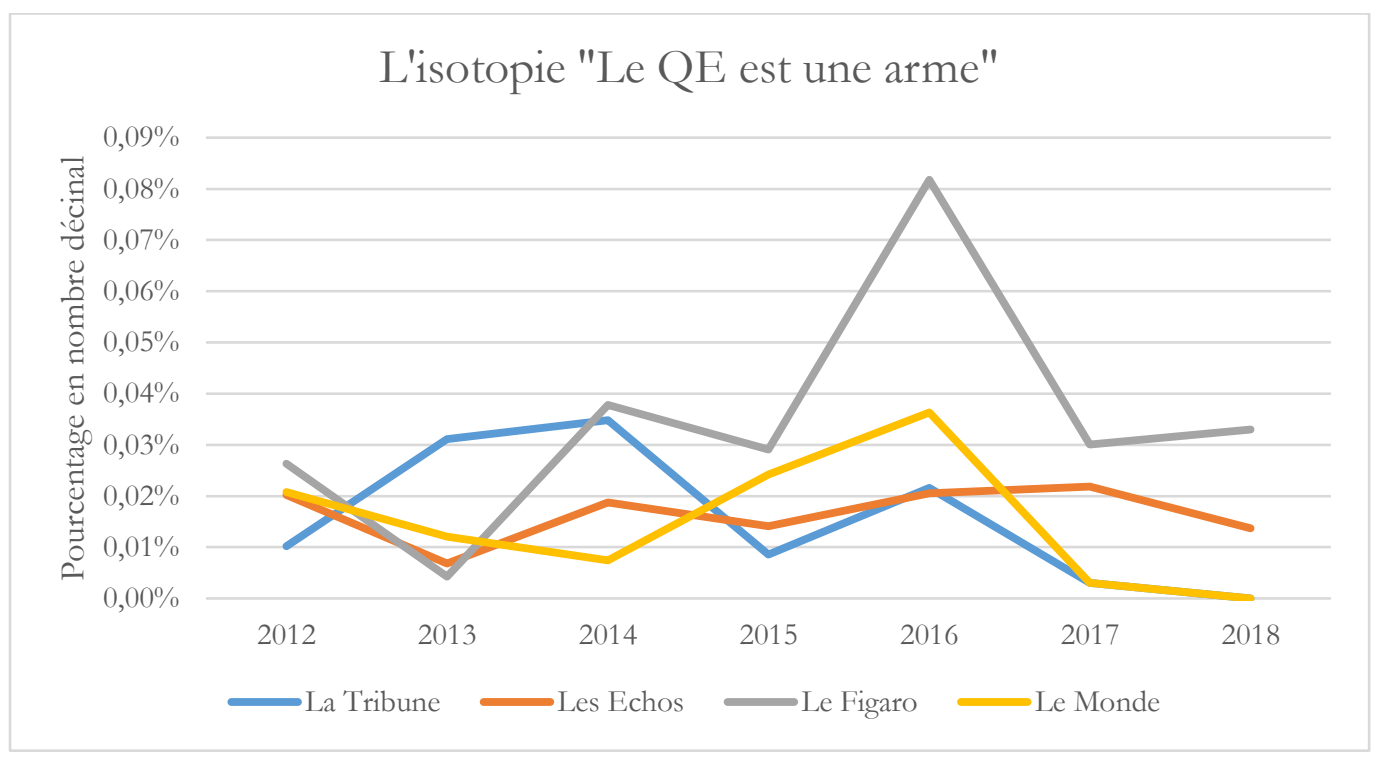

Fig. 5

\footnotetext{
11 «Long Term Refinancing Operation » (« opérations de financement à long terme »).

${ }^{12}$ Les figures 5 et 6 comptabilisent les occurrences de tous les types d'armes (par ex. bazooka, Grosse Bertha, arme blanche, artillerie, pare-feu, etc.), que le mot arme soit présent ou non.
} 


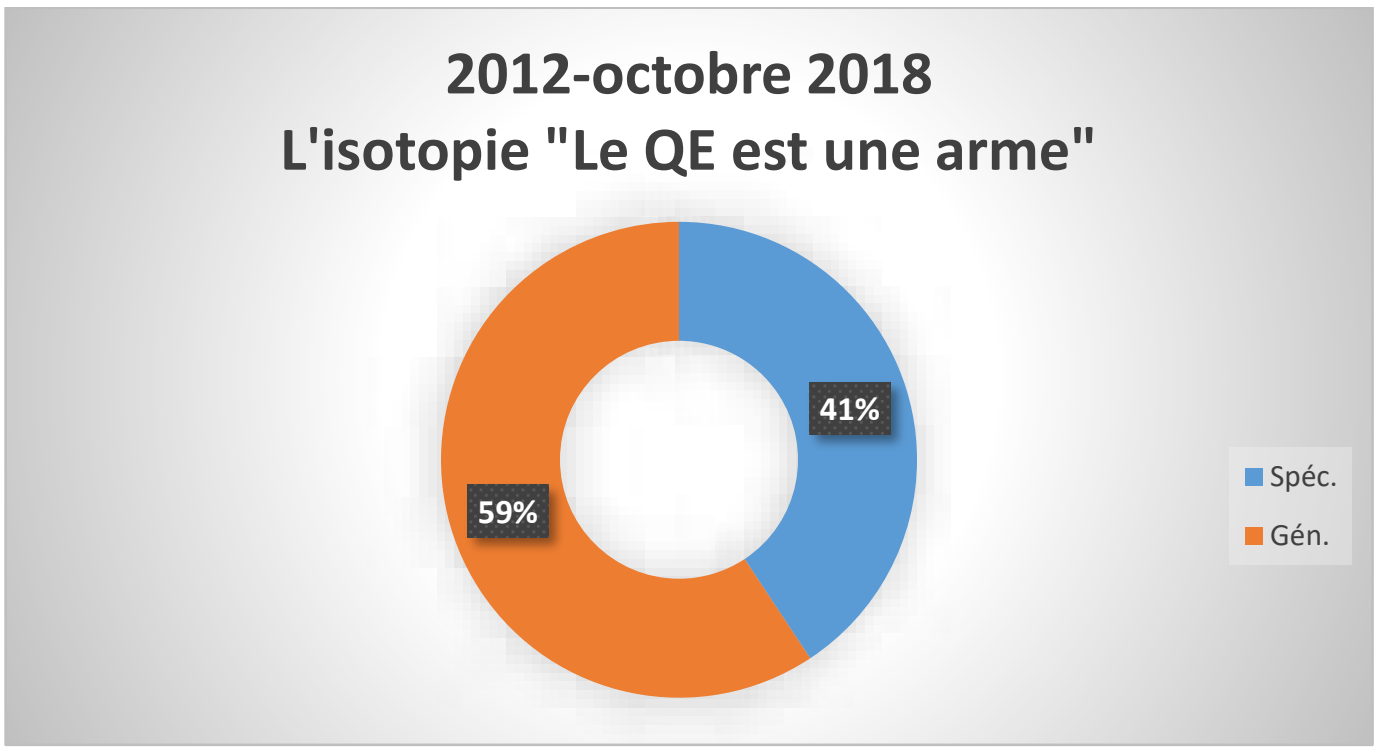

Fig. 6

Intéressons-nous enfin à la charge idéologique de la métonymie référentielle de la planche à billets. Cette figure, qui plonge ses racines dans l'histoire et dans la littérature, oriente, par sa charge prosodique négative, la perception du QE. Privilégiant l'instrument prototypique qui sert pour battre la monnaie, elle a non seulement une dimension linguistico-sémantique mais aussi une dimension conceptuelle qui fournit une vision simplifiée, voire simpliste, du fonctionnement du QE et dont le sens est reconductible à celui de l'«argent facile» ou de la "solution de facilité ». Comme le documente le Trésor de la langue française, la locution verbale «faire tourner la planche à billets » a une connotation péjorative, notamment dans la théorie économique où elle indique « [é]mettre du papier-monnaie de manière excessive et pouvant provoquer une inflation $[. ..] »^{13}$.

Or, la BCE, de par ses statuts et contrairement à la FED, ne peut pas fabriquer de la monnaie ex-nibilo, (rappelons également que la création de monnaie se fait par voie électronique), ce qui signifie qu'elle ne peut pas financer directement la politique économique d'un pays de l'Union et se doit de rester indépendante ${ }^{14}$. Les locutions « faire tourner la planche à billets » et « battre de la monnaie » en référence à une Banque centrale signifient que cette dernière achète directement à un pays les titres de sa dette : dans ce cas le pays concerné vend ses titres à la banque centrale et reçoit de l'argent frais à injecter dans son économie. Draghi évite d'utiliser cette expression qui ne correspondrait pas à l'essence de sa politique : rachat de titres sur le marché secondaire, sans financement direct des pays émetteurs ${ }^{15}$.

La Fig. 7 montre que la métonymie de la planche à billets, offrant une vision simplifiée, voire simpliste, du fonctionnement du programme de Draghi, est plus fréquente dans Le Figaro qui affiche une fréquence plus élevée sur toute la période considérée par rapport aux autres journaux et un rebond de fréquence entre 2017 et 2018, toutefois concentré en un nombre réduit d'articles. La Fig. 8 confirme que cette métonymie est nettement plus fréquente dans la presse généraliste par rapport à la presse spécialisée.

\footnotetext{
${ }^{13} \mathrm{http}: / /$ stella.atilf.fr/Dendien/scripts/tlfiv5/visusel.exe?11;s=250739715;r=1;nat=;sol=0.

${ }^{14}$ Voir à ce propos Dell'Olio (2015).

${ }^{15} \mathrm{La} \mathrm{BCE}$ et la FED se différencient également en raison de leurs statuts : si la mission principale de la BCE est la stabilité des prix et la sauvegarde de l'euro, celle de la FED vise un taux d'emploi maximum, suivi par la stabilité des prix. Or, la véritable ligne de démarcation est l'ancrage des mesures non conventionnelles de la FED à la situation du marché du travail, donc à un indicateur économique, tandis que les rachats de titres de la BCE dépendent plutôt de variables d'ordre politique. Voir à ce propos l'article Bce e Fed: differenze di obiettivi a cavallo, dell'Atlantico disponible sur le site de Borsa italiana.
} 


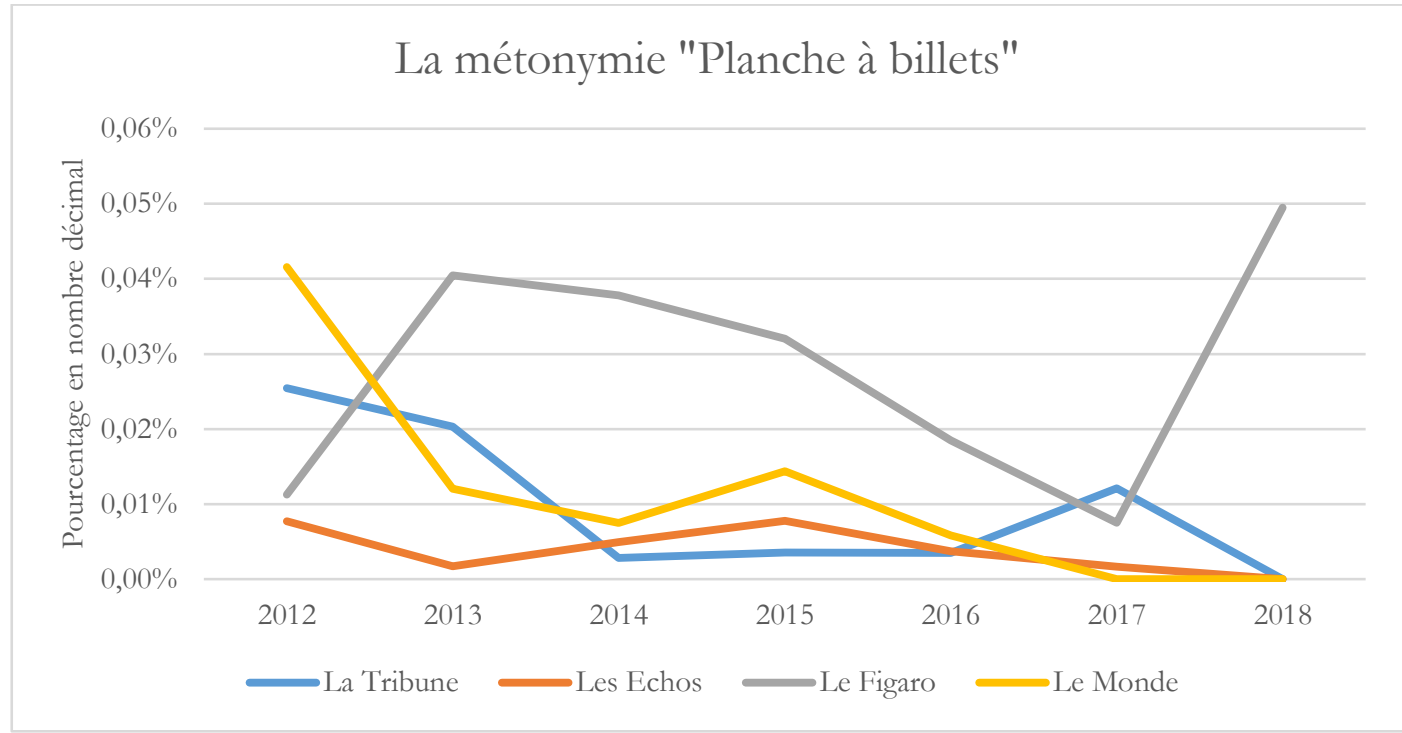

Fig. 7

\section{2-octobre 2018 La métonymie "Planche à billets"}

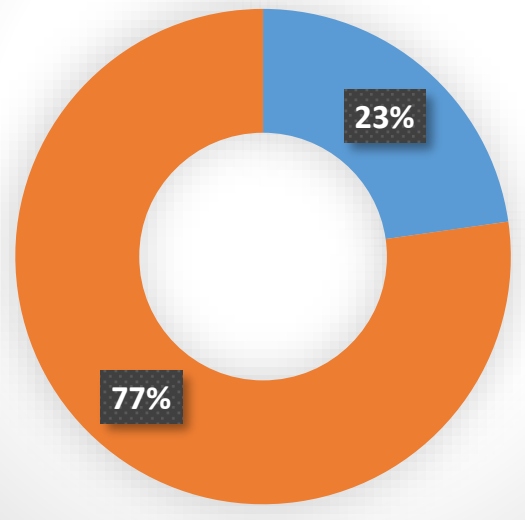

Spéc.

Gén.

Fig. 8

Penchons-nous maintenant sur l'orientation, positive ou négative, des isotopies que nous venons d'analyser. D'après l'exploration de l'entourage textuel des énoncés métaphoriques, l'orientation de l'isotopie "L'argent est un liquide », et en particulier des terminologies lexicalisées qui sont très fréquentes dans nos sous-corpus, varie en fonction de l'utilisation en contexte du substantif injection ou du substantif inondation, tout comme des infinitifs respectifs. Alors que la tête de syntagme injection (come dans le cas de injection de liquidités) définit en quoi consiste le QE et, en fonction du modificateur, peut focaliser les conséquences ou les bienfaits de cette mesure, le substantif inondation (come dans le cas de inondation de liquidités) est connoté négativement et fait état d'une dimension polémique qui finit par amplifier des contextes déjà négatifs.

Quant à l'orientation de l'isotopie de l'arme, elle est essentiellement positive. Elle focalise la force et l'impact possible des mesures de Draghi, sauf dans les cas isolés où, dans l'argumentation, 
le QE est assimilé à une arme «qui fait long feu » ou « émoussée ». De même pour la métaphore de l'bélicoptère, une arme possible pour la BCE, que Draghi juge positivement.

Le cas de figure de la métonymie de la planche à billets mérite de s'y attarder. La métonymie est une figure qui, entre autres, remplace un concept par un autre en substituant la cause à l'effet. À cet égard, planche à billets active un transfert métonymique où le mécanisme de fabrication du papier monnaie est utilisé pour indiquer le procédé, à savoir la fabrication de papier-monnaie : la planche n'est pas de la « monnaie » mais elle sert pour « battre de la monnaie ». Ce qui confirme la définition d'«interprétation métonymique» fournie par Bonhomme : «[...] évaluation d'une refonctionnalisation discursive affectant un univers cognitif, sans que cette refonctionnalisation n'outrepasse les limites isotopiques de ce dernier» (2005 : 121). En effet, planche à billets ne sort pas du champ notionnel de la création de monnaie ou de l'injection de liquidités, à laquelle le QE est assimilé. Or, il est intéressant de remarquer que cette métonymie assume un caractère métaphorique lorsqu'on apprend que la BCE, de par ses statuts, ne peut pas « battre de la monnaie ». Assimiler le QE à une planche à billets signifie établir une similitude orientée négativement, où le QE est le «cadre » et le fait de battre de la monnaie, le "foyer». Cette similitude fédère tous ceux qui assimilent le QE à une planche à billets que les États européens feraient tourner pour soulager leurs économies «à l'image de ce que la Fed a fait et qu'elle est en train de ralentir » (Godin 2014). Du point de vue conceptuel, cela revient à dire que la BCE est en train d'utiliser une arme « illégitime ». L'image de la planche à billets a donc une valeur argumentative fortement péjorative, assimilable à une métaphore proportionnelle très fortement évocatoire, dont l'objectif est le transfert aux mesures de Draghi du jugement négatif porté sur le QE américain. L'objectif de l'argumentation métonymique du type «tout ce qui vaut pour les uns vaut pour les autres » (Plantin 1996 : 58) appliqué à planche à billets est finalement celui de bâtir un positionnement fort en opposition au crédo de Draghi.

La bataille des mots que se livrent les partisans de la politique de Draghi et ses détracteurs laisse entrevoir les profondes dissensions quant au recours à l'outil du « QE à l'européenne » et à son efficacité :

\footnotetext{
En faisant tourner la planche à billets, la BCE sème-t-elle vraiment les graines de la prochaine crise financière, comme l'assurent ses détracteurs ? Ou bien les effets positifs de son arme de relance monétaire massive, parfois surnommée "bazooka", l'emporteront-ils ?. Reponse : En vérité, personne n'est capable d'y répondre, car jamais les banques centrales ne sont allées aussi loin dans les politiques monétaires non conventionnelles (Charrel 2015).
}

De même, sur fond de cette lutte, s'érige le conflit larvé entre la politique allemande et la BCE. Le Gouvernement allemand craint que le lancement du QE n'ouvre la porte à la mutualisation des dettes et à la socialisation des risques : « outre-Rhin » nous dit Robin «tout ce qui s'assimile à une mutualisation des dettes publiques en Europe est voué aux gémonies » (2017) et le programme de la BCE est perçu «comme une défaite de la "culture de stabilité" allemande » (Godin 2015). La $\mathrm{BCE}$, pour sa part, craint que cette mesure puisse pousser les pays européens à ne pas poursuivre leurs politiques de consolidation fiscale. L'bélicoptère non plus ne fait pas l'unanimité. Wolfgang Schäuble, ministre allemand des Finances, le considère bel et bien « comme la ligne rouge à ne pas franchir » au vu du mandat de la BCE (Madelin 2016).

Pour finir, un doute semble traverser Janson (2015) : « [1]'expression de « planche à billets » est souvent utilisée pour caractériser la politique de QE ("quantitative easing") déployée par les banques centrales. Est-ce un abus de langage ?» Et encore «La politique de QE serait-elle une interprétation moderne de la planche à billets ? ». Et l'auteure de conclure : «La seule différence entre la bonne vieille planche à billets et le $\mathrm{QE}$ aujourd'hui tient à ce que les titres souverains sont achetés sur le marché secondaire et avec certaines limites!». Fiat. 


\section{Conclusion}

Nous avons présenté ici les résultats d'une première analyse basée sur l'exploration de quatre sous-corpus. Dans l'avenir, il serait souhaitable d'élargir la recherche à la presse francophone dans son ensemble ou aux corpus de troisième génération composées de textes récupérés automatiquement sur Internet. QE est un exemple prototypique de néologisme d'emprunt opaque, dont le concept et le fonctionnement appellent une cohorte de lexies métasémiques (métaphores et métonymies). Le repérage des figures statistiquement plus significatives a permis d'apprécier la distance entre le discours officiel de Draghi et le discours divulgué par la presse généraliste et spécialisée. Le fait que la presse se focalise sur une facette déterminée du prisme conceptuel de QE, le pliant à ses exigences de divulgation, induit des mystifications qui se cristallisent autour de véritables saillies métonymiques, comme dans le cas de l'assimilation du QE à l'européenne à la planche à billets. Celle-ci, comme l'isotopie de l'arme, est à même de modéliser et orienter des visions fédératrices. Du point de vue statistique, les deux isotopies, «Le QE est une arme » et «L'argent est un liquide », en raison de leur argumentation rapide et efficace, et la métonymie de la planche à billets, en raison de sa vision simpliste du QE, sont plus fréquentes dans la presse généraliste par rapport à la presse spécialisée. La métaphore de l'bélicoptère, par contre, étant perçue comme plus « technique », est plus fréquente dans la presse spécialisée par rapport à la presse généraliste.

Sur fond de cette guerre de métaphores médiatiques, deux camps semblent enfin se dessiner, reflet des divisions qui déchirent l'Europe : celui des partisans de la force de la politique de la BCE et celui de ses détracteurs, parmi lesquels se détache la Banque centrale allemande contraire à la politique d'expansion monétaire mise en place par Draghi.

\section{Bibliographie}

BEST David Albert et Cosmai Domenico (2018), «"Naming things" and "changes in meaning" on the EU politico-legal landscape: Term Creation as an inherent feature of the European project." Altmanova Jana, Centrella, Maria, Russo, Katherine (éds.)Terminology \& discourse/Terminologie \& discours, Berne, Peter Lang, p. 153-177.

BANG NiElSEN Catrine (2017), «Usages argumentatifs de la métaphore er représentation des mouvements migratoires dans la presse francophone ». BONHOMME Marc, PAILLET AnneMarie et WAHL Philippe (éds.) Métaphore et argumentation, Louvain-la-Neuve, L'Harmattan, p. 355-371.

Bonhomme Marc, Paillet Anne-Marie et Wahl Philippe (2017), Métaphore et argumentation, Louvain-la-Neuve, L'Harmattan, coll. « Au cœur des textes ».

Bonhomme Marc (2005), Pragmatique des figures du discours, Paris, Honoré Champion Éditeur.

BOULANGER Pier-Pascale (2016), "Quand les médias traduisent la crise : les métaphores utilisées par la presse généraliste pendant la crise de subprimes », Meta : Journal des traducteurs, 61, Horssérie, p. 144-162.

GAUDIN François (2003), Socioterminologie. Bruxelles, De Boeck.

LAKOFF George et JOHNSON Mark (1980), Metaphors we live by, Chicago-London, The University of Chicago Press., Les Éditions de Minuit.

LAKOFF George et JOHNSON Mark (1985), Les métaphores dans la vie quotidienne (Traduction de Defornel Michel en collaboration avec Jean Jacques LeCERCLE, Paris, Les Éditions de Minuit.

LOUBIER Christiane (2003), Les emprunts : traitement en situation d'aménagement linguistique, Québec, Les publications du Québec, coll. «Langues et sociétés », 41.

MALDUSSI Danio (2019), «Aspects perlocutoires, discursifs et traductionnels dans la terminologie de la BCE. Un regard croisé franco-italien. Un regard croisé français-italien », BARBIN Franck, Monjean-Decaudin Sylvie (éds.) Aspects théoriques et pratiques de la traduction juridique et 
économique, Classiques Garnier, Paris, p.85-97.

OLIVEIRA Isabelle (2010), «La métaphore dans le processus de néologie terminologique en portugais », Studia Ubb. Philologia, LV, 4, [ En ligne] https: $/ /$ www.google.com/url? sa $=t \& r c t=j \& q=\& e s r c=$ s\&source $=$ web\&cd $=1 \& v e d=2 a h U K E$ wiPrIzT7djeAhWD14sKHQQAB6YQFjAAegQICRAC\&url=http $\% 3 \mathrm{~A} \% 2 \mathrm{~F} \% 2 \mathrm{Fwww}$.diacro nia.ro $\% 2$ Findexing $\% 2$ Fdetails $\% 2$ FA $15587 \% 2$ Fpdf\&usg $=$ AOvVaw0xPi-

YSVIRPV5iWcogS6O (consulté le 16 octobre 2018).

PLANTIN Christian (1996), L'argumentation, Paris, Seuil.

PRANDi Michele et MATTERA Marina (2012), " Métaphores verbales, projection, essaims métaphoriques : le monde comme être vivant dans les romans de Bosco », NEVEU Franck, Blumenthal Peter, Le Querler Nicole (éds.) Au commencement était le verbe Syntaxe, sémantique et cognition, Mélanges en l'honneur du Professeur Jacques François, Francfort, Peter Lang, p. 403-425.

Rossi Micaela (2017), «Sentiment terminologique et sentiment métaphorique dans la création néonymique », Neologica, 11, p. 153-170.

\section{SITOGRAPHIE}

Banque centrale européenne, La BCE annonce un programme étendu d'achats d'actifs, Communiqué de presse, https://www.ecb.europa.eu/press/pr/date/2015/html/pr150122 1.fr.html (consulté le 10 octobre 2018).

Borsa Italiana, Bce e Fed: differenze di obiettivi a cavallo dell'Atlantico, https://www.borsaitaliana.it/notizie/speciali/politicamonetariaevitareale/europa/bce-fedobiettivi-differenti/bce-fed-obiettivi-differenti.htm (consulté le 12 octobre 2018).

Business Insider, What is Quantitative Easing? http://www.businessinsider.com/what-isquantitative-easing-2010-8? IR $=\mathrm{T}$.

Trésor de la Langue Française informatisé, http://atilf.atilf.fr/ (consulté le 16 octobre 2018).

Wikipedia : $\quad$ Hélicoptère monétaire https://fr.wikipedia.org/wiki/H\%C3\%A9licopt $\% \mathrm{C} 3 \% \mathrm{~A} 8 \mathrm{re}$ mon $\% \mathrm{C} 3 \% \mathrm{~A} 9$ taire (consulté le 16 octobre 2018$)$.

\section{ARTICLES DE PRESSE CONSULTÉS}

CHARREL Marie, «Le jour où la BCE fera pleuvoir les billets sur les ménages » Le Monde, 18 mars 2016.

Dell’Olio Luigi, Bce, Mario Draghi prepara le misure non convenzionali. Otto cose da sapere sul bazooka, l'arma contro la deflazione, https://www.huffingtonpost.it/2015/01/19/bce-mario-draghi-ottocose-da-sapere-sul-qe n 6501404.html (consulté le 14 octobre 2018).

GODIN Romaric, «Zone euro : l'Allemagne perd-elle la main ?», La Tribune, 23 janvier 2015.

GODIN Romaric, « La BCE, combien de divisions ? », La Tribune, 6 Février 2014.

JANSON Nathalie, « Politique monétaire : en finir avec la planche à billets ». Les Echos, 23 avril 2015.

LEMASSON Alain, «Enseigner l'économie autrement », Les Echos, 21 juillet 2017.

MADELIN Thibaut, «Le ton monte entre Berlin et la Banque centrale européenne », Les Echos, 11 avril 2016.

RoBIN Jean-Pierre, «Le compte à rebours pour la succession de Mario Draghi à Francfort a déjà commencé », Le Figaro, 21 Juillet 2017.

RoBIN Jean-Pierre, "L'activisme de Draghi à la tête de la BCE, échec ou réussite ? », Le Figaro, 1 décembre 2015. 


\title{
Figement des composés néologiques du type $\mathbf{N}+\mathrm{Npr}$ et $\mathrm{Npr}+\mathbf{N}$ en français et en italien
}

\author{
Jana Altmanova - Rosa Piro \\ Université de Naples "L’Orientale”
}

Résumé : Notre contribution se situe dans le cadre de la néologie de composition par juxtaposition. Nous nous occuperons de plus près des innovations créées sur le patron combinatoire $\mathrm{N}+\mathrm{Npr}$ en français et en italien afin de comparer les constructions néologiques dans les deux langues romanes et leurs paradigmes comportementaux face à ce type de formant. Après avoir éclairé les spécificités d'ordre théorique et métalinguistique quant au traitement de ce type de composés, nous nous concentrerons sur l'analyse de cas d'étude parmi les plus fréquents dans les deux langues en tenant compte des facteurs motivationnels, étymologiques (l'influence de l'anglais y est évidente) ainsi que des contraintes linguistiques propres à chacune des deux langues.

Mots-clés : composés nominaux, apposition, néologie, juxtaposition, néologie combinatoire.

\begin{abstract}
Our contribution is within the framework of compound neologisms formed through juxtaposition. We will take a closer look at lexical innovations created on the combinatorial pattern $\mathrm{N}+\mathrm{PrN}$ in French and Italian in order to compare the neological constructions in the two Romance languages and their behavioral paradigms with regards to this type of composition. After having clarified the theoretical and metalinguistic specificities regarding the treatment of this type of compound, we will focus on the analysis of some of the most frequent case studies in both languages, taking into account the motivational and etymological factors (the influence of English is obvious) as well as the linguistic constraints specific to each of the two languages.
\end{abstract}

Keywords: nominal compounds, apposition, neology, juxtaposition, combinatorial neology. 


\section{Introduction}

Les patrons combinatoires $\mathrm{N}+\mathrm{Npr}$ et $\mathrm{Npr}+\mathrm{N}$, productifs aussi bien dans la presse en français qu'en italien, appellent des réflexions lexicologiques spécifiques et participent dans une certaine mesure de la néologie de composition par juxtaposition (Cabré 2002, Sablayrolles 2003). Ce type d'analyse est assez problématique du point de vue théorique et cela principalement pour deux raisons : d'abord parce qu'un nom propre ne rentre a priori pas dans une réflexion lexicologique puisqu'il est considéré comme étant en dehors du lexique (Gary-Prieur 1991 ; Lehmann \& MartinBerthet 2008) ; ensuite, parce que les exemples que nous citons sont surtout des néologismes de dénomination encore en voie de figement (Kleiber 1984). Cependant, par sa capacité à enrichir le lexique d'une langue, la néologie dénominative (Petit 2006 ; Leroy 2003), mérite, nous semble-t-il, un approfondissement dans une perspective plus proprement lexicologique (Adamo \& Della Valle $2017)^{1}$. Le but de la présente réflexion est donc d'analyser des cas prototypiques de figement des composés $\mathrm{N}+\mathrm{Npr} / \mathrm{Npr}+\mathrm{N}$ et, en particulier, de ceux créées sous l'influence de la langue anglaise et tendant à s'amalgamer. Après avoir défini le contexte d'analyse et la perspective adoptée dans le vaste champ d'études amalgamatives (Renner 2015), nous nous concentrerons sur l'analyse de quelques cas de figures prototypiques nous limitant au patron énoncé afin d'esquisser leur fonctionnement.

\section{Méthode et constitution du corpus}

Le corpus de départ a été constitué à partir de la liste de néologismes en langue italienne répertoriés dans la section «Neologismi » du Dizionario Treccani ${ }^{2}$ et issus des quotidiens italiens. C'est à partir de cette liste de néologismes, dont nous n'avons retenu que les composés N+Npr et $\mathrm{Npr}+\mathrm{N}$, que nous avons recherché les équivalents morpho-sémantiques en langue française dans le corpus journalistique français par le biais de la plateforme Néoveille ${ }^{3}$ (Cartier 2016), afin d'analyser leurs équivalents de forme et de sens. Pour examiner les tendances générales de figement de cette catégorie lexicale, nous avons pris en compte tous les exemples répertoriés dans la section de néologismes dont les premières occurrences remontent jusqu'en 2005 (67 items). Nous avons ensuite repéré l'environnement lexical correspondant pour mieux circonscrire la lexie. Notre but ici n'est pas de quantifier ce phénomène - ce qui serait également intéressant - mais plutôt d'analyser des cas prototypiques pour observer le fonctionnement des noms propres en discours dans des contraintes syntaxiques précises.

Étant donné que la plupart des compositions concernent le domaine politique, nous avons limité notre analyse à ce domaine. Dans la plupart des cas, les constructions $\mathrm{N}+\mathrm{Npr}$ n'ont pas, ou pas encore, été lexicalisées ; elles figurent donc soit comme candidats aux néologismes soit comme structures syntaxique prototypiques qui donnent lieu à la création de matrices lexicales.

\section{Compositions $\mathbf{N}+\mathbf{N p r}$}

La première considération tient au rapport hiérarchique entre les composants du syntagme qui est déterminant pour notre réflexion. Si les composés binominaux $\mathrm{N}_{1}+\mathrm{N}_{2}$ (Arnaud 2018) peuvent être aussi bien sous-catégoriels (bateau phare) qu'adjectivaux (magasin phare), dans les composés $\mathrm{N}+\mathrm{Npr}$, le Npr est le plus souvent adjectivé, c'est-à-dire une épithète (capitalismo Gucci, effet Compton). Cela veut dire que ces composés doivent être appréhendés différemment, parce que le Npr n'a pas le même statut que le nom constituant le lexème-source (Renner 2006 : 130, Léturgie 2012 : 86), au moins à l'origine de sa création. Les enjeux interprétatifs sont donc complexes et c'est sur ce

\footnotetext{
${ }^{1}$ BALNAT Vincent et GÉRARD Christophe (éds.) (2018), « Néologie et noms propres », Cabiers de lexicologie, vol. 2, numéro 113 , Paris, Classiques Garnier.

2 Dirionario Treccani, section «Neologismi »: http://www.treccani.it/magazine/lingua_italiana/neologismi/.

${ }^{3}$ https://lipn.univ-paris13.fr/neoveille/html/login.php?action=login.
} 
point-là en particulier que nous développerons notre réflexion. Nous présenterons ici les cas relevés selon l'ordre de leur prévisibilité interprétative, tout en montrant des évolutions sémantiques collatérales que l'analyse des exemples nous permettra de nuancer. Nous sommes donc face à des innovations discursives qui, dans certains cas, aboutissent au figement (Mejri 2005).

\section{1. $\mathbf{N}+\mathbf{N p r}$ : de la fonction référentielle à l'épithète voire l'antonomase}

Le premier cas que nous présentons ici est constitué par une combinatoire de noms dont le sens référentiel est tout à fait transparent, puisque le complément déterminatif, constitué par un nom propre et figurant en seconde position du composé binaire, spécifie le nom. Dans les locutions concernant les lois notamment, le Npr peut avoir une valeur d'appellation, ce qui nous donne des indications sur le fonctionnement en discours de ce type de combinatoire. Par exemple, dans le cas de legge Fornero (2011) pour l'italien ou de loi Macron (2015) pour le contexte français, le patronyme de l'auteur fait partie de la dénomination de la loi elle-même. Ajoutons à ce constat que les appellations institutionnelles ne correspondent presque jamais aux reformulations que l'on trouve dans la presse. La dénomination exacte de la loi Fornero est « Les disposition relatives au marché du travail dans une perspective de croissance », alors que la loi Macron titre «La loi pour la croissance, l'activité et l'égalité des chances économiques ». Les dénominations abrégées représentent donc déjà des formes condensées auxquelles les locuteurs ont recours dans le discours et qui sont censées produire des significations supplémentaires et connotées (dans la plupart des cas négatives), pouvant contribuer au figement du syntagme. Le figement d'une suite d'unités sans aucune marque particulière est ici entendu dans son acception la plus large possible en tant que première étape d'une lexicalisation potentielle. Voici quelques résultats :

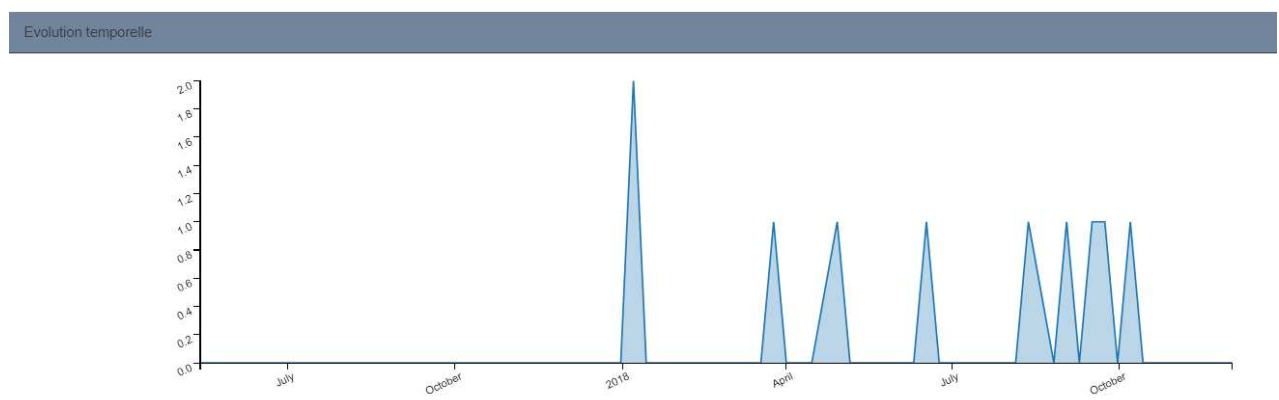

Figure 1. Fréquence de la dénomination legge Fornero dans La Repubblica en 2018 (Néoveille).

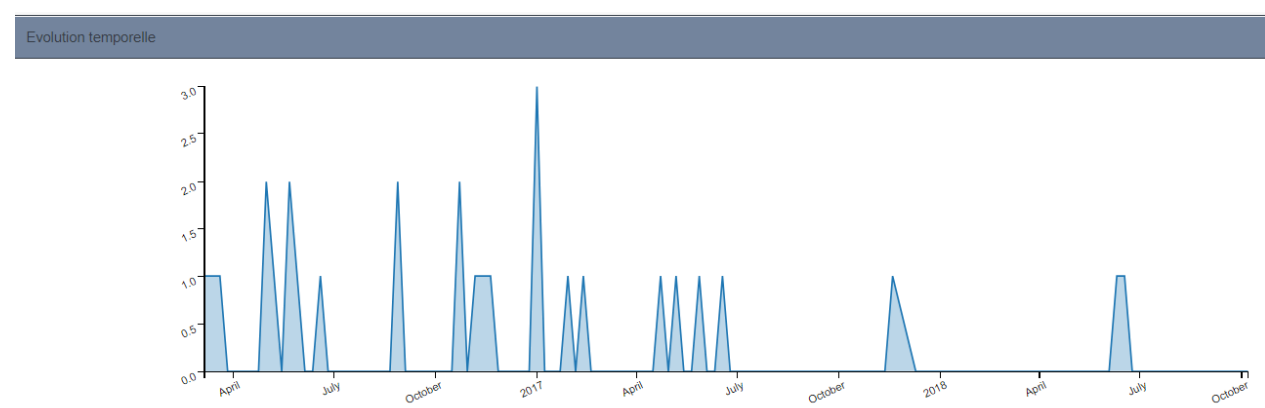

Figure 2. Fréquence de la dénomination loi Macron dans Le Monde entre avril 2017 et octobre 2018 (Néoveille).

Or, étant donné qu'à l'intérieur du syntagme le nom propre est hiérarchiquement subordonné - il y a en effet la fonction de déterminatif voire d'épithète - l'autonomisation sémantique ne concerne qu'un seul composant du syntagme, c'est-à-dire le Npr. Celle-ci contribue à la création d'un paradigme lexical polyfonctionnel et productif, en particulier dans les discours politique et administratif, donnant lieu à de nombreux composés libres tels que : ordonnances Marcon, riforma 
Fornero, pensioni Fornero ${ }^{4}$. En d'autres termes, l'interprétation relationnelle (Arnaud et Renner 2014) existant entre [loi] et [son auteur] et qui marque la "propriété » s'affaiblit dans certains syntagmes cités ci-dessus comme par exemple pensioni Fornero [pensions Fornero], où le rapport de propriété disparait (les pensions ne sont pas « de » Elsa Fornero). Ce rapport devient d'ordre analogique voire métonymique dans la mesure où les pensions Fornero partagent les principes de la loi Fornero dont le sème principal est d'être [réduites/basses]; de plus, pensioni Fornero désigne également des individus touchés par cette même réforme. La dernière étape du figement aboutit ainsi à l'antonomase du Npr: en italien, dans le cas de la Fornero qui indique aussi bien l'ex-ministre que sa loi ; en français avec l'antonomase issue du Npr Macron, le Macron, où le Npr désigne la langue du Président définie comme stylée et précieuse (de Thalès 2017).

\section{2. $\mathbf{N}+\mathbf{N p r}$ : le rôle du classifieur dans le processus de figement}

Dans ce type de constructions syntagmatiques, le rôle du classifieur nous semble déterminant - il s'agit d'une sorte d'indice - pour établir le degré de transparence désignative. Dans le cas de la syntagmatique de la dénomination propre, la construction du sens ainsi que la catégorisation du référent sont complexes. C'est ainsi que, selon Lecolle (2009), le syntagme la guerre d'Afghanistan, pour reprendre l'exemple cité également par Noailly (1991), ne désignerait pas que la guerre qui a eu lieu en Afghanistan, mais aurait aussi une connotation temporelle précise et se chargerait, dans le discours, de connotations multiples. Les classifieurs tels que guerre, génocide, crise, etc. suivis d'un $\mathrm{Npr}$ (généralement un toponyme - l'Afghanistan, le Rwanda, etc.) dont on peut dire qu'il a une valeur non seulement spatiale mais, le plus souvent, aussi temporelle voire socio-historique, etc. ${ }^{5}$, confèrent donc au syntagme un sens descriptif voir une fonction « résomptive » :

Ce glissement sémantico-référentiel, qui relève d'une forme spécifique de fixation, se manifeste notamment par l'installation dans la compétence discursive du « scénario » de l'évènement, et confère alors au toponyme une fonction résomptive » (Lecolle $2006: 36$ )

Bien que nous partagions l'idée de Lecolle concernant l'extension plus ou moins occasionnelle de la référence du syntagme en fonction du contexte, il est évident que ce type de syntagme dénominatif demeure lié dans la plupart des cas au référent initial et qu'il n'acquiert des effets de sens qu'en discours (Noailly 1991). Nous nous approchons ici également de la valeur de thème que Gary-Prieur, dans le sillage de Cadiot (1988), attribut au Npr, lorsqu'elle affirme : "plus qu'un référent, le Nom Propre fixe [...] le thème du discours, avec une signification beaucoup plus large que le simple prédicat de dénomination » (Gary-Prieur 1991).

Grâce aux exemples tirés du corpus, on a pu constater que pour établir la probabilité de lexicalisation d'un syntagme, la nature du classifieur est déterminante pour la constitution des significations qui se rattachent au sens référentiel de départ. Ainsi, la référence des syntagmes un/le syndrome Ben Ali, appelé aussi syndrome autoritaire, fait allusion à la politique autoritaire de Ben Ali en Tunisie. Cela nous semble être déterminé en grande partie par le fait que le mot support, syndrome, apparait dès le départ hors du contexte naturel d'usage, c'est-à-dire le contexte médical, auquel il a été empruntét. Le syntagme évoque ainsi dès sa diffusion des connotations, vaguement ironiques, souvent négatives ${ }^{7}$ et contribue à la création d'un milieu lexical potentiellement néologène.

\footnotetext{
${ }^{4}$ Par exemple, dans le cas de loi Fornero, il est question d'une loi dont l'auteur est représenté par l'anthroponyme indiqué dans le syntagme (prédicat dénominatif) -, alors que la locution s'opacifie en fonction du lexème-source qui le précède.

${ }^{5}$ Comme le souligne Lecolle, d'après Noailly, on ne peut pas parler de lexicalisation, « puisqu'on n'a pas affaire à la création d'une unité lexicale : le nom reste un $\mathrm{Npr}$, mais passe de manière stable du statut sémantique de nom de lieu à celui de nom d'événement » (Lecolle, $2006: 36$ ).

${ }^{6}$ Le principe de décontextualisation d'un mot est souvent à la base de la néologie sémantique, mais celle-ci peut être moins facile à déterminer (automatiquement surtout) dans le cas des noms propres.

${ }^{7}$ De façon semblable - bien que l'on puisse parler ici d'une véritable matrice lexicale - se comporte le patron affaire + Npr, (sous la base d'Affaire Dreyfus, etc.). Nous avons repéré des syntagmes tels que l'affaire Guérini, impliquant plusieurs hommes d'affaires dont Alexandre Guérini et son frère, mais désignant une affaire politico-financière française, déclenchée en 2009. À partir, des affaires les plus connues, ce formant s'est répandu aussi bien en français qu'en italien. Ces constructions incluent d'autres catégories de noms propres telles que, entre autres, noms des entreprises comme dans le cas d'affaire Fincantieri-Stx ou affaire Vivendi-Mediaset ou
} 


\section{3. $\mathbf{N}+\mathbf{N p r}$ : figement et défigement}

Un autre cas où le figement est plus évident peut être représenté par une expression datant de l'après-guerre mais qui s'actualise dans le discours journalistique, à savoir le plan Marshall, renvoyant originairement au projet du secrétaire d'État américain, George Marshall, qui a octroyé des prêts en 1947 pour la reconstruction d'une Europe détruite par la Seconde Guerre mondiale. Aujourd'hui, l'expression le plan Marshall (55 occurrences dans Google au 3 juillet 2018) calquée sur The Marshall Plan, conserve une forte actualité et a été réemployée dans de nouveaux contextes, comme par exemple en parlant de l'action en faveur des banlieues dans les années 1990 et 2000, ou pour évoquer les aides destinées à l'Afrique, l'agriculture, l'emploi, etc. Cette expression constitue en soi une locution figée, qui s'est donc détachée de sa signification purement référentielle, signifiant par extension, « un plan de grande ampleur pour faire face à une situation d'urgence économique et humanitaire ». Preuves en sont les occurrences du syntagme au pluriel telles que les plans Marshall, nombre de plan Marshall, d'autres plans Marshall, mais aussi l'expression énième plan Marshall. La locution est donc privée de l'unicité garantie par le nom propre et entreprend la voie de la lexicalisation (Sablayrolles 2003). Celle-ci semble avoir eu lieu, étant donné que l'on assiste déjà au défigement de cette même expression qui conduit à la création de syntagmes tels que le plan Merkel qui témoigne de la naissance d'un paradigme, là où c'est le classifieur, le mot plan en l'occurrence, qui devient la tête du syntagme. En d'autres termes, le Plan Merkel est «le Plan Marshall mis en place par Merkel ». Ce syntagme a été créé par les journalistes lorsque la chancelière allemande a profité de sa présidence du G20 pour recevoir dans sa capitale les dirigeants africains et les investisseurs mondiaux en envisageant des soutiens. Dans ce cas, le poids sémantique a été entièrement absorbé par le mot générique plan. C'est ainsi qu'un nouveau paradigme a été créé par plan $+\mathrm{Npr}$.

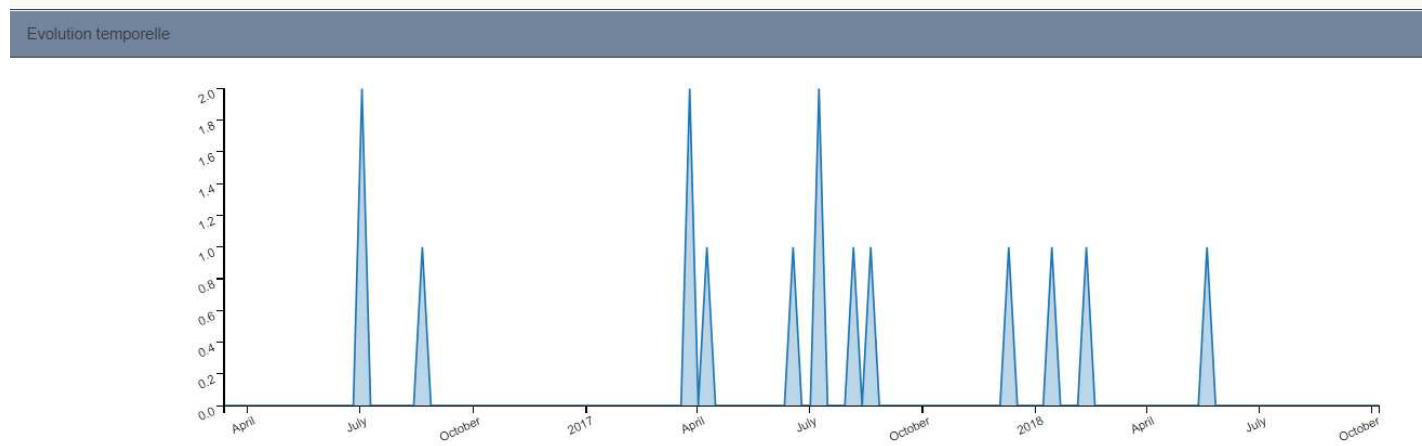

Figure 3. Fréquence de la dénomination le plan Marshall dans Le Monde entre avril 2017 et octobre 2018 (Néoveille).

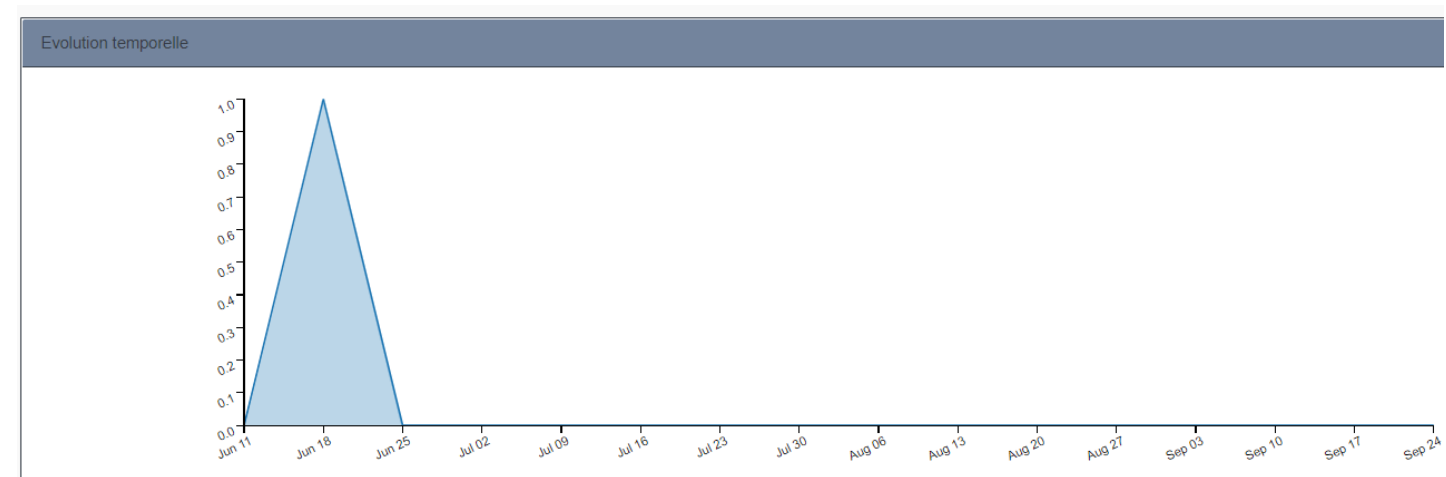

Figure 4. Fréquence de la dénomination le plan Merkel dans Le Monde en 2018 (Néoveille).

le composé de deux noms propres renvoie à une des relations entrepreneuriales franco-italiennes parmi les plus importantes. Dans ce cas-là, bien que sur le plan interprétatif, le rapport entre les deux composants soit relationnel et désignationnel, le second élément n’a pas toujours une valeur purement référentielle et le classifieur affaire est connoté négativement. 
Cependant, une tendance de lexicalisation opposée, c'est-à-dire de gauche vers la droite, se vérifie lorsque l'antonomase a lieu. C'est par exemple le cas de Président Téflon raccourci en Téflon. Président Téflon est une traduction de l'expression anglaise Teflon Président, qui renvoie d'abord à Ronald Reagan (1983) et plus récemment à l'ex-Président sud-africain, Jacob Zuma, surnommé ainsi pour sa capacité à résister aux nombreux scandales le visant (la métaphore du téflon, matériau résistant et qui fait glisser, est très claire) qui datent surtout de 2016. Le degré de figement varie d'une langue à l'autre : la langue italienne garde l'expression syntagmatique sans jamais arriver à l'antonomase, la préposition de dans Presidente di Teflon servant à mieux expliciter les rapports sémantiques entre les mots, alors que le français adopte une structure binaire sans préposition qui va jusqu'à l'antonomase. Si la plupart des occurrences de cette lexie datent de 2016, on les retrouve aussi plus récemment en référence au président Macron défini comme un Président Téflon, ce qui confirmerait la nature figée de la lexie dont le sens se transformerait de référentiel à catégoriel selon la définition de Leroy (Leroy 2009), en l'occurrence, celui d'un "président insensible aux scandales ».

\section{4. $\mathbf{N p r}+\mathbf{N}$ : compositions exogènes et évolution de la syntaxe}

Nous examinerons à part les compositions dérivant de l'anglais ou mixtes en les divisant suivant le critère étymologique. Sur le plan syntaxique, les exemples cités jusqu'ici apparaissent assez réguliers et gardent l'ordre progressif caractérisant les langues romanes : déterminé + déterminant. C'est le cas de plan Marshall calqué sur The Marshall Plan ou de Président Téflon calqué sur Teflon President par lesquels le locuteur (dans la plupart des cas les journalistes) privilégie la syntaxe française voire italienne. Cependant, l'influence de la langue anglaise pousse à modifier la syntaxe des deux langues romanes en privilégiant l'ordre déterminant + déterminé que ce soit dans le cas des emprunts, des allogénismes (Humbley 2016) ou des constructions hybrides.

En analysant les exemples relevés du corpus, on a pu constater que les bases productives issues de l'anglais existent aussi bien en français qu'en italien telles que, pour n'en citer que quelques-unes, -boy, -tax, -gate, -pride, -day, etc. En italien, par exemple, l'expression Salvini-tax est créée sur flat-tax, impôt proportionnel remplaçant des taux d'impôts marginaux multiples pour instaurer un taux unique, qui attribue au politicien Salvini, représentant de la droite et partisan de la flat-tax, une certaine visée politique. Cette matrice syntaxique $(\mathrm{Npr}+\mathrm{N})$ est de plus en plus productive, ce qui ne nous surprend pas davantage, étant donné que le nominale compounding est à la base d'un grand pourcentage de nouvelles formations en langue anglaise depuis 1750 (Ryder 1994: 4) et qu'elle constitue un modèle linguistique dans plusieurs domaines qui ont des influences inéluctables sur les deux langues romanes. Ces combinatoires sont non seulement fréquentes mais elles créent à leur tour des paradigmes, ce qui prouve leur acclimatation dans le lexique. C'est par exemple le cas des syntagmes composés en -boy dont le Npr est dans la plupart des cas le nom d'un politicien/une politicienne : Bondiboy, Crimi-boys, Ciampiboy/Ciampi boy, D'Alema boy, Fazioboy ou Gelmini-boy pour indiquer de manière ironique des partisans ou collaborateurs subordonnés du politicien :

Se i cardinali non risolveranno loro la crisi di governo nominando Berlusconi papa (con beatificazione immediata su richiesta dei Bondiboys), nei prossimi giorni si corre seriamente il rischio che la proclamazione del Pontefice coincida con l'annuncio della lista dei nuovi sottosegretari, La Stampa $16 / 04 / 2005$.

Una nota goliardica i "Ciampi boys" che invocano: "Carlo Azeglio santo subito", la Repubblica 26/04/2005.

Sul Frecciarossa con i Crimi-boys. A prima vista sembra un gruppo aziendale in vacanza premio, L'Espresso $13 / 06 / 2013$.

Oltre allo stesso D'Alema, i dalemiani più in vista sono i famosi D'Alema boys, il cui limite è di essere ancora molto potenti, ma nel centrodestra, L'Espresso 09/07/2009.

\footnotetext{
${ }^{8}$ En français, il existe aussi l'expression Président Tefal (ou Président Téfal) qui exploite la marque française Tefal spécialisée dans les articles culinaires anti-adhésifs.
} 
Fazioboy in Parlamento e in caduta libera, Il Venerdi di Repubblica 09/06/2006.

Il sorriso sui volti dei "Gelmini-boys", però si spegne man mano che da radio e televisione rimbalzano titoli di notiziari e reazioni politiche a raffica, La Stampa 04/08/2007.

En français, bien que le concept de -boy partisan voire fantoche (dans son acception négative) d'un politicien existe, des composés en -boy sont moins diffusés. Les expressions que nous avons repérées dans notre corpus correspondent aux formations telles que sarko-boy/sarkoboy, ou ex-sarko $b o y^{9}$; en dehors de la fenêtre temporelle et du corpus de référence quelques autres expressions peuvent être relevées, mais cette matrice lexicale ne semble pas particulièrement productive en français. Cependant, pour le mot sarkoboy, le graphique ci-dessous montre bien un pic de fréquence en 2018 qui est dû à des facteurs extralinguistiques largement décrits dans la presse, entre autres, à l'affaire de Benalla, chargé de mission de Macron, ou à celle liée à l'ancien ambassadeur de Tunis, Boris Boillon, auxquels on attribue la fonction de sarkoboy.

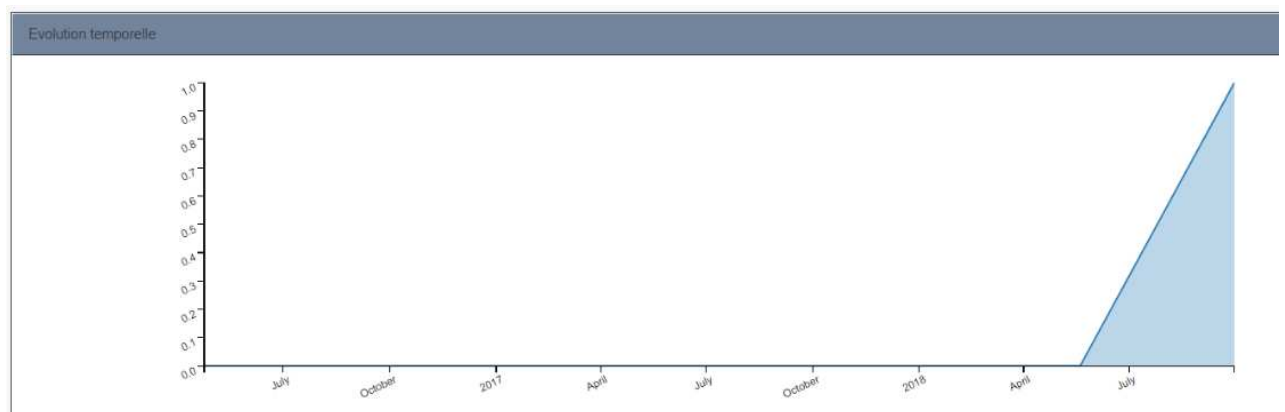

Figure 5. Fréquence de la dénomination sarkoboy dans Le Monde en 2018 (Néoveille)

De la même manière fonctionnent les mots pride et day qui se prêtent à de nombreux composés. Le mot pride, par exemple, apparaît dans notre corpus surtout en tant qu'emprunt autonome mais aussi à l'intérieur des mots composés dont le nombre est assez limité tels que Gaypride/Gay-pride, Europride, Interpride (nom d'une organisation) et Worldpride. En italien le mot pride est beaucoup plus productif qu'en français, notamment en combinaison avec des noms propres que ce soient des anthroponymes (Bondi-pride) ou des toponymes (Palermo Pride ou Milano Pride).

En plus de cette variété qui puise dans différents domaines de la vie sociale et politique, le nom propre qui précède pride a le pouvoir d'en localiser la référence si pride est employé dans son sens le plus fréquent de [fiertés] et, en particulier de [fiertés homosexuelles] (gay pride), comme dans le cas de Palermo Pride ou Milano Pride qui indiquent toutes les villes où a eu lieu une gay pride. Toutefois, cette référence peut aller bien au-delà du sens strictement référentiel comme dans Book Pride [l'orgueil de la lecture] ou dans Lazio Pride antimafia qui désigne, en le localisant, l'orgueil des politiciens impliqués dans la lutte contre la mafia. En d'autres termes, ces mots fonctionnent de manière analogue à l'expression plan Marshall où plan, mot commun, a englobé le sens du syntagme qui lui a donné origine. Cela dit, un certain excès interprétatif dans le cas des noms propres est inévitable (Gary-Prieur 1991), car l'analyse de leur fonctionnement en discours se joue presque exclusivement sur ce plan.

Un autre exemple est représenté par le mot day (dérivant sans doute de $D$-day), que l'on retrouve souvent en combinaison avec un nom propre de politicien. C'est le cas de Clemente-day, Gelmini Day pour indiquer le jour spécial consacré à un personnage politique. Comme on peut le lire dans les exemples qui suivent, le sens est le plus souvent ironique, voire négatif :

Il Clemente-day: io, poveretto di Ceppaloni, l'inchiesta vada avanti, il Messaggero 24/10/2007

\footnotetext{
${ }_{9}^{9}$ D'autres combinaisons avec Npr sont Sarko One voire Air Sarko One calquant la dénomination d'une compagnie aérienne, suite à l'affaire concernant l'ex-Président et à l'achat d'une compagnie aérienne.
} 
Non capisco [don Vitaliano della Sala] il motivo per il quale adesso si senta il bisogno di celebrare un Gelmini Day, il Riformista 08/08/2007

Dans le corpus français, la fréquence de day est assez élevée si l'on s'en tient aux données issues du corpus Le Monde (919 occurrences). Cependant, la plupart des occurrences concernent des dénominations anglaises ou des citations en anglais et ne sont donc pas pertinentes pour notre analyse. Un des exemples le plus intéressant relevé dans le corpus du Monde mais qui concerne un néologisme italien est $V$ affa Day ou $V$-day, littéralement le «jour du va te faire foutre », au départ lancé comme une boutade par un comique italien, Beppe Grillo (Le Monde 21 mai 2018). Ce syntagme, comme le souligne Santone, outre qu'il « recouvre une sphère sémantique sexuelle, désigne par extension une expression de rejet, une formule de congé brutal relevant d'une rhétorique injurieuse et vulgaire » (Santone 2014).

Parmi les néologismes relevés, il y a aussi des composés mixtes en gate et exit qui sont combinés aussi bien à des toponymes qu'à des anthroponymes.

Le gate par excellence a été le Watergate de 1972, lié au Président Nixon. Suite à ce scandale il y en a eu beaucoup d'autres tels que le sexygate, dans lequel le président américain Bill Clinton était impliqué, et qui a ensuite rendu célèbre le composé. Ce sont surtout les journalistes qui créent ces nouveaux composés suivant des paradigmes internationaux comme :

Irangate, Irakgate, Irpiniagate, Mitterandgate, Ciagate, Nigergate, e ora calciogate, tutti neologismi di recente conio, e se ne produrranno man mano degli altri, che partono dall'inglese d'America Watergate (1972), sorto ai tempi di uno scandalo che rimonta alla presidenza di Nixon, La Stampa 27/05/2006

Dans la plupart des cas, il s'agit d'emprunts intégraux qui existent aussi bien en français qu'en italien. Cependant, à la différence du français, l'italien s'approprie plus facilement le mot pour en créer d'autres. En voici deux exemples :

Le spine di Prodi Il Calabria-gate, La Stampa 14/07/2007

Storace: altro che Laziogate, è un Waltergate, il Messaggero 20/03/2005

Le type de composés avec gate est utilisé dans certains cas aussi dans le langage commun, comme dans le cas de Coronagate, où le composé désigne la malfaisance d'un homme de spectacle :

Nina Moric. Perennemente in copertina causa Coronagate, ha pensato di lanciare "Basic Instinct", La Stampa 25/08/2007

Dans le domaine journalistique, nous enregistrons l'utilisation de gate dans le composé idiotagate, désignant l'affaire qui a eu lieu entre Donald Trump et Rex Tillerson, le secrétaire d'Etat américain, qui aurait traité Trump de débile (" a moron ») à la fin d'une réunion au Pentagone :

Trump: totale fiducia in Tillerson 1'"idiota-gate" oscura l'arrivo in Nevada», la Repubblica 05/10/2017.

De la même manière, les composés créés avec -exit, autour du cas politique Brexit, se sont particulièrement diffusés et sont associés aussi bien aux toponymes (Italexit) qu'aux anthroponymes (Merkelexit). Comme on peut l'observer dans le cas ci-dessus, la plupart des néologismes ne suivent pas la syntaxe traditionnelle déterminé + déterminant mais plutôt la syntaxe anglaise voire classique (gréco-latine), à savoir déterminant + déterminé :

Dieci, cento, mille "Leave". E allora dopo Brexit, ecco manifestarsi lo spettro del "Grexit", "Italexit",

"Nexit", "Frexit", l’Unità 27/06/2016 
Incubo Merkelexit. Tra il 27 agosto e il 22 ottobre si vota per il Bundestag tedesco. La cancelliera Angela Merkel corre per il quarto mandato, la battaglia più difficile della sua carriera, L'Espresso 08/01/2017.

Il n'est pas sans intérêt de souligner que les déterminés issus de l'anglais sont monosyllabiques et que cela semble favoriser la formation de composés déterminant+ déterminé en français et en italien. On a pu remarquer en effet que, dans le cas de Président Téflon et de Plan Marshall, l'emprunt direct à l'anglais n'a pas été lexicalisé et que l'expression s'est adaptée à la syntaxe romane. On peut ainsi avancer l'hypothèse qu'outre les raisons extralinguistiques, cette contrainte phonotactique détermine l'acceptation d'un composé ayant une base exogène. En ce qui concerne le déterminant, celui-ci est le plus souvent bisyllabique (Ciampiboy), plus rarement trisyllabique (D'Alema boy). On peut également en déduire que la présence significative de ce type de composés en italien est due non seulement à une perméabilité aux emprunts plus grande en italien qu'en français, mais aussi à la conformation de la langue italienne qui est une langue à prédominance vocalique. En effet, les noms propres bisyllabiques qui se terminent par une voyelle (Ciampi, Bondi) s'enchaînent bien avec les emprunts monosyllabiques à l'anglais. La longueur, ou plutôt la brièveté, du déterminé permet d'accepter la syntaxe anglaise même dans le cas des compositions endogènes et de créer un mot unique.

Les exemples bobocrazia et craxi-sauri confirment cette tendance car, dans ces cas-là, ce même modèle est appliqué à des composés endogènes. La syntaxe est toujours inversée par rapport à la composition italienne actuelle bien que le déterminé (le deuxième élément) ne soit pas un mot complet, mais un confixe ou un fracto-lexème d'origine grecque ou latine et donc un élément bisyllabique. Ainsi, bobocrazia désigne le réseau de pouvoir et corruption de Roberto Maroni, alias Bobo, alors que Craxi-sauri, indique les dinosaures du politicien Craxi, c'est-à-dire les partisans de Craxi survécus à son époque :

\begin{abstract}
Bobocrazia. Una gigantesca rete di potere, clientele e amicizie. Che va dall'Expo alle aziende partecipate. Ma si estende anche oltre la Lombardia. E oltre la Lega. Così il governatore Roberto Maroni tesse la tua tela, Espresso Repubblica 27/06/2015;
\end{abstract}

Resta il fascino sempreverde dei "Craxi-sauri", il Messaggero 23/10/200510.

Cette tendance ne se limite bien sûr pas à ce type de composés. En plus des composés déjà cités, il existe également dans le dictionnaire Treccani des termes dont les deux éléments forment un faux anglicisme (Humbley 2016). Ces types de composés ont été inventés par les locuteurs italophones à partir du matériau lexical étranger. Nous pouvons retrouver cette pratique dans le célèbre Jobs Act, entièrement inventé par le gouvernement Renzi qui a baptisé ainsi la réforme du travail en $2015^{11}$. En suivant ce paradigme d'autres syntagmes ont été créés tels que Family Act, désignant la nouvelle loi concernant la famille («Un Family act per uomo e donna. Alfano rilancia. Tensione con il Pd», Corriere della Sera 22/02/2015), mais aussi calciomercato, composé endogène, dont la syntaxe est également déterminée par l'influence du modèle anglo-américain (Giovanardi, Gualdo, Coco 2008).

\title{
5. Conclusion
}

Dans le cadre de la néologie dénominative, on a pu remarquer une distinction entre les composés $\mathrm{N}+\mathrm{Npr}$ et les composés $\mathrm{Npr}+\mathrm{N}$ en ce qui concerne le figement. Si les deux langues romanes semblent réagir de manière assez semblable face au patron $\mathrm{N}+\mathrm{Npr}$ qui respecte la syntaxe progressive, elles ne se comportent pas de la même façon face aux emprunts à l'anglais ayant la fonction de déterminé. Dans le premier cas, les syntagmes deviennent des collocations

\footnotetext{
${ }^{10}$ Le type de composé est également productif dans d'autres domaines de la langue commune. Par exemple dans le composé cinafonino: -fonino in cinafonino (Cinafonini, guerra dei cloni a preziz stralciati, La Repubblica 06/11/08) : le suffixe est devenu productif à partir de 2007, date de la commercialisation du premier téléphone portable Apple.

${ }^{11}$ Le Jobs Act est une réforme de travail mise en place per le gouvernement italien guidé par Matteo Renzi en 2015.
} 
préférentielles voire des lexèmes là où le figement a lieu, bien que quelques différences puissent être esquissées en tenant compte du degré de lexicalisation des composants. Dans le deuxième cas, les deux éléments tendent à s’amalgamer en créant un seul lexème.

L'aspect évolutif est particulièrement évident dans le degré de lexicalisation qui est variable sur le plan intra et interlinguistique en français et en italien et se manifeste par exemple par la présence ou l'absence de la préposition « de » dans le syntagme Presidente di Teflon vs Président Téflon. La préposition présente dans la synapsie explicite le lien entre le classifieur, alors que son absence dénote un degré de lexicalisation majeure qui peut amener, comme c'est le cas en l'occurrence, à l'antonomase (Président Téflon voire Téflon).

En ce qui concerne les composés $\mathrm{Npr}+\mathrm{N}$, qui sont tous créés sous l'influence de l'angloaméricain, des différences entre le français et l'italien semblent être plus évidentes. S'il est vrai que les deux langues intègrent à leurs systèmes l'inversion de l'ordre syntaxique non seulement en ce qui concerne des formes empruntées et des calques mais aussi dans le cas des formations faussement anglophones du type ciampiboy, elles n'enregistrent pas la même distribution de ce phénomène. Dans notre corpus les composés en $\mathrm{Npr}+\mathrm{N}$ sont moins fréquents en français qu'en italien qui est connu pour sa perméabilité à l'emprunt. Toutefois, cette tendance semble être liée non seulement à des facteurs extralinguistiques, mais aussi à des raisons phonétiques et morphologiques. En ce qui concerne la lexicalisation, nous avons pu constater, qu'en dépit de la même valeur référentielle, la forme monolexicale des composés du type $\mathrm{Npr}+\mathrm{N}$ tels que sarkoboy facilite la perception du figement avancé de la part des locuteurs et favorise, indirectement, nous semble-t-il, l'attribution du statut néologique à la lexie, à la différence des séquences $\mathrm{N}+\mathrm{Npr}$ qui apparaissent moins autonomes.

\section{Bibliographie}

Adamo Giovanni et Della Valle Valeria (2017), Che cos'è un neologismo, Carocci Editore, coll. «Bussole».

ARNAUD Pierre et RENNER Vincent (2014), «English and French [NN]N lexical units: A categorial, morphological and semantic comparison », Word Structure, 7 (1), p. 1-28.

ARNAUD Pierre (2018), «Bateau phare, magasin phare : composés $\left[\mathrm{N}_{1} \mathrm{~N}_{2}\right]_{\mathrm{N}}$ et séquences syntaxiques $\mathrm{N}_{1}+\mathrm{N}_{2}$ à $\mathrm{N}_{2}$ adjectivé », Travaux de linguistique, 2018/1 nº 76, p. 7-26.

Balnat Vincent et Gerard Christophe (éds.) (2018), « Néologie et noms propres », Cabiers de lexicologie, vol. 2, numéro 113, Paris, Classiques Garnier.

CABRÉ Maria Teresa (2002), "La neologia, avui: el naixement d'una disciplina", dans CABRÉ María Teresa, SOlÉ Elisabet, FreIXA AYMERICH Judit (éd.), Lèxic i neologia, p. 29-42.

CADIOT Pierre (1988), «Le thème comme synecdoque », Langue française, $\mathrm{n}^{\circ}$ 78, p. 17.

CARTIER Emmanuel (2016) : «Néoveille, système de repérage et de suivi des néologismes en sept langues », Neologica n¹0, p. 101-131.

CONDAMINES Anne (1999), Analyse des structures "Nominalisation + de N", “ Nominalisation $+\mathrm{N}$ ", "Nominalisation + Adjectif relationnel " dans un corpus spécialisé, dans Michel Aurnague, Anne Condamines, Jean-Pierre Maurel, Christian Molinier, (éds.), L'emprise du sens, Amsterdam/Atlanta, Rodopi, p. 61-82.

DE THALES Sophie (2017), Le Petit Macron de la langue française. Décryptage savoureux des formules, mots rares et expressions de notre Président, Paris, Éditions Tut-Tut.

Diqionario Treccani, section « Neologismi », version en ligne, URL: http://www.treccani.it.

GARY-PriEur Marie-Noëlle (éd.) (1991), "Syntaxe et sémantique des noms propres », Langue Française, 92.

GIOVANARDI Claudio, GuALDO Riccardo et COCO Alessandra (2008), Inglese-Italiano 1 a 1. Tradurre o non tradurre le parole inglesi, San Cesario di Lecce, Manni. 
Humbley John (2016), «La classification des faux emprunts : une question de point de vue », Z. Hildenbrand, A. Kacprzak and J.-F. Sablayrolles (éds.), Emprunts néologiques et équivalents autochtones en français, en polonais et en tchèque, La Lexicothèque, Limoges, Marc Arabyan. Editions Lambert-Lucas, p. 37-58.

KLEIBER Georges (1984) : «Dénomination et relations dénominatives », Langages, 76, p. 77-94.

KLEIBER Georges (1995): "Sur la définition des noms propres, une dizaine d'années d'après ", dans NoAilly Michèle (éd.), Nom propre et Nomination, Paris, Klincksieck, p. 11-36.

LECOLLE Michelle (2006), «Changement dans le lexique - changement du lexique : Lexicalisation, figement, catachrèse », Cabiers de praxématique, 46, p. 23-42.

LECOLLE Michelle (2009), "Changement de sens du toponyme en discours : de Outreau «ville» à Outreau «fiasco judiciaire»", Les Carnets du Cediscor, 11, en ligne, URL : https://journals.openedition.org/cediscor/773.

Lecolle Michelle, PaVeau Marie-Anne et Reboul-Toure Sandrine (2009), « Le nom propre en discours, Les sens des noms propres en discours ", Les Carnets du Cediscor, 11, en ligne, URL : https://journals.openedition.org/cediscor/736.

Lehmann Alise, Martin-Berthet Françoise (2008), Introduction à la lexicologie. Sémantique et morphologie, Paris, Armand Colin, coll. «Lettres sup », III ${ }^{\text {ème }}$ édition.

LEROY Sarah (2003) : «Antonomase, métaphore et nom propre : identification ou catégorisation », Travaux linguistiques du CerLiCO, 16, p. 161-178.

LEROY Sarah (2004) : De l'identification à la catégorisation. L'Antonomase du nom propre en français, Louvain-Paris-Dudley MA, Peeters.

LETURGIE Arnaud (2012), L'amalgamation lexicale en français : approches lexicologique et morphologique, Vers une grammaire de l'amalgamation en français, thèse de doctorat, Université de Cergy-Pontoise.

MEJRI Salah (2005), « Figement absolu ou relatif : la notion de degré de figement », Linx, 53, p. 183196.

MEjRi Salah (2013), «Figement et défigement: problématique théorique », Pratiques, 159-160, p. 79-97, URL : http://journals.openedition.org/pratiques/2847

NOAILly Michèle (1991), «L'énigmatique Tombouctou » : nom propre et position de l'épithète », Langue française, 92, p. 104-112.

PETIT Gérard (2006) : Le nom de marque déposée : nom propre, nom commun et terme, in Meta : journal des traducteurs/ Meta: Translators' Journal, 51, 4, p. 690-705.

RENNER Vincent (2006) : Les composés coordinatifs en anglais contemporain, thèse de doctorat, Université Lumière Lyon 2.

RENNER Vincent (2015), «Panorama rétro-prospectif des études amalgamatives », Neologica.n9, Paris, Classiques Garnier, 9, p. 97-112.

RYDER Mary Ellen (1994), Ordered Chaos: The Interpretation of English Noun-noun Compounds, Berkeley, University of California Press.

SABLAYROLLES Jean-François (2011), " De la "néologie syntaxique" à la néologie combinatoire », Langages, 3/183, p. 39-50.

SABlayROLLES Jean-François (éd.) (2003), L'innovation lexicale, Paris, Honoré Champion.

SANTONE Laura (2014), "Quand la politique tire la langue. Le Vaffa day du M5S (Movimento 5 Stelle)», Mots. Les langages $d u$ politique, 106, en ligne, URL: http://journals.openedition.org/mots/21810.

TOURNIER Jean (1991) : Précis de lexicologie anglaise, Paris, Nathan.

VAXELAIRE Jean-Louis (2009) «Lexicologie du nom propre et onomastique », Nouvelle revue d'onomastique, 51, p. 301-315. 


\title{
La néologie par emprunt: analyse des blogs féminins portugais et brésiliens
}

\author{
Edyta Jabłonka \\ Université Marie Curie-Sklodowska (UMCS)
}

\begin{abstract}
Résumé : L'emploi des emprunts est vu comme un phénomène très fréquent dans les différentes langues. Pourtant, la présence des mots étrangers est parfois considérée comme un obstacle pour la compréhension des textes en général, et aussi dans le cas des blogs qui constituent notre corpus. Néanmoins, c'est un phénomène de plus en plus fréquent dans toutes les langues de spécialité, par exemple: informatique, médecine, économie, gastronomie, télécommunications, mode, technologie etc. Comme résultat de notre intérêt pour l'emploi des emprunts, nous présentons différents exemples rencontrés dans les blogs féminins portugais et brésiliens, surtout d'origine anglaise, et nous essayons d'expliquer les raisons de leur usage. Cette étude a été divisée en deux parties: dans la première, nous avons brièvement décrit les problèmes théoriques concernant la néologie par emprunt; ensuite, nous avons énuméré les cas particuliers d'emploi d'emprunts. Selon nous, l'emprunt dans les blogs se définit avant tout comme élément stylistique ou bien lié avec les nouveaux objets ou phénomènes qu'apparaissent dans le monde sans cesse. La présentation du corpus nous permet aussi de noter l'apparition d'un nombre assez significatif d'emprunts dans la langue portugaise contemporaine.
\end{abstract}

Mots-clés: emprunt, néologisme, néologie, portugais, blog.

Abstract: The use of loan words is regarded as a very frequent phenomenon in different languages. However, the presence of foreign words is sometimes considered as an obstacle in understanding texts in general, and also in the case of blogs which constitute our corpus. Nevertheless, this is a more and more frequent phenomenon in all languages of specialized domains, for example: IT, medicine, economy, gastronomy, telecommunication, fashion, technology etc. As a result of our interest in the use of loan words, we present various examples recognized in Portuguese and Brazilian female blogs, above all these of English origin, and we try to explain the reasons of their use. The present study is divided into two parts. In the first one, we briefly describe theoretical problems concerning neology through loan words; subsequently, we enumerate particular cases of using loan words. In our opinion, loan words in blogs are defined above all as a stylistic element or an element well-linked with new objects or phenomena which appear in the world non stop. The presentation of the corpus also allows us to notice the presence of a quite significant number of loan words in contemporary Portuguese.

Key words: loan word, neologism, neology, Portuguese, blog. 


\section{Introduction}

Cet article a pour objectif général de présenter les néologismes par emprunt sélectionnés des blogues féminins portugais et brésiliens. Pour comparer les deux versions de la langue, nous avons décidé d'analyser les blogs les plus populaires au Portugal et au Brésil.

$\mathrm{Au}$ long des siècles, les langues étrangères ont enrichi le lexique portugais et l'influence des langues telles que le français, l'anglais et l'italien a marqué différentes phases de l'évolution du portugais, et, sans doute, jusqu'à aujourd'hui elle reste actuelle. L'entrée des emprunts se déroule d'une manière naturelle et fait part du procès de l'évolution de la langue, de son histoire, ce qui est observable pendant l'analyse de l'histoire du lexique portugais. L'emploi des emprunts peut être une contribution enrichissante, mais, quelle est la nécessité réelle des emprunts présents dans la vie quotidienne? Pour l'expliquer, il nous semble indispensable de rappeler quelques définitions importantes pour notre étude relationnées avec les emprunts.

Selon Guilbert, il faut que la volonté d'adoption se manifeste par une certaine extension du terme étranger. Il n'y a de néologisme à proprement parler que s'il existe un certain usage dans la société pendant un certain temps. On distingue d'abord une première situation où le terme étranger est introduit dans le corps d'une phrase française en référence à un signifié propre à la langue étrangère. On peut le qualifier de xénisme parce qu'il demeure effectivement étranger. (Guilbert 1975: 93)

Pour Guilbert, le facteur décisif de l'incorporation des termes étrangers, c'est le fait de l'introduire avec son référent, l'objet ou le concept déterminé, sinon, son statut dans la langue importatrice est moins significatif. Deroy, dans son étude dédiée aux emprunts, propose une division des unités lexicales d'origine étrangère dans laquelle il distingue les pérégrinismes ou xénismes, c'est-à-dire les mots sentis comme étrangers et en quelque sorte cités, et les emprunts proprement dits ou mots tout à fait naturalisés (Deroy 1956: 224). En comparant la terminologie, il est possible de voir la proximité des termes estrangeirismo en portugais, xénisme et pérégrinisme. Guilbert souligne la différence entre sa terminologie et celle de Deroy, en expliquant que le pérégrinisme de Deroy c'est un terme relationné avec la première phase de son installation et avec la phase de pérégrination du mot pendant laquelle le mot étranger est en train de souffrir les altérations pour arriver au statut d'emprunt. Pour Guilbert, il s'agit de la phase néologique.

Haugen (1950) a proposé une classification très connue qui compte trois types d'emprunts tels que loanwords (importés directement des autres langues), loanblends (les calques) et loanshifts (emprunts sémantiques). Selon Rusiecki, dans le cas d'emprunt, il s'agit de « [...] pairs of words, one in language $A$ and the other in language $B$, such that the meaning of the language $-\mathrm{B}$ word is the same as at least one (possibly more) of the meanings of the equivalent language - A word; at the same time the two words are similar in spelling, pronunciation, or both, so that, the language - A word can be readily understood by native speakers of B who have never learnt A. » (Rusiecki 1980: 80-81)

Bloomfield (1933) a dédié une part de son oeuvre Language à la provenance des mots étrangers fonctionnants dans la langue anglaise en usant le terme borrowing. ${ }^{1}$ Cet auteur décrit une langue comme le conjoint de formes traditionnelles basiques (basic tradition). L'apparition des formes différentes de celle basique indique qu'il s'agit des éléments étrangèrs qui ont été introduits pour différentes raisons dans un moment historique déterminé. Mattoso Câmara Jr. (1979) profite des considérations de Bloomfield pour élaborer la thèse sur les emprunts «culturels et intimes.» ${ }^{2}$ Dans ce cas, les deux langues coexistent à l'intérieur d'une communauté constituée par la même population du point de vue topographique et politique, par exemple pendant la conquête de nouveaux terrains ou la migration. Selon Bloomfield, ce procès

\footnotetext{
${ }^{1}$ Il est possible de considérer ce terme equivalent à empréstimo en portugais.

${ }^{2}$ Selon cette théorie, les emprunts culturels dépendent des contacts politiques, commerciaux et artistiques entre différents pays.
} 
est très important, et la langue dominante est parlée par le groupe privilégié qui domine l'autre groupe et implique sa superiorité également grâce à l'introduction d'une autre langue.

Saussure lui-même parle aussi de la même situation et du mélange des langues qui résulte de la vie commune dans un territoire déterminé et sous la domination d'une des langues existantes sur ce territoire:

Il peut arriver d'abord que la langue d'une nouvelle population vienne de superposer à celle de la population indigène. Ainsi dans l'Afrique du Sud, à coté de plusieurs dialectes nègres, on constate la présence du hollandais et de l'anglais, résultat de deux colonisations successives;[...] Le plus souvent cette superposition de langues a été amenée par l'envahissement d'un peuple supérieur en force; mais il ya aussi la colonisation, la pénétration pacifique. (Saussure 1967: 265-276)

Ces théories peuvent être relationnées avec la période de la colonisation et de l'expansion de la langue portugaise dans le monde entier, quand le portugais occupait un lieu privilégié en face aux autres langues dans les territoires colonisés ${ }^{3}$.

Dans les analyses des emprunts, le facteur de prestige (ou le manque de prestige) joue un rôle assez important. Le prestige est relationné avant tout avec l'emploi fréquent des mots étrangers. Il existe aussi des cas où l'usage des emprunts résulte de la volonté de rendre le texte plus intéressant et plus attractif pour les lecteurs. Pour les bloggers, le contact avec le public est très important. Dans ce cas-là, il est opportun de citer les mots du chercheur brésilien Bagno:

Tentar preservar, impor e cobrar um padrão de comportamento lingüístico único, aristocrático e obsoleto é um projeto que se contrapõe de maneira gritante a toda essa dinâmica da sociedade, da cultura e da língua. Uma sociedade e uma cultura multifacetadas e plurais só podem abrigar uma língua multifacetada e plural. Nossa luta tem de ser pelo reconhecimento, admissão e valorização da diversidade, da variedade e da pluralidade em todas as esferas da vida social, [... ] (Bagno 2002: 39).

Le linguiste brésilien Rajagopalan (2003) considère qu'il n'y avait qu'un motif pour que quelqu'un veuille apprendre une langue étrangère: c'est l'accès à un monde meilleur. Les gens veulent parler les langues étrangères pour le prestige, pour être plus intelligents et cultes. (Rajagopalan 2003: 65) Alors, employer les mots étrangers signifie qu'une personne appartient à une sphère sociale déterminée, une élite. Montrer sa capacité de communiquer dans une langue étrangère signifie aussi être membre du monde globalisé. Avec l'évolution du monde, apparaissent les nouvelles formes et phénomènes linguistiques qui modifient la structure de la langue. Cela est observable dans la néologie où il y a un espace pour le changement, la nouveauté, l'innovation et la créativité.

Le procès de l'importation des unités lexicales est très productif en portugais et nous sommes témoins de ce procès dans différentes ambiances et situations de communication, quand son usage est fréquent pour appeler l'attention des autres ou surprendre. On peut observer que la langue rend possible la création des différentes tonalités qui nous aident à dire quelque chose avec différents outils, comme le décrit Carvalho: «A língua, espelho da cultura, reflete essa busca frenética de novidade, evoluindo rapidamente introduzindo novos termos, logo aceitos. Se vocábulos novos foram considerados pelos gramáticos "vícios" da linguagem, hoje em dia são aclamados e consagrados de imediato.» (Carvalho 1984: 7-8)

Les termes nouveaux qui apparaissent dans la langue contribuent pour son évolution et indiquent les nouvelles directions. Il y a toujours des facteurs sociaux et politiques qui motivent les modifications dans la langue. Actuellement, cette transformation est plus rapide grâce à l'Internet, la télévision, les réseaux sociaux et les techniques, ainsi qu'à l'accès plus facile aux équipements. Selon Alves (2004), le lexique d'une langue ne s'enrichit que par les formes déjà existantes - les contacts entre les communautés linguistiques se reflètent lexicalement et la phase

\footnotetext{
${ }^{3}$ Cette position est relationnée avec la dominance politique, militaire et commerciale des Portugais. L'autre facteur très important c'est l'émigration causée par la crise économique au XIX siècle. On retrouve cette situation aussi dans les temps de la présence espagnole au Portugal et de l'imposition de la langue espagnole au peuple portugais aux XVI et XVII siècles.
} 
néologique de l'emprunt commence par son intégration. Cela se manifeste par son adaptation graphique, morphologique ou sémantique (Alves 2004: 72).

\section{Classification}

Les définitions et les considérations présentées sont importantes pour la deuxième partie de notre étude où se trouvent les exemples des blogs portugais et brésiliens. Il est possible d'observer qu'il s'agit surtout des cas d'emploi stylistique d'emprunts qui possèdent leurs équivalents en portugais.

«uma xicara de chá de blueberries, dois punhados de uvas, um limão, um punhado de espinafre, um punbado de couve, algumas folbinhas de salsa» http://blog.quaseperfeita.com.br/

"Para casa trouxe queijo de cabra, tomate cherry, fiambre de peru e tomilho.» http://apipocamaisdoce.sapo.pt/

«Fiz. um frango grelhado com green beans. » http://blogdaroana.com/

«Misturar o iogurte com o maple e fazer camadas alternadas da mistura vermelha com a de iogurte até quase encher as forminhas. Se possivel, que sejam menos calóricos, feitos com iogurte natural e adocantes naturais como o mel e o maple syrup.» http://ananasehortela.blogspot.pt/

«Pedimos a batata comum, que vem com uma maionese deliciosa, e também a versão com pastrami e sour cream.» http://chatadegalocha.com/

Comme nous pouvons observer, dans ce domaine l'influence de l'anglais est très forte. Pourtant, les raisons de son utilisation sont, dans notre opinion, surtout stylistiques. Dans tous les cas cités, il existe une forme correspondante en portugais, c'est pourquoi nous pouvons observer que son usage n'est pas indispensable. Le même phénomène est observable aussi dans les autres domaines, comme nous montrent les exemples suivants:

«Vocês sabem que eu sou fã de jumpsuits e por isso tenho um super giro para oferecer a uma de vocês, da Coquelicot.» http://www.amiudadossaltosaltos.com.pt/

«A peça mais desejada desse verão é sem dúvida, o macacão, que pode ser forma de jumpsuit ou short. $»$ http://bigbeautifulgirls4.blogspot.com/pt

«á devem ter reparado que raramente ando sem um red lipstick.» http:/ / amberhella.com/

«Duram imenso tempo, sendo que as cores mais fortes por vezes até deixam um tint nos lábios depois de saírem.» http://modaebeleza.blogs.sapo.pt/

«Sempre gostei de comprar no início, pelo instinto, pelas peças que falam connosco, e não por estarem a bombar em todo o lado e serem trend.

«Nunca pensei, aos 33, continuar a ter a mesma paixão por cabelos coloridos, mas a verdade é que tenho. Desde 2009 que voltei a esta trend." http:// amberhella.com

«não avisamos que a trend era uma boa?! http://www.garotasestupidas.com/

«Isto e um coque ou um ponytail. Também compenso na maquilhagem.» http:/ / amberhella.com

Pour les objectifs de notre étude, nous avons sélectionné aussi quelques cas relationnés avec différents emplois stylistiques. Il est intéressant d'observer que dans ces contextes, les emprunts fonctionnent avant tout comme un moyen pour appeler l'attention des lecteurs et rendre les textes publiés plus intéressants et plus originaux.

«Sim, Ana Paula tem 49 anos - amazing, né?! E segundo matéria da Veja, fatura no mínimo 1,8 milhão de reais por ano. Então tá tudo certo.» http://www.belezacomprada.com/

«Numa era em que há mais de tudo e em que parece que mais é melhor, existem demasiadas pessoas a sofrer de stress, a passar por burnouts e a viverem infelizes para que esta ideia de que ter mais e mais seja uma coisa realmente boa. » http://www.look-a-day.com/ 
"é inspirada no anos 80, nos fatos de banho super decotados e subidos, onde as pernas ficam gigantes, onde nos lembramos da série Baywatch, e onde somos girls com atitude.» http:/ / amberhella.com

«Emilio Pucci e Margiela optaram pela versão tradicional bandmade, com cúpula irregular e faixa fina próxima à aba.» http:// camilacoelho.com/

«Colocámos uma placa preta mate - de um material qualquer cujo nome têm que perguntar ao João, nosso bandyman que concretiza todas as nossas ideias - que não se vê quando a portada está aberta e também não se vê à noite quando a portada está fechada.» http:/ / mariaguedeslisboa.clix.pt/

«nunca se sabe se a pessoa vai gostar on sequer se já tem, por isso gosto mais de apostar nos presentes homemade.» http://amisschica.blogspot.com

«Mix de flores com Lisianthus, Rosas nacionais e colombianas, Altroemérias e pingos de chuva de prata em um lindo bowl branco.» http://www.lalarudge.com.br/lala-rudge/

Que tal ter a foto da pessoa on do seu pet em suas unhas?h http:/ / www.janasabrina.net/

«Esses pets são animais muito ativos e espertos e precisam de algo que mantenha sua curiosidade...» http://www.bolsademulher.com/pet

Meu look foi relax, com camisa azul listrada e saia midi branca - peça super verão! [...] No «look de hoje fiz uma produção mais relax e casual com uma saia rodada em couro.» http:// camilacoelho.com/

Observons aussi quelques exemples relationnés avec le monde virtuel et les nouvelles technologies. Commençons par le mot selfie, sans lequel il parait impossible d'imaginer les langues contemporaines, pas seulement le portugais. De cet emprunt, nous avons obtenu quelques mots dérivés tels comme belfie, brelfie et les mots composés - work selfie, selfie stick, belfie stick, populaires surtout entre les jeunes:

«Em época de redes sociais e smartphones, as selfies estão por todos os lados. Se você faz, parte do grupo de internautas que não passa um dia sequer sem postar uma selfie, veja na galeria seis maneiras de deixá-la ainda mais atrativa - e conquistar muitos likes.

Depois da febre da "selfie", outra moda popular no Instagram: A da "belfie", que nada mais é do que a foto que deixa as nádegas em destaque.» http://ego.globo.com/famosos/noticia/2014/11/famosas-daodicas-para-fazer-belfie-foto-do-proprio-bumbum-perfeita.html)

«Brelfie! Uma moda estranha envolvendo as selfies!

Uma moda estranha envolvendo o mundo das selfies rolou nas redes sociais: a brelfie selfie! São selfies batidas com as mães dando de amamentar para os seus filhos» http://www.selfieblog.net/artigos/brelfie-umamoda-das-selfies/

«Linkedin publicou dicas em sua rede social de como as pessoas podem tirar uma selfie de trabalho para colocar no perfil da rede e ter maior chance de sucesso na seleção de vagas, entrevistas e contratação. Ao todo foram publicadas 7 dicas para work selfie em um material exclusivo em inglês.

Selfies fail: Outras 10 selfies que não deram muito certo!

Com a popularização do selfie, surgiram alguns acessórios para incrementar a prática do autorretrato. Um exemplo é o monopod (bastão para fotos também chamado de monopé), que resolve um problema comum nesse tipo de clique: braço curto demais para mostrar toda a paisagem ou os amigos na foto.» http://tecnologia.uol.com.br/noticias/redacao/2014/07/28/monopod-bastao-para-cameraajuda-a-encaixar-todos-amigos-em-selfies.htm

Dans le cas de ce mot, il y a toujours une différence quant à son genre. Observons les définitions du Dictionnaire da Porto Editora et du dictionnaire brésilien online:

«Selfie é uma palavra de origem inglesa, de entrada recente no vocabulário da língua portuguesa. A força de uso do vocábulo justifica a sua inclusão no dicionário como nome do género feminino. Verifica-se, no entanto, que ainda há alguma hesitação na fixação do género, podendo ocorrer também no masculino. O uso ditará o género que irá prevalecer, mas a palavra classifica-se, por enquanto, na categoria de nome feminino, porque se subentende, de uma forma generalizada, como uma especificação do termo fotografia.» 
http://www.portoeditora.pt/espacolinguaportuguesa/duvidas-da-linguaportuguesa/detalheduvidas-lp/ver/?id=24982

«Selfie - substantivo de dois géneros. Corruptela do inglês self, que significa 'en próprio'. É um neologismo originado da locução self-portrait, autorretrato. Selfie designa autorretrato (fotografia ou ilustração) compartilhada na internet. A particularidade de um (ou uma) selfie é que ela é clicada com o objetivo de ser compartillhada em uma rede social (Facebook, Orkut. Myspace e outras), por exemplo.» (http://www.dicionarioinformal.com.br/selfie/)

Les autres mots récents trouvés dans les blogs sont relationnés aussi avec le monde virtuel, par exemple cosplay, emoji, nerd ou geek. Cosplay c'est l'abréviation de costume play ou de costume player que l'on utilise pour déterminer une personne imitant l'aspect d'un personnage réel ou fictif des jeux, manga ou anime. Le substantif cosplay fonctionne aussi comme adjectif (fantasia cosplay). Les emoji sont les faces différentes usées dans les applications et d'autres systèmes. Nerd c'est le nom qui détermine une personne très intelligente et passionée pour les nouvelles technologies, mais, en même temps, s'applique à une personne peu sociable. Le mot geek est un peu pareil à nerd et principalement détermine quelqu'un qui s'intéresse beaucoup à la technique, les ordinateurs et l'Internet en négligeant son aspect physique.

En analysant les emprunts, il faut aussi avoir en compte sa présence dans les dictionnaires et les différences entre les dictionnaires portugais et brésiliens. Par nécessité ou par la mode, l'entrée des emprunts est inévitable, néanmoins, vers le dynamisme du lexique, essayer de réaliser la normalisation n'est pas facile. Pour cette raison, dans notre opinion, il est nécessaire d'observer la présence des emprunts dans les dictionnaires pour pouvoir établir des critères lexicographiques objectifs et comparer les emplois des emprunts au Portugal et au Brésil. Il est possible d'observer qu'il n'y a pas de règles claires ni de transparence quant à l'introduction des mots étrangers dans les dictionnaires. ${ }^{4}$ Il faut souligner que les dictionnaires quelquefois présentent différentes versions du même mot ou bien les versions déjà modifiées, dont le nombre peut varier selon le dictionnaire. Pour cette raison, nous croyons important d'indiquer quelques exemples à cause de la coexistence de deux (ou bien de plus de deux) formes. ${ }^{5}$ Les exemples sont très nombreux, c'est pourquoi nous nous sommes limités à la présentation de quelques cas intéressants.

Notre premier exemple, le mot buffet présente trois graphies différentes; dans le dictionnaire Infopedia de Porto Editora nous pouvons distinguer toutes les formes possibles: buffet, 'bufê' e 'bufete.' La même classification a été proposée par le dictionnaire Priberam, pourtant, les dictionnaires brésiliens ne présentent que les formes déjà modifiées. Néanmoins, chaque dictionnaire contient une entrée différente: le Dictionnaire Michaelis propose la forme 'bufete' et dans le Dicio-Dicionário online nous rencontrons la forme 'bufê'. Le Dictionnaire de l Académie Portugaise, sauf la forme originale, suggère aussi la forme adaptée 'bufete', ainsi que le dictionnaire brésilien Aulete. Le Dictionnaire Aurélio ne présente qu'une version - la forme adaptée 'bufê', lorsque Léxico online nous propose le mot 'bufete.' Alors, en réalité, chaque dictionnaire présente une attitude complètement différente dans le traitement de cet emprunt. Dans les blogs portugais et brésiliens choisis pour l'analyse, nous avons rencontré le mot originel, non adapté:

«Através do Booking reservámos uma semana no hotel Nau S. Rafael Suites, em regime de tudo incluido, e que ainda nos dava umas ofertas de jantares extra nos restaurantes (sem ser em regime buffet) do botel. » http://www.perturbacoesdeamor.com/

«Para além de sushi a rodos (todos os dias haverá um jantar em buffet volante, à discrição [...]» http://apipocamaisdoce.sapo.pt/

\footnotetext{
${ }^{4}$ Pour les objectifs de notre étude, nous avons choisi quatre dictionnaires différents de portugais européen et quatre de portugais brésilien.

${ }^{5} \mathrm{Il}$ est fréquent que les formes adaptés qui se trouvent dans les dictionnaires sont différentes, il y a aussi une divergence entre la version européenne et brésilienne de la langue portugaise.
} 
«A TH cuidou de todos os detalhes da casa, das lembrancinhas e organização, incluindo as flores que foram feitas pela Verbena Flores (filmamos até isso para vocês) e o buffet foi o Grecco Coppola da Bia, minha amiga desde pequena.» http://www.lalarudge.com.br/lala-rudge/

Ce qui a été assez surprenant, c'est la différenciation du genre et du nombre de l'emprunt jeans. Les exemples réunis rendent évidente le manque d'unanimité dans le traitement de ce mot. En commençant par le dictionnaire de Porto Editora, il est possible de noter que le substantif est décrit comme «jeans - nome masculino ou feminino plural», ce qui nous montre l'hésitation quant au genre. Ensuite, dans le Priberam nous trouvons une définition pareille, mais au singulier: «jean substantivo masculino ou feminino». Le mot n'est pas mentionné ni dans le Dicionário Michaelis ni dans le Dicionário Aurélio; dans le Dicio-dicionário online on trouve seulement le pluriel. Le mot jeans est cité par le Dictionnaire de l'Académie et dans le Léxico online. Cette hésitation est visible aussi dans les exemples énumérés que nous avons trouvés dans les blogs portugais et brésiliens. Dans la variante européenne, le substantif fonctionne au masculin ou au féminin toujours pluriel, lorsque dans la variante brésilienne le même mot est accompagné toujours par le déterminant au masculin et au singulier.

«Para hoje proponho-vos um look descontraido com uns jeans rasgados e uma camisola verde fluorescente, com uma mala de franjas em camurça castanba, uma das grandes tendências da estação.» http://amulherequemanda.sapo.pt/

"Conhecidos pela sua estética e estilo anos 90, esta nova coleção para a TopShop tem a sua imagem de marca - as jeans e ganga rasgada.» http://backstagepass.blogs.sapo.pt/

«Não costumo sair de jeans, mas nesse dia foi preciso devido ao jogo. Coloquei meu jeans rasgado da Zara super velhinho e uma blusa de alça fina lisa já que eu caprichei nas correntes.

«Outra coisa que estou usando sem parar é esse jeans. Tipo, eu uso ele praticamente todo dia. habahaba. Pense em um jeans confortável e gostoso de usar. Adoro jeans rasgado, adoro jeans skinny e adoro ainda mais um jeans quando ele cai bem no corpo. Meu jeans favorito!

Hoje vamos falar do Jeans básico, queridinho de todos, já tivemos vários guias aqui e percebi que vocês gostaram, então hoje o guia é do jeans.» http:// niinasecrets.com.br/

L'emprunt drink présente aussi quelques doutes quant à sa présence dans les dictionnaires consultés parce que dans les ouvrages européens est décrit comme une expression utilisée au Brésil, pourtant, le dictionnaire Porto Editora ne le mentionne pas. Au contraire, nous le trouvons dans les dictionnaires Priberam, Aurélio et le Dictionnaire de l'Académie, aussi dans une version adaptée 'drinque', lorsque dans Dicio-Dicionário online, Aulete e Léxico online nous trouvons seulement la graphie étrangère. Le Dicionário Michaelis ne contient aucune référence.

«Tomar drinks: talvez. quem me acompanhe nas redes sociais fique pensando que eu bebo muito, porque não é raro eu postar fotos com drinks. Realmente eu bebo com frequência, porque experimentar drinks novos é algo que me deixa muito feliz mesmo, acho que drinks animam qualquer situação.» http://delarosa.com.br/

\section{Conclusion}

En terminant notre étude, il nous parait opportun ajouter quelques considérations générales. Notre thèse principale c'est celle que la langue est vivante, elle souffre toujours le changement, grâce aux emprunts aussi, comme nous rappelle Bagno: «A língua [...] é um sistema autoregulador, que dá conta de suas próprias carências e necessidades. Ela mesma acolhe o que tem serventia e descarta o que é dispensável. Isso ocorre porque existem seres humanos, inseridos em contextos sócio-históricos específicos, que querem se fazer entender, interagir, comunicar-se uns com os outros» (Bagno 2002: 82-83).

Entre les linguistes et les autres personnes qui s'emportent avec l'état actuel de la langue, il existe toujours une polémique entre ceux qui préfèrent la «pureté» de la langue et réclament la 
création des lois limitant l'usage des emprunts, et les autres qui choisissent l'option qu'il s'agit d'une phase par laquelle la langue est en train de passer, une phase qui peut être considérée une conséquence de l'histoire de la langue, une étape qui constitue un résultat des altérations passées et de la situation actuelle relationnée avec la situation dans le monde contemporain. Il faut ajouter que ce n'est pas exclusivement le cas du portugais parce que cette influence des emprunts, surtout de l'anglais, est observable dans les différentes langues dans le monde entier. Alors, même contre notre volonté, les emprunts, et avant tout les anglicismes, marquent la vie quotidienne de plusieurs pays - nos activités, les produits que nous achetons et que nous utilisons, les journaux et les revues que nous avons habitude de lire, les programmes que nous voyons à la télévision, l'Internet et les réseaux sociaux, le monde virtuel sans lequel beaucoup de gens ne peuvent plus imaginer son existence. Les mots étrangers abondent dans tous les domaines.

Notre proposition c'est celle de construire le modèle «modéré», ce qui signifie que l'on ne peut pas éviter l'entrée des emprunts dans la langue, pourtant, il faudrait tenter d'éviter les formes étranges et déformées ou bien inadéquates dans le contexte donné, et aussi éviter une grande accumulation d'emprunts dans le même texte. Il faut observer toujours le contexte général de l'apparition des emprunts. Dans l'histoire de la langue portugaise il y a eu déjà beaucoup de discussions sur le problème avec les emprunts, beaucoup de polémiques et de débats pendant lesquels on commençait à discuter les questions relationnées avec le patriotisme et le civisme. Le problème des emprunts laisse appartenir à la linguistique - il est considéré dans les catégories sociales, morales et politiques, il s'agit du patriotisme, cosmopolitisme et, quelquefois, des émotions très fortes.

Pourtant, chaque langue, pour fonctionner comme outil de communication, a besoin de s'enrichir et renouveler ses ressources lexicales à cause de l'apparition de nouveaux objets et phénomènes. L'emprunt constitue un des éléments très importants de ce procès et les nécessités d'une langue deviennent un critère important aussi. On utilise les emprunts quand il n'est pas possible de les substituer par les mots équivalents de la langue maternelle. Il ne faut pas les utiliser pour les raisons «snobs», enrichir le style pour obtenir un effet spécial, impressionner les autres, pour paraitre une personne culte et moderne qui connaît les tendances actuelles, et aussi lorsqu'on ne connait pas bien la prononciation ni l'orthographe des emprunts. Il ya aussi des situations où quelqu'un n'est pas capable de comprendre les emprunts et c'est une autre raison pour ne pas utiliser les mots étrangers.

Comme nous vivons dans une époque de nouvelles technologies et de communication électronique, notre société se transforme très vite. Les façons de penser et d'agir provoquent le besoin de dénommer des réalités changeantes et des phénomènes récents qui sont bien nombreux.

\section{Bibliographie}

ALVES IEDA MARIA (2004), «A unidade lexical neológica: do histórico-social ao morfológico», As ciências do léxico: lexicologia, lexicografia e terminologia, Campo Grande, Editora UFMS, p. $77-$ 87.

BAGNO Marcos (2002), «Cassandra, Fénix e outros mitos», Faraco, C. A. (org.), Estrangeirismos - guerras em torno da lingua, 2 ed., São Paulo, Parábola, p. 49-83.

BLOOMFIELD, LEONARD $(1933,1984)$, Language, University of Chicago Press.

CÂMARA, JoAquim MATtoso Jr. (1979), História e estrutura da lingua portuguesa, Rio de Janeiro, Padrão - Livraria Editora, 1979.

CARVALHO Nelly De (1984), Neologismo: o que é neologismo, São Paulo, Brasiliense.

DEROY JEAN (1956), L'emprunt linguistique, Paris, Les Belles Lettres.

GUILBERT LOUIS (1975), La creativité lexicale, Paris, Librairie Larousse.

HAUGEN EINAR (1950), «The analysis of linguistic borrowing», Language 26, 2, p. 210-231. 
RAJAGOPALAN Kanavillil (2003), Por uma linguística crítica: linguagem, identidade e a questão ética, São Paulo, Parábola.

RUSIECKI JAN (1980), «Latent Bilingualism», Papers and Studies in Contrastive Linguistics, 12, p. 8198.

SAUSSURE FERDINAND DE (1967), Cours de linguistique générale, Paris, Payot.

Dictionnaires consultés :

Dicionário de Porto Editora on-line, www.infopedia.pt

Dicionário de Língua Portuguesa Contemporânea, Academia de Ciências de Lisboa, Verbo, Lisboa 2001.

Dicionário de Língua Portuguesa Priberam, http://www.priberam.pt/

Dicionário Léxico, www.lexico.pt

Moderno Dicionário de Português Michaelis, http://michaelis.uol.com.br/

Novo Dicionário Aurélio, Editora Nova Fronteira, Nova Edição Revista e Ampliada, Rio de Janeiro 1986.

Dicionário Aulete, http://www.aulete.com.br/

Dicio-Dicionário on-line, http://www.dicio.com.br/ 